\title{
Tord $=\operatorname{Tog} 0$ und
}

feine wejtliche Prachbarjchaft

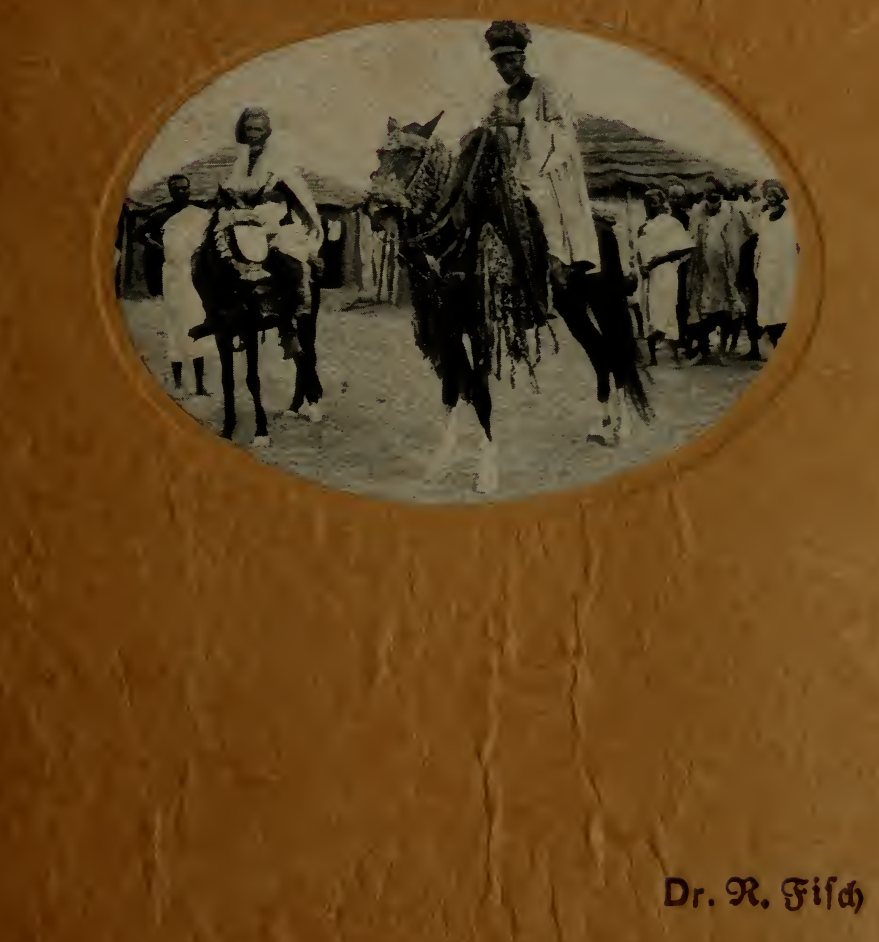




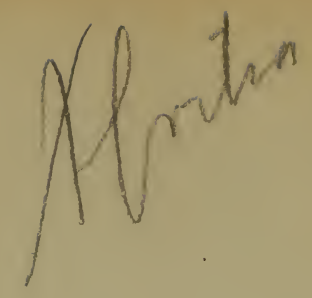

- 
Besta Scheler-Ucier

35

v. Schvester Pauline Mai'1944

99525 




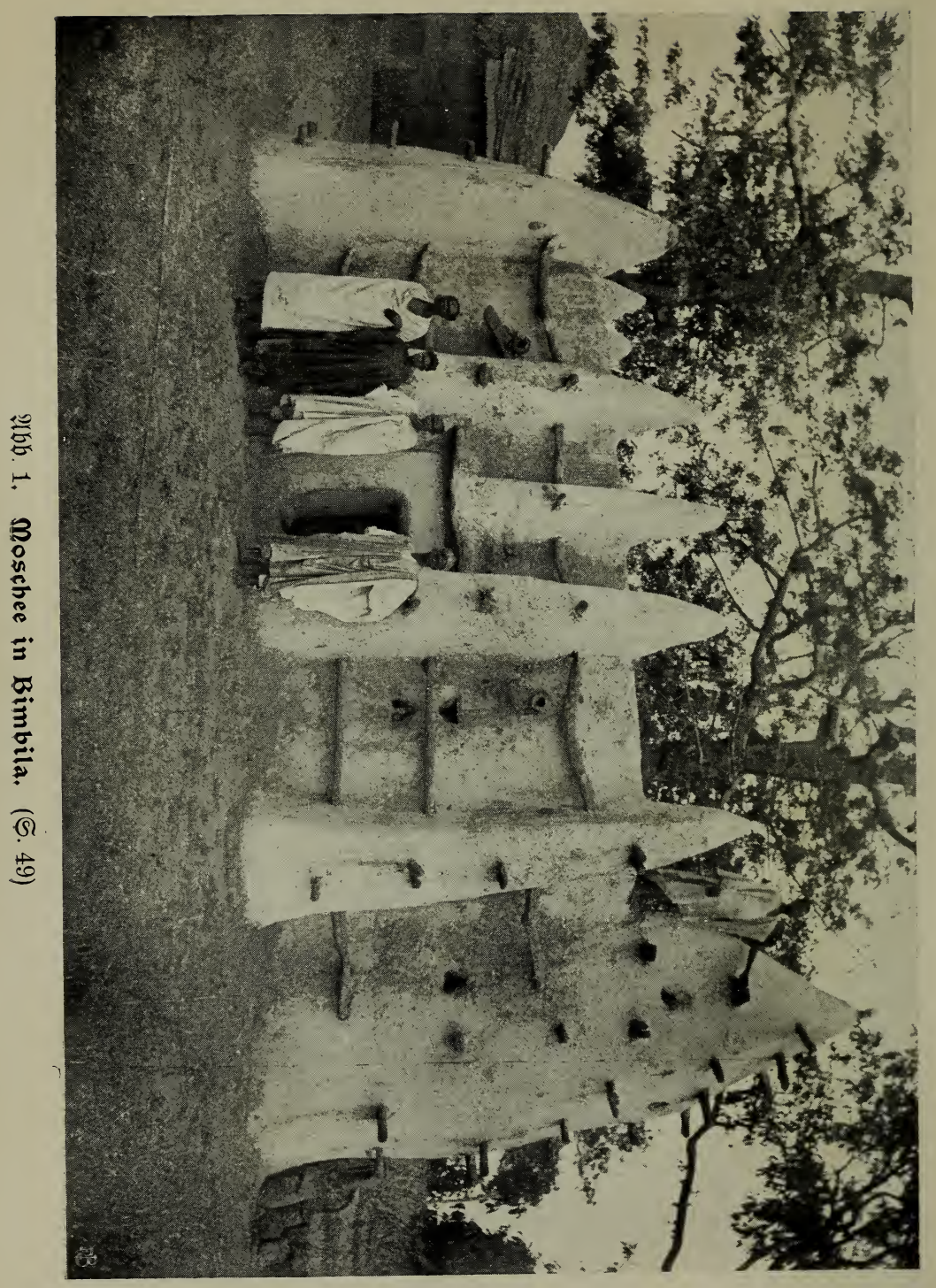




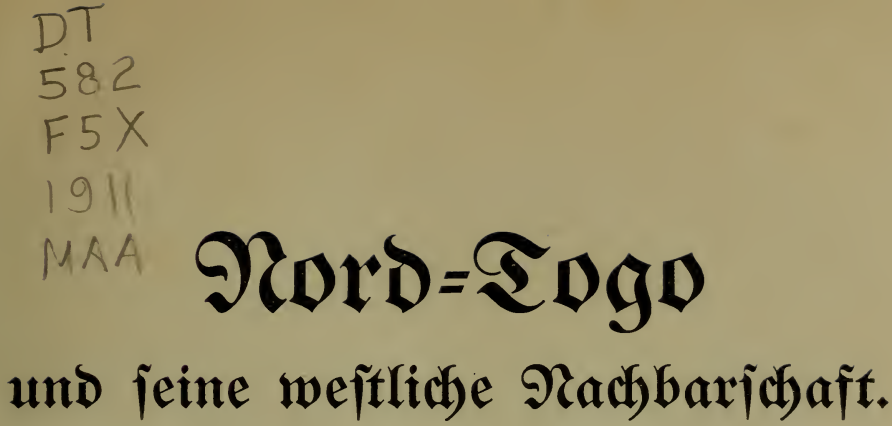

\section{In 2 illdern und Gfizzen}

für Mififion $=$ umb Rolonialfreunde

Dargejtellt von

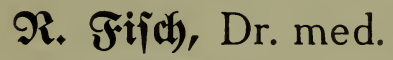

Mififionzåarzt.

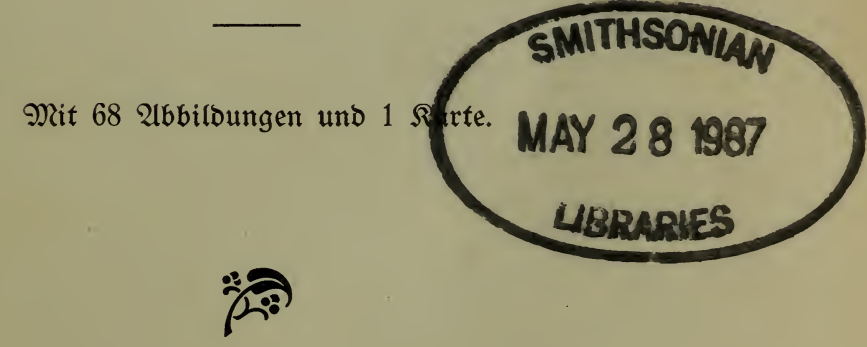

\footnotetext{
Bajel

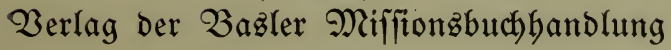

1911.
} 



\section{Borwort.}

„(5ott will es!“ Bie ein eleftrifierender Rriegsruf ift es damals von Mund ju Mund gegangen, als es galt, bas „Seilige Land“ Den Şänden ber Sarazenen zu entreí̋en. (5anz rein war ja wohl bie Begeifterung bei vielen niđt, aber gewíb hat mander in ber Ueberzeugung, er tue bamit Gottes Willen, Sđloßj oder Sü̈te, bie Seinigen und das Seinige verIallen und bie Strapazen und Gefahren bes Seerzugs willig auf fid genommen, (it

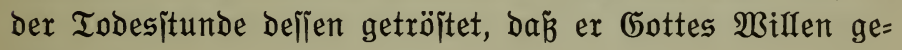
tan habe.

„Gott will es!“ Das joll auđ bies Büđlein ben lieben Chriften zurufen, wenn es von $\mathfrak{A}$ ufgaben exzählt, bie Gott uns itellt. Es gilt nidft mehr, mit $\mathfrak{y e e r}$ und Sriegstunit Qänder zu erobern und bie Feinde mit $\mathfrak{B a f f e n g e m a l t ~ n i e b e r = ~}$

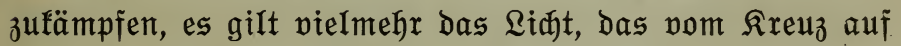
Golgatha und vom Ihron bes $\mathscr{A} u$ feritandenen ausgeht, in die $\mathfrak{B o ̈ l f f e r ~ u n d ~ M e n i đ j e n h e r z e n ~ h i n e i n l e u d t e n ~ z u ~ l a f i e n , ~}$ in benen es heute nod Dunfel ijt. Es iit nidjt mehr wie jrüher, wo bie politiןde Madt Den Boten Des Enangeliums jolgte. Es gilt vielmehr ben $\mathfrak{B o ̈ l f e r n , ~ d i e ~ i đ o n ~ j e i t ~ J a h r e n ~}$ unter ber beutiðen und englijßjen Regierung bie gropen Segnungen bes Friebens und des aufblühenden Wohlitandes

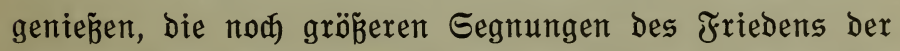
Geele und bes Reidtums in Gott $\mathfrak{z}$ u bringen. Die $\mathfrak{B e g e}$ zu ben Bölfern itehen uns offen. Die Bölfer in Iogo 
insbejondere find uns won Gott vor die Tür gelegt; wir bürfen nidgt an ifnen worbeigehen.

Dem Berfaffer war es vergönnt, in fajt brei Monate bauernder Reije die nörblidhen Teile ber englijøen Gold: fiijte und fajt ganz Iogo zu burdyjiehen, und zwar gemein= fam mit zwet Miffitonaren der Basler Miffion. Was wir bort gejehen und erlebt haben, joll bas Bud in Mort und Birl zur $\mathfrak{A n}[$ đaauung bringen.

Gott will, Dá wix Geine Mitarbeiter feien am herr= Iidjiten $\mathfrak{B e r f}$, bas auj Erben geidieht: am $\mathfrak{B a u}$ bes emigen Reidhes Gottes. Soldhe Mitarbeiter zu werben für jene Bölfer ift ber 3wedf diejes Buches.

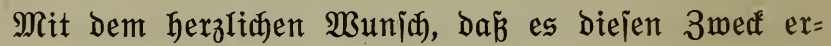
reichen möge, joidft es auf jeinen $\mathfrak{B e r b e g a n g}$

Der Zerfafier. 


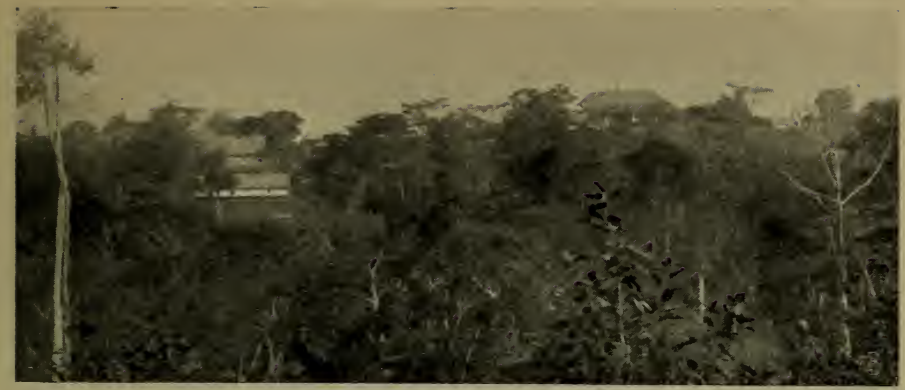

2イbb. 2. Hmedschowe von Süden geseben.

\section{Siniiber iiber Den Bolta!}

Sđjon vor Jahrzehnten haben fid bie Blife ber Mij= itonare auf Der Goldfïite nad) Dem Rorben gewendet. Das Berlangen, jenen $\mathfrak{B}$ ölfern bas Evangelium zu bringen, wurbe immer bringender, je mehr unjere $\mathfrak{O r b e i t}$ hier in ein Stadium eintrat, bas uns beredtigte, baran zu Denfen, weitere $\mathfrak{A} \mathfrak{u f g a b e n}$ in $\mathfrak{A}$ ngriff $\mathfrak{z} \mathfrak{u}$ nehmen.

3wei frühere Berjudide, nad) Rorben vorzubringen, find

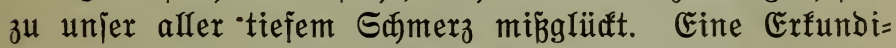
gungsreije, die von zwei Miffitonaren vor fünf Jahren in bas nörblidbe Iogo gemadt wurbe, hatte feine greifbaren Folgen. Jmmer wieder war bas Berlangen nad einem frijđen, fräftigen Boritó̉ auf gebulbiges ßarten verwiejen. Das Barten ift für einen Miffitonar feine leidfte $\mathfrak{A}$ ufgabe, wie es aud für eine Iruppe feine leidte Sadje ijt, (5emehr

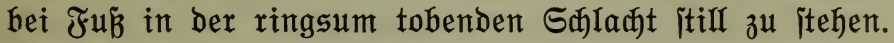
Das Berlangen vorwärts zu gehen ijt aber in ber langen Wartezeit niđjt iđwäd)er geworden, jondern es hat itđ ver= tieft und verebelt. Täglid bringen wir auf allen Stationen gemeinjam unjere Bitte, Dá̉ ben Bölfern fern im Norben bas Evangelium gebradt werbe, vor ben Serrn aller Serren. 
Es wax uns Darum eine grop̉e Freube, als brei MiF= fionare auf ber Goldfuijte mit Der ehrennollen 2 ufgabe be traut wurben, eine Erfundigungsreije bis an bie Rord: grenze ber englifichen Rolonie und von Deutī $=\mathfrak{T}$ ogo zu unternehmen. Es war Der Derzeitige $\mathfrak{B r a ̈ j e s ~ D e r ~ B a s l e r ~}$

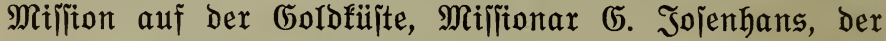
Bräjes bes Tiđjidiftrifts, Mijpitonar $\mathfrak{B}$. Groh, und ber $\mathfrak{B e r}=$ falfer, weldye bie Reije unternebmen jollten. Arlle brei find zwar feine Sünglinge mehr. Mehr als 20jährige $\mathfrak{A} x \mathfrak{b e i t}$ auf ber Goldfüite haben unjere Saare ergrauen Ialfen, aber wir haben ben $\mathfrak{A} u f t r a g$ mit jugenditcher Begeipterung und Freube angenommen und trafen ungejäumt unjere $\mathfrak{B o r}=$ bereitungen. Die amtridjen (bejđäfte ber beiben Miffitonare wurben Stellvertretern ïbergeben, Der Berfafier murbe burd einen jungen Rollegen abgelöjt.

Der oberite englijace Beamte ber nördithen Gebiete ber Golofiulte hatte fur geladen, Dort eine $\mathfrak{A}$ rbeit in $\mathfrak{A} n g r i f f$ zu nehmen. Das ganze meite Gebiet wax uns geöffnet Der Gounerneur von Iogo erlaubte uns gütigit, die jegt nod geiperrten Gebiete in Ingo zu bereijen, und itellte uns weitgehende $\mathfrak{U}$ nterjtïbung Durd bie Bezinfs= und Stationsleiter in $\mathfrak{A}$ wsjutht. Die Bahn war frei.

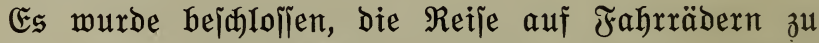
madyen, wie bie erjte Erfundigungsreije vor vier Jahren. Die Gründe, die baz̆ bejtimmten, waren folgende: Bir

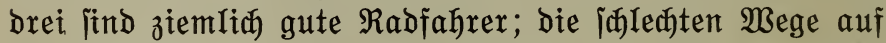
ber Goldfuijte und die vielen Reijen, die wir ju madhen haben, find unjere Lehrmeijter gemejen. Des Reitens und ber Behandlung von $\mathfrak{P f e r d e n ~ f i t n d ~ w i r ~ g a ̈ n z l i t h ~ u n f u n d i g . ~}$ Das fommt baher, weil wir auf ber Goldfiilte mit alleiniger Yusnahme des ßüitenjtridas feine Pferbe halten fönnen wegen ber jonjt überafl vorfommenden Tietiefliege. Mit Räbern fonnten wix jeden Iag, eigenes $\mathfrak{B o h l j e i n ~ v o r a u s = ~}$

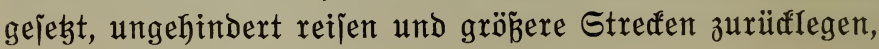


als wir es zu Pferd vermodt hätten. Die $\mathfrak{W a h r j h e i n l i d y = ~}$ feit, burd Rabbruch aufgehalten zu werben, exidien uns geringer als die Bahrideinliđfeit, Durd Rranfheit oder Iod eines $\mathfrak{B f e r d e s}$ gehindert $\mathfrak{u}$ werben. 3ur Sidjerheit gegen Rabbrud follte ein uns begleitender Regerjüngling, ein im Dienjt ber Mifíion itehender $\mathbf{L e h r e r}$, mit einem $\mathfrak{R a d}$ ausgeriijtet werben, bas wir im Rotfall als Rejerve be= nüben fönnten. Es wurben ferner Durđ bie Benü̈bung von

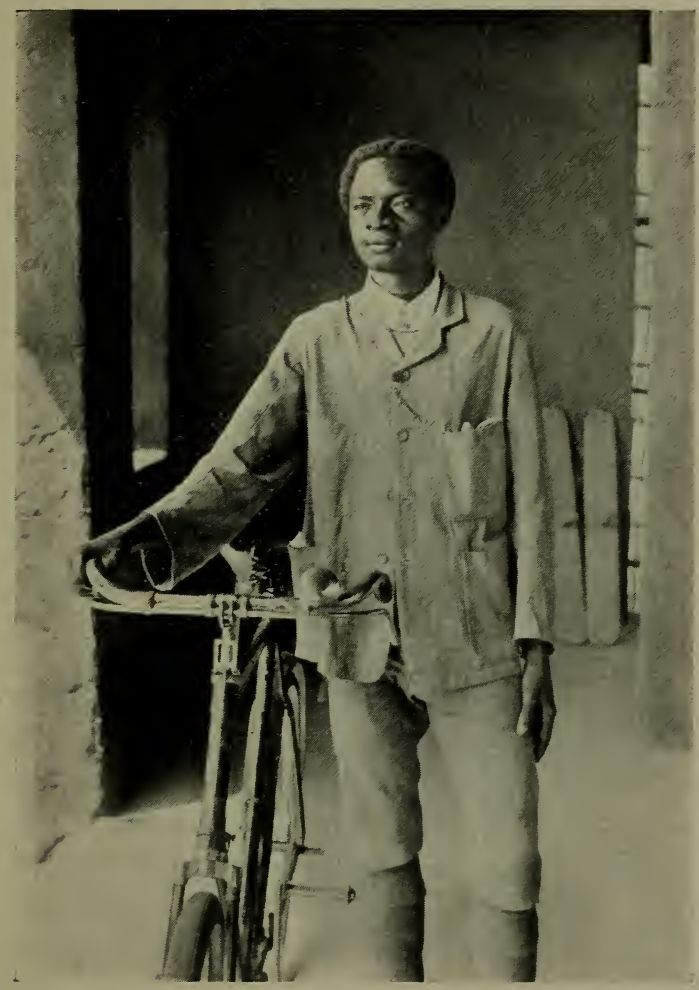

YGb. 3. Cebrer Seku. 


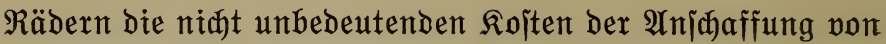
Pferden und $\mathfrak{P f e r d e b e b i e n u n g ~ e r i p a r t . ~}$

Der junge Mann, dex uns begleiten follte, möge mit ein paar Worten hier eingeführt werben, um io megr, als jeine Gejaidfte reat merfmürdig iit. Er wurde geboren

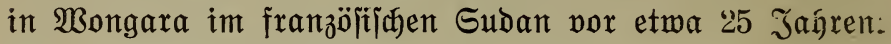
HIs er etwa 10 Jahre alt war, ïberfiel ber berübtigte Sflavenjäger Samori mit jeiner Sorde jene Gegend. Afles floh in bie Wälder. Den Rnaben trieb Der Bormib, nod) einmal zuriudzugehen. Dabei fiel ex ben Sflavenjägern in die Sände. Da er unaufhörlid weinte, wurbe er bald ver= fauft und geriet in einen andern Gfiapentransport. Einte Abteilung Der engIifaen Srabtruppe überfiel Den Irans= port und befreite bie Gflaven. Dieje murben nad Rumaje in Das won ber Baslex Miffiton unterhaltene Sflavenheim

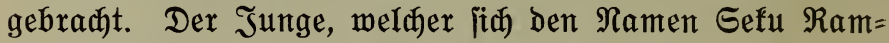
jener beilegte, bejudte bie Saulen in Rumaje, bant bie

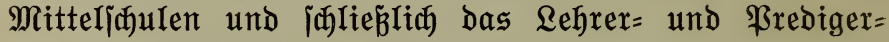

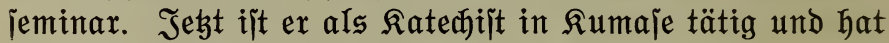
(iid) fürzlid mit einer mit ihm jugleid) befreiten Ranbs= männin verheiratet. Er jollte uns als Dolmetiđjer bienten. ( $\mathfrak{A b \mathfrak { b } . 3 . )}$

Unier Gepäd wurbe auf bem Bolta nadh Rratīji hin= auf gejhafft. Bei ber Sdywerigfeit, oder befier geiagt, bei Der $\mathfrak{U}$ nmögliðffeit hier Träger zu befommen, war bas ber

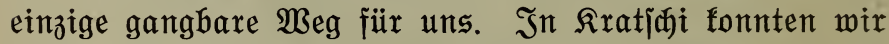
hoffen, mit Silfje der Deutiđen Regierung Träger für ben Transport unjerer Sadjen z̆ befommen. Es blieb nur

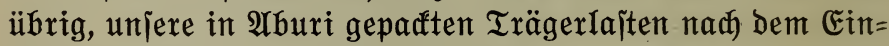
idiffungsplał am Bolta, nad Pong, eine itarfe Tagereife

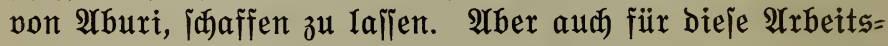
leiftung war niemand zu finden, auß̌er zu ganz unannebm= barem Lohn. $\mathfrak{A}$ us biejer Sdiwierigfeit fonnte uns unjer Reijegefährte, Mifjitonar Jojenhans, mit Unteritübung bes Rönigs won Doumaje helfen. Eines Morgens traten eine 
$\mathfrak{A} \mathfrak{z} a \mathfrak{l}$ fräftiger junger Männer von Dbumaje in $\mathfrak{A b u r i}$ an

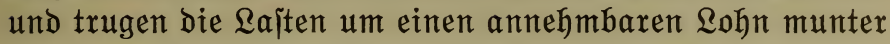
nad Dem Einjøiffungsort. Mit jehr erleidtertem Serzen iahen wir iłnen nach. Es blieben nur nod zwei Rijten ïbrig, bie nidft auf bem $\mathfrak{B a f f e r m e g ~ b e f o ̈ r b e r t ~ w e r b e n ~ j o l l t e n . ~}$ Die eine war für unjern ßođ bejtimmt, für bie andere fanden wir einen jebr betrübt in bie Belt iđauenden, aber vielgereijten und ipradjfundigen Mann, namens $\mathfrak{h r u}$. Der Rod, Den wix mit gemijhten (GefühIen in Dienjt nahmen,

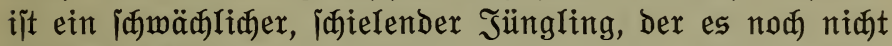
zu etwas Re(htem gebracht hat, und ber bas fehlende $\mathfrak{B e r}=$ trauen bann aud glänzend rechtfertigte.

Unjere Reije follte ïber Doumaje, Înum und die Bremer Miffionsitation $\mathfrak{A m e b j}$ fowe gehen, weil mir ber ehrenvolle $\mathfrak{A} u f t r a g$ gemorden war, bor ben zu einer all= gemeinen ßonferenz periammelten Bremer Mifífonaren

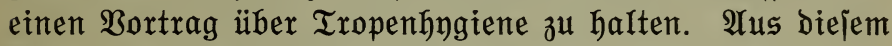
(5rund trat id bie Reije adft Tage vor meinen Begleitern

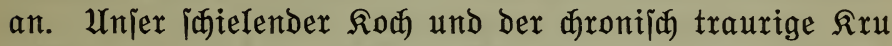

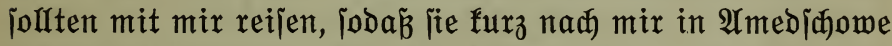
eintreffen fonnten. $\mathscr{A} m$ 18. Sanuar hatten jie Den $\mathfrak{B e g}$

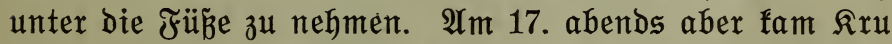
mit nod betrübterer Miene, als er für gewöhnlid zur Sdfau trug, und exöffnete mir, dá̉ ex morgen nidgt auffrechen fönte; in 8 bis 14 Tagen wolle ex bann jehen, ob es ihm mögliđ jein werbe. Es iđulde inm nämlid einer nod 12 Sdilling, und bieje Gumme mïlie ex junor eintreiben. $3 \mathfrak{u}$ biejem 3wef braude ex mindejtens adyt Tage, benn jein

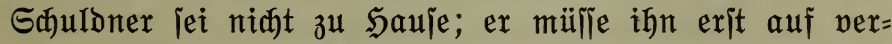

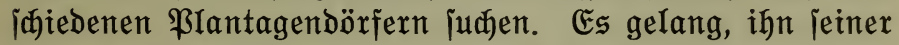
Sorge um bas Geld lebig ju madhen, indem ein Ângeftellter Der Miffiton veripra氏, für bie Beibringung Desjelben zu

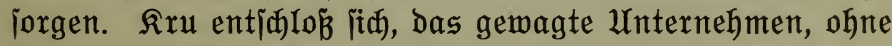
ieine Gelo abzureijen, auf fïd zu nehmen.

Der Morgen bes 18. Samuars 1910 brad an, aber 


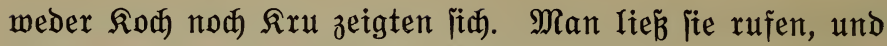

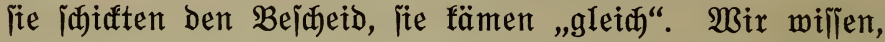
was bas bei ben Negern heibt, und wix waren nidht ex= itaunt, als exít gegen Mittag bie fitch häufenden Sd)wierig= feiten einer zeitigen $\mathfrak{A b r e i j e ~} \ddot{u}$ berwunden waren: Unver=

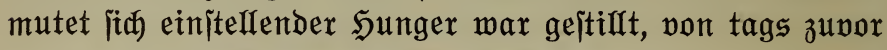

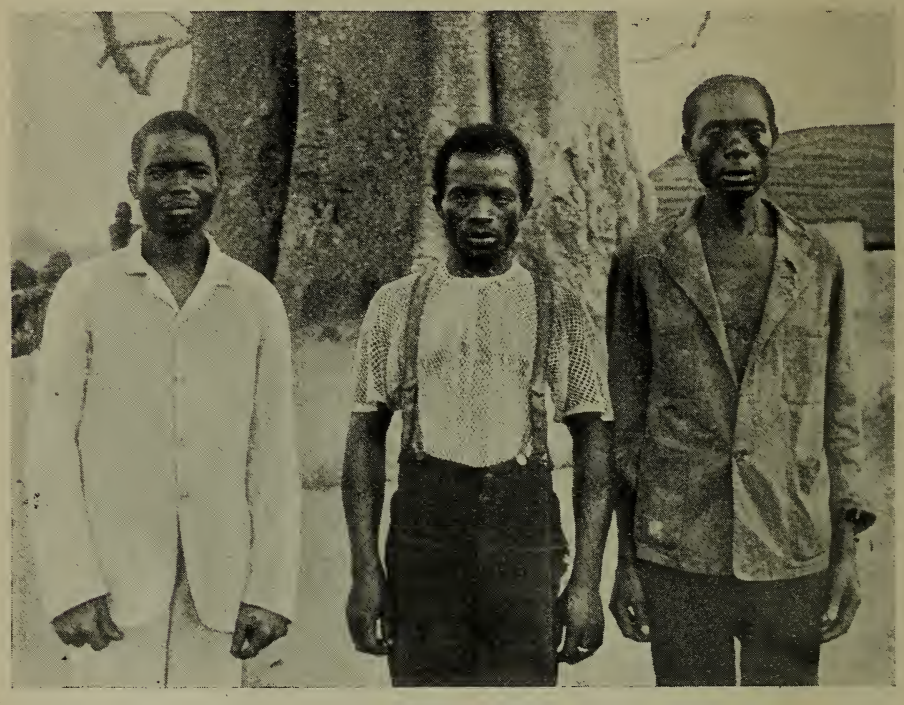

Miuja von Raraga.

Lorenz Der fioch.

Siu bex Traurige.

2Ybb. 4. Die 3 Begleiter.

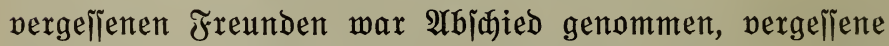
oder verlegte Gadjen waren geholt und gefunden. Mit grimmer Entid)lofienheit nahmen unjere Shelden ihre Trag= Iaiten auf und gingen zum Tore hinaus. Der Rod hatte (it) als $\mathfrak{B a f f e}$ und zugleid) als Zeidjen jeiner Bürbe ein langes Mefier umgegürtet und jă jo verwegen aus, als es mit feinen Mitteln mögliđ war; $\mathfrak{R}$ ru war ergeben, aber nod) trauriger als jonit, benn bie 12 Gdillinge modten ifm Eorge bereiten. 


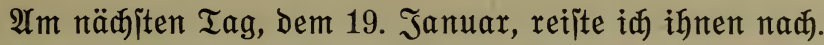
Mand freundlides "glüaflide Reife“ tönte mir unterwegs nad). Gegen Mittag war uniere Station Doumaje ex= reidit, und gleid beim Eintritt ins Miffionshaus traf id

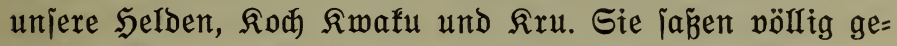
fniđ̛t auf einem Bänflein, während fie jđon längit jenjeits bes Bolta bätten jein jollen. Der ßod hub an und ex= zählte mix folgendes: In jeiner İugend habe er einmal bas Unglüa gehabt, bas Geniđ zu brechen. Seit ber Zeit fönne er feine $\mathfrak{L a j t}$ mehr tragen. Er habe bas leiber vergelien mir in $\mathfrak{U}$ bri za jagen, und nun habe er bies Berjäumnis

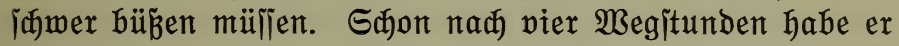
bie Traglajt nidht mehr auf bem Ropf ertragen fönten, und ex habe baher einen Mann bitten miilien, ihm die $\mathfrak{L a j t}$ nad) Doumaje zu tragen. Sein altes Leiben babe fin in uner= hörter Seftigfeit eingeitellt, und er bitte uns, inm boch ja nid)ts mehr zum Iragen zu geben, jonjt fönnte es jein Iod jein.

Es wurbe nun beîtimmt, Dá̉ die Tragla armen Rod fajt ben Sals vollends gebrodien hatte, wohl ober ïbel aud auf bem Baflermeg Den Bolta hinauf $\mathfrak{u}$

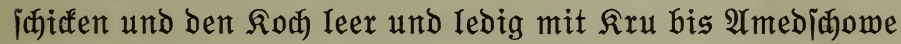
gehen zu Iaflen, in Der Soffĩnung, Dort einen Erjagmann für

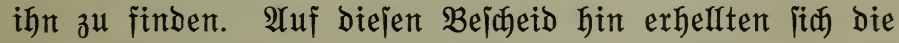
3üge unirex beiben Selden, und ziemlid getröitet zogen fie von bannen. Sie jollten jĭh über ben Bolta jegen Iafien

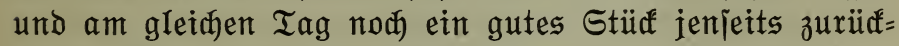

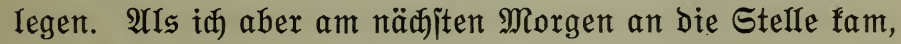
wo ein im Dienjt der Regierung itehender Fährmann bie Reijemben über ben breiten Bolta zu jeben hat, fand id meine beiden Freunde hödjt vergnügt auf bem hohen $\mathfrak{u}$ fer

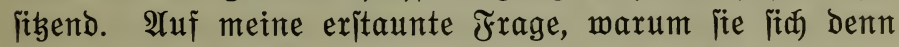
nidbt hätten überjeben Iallen, jagten jie mix, fie bätten ge= badft, es fei beller, wenn jite auf mid warten würben; in

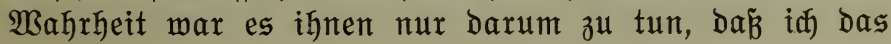


Fährgeld für fie bezahle. 3ehn झ̧ennige wurben ifnen baburch expart, und mir eit voller Iag Bartezeit auf= geladen.

Bis das Fährboot in Stand gejegt war, verging noch eine geraume 3eit. $\mathfrak{I}$ f füllte fite aus, indem id einem gerabe Gier burdreijenden englijđen Regierungsbeamten einen $\mathfrak{B} e=$ fud madhte. Wix unterhielten uns harmlos, bis bie Fähre zum (5ebrauch fertig mar. Erit in $\mathfrak{A}$ mum erjah id aus bem

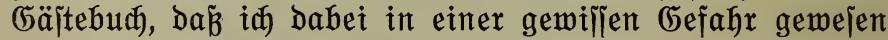
war. Der Sherr war auf jeiner Durdreije in Ânum (5ajt ber Dortigen Miffionsfamilie gewejen und hatte itđ mit folgendem (Gedidt im (bäjtebud der Miffitonsfamilie gefenn= zeidinet:

If I would be in Berbery

And live in Timbuktu,

Then I would eat a missionary

And Bible and hymnbook too.

In beutia überjegt mürbe bas etwa Iauten:

Benn id in Der Berberei wär Und wohnte in Timbuftu,

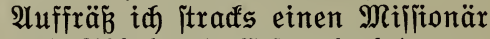

Und $\mathfrak{B i b e l}$ und Gejangbud da bau.

Der Serr hatte offenbar einen etmas unheimlichen Ippetit; auf einen Miffitonsarat war er aber nidht gefaß̧t. Go fam id nod unverjehrt ins fährboot und heil ans jen=

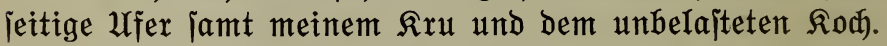
Dort iajieben fith nun uniere Bege. Sie gingen gerabe=

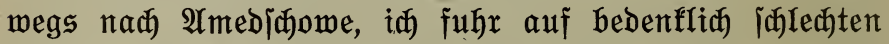
Wegen nad̆ Der nördlid gelegenen Basler Mififionsitation $\mathfrak{A}$ num, ber hodgelegenen Warte, won ber iđjon viele Jahre bie Blife lebnjü̈htig nad den Rändern im Rorben geridtet und bie Chrijten und Seiden bis nad Rratidi hinauf mit Dem Wort Gottes bebient morben into. In 2 num hat bie englijøe Regierung einen $\mathfrak{A r}_{3}$ t itationiert, Deflen $\mathfrak{A} u$ fgabe es iłt, Die Sălaffranfheit z̆u befämpfen. Es war hiezu ein 


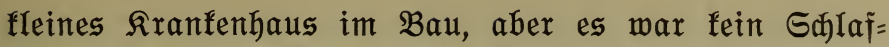
franfer weder in Behandlung nod in Beobadtung. Das gleidfe war ber Fall $2^{1 / 2}$ Monate ipäter bei unirer Rüaf́lebr.

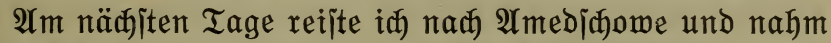
aljo Arbjhied won ben lebten Basler Miffitonsleuten. Wie viele Riebe haben uns bie Mifitonsgelđwijter unirer Sta= tionen erwiejen, und mit wie herjlichen Wünjøen uns Lebe= mohl gejagt! Es ijt ein erhebendes (5ejühl, zu willen, Dás

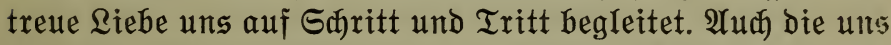
jo nahe itehenden Mififonare der Bremer Mifijon haben es nidyt an joldher Riebe fehlen Iaflen. Shon ehe id auf ihre

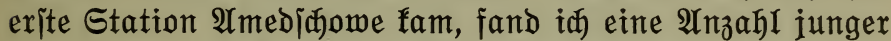
Leute am Fun ber iteilen Berglette, auf Deren $\mathfrak{K a m m}$ in

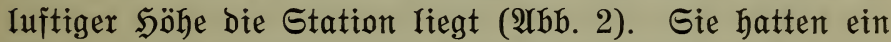

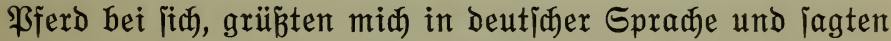
mix, als id abjtieg und ihren (5rub erwiberte, fie jeien von

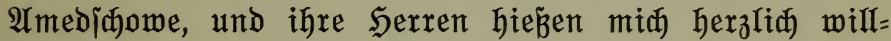

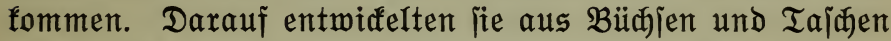
eine Jülle von allerlei ßegzehrung, barunter herrlitfe Drangen. Sđjon bie Berpadfung zeugte von wahrhaft mütterlicjer Riebe. Dann führten jie bas $\mathfrak{P}$ jerb herbei und

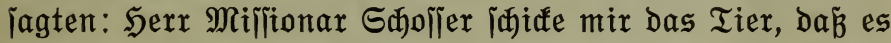
mid) Den Berg hinauftrage. So jehr id nun bieje Grïte

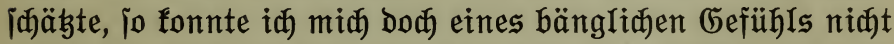
erwehren, benn jeit ber 3eit meiner frühen Jugend, als mid einjt ein freundidger Fuhrmann auf jeinen mehr als zahmen S(jimmel gejegt hatte, hatte idj auf feinem $\mathfrak{P f e r d}$ mehr geiefien. Dod halt, bas ijt nidht ganz ridhtig! Jah war ja vor 21 Jahren einmal $\mathfrak{P f e r b e b e j i z e r ~ g e m e j e n , ~ h a t t e ~ m i r ~}$

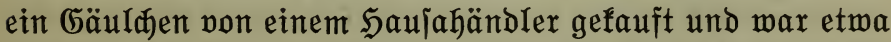
breimal mit ifm ausgeritten. Das arme Tier fonnte aber nidat mehr traben und ijt bald barauf gejtorben, da es iळon tjetjefranf in meine Sände fam. Das hier mar mun aber ein ferngejundes Tier; was fonnte bas alles für ver= wegene Sprünge mađjen, wenn es fühlen würbe, wie 


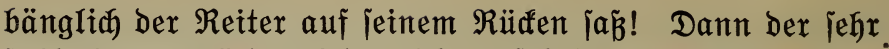
iteile Berg: würbe id ba nidft unfehlbar, ben Gejeben bes freien Falls entipredyend, weldye uns jeinerzeit unjer ver= ehrter Lehrer an einer iđiefen Ëbene vordemonitriert hatte, hinten abrutiđen? Der Sinwanz des

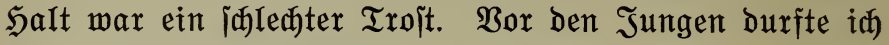

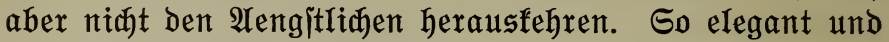

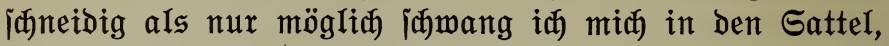
und mein $\mathfrak{P f e r d}$ jebte fid in Trab. So hatte mid dod mein

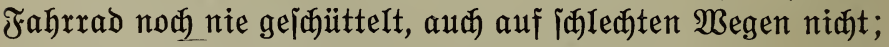
bod es ging ganz gut, und meine Danfbarfeit murbe immer ungetrü̈ter, je höhex das Tier mid den $\mathfrak{B e r g}$ hinauf trug. Es trat jo jither auf Dem iamalen, iteilen $\mathfrak{P f a b}$ auf, fletterte über Steinblöđe und jebte über Gräben, Dá̉ alle Sorge verging und id mid ungejtört bem (Genú bes herrliden Randianaftsbildes hingeben fonnte.

Satte der Weg bis an Den Fun bes Berges durd zum Teil von der Gonne verbrannte, zum Ieil Durd) Grasbrände verfohlte Gegenden geführt, jo prangten nun ringsum bie

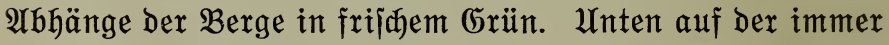
mehr (ï) ausbreitemben Ebene Iag goldener Sonnenichein. Bald war bas lieblid wie im Sajo bes berges gelegene Dorf Biafpa erreidyt. Senjeits Iabte ein friltallflares Bäd)= Iein $\Re o \tilde{B}$ und Reiter, und bann ging es bie lebte, jehr iteile und hohe Salde bes Berges hinauf. Im Rorben ragt ber gemaltige $5 \mathrm{emmi}$, eine grasbemadjiene $\mathfrak{R}$ uppe mit einem "Steinmannli" auf bem oberiten Gipfel, in hellem Gold= gelb bes bürren Grajes; finiter und brohend aber idjauen die jähen felsabjtürze an jeiner Wejteite herüber. Wie herrlidje frifde Suft ba broben weht! Im verfallenen und lieberlid ausjehenden $\mathfrak{A}$ vatime=Dorf $\mathfrak{A}$ medjugwe itanden eine Menge Leute auf ben $\mathfrak{B l a ̈ g e n ~ u n t e r ~ b e n ~ S d i a t t e n = ~}$ bäumen und bereiteten jĭd vor, bie Totenfeierliaffeiten für einen veritorbenen Säuptling zul veranitalten. Sn ben näßjten Tagen haben bann bie Gemehre ber $\mathfrak{A}$ atimer bei 
Tag und Raøt ihrem Toten zu Ehren gefnattert, und mander, der bem Branntmein allzu jehr zugeiprođen hatte, ijt mit unjidyerm Saritt bie iteilen Wege hinuntergetorfelt. Es wäre eine groß̉e Wohltat, wenn dieje Totenfeierlidfeiten

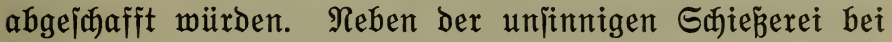
Iag und Rađt wirb pon ber Familie bes Berjtorbenen ber ganzen Stadt ein Freijđnaps geipendet. Jebe Familie judt die andere barit ou übertrumpfen, und jo arten bieje "Jeierlidfetten" in wïjte Saufereien aus; nur zul oft find fait alle Männer, Frauen und Rimber eines Dorfes be= trunfen.

Im Rreis Der Bremer Miffitonare mirb es einem Basler gar bald wohl. $\mathfrak{A}$ uদ die Bremer Miffitonare exhalten in Bajel ifre $\mathfrak{A}$ wsbiloung, und ein edler Rorpsgeift verbindet die Mifítonare beiber Gejellinaften. Drganijation und Praris beiber Gejelliaraften ijt fajt ganz biejelbe, und zu= bem find die Bölfer, unter benen die beiden Mifítonen ar= beiten, jehr nahe perwandt, jodá̉ die gleiden Leiden und Freuben uns Berjtänonis Der gegenjeitigen $\mathfrak{A}$ rbeit ermög= Iidxen.

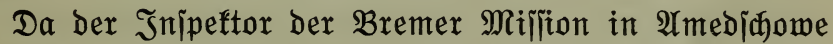
anwejend war, madyte in jenen Tagen ber Dberhäuptling

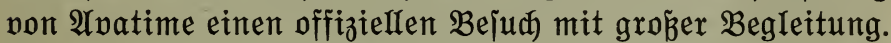
$\mathfrak{A b b}$. 5 zeigt ihn linfs, die $\mathfrak{U}$ mitebenden überragend, unter bem runden Sđirm mit meiß̈en Franjen. Er trägt einen groß̈en Tropenhelm und jït in jeiner Söngematte. Linfs trägt einer jeiner Diener jeinen Säuptlings|tab, reats find jeine beiben IrommeIn, und vor biejen itehen jeine zwei Sofnarren, die eine ßrügelizene barjtellen.

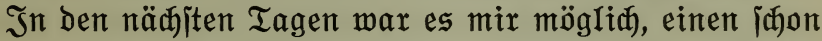
lange gehegten \$lan auszuführen, nämlid bas Ğlaf= franfendorf bei Mijahöhe zu bejuchen. Mein Weg führte

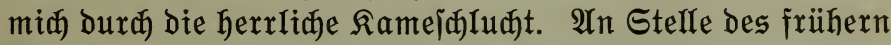

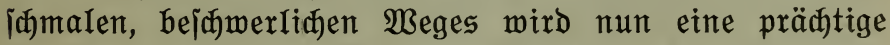

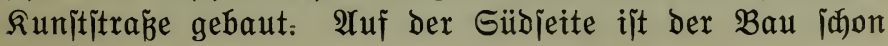




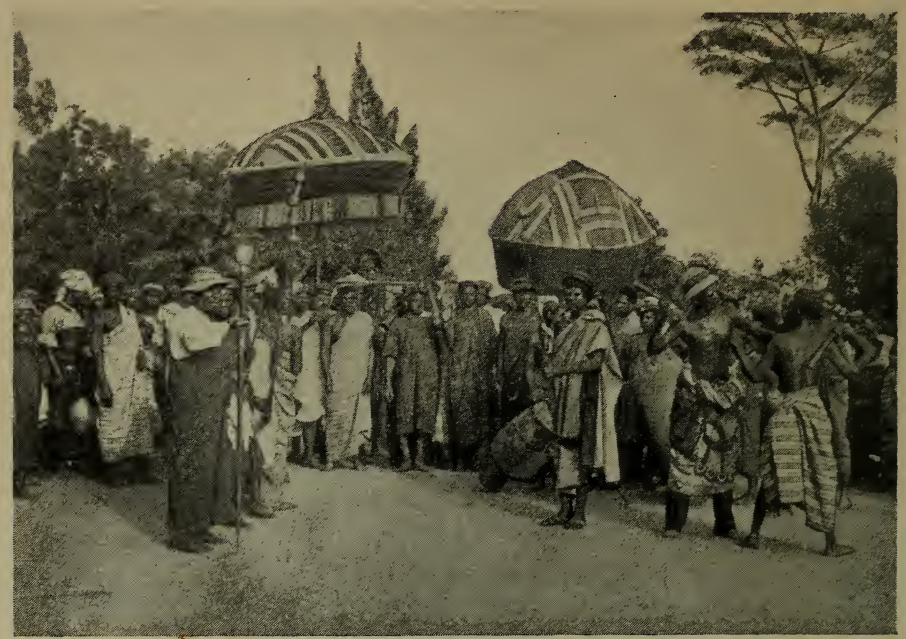

Säuptling

Sofnarxen.

Irbb. 5. Besuch des Gäuptlings von Hvatime.

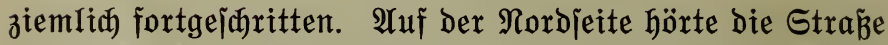
ganz unvermutet plöglich auf, und über Stod und Stein führte mein Weg hinab an den jđäumenden Ramebach.

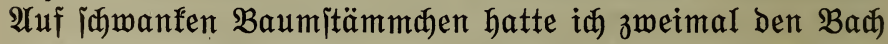
zu freuzen; Dafür fonnte man bann aud bie intimen Reize

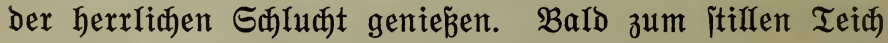
erweitert, bald in ¡đäumendem Lauf über Feljen, itrömt

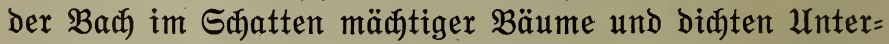
holzes dahin. Zierlidbe Jarrenfräuter jäumen jein Bett ein und mađjen auf Jeljen im Bett jelbjt; bariber bängen

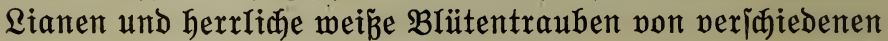

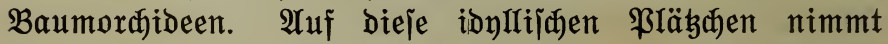

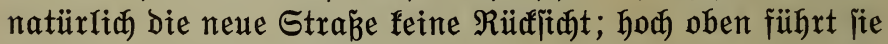
am Bergabhang entlang. Der moberne Berfehr jieht all= gemad in Iogo ein, und wie baheim, fo aud in ben Iropen, 


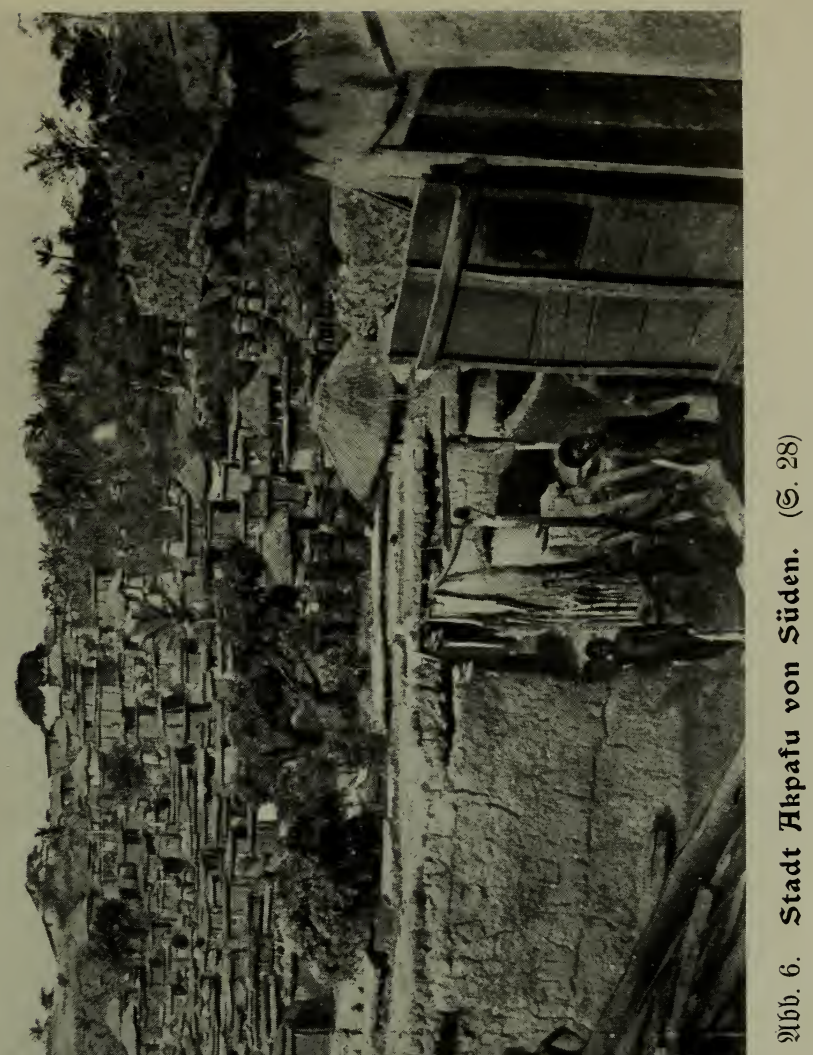





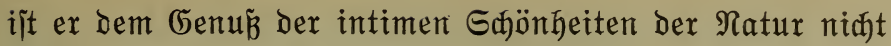
hold.

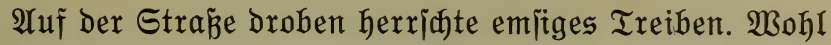
200 Arbetter waren bejä̈ftigt, die fahrbahn zu ebnen, Gräben auszuwerfen, ober Eprenglöׁer in Jerjen zu hohren. Ein freundidger beutiळer Iennifer Iud mich in leine Sütte zu einer Eririjøung ein. In traurichem Ge= plauber verging raj̄ ein Biertelítündan. Mein freund= licher Gaitgeber begleitete miđ nod eine Streffe weit, und

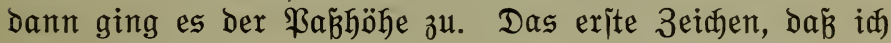

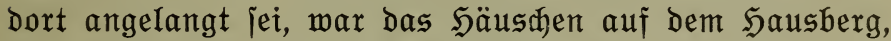

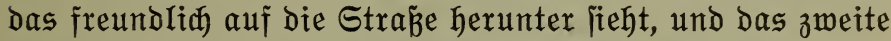

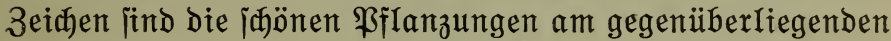
Bergabhang.

Das Shlaff́xanfendorf liegt am Ende eines Sodtals, das in die ßaß̧̧ö̆he mündet.

Die

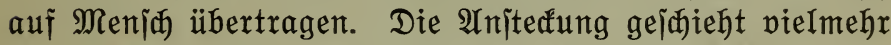
auf folgende Weije: Ein Shlaffranfer hat ju bejtimmten 3eiten die Baraliten, welde die Rranfheit verurjadhen, im zirfulierenden BIut. Stidt nun einen jolden হranfen eine gemilfe $\mathfrak{A}$ rt Tetjefliege, jo jaugt dieje mit dem Blut einige Barajiten ber Shlaffranfheit in fid hinein. Jn Der Jliege finden die ßarajiten günitige Bebingungen zux Beiter= entmialung. Die Jolge ijt, Dá̉ menn Dieje Fliege nach einiger 3eit einen andern Meniðen itidt, nun einige ßara= fiten aus Der Fliege in bas BIut bes Gejtonenen hinüber= gelangen. Damit ijt ber Unglüßtid)e mit Salaffranfheit angejtedt. Wenn aljo aud ein Salaffranfer jeine Neben=

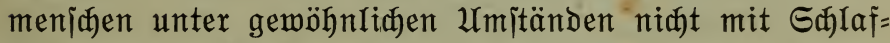
franfheit anjecten fann (auber es gelange etras von jeinem BIut in bas eines feiner Rebenmenichen), fo ijt bod ein

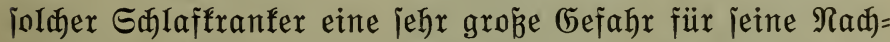
barn, wenn Ijetjefliegen vorhanben ïnd, Dura wela die Unitecúng verbreitet werben fann. Will man aljo in einem 


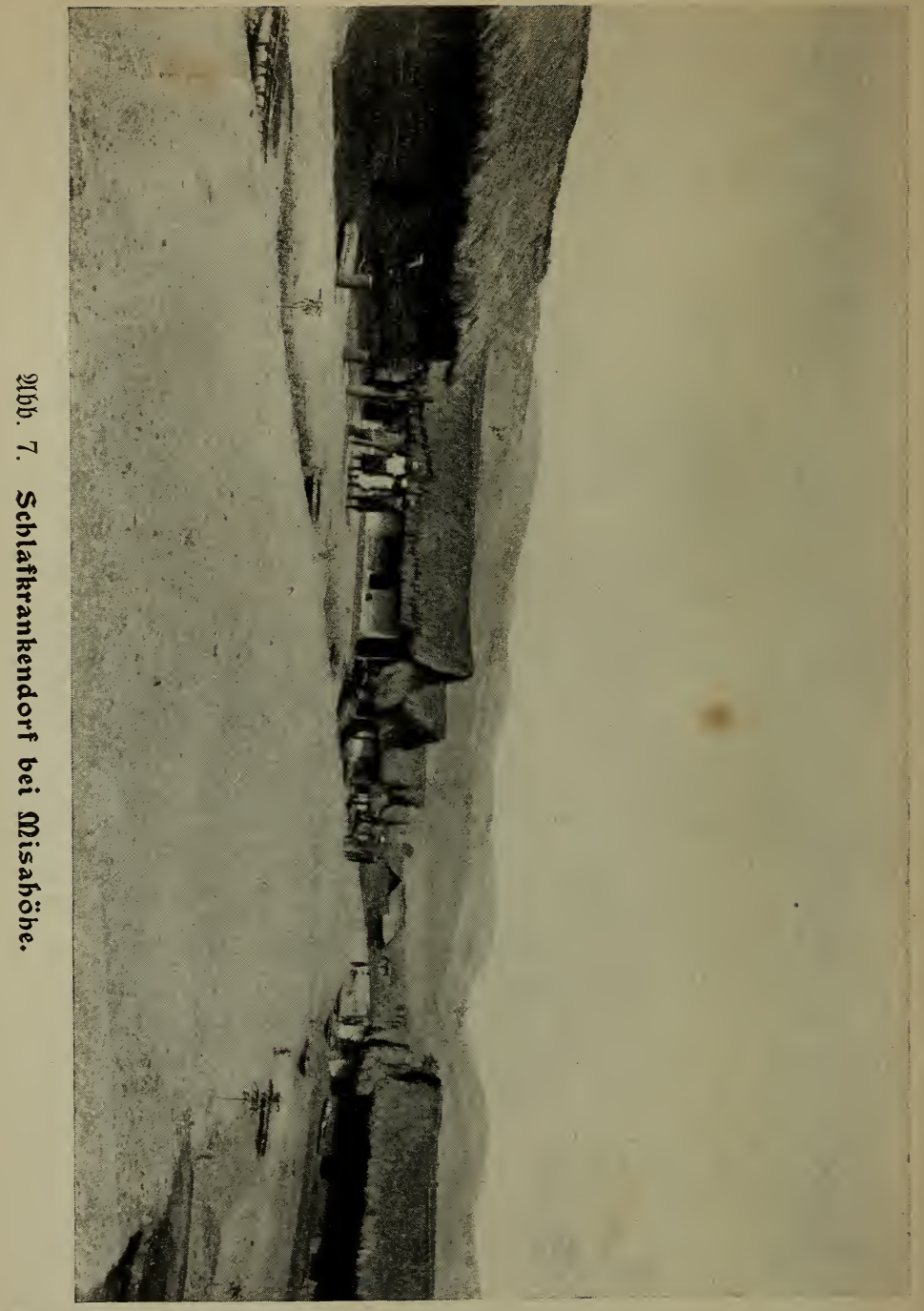


Land die Gălaffranfheit befämpfen, io müî̄en neben $\mathfrak{M a} \tilde{\mathfrak{B}}=$ nahmen, bie gegen bie Tietiefliegen geridtet find, wor allem bie $\mathfrak{r}$ ranfen an einen Drt gebradt merben, an meldyem feine Tietiefliegen worfommen. Dies ift nun aud wirflid in weitem $\mathfrak{U}$ mfreis um bas Sdhlaffranfendorf herum ber Fall.

$\mathfrak{U}$ m den Edhlaffranfen den $\mathfrak{A}$ ufenthalt im Dorf mögliajt angenehm ju mađhen, erlaubt bie Regierung, Dá nä̋jite Ângehörige Der ßranfen iie im Dorf verpflegen bürfen, ja fie jegt ben $\mathfrak{K}$ ranfen und ihren $\mathfrak{P}$ flegern ein Tagegelo aus, bas zu ihrer Berföittigung ausreidt. $\mathfrak{A} m$ Eingang bes Dorfs itehen bie Gebäude für Den $\mathfrak{A r}_{\mathfrak{r}} \mathrm{t}$, für $\mathfrak{A p o t h e f e}$ und Laboratorium. Leider jind bieje Gebäude jehr eng und flein geraten. Man merft baran etwas won ber Unter= ernäfrung dex Rolonie Durd) Das Mutterland. Das Dorf jelbit ijt jehr nett und regelmäß̈ig angelegt. $3 \mathfrak{u}$ beiben Eeiten Der breiten Sauptitraß̉e, weldhe das Bild zeigt, fïnd Mangobäume angepflanzt. In etwa jechs Jahren werben iie wohltuenden Edjatten und herrlidje Jrüdte ipenden. Linfs im Bild ift eine ber beiben öffentlidjen אühen zu iehen. Bor ihr itehen, in Den Boden eingerammt, vier ausgehöhlte Baumitämme. In ihnen wird ber Reis für die Bewohner geitoß̈en.

Das Dorf beherbergte damals 78 Ģlaffranfe. Ueber= all herriðte groß̉e Reinlidfeit und wohltuende Stille. Es

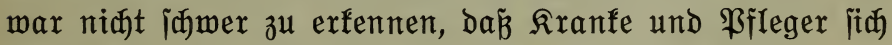
unter ber liebenollen Dbhut des $\mathfrak{A r z t e s}$ wohl fühlten.

Dberflädylid) betradytet iīt bas Sd)laffranfendorf eine nicht gerabe impoiante Einridytung, in Bahrheit aber ijt es ein berebtes 3eugnis des Beitbliứs, Der Shmanität und Der Energie Der Regierung, bie vor feiner Sđjwierigfeit $\mathfrak{z} u$

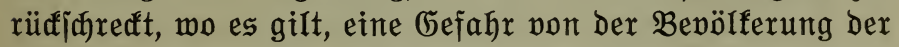

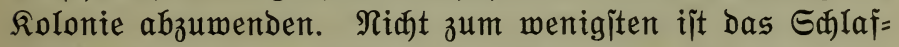
franfendorf und bie bort getane $\mathfrak{A}$ rbeit ein Denfmal hin=

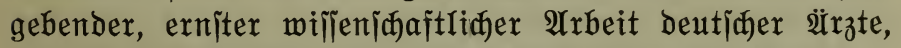
auf bie wix Deutiche mit allem Recht itol z jein fönnen. 


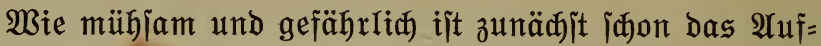
judjen Dex Gdfaffranfen in Den infizierten Dörfern! Nux wer bie Reger fennt, weiß̄, was für ein Rapital von Geduld und Rlugheit $d a \mathfrak{z} \mathfrak{u}$ gehört, alle Einmohner zur $\mathfrak{U}$ nterjudung zu befommen. Daju fommt nod die perjönlidge (5ejahr, ber man fị ausfebt, indem man längere 3eit in infizierten

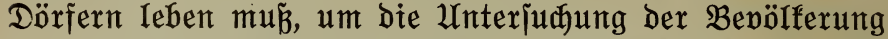
Durdjuführen. Die Berantwortung, Salafafranfe zu über= jehen und bamit weitere Rreije Der Bevölferung Der (5e= fahr, won der iđredfliden হranfheit befallen ju werben, aus=

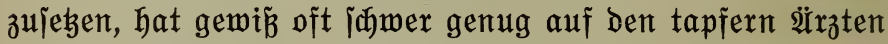

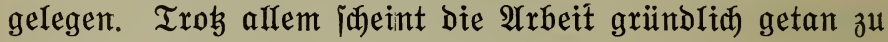
werben.

Bon Der aufreibenden, eintönigen 2 rrbeit ber $\mathfrak{P}$ flege ber Rranfen im Dorf melden mur fnappe Beridte und Tabellen. Die wenigiten, bie fie Iejen, haben eine flare Boritelfung von ber gewaltigen $\mathfrak{A}$ rbett, bie hinter ben furzen $\mathfrak{A}$ us= fübrungen und Tabelfen itedt.

So arbeiten bie ïrrate bort in bem weltfernen Dorf́. Sie menden Durd ifre Arbeit die furdtbare (befahr ber Sranfheit von Den Einmohnern Der Kolonie, unberïhrt pon Den Lodfungen Der Welt, bie ifnen auf andern Begen Reid $=$ tum und Ehre anbietet. Daneben hindern nod Die fnappen Mittel und die bedrüffende Enge ber Raboratorien. Niðt jum Iegtenmal in Togo befamen wir aber Den Eindruat,

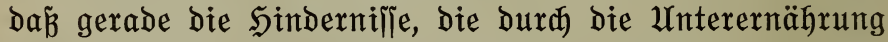
Togos gegeben find, niøht nux Durch Den Fleiß̄, Die Genüg= jamfeit und Tü円tigfeit Der Regierungsbeamten übermunden

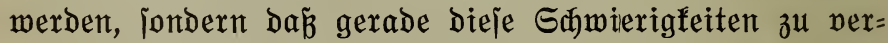
mehrter $\mathfrak{A r b e i t s l e i j t u n g ~ u n d ~ D e m ~ i t o l z e n ~ ( G e f u ̈ h l ~ f u ̈ ̆ r e n , ~ m i t ~}$ Den benfbar geringiten Mitteln wirflid $\mathfrak{B e w}$ undernswertes zu Ieijten. Wix jøieden von bem jonjt zu trüben Betrad)=

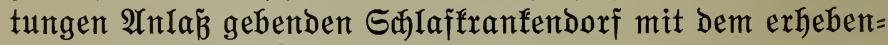

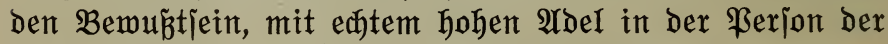
Dort arbeitenden $\mathfrak{U}$ razte in Berïhrung gefommen zu jein. 
Iuch gegen andere Bolfsjeuden wird in Togo ber Kampf jo energija als möglid) geführt. Die Bezirf́sleiter

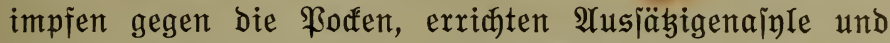
jorgen für Siolierung won an Gentufitarre Leidenden. Go hohe Inerfentung bies aber aud werbient, jo ift bod offen=

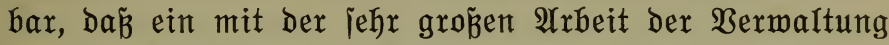
Der Bezirfe bejđäftigter Mann ganz unmögrid) (itđ aud noch in genïgender Weije der Befämpfung diejer Rrantheiten wiomen fann. Es liegt hier ein neues 3eidjen ber iđjon erwähnten $\mathfrak{U}$ nterernährung vor. Nux allein im Bezinf Some und Mijahöhe jind brei थ̈rzte, auß̉er bem einen im EdhIaffranfendorf; nadh Itafpame ioll einer itationtert werden, die gemaltig grożen Bezirfe Gofode und Mangu

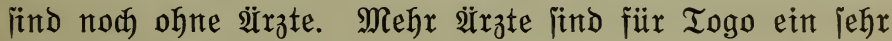
bringendes Bedürintis.

Bom Shlaffranfendorf fieht man gegen Sïben einen iteilen $\mathfrak{B e r g}$, in Der $\mathfrak{L}$ uftlinie etwa zwei $\mathfrak{\text { Rilometer ent= }}$

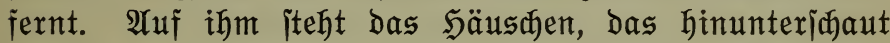

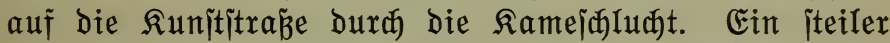
Weg führt an ber Lehne bes Berges ju bem einjamen $\mathfrak{S a u s}$ hinauf. Man jah eine $\mathfrak{A} \mathfrak{z} \mathfrak{a h \mathfrak { I }}$ Männer bamit bejuäftigt, den $\mathfrak{B e g}$ in Stand $3 \mathfrak{u}$ jegen. Regierungsrat Dr. Grutrer weilte gerabe in bem $\mathfrak{S a u s}$ und erholte iid von einem Sđ̆warzwa überitanden hatte. Die Gelegenheit, ben hodyerbienten

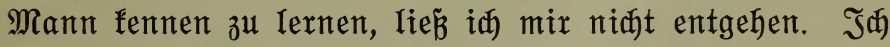
wurbe mit größ̈ter Freundidffeit aufgenommen, und es ent=

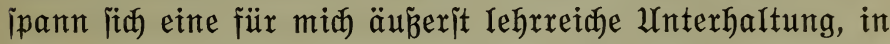
weldyer mix mein- liebenswärbiger (5ajtgeber aus feiner reiden Erfahrung Die Wege zeigte, weldye zur Entwidłlung Der Rolonie eingeidlagen wurben. Mit jeiner gütigen (5e=

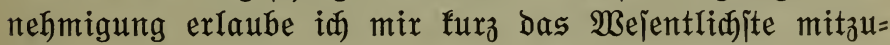
teilen.

Rarbem in ben neunziger Jahren bes vorigen Jahr=

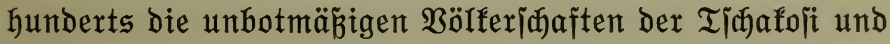


Dagomba in veridjedenen, für bie fleine Gdubtruppe fieg= reiden Ireffen gründid, unterworfen waren, wurbe aIs

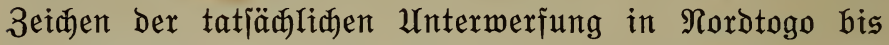
nad) $\mathfrak{O}$ tafpame im $\mathfrak{J} a \mathfrak{h r} 1898$ die Fronarbeit eingeführt. Jeber erwachjene, arbeitsfähige Mann hatte brei Tage für bie Regierung unentgeltlid o $^{\mathfrak{u}}$ arbeiten. Dadurd murbe es möglid, trob ber geringen bewilligten Mittel Stationen,

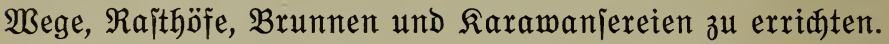
Im folgenden $\mathfrak{I} a \mathfrak{l}$ re wurde von Serrn Dr. Gruner dieje Fronarbeit aud im Mijahöhe=ßezint eingefïhrt. Es war die allerhörjite Zeit. In Der Borausitht, dá bie Ein=

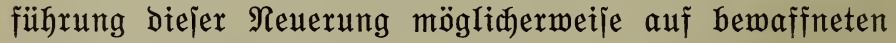
Bideritand itoß̉en fönnte, vermehrte man die Edjugtruppe bon 24 auf 100 Mann. Es ging haariðari an Rämpfen

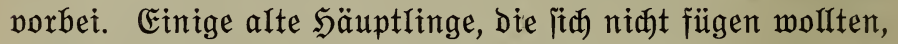

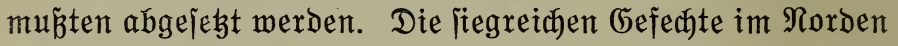
hatten aber Den Reuten Repeft eingejagt, und fie wagten es nidht, offen gegen bie Regierung aufzutreten; Dejto beharr= Iidjer leijteten fie paijitnen Widerjtand. In biejem 3weig menidhlicher Tätigfeit leijten unjere Bölfer hier anerfanter= maß̌en Bewunderungswürdiges. Es bedurfte grozerer Fejtig= feit, wohl aud etwa eijerner Strenge, bis enditid biejer Biberitand aufyörte. Die Fronarbeit wurbe zunädjit in ber Seimat ber Reute ausgeführt; ipäter permandte man bie Leute aud für $\mathfrak{A}$ rbeiten auswärts, Dodh wurben bann itatt acht Tage mux Drei Tage verlangt. Seit 1907 werden im Jahr zwei Bodhen Fronarbeit verlangt. Srhon im Jahr

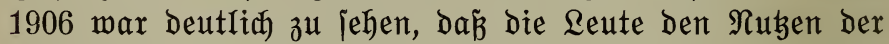
Fronarbeit erfannten. Ein unermarteter Gewinn berjelben

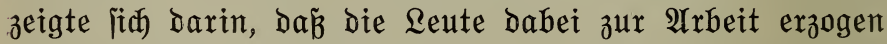
wurben. Âts Direfte Folge biejer (Erziehung madhte fith zunehmender $\mathfrak{B o h l i t a n d}$ Der betreffenden Stämme bemerf= lid). Im $\mathfrak{s} a \mathfrak{h r} 1907$ wurbe aud im jüblidjen Teil Iogos die Fronarbeit eingefïhrt.

Da (ith nach und nad ber Wohlitand gehoben hatte, 
mar es ein Reintes, an Stelle der $\mathfrak{A}$ rbeitspiteuer eine Geld= iteuer einzuführen. Die Reute freuten fing gerabezu, ifre Steuer nummehr in Geld entriaten zu fönnen. Boraus= fidtlid fann bie Steuer in etwa fünf Jahren in ben wohI =

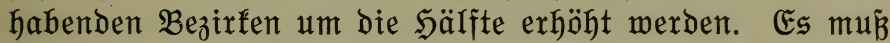
mit Genugtuung exfüllen, Dá̉ es gelungen ijt, troł der geringen Sđubtruppe ohne Rämpfe über dieje jđwierige 3eit hinüberzufommen. Es bedurfte aber einer zehn= jährigen, unaufhörliðhen, ermübend einförmigen $\mathfrak{A}$ rbeit. Jebt find es nur nod wenige Sinterwäldler, die ben Nugen ber Gteuerentridtung nod nidt einjehen. Die meitaus

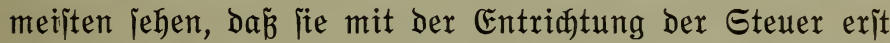
die vollen Reate von Untertanen ermerben. Bon Steuer und Jronarbeit frei find die arbeitsunfähigen Männer und jolahe, die längere 3eit franf maren. Jeber Jron= arbeiter und Steuerzahlex befommt eine Bejaeinigung hier=

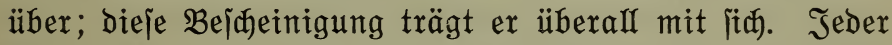
Polizijt fann die Bormeijung diejer Bejđeinigung verlangen, und bei Geriđtsperhandlungen দaben Rläger und $\mathfrak{A} n=$ geflagte inre Steuerzettel vorzumeifen. So gibt ber $\mathfrak{B e r}=$ fehr und die Berwaltung bie Mittel an bie Sand, modurá die Gteuerleijtung übermant werben fann.

Sajon oben erwähnte iđ die ßrfanzungen, die von ber

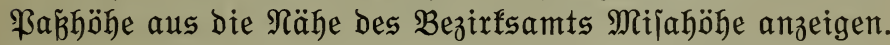
YUf jeder Regierungsitation itnd jebr anjehnlidbe Länder= itreffen mit $\mathfrak{B e r}$ ud jolden $\mathfrak{P f l a n z u n g e n ~ n o d ~ m e h r e r e m a l e ~ b e g e g n e n . ~ I m ~ M i j a = ~}$ höhe=Bezinf find joldhe Bflanzungen in Mijahöhe jelbjt, in So und in Rpando angelegt. $\mathfrak{A} u \tilde{B} e r$ diejen find weitere zwölf fleinere Berjuchsgärten angelegt, in welđen nur bie

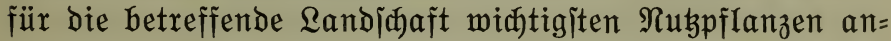
gebaut find. Eingeborene halten bieje Berjuðsgärten in Stand. Für dieje $\mathfrak{A r b e i t ~ m i r d ~ i n n e n ~ D e r ~ E r t r a g ~ D e r ~ G a ̈ r t e n ~}$ übermiejen. Sie jollen babura angelernt und ermuntert werden, die für ifre Randjaft pafienden Ruspflanzen jelbjt 


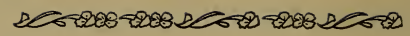

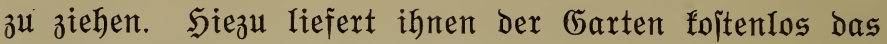
Gaatgut. Bejondern Rađborud legt bie Regierung auj bie IInpflanzung von ölpalmen. So gibt jid̆ bie Bermaltung alle erbenfliche Mühe, Nubbäume in ber Rolonie zu ver= breiten und folde aud an ben Strápen entlang anzu= pflanzen. Der Stráa burd die Ramejhludt entrang find Mangobäume gepflanzt, und zwar in jehr feinen $\mathfrak{U}$ rten. Die herne ber Frübte werden ihren $\mathfrak{B e g}$ in bie entregeniten Dörfer finden. Wo weniger bidter Sdratten ermünjht ijt, wird eine paflende $\mathfrak{A} f a z i e n a r t$ den Begen entlang ge= pflanzt.

Das alles find für joldhe, bie auf ber Goldfuijte leben,

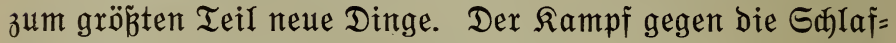
franfheit wird hier lehr läfilitg geführt, und füx bie $\mathfrak{A}$ us=

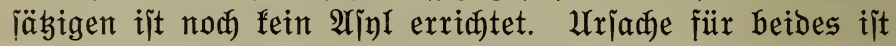

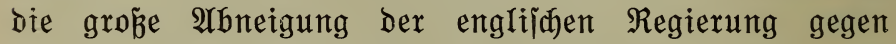
3wangsmä́regeln, und boch iit ohne joldhe ber Rampf gegen bieje Rranfheit nidht möglid). Eine Ropfitener gibt es auf ber Goldfiilte aud nidt, was allerdings von ben Bewohnern nidyt aIs Nadyteil empfunden wirb. In neuerer 3eit tut

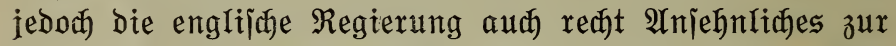
Sebung Der Landeserzeugnifle; aber es reidgt weitaus nidt

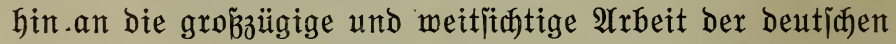
Regierung. Die herrlidjen Beitände von Teafholz, won Mahagoni, D̈lpalmen, Rautiðufarten und einer ganzen

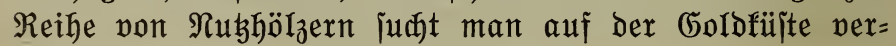
gebens.

Gdon jenfte fid die Sonne bedenflid, als id von bem

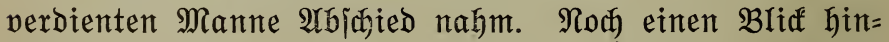
unter ins $\mathfrak{I} a l$, in weld,em bie Station Mijahöhe lieblid in iajönen, jauber gehaltenen $\mathfrak{A}$ nlagen gebettet liegt, hinaus in

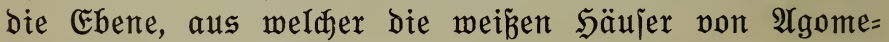
Balime uns entgegenleudten, hinïber an ben iđgönen (be=

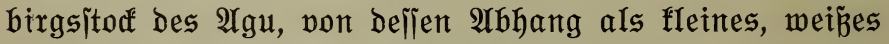
Pünftchen bie Bremer Miffínsitation $\mathfrak{A g u}$ herüberwinft. 
Bald ging's in jaujender Fahrt die herrlidje Gtraß̉e hinunter; redts liegt bas Bezirfsamt jirfa 600 Meter ab $=$

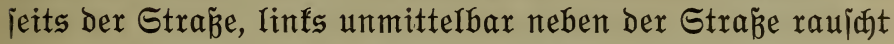
ber allerbings etmas bejheidene Gdimeinfurthfall. Die

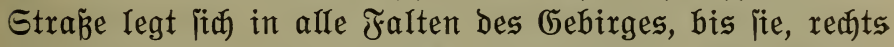
abbiegend, nad) $\mathfrak{A}$ gome=\$alime hineinfiihrt. Es herriøte nod reges Leben auf Den Strä̉en. Etwas aü̈erhalb Des Drts liegt bas iđmude Saus bes Regierungsarztes, bann reift fith ein Sandelshaus an bas andere. YUuf einigen Etraß̃en fojtete es Mühe, Durd Das (bedränge zu fommen, weil Rleinhändlerinnen auf offener Strä̉e ifre Waren:

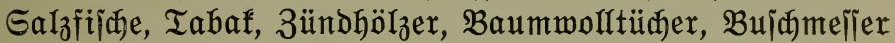
und Dergleichen auf Matten ausgebreitet hatten. Für biejen Rleintandel Dürfte wohl bie Erridtung einer Marfthalle niabt mehr lange auf jid warten Iaflen.

Nodh eine gute Beile Dauerte bas bewegte Treiben auf

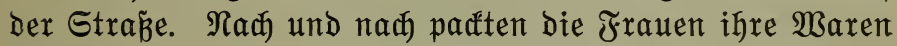
jujammen, und es wurbe itifler. Die Faftoreien ialoifen ihre Berfaufsläben, und Durd ben bämmernden Abend ertönte aus irgend einem ber benadjbarten Sandelshäuler ein Grammophon mit weitfin iffallender, tremolierender Etimme: „Deutidiand, Deutidland über alles."

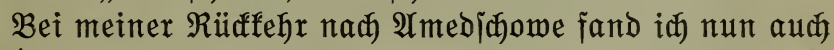
bie beiben mehrfach ermähnten Selden, Den hod Kmału mit bem gebrochenen Genitf und Den immer traurigen $\mathfrak{R}$ ru. Fïr eritern fand jiđ ber gemünjđte Erjagmann. Bir waren jo froh, Eriałg gefunden zu haben, bá̉ wir ein Bedenfen,

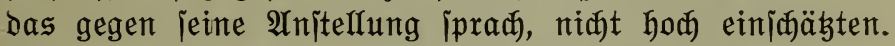
Der neue Rod, Lorenz mit Ramen, fonnte nur Eme und ein paar wenige Borte Deutið. Kru exidien hier als Rettex, Denn ex veritand Ewe. Ein anderes Bedenfen war,

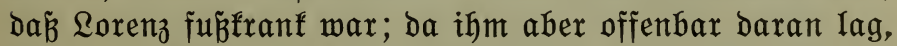

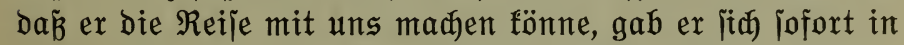
meine Behandlung und periidjerte gleid nacher, er ipüre Gedeutende Befierung. 
$\mathfrak{A m}$ 27. Januar langten meine beiðen Reijegejährten in $\mathfrak{A m e d j}$ ifowe an. Der eine von ihnen hatte nod als $\mathfrak{A n}=$ benfen an bie inlechten Bege auf ber Goldxiulte ein Lod gerabe über bem linfen $\mathfrak{A}$ uge und eins in jeinem Beinfleid

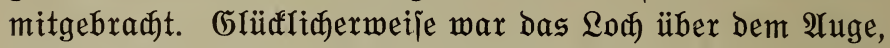
Durd Splitter bes einen Brillenglajes verurjadt, nidft be= Denflid). Das in ben Beinfleibern hatte ein kunjtweritän= biger Lehrer iđon auf Dem Bege mittelít eines redt= winfelig geiđnittenen Einjabes repariert.

\section{NorDwärts.}

Am 31. Jamuar braden wir auf und reijten nad ber Iebten Bremer Station $\mathfrak{A}$ kaju. Der $\mathfrak{B e g}$ jührt iteil Den Berg hinab, bann eine Beile am Juß ber Bergfette ent= Iang, bis er (ï) nad Norden wendet und ïber eine breite Ebene an Den Fun Der Berge von Eantrofofi führt. Wie

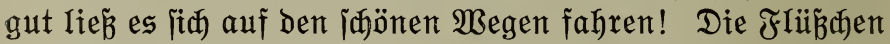
waren alle ïberbrüatt, und ber frijtallflare Daji war io ver= Iodfend, daßj wir alle brei ein exquiffendes Bad darin nahmen. Wir fonnten das wagen, Denn glǚflitherweije halten iid an jeinen 2 ffern bort feitre Tietjefliegen auf. Durd eine mit iळönen Fäderpalmen beitandene Ebene, zur Re(bten öptlid bie Gantrofofitberge, zur Linfen im $\mathfrak{B e j t e n}$ bie Berge von $\mathfrak{N t}$ thumuru, führt ber $\mathfrak{B e g}$ in bie neu an= gelegten Gantrofofiö̈rfer. Früher lagen fie hod oben in Den Bergen, wie bie $\mathfrak{H}$ atime $=$ und $\mathfrak{A}$ fpojobörfer, benn bort waren fie ficher vor feindridgen überfäflen ober fonnten boch Ieidyt verteidigt werden. Die Zeiten haben fid aber mun glïłfliłerweije geändert. Die Regierung jorgt für Frieden, und neue Erwerbsquellen öffnen ïd. I Im Tal jiehen gute

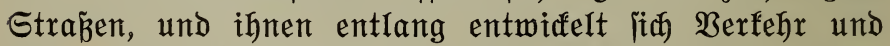
Gandel. Da fant man nidgt mehr broben bleiben, wenn man voranfommen will. Darum find bie Santrofofileute Ginab ins Tal geitiegen und bauen fith nun an ber Straß̉e 


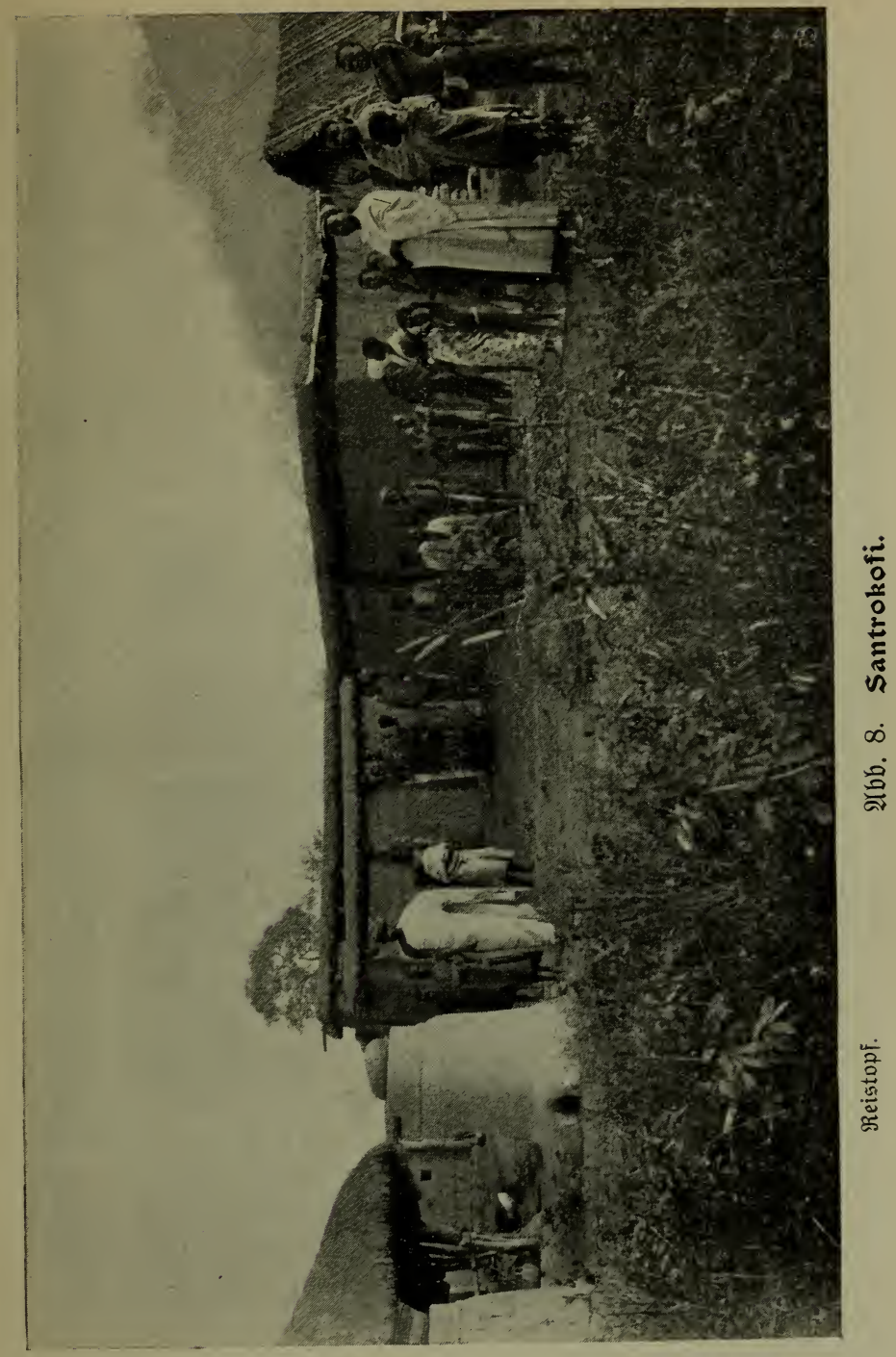


zwei neue Dörfer; aber die Bauart ihrer Säuler baben fie beibehalten. Wie ihre Bornäter bauen aud jie ihre Säujer mit flachen Dächern (भூb̆. 8). Sie legen auf bie Lehm= mauern iłrer Säuler zunäøjt eine Lage itarfer Baum= itämmđhen quer, barauf fommt eine engere Lage etwas bünnerer Stämmđen, und längs auf bieje wirb bann eine

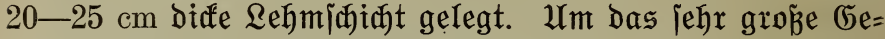
widt biejer Lehmjaidgt nidt ganz allein auf ben Mauern ruhen zul Iaffen, werden auf ber Rängsfeite zwei bis vier Etüben außerhalb des Saujes angebradt. Die Mohnhäuler ber Reute tragen alle joldhe flache Dä̈her, nur bie linf́s im Bild fithtbare Marfthütte und ber fleine Sdyreinerifuppen

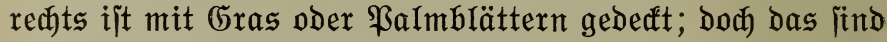
neumodijaje (5ebäude, bie man in ben uriprünglichen $\mathfrak{S e}=$

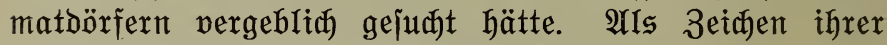
Runjtfertigfeit iteht neben ber Marfthalle ein jäner, aus Lehm geformter Reisbehälter, oben mit einem gefälligen

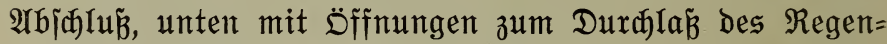
wailers. Das Ganze ijt nod mit heller $\mathfrak{S o l}_{z}$ ajde angejtridgen. 3ugededft wird ber Behälter mit einem runden, ipizen Etrohhut.

Bährend die Gantrofofileute ins Tal gezogen find,

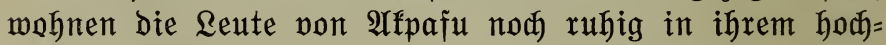
gelegenen Bergiattel, zu bem früher unheimlid iteile Bege Ginaufführten. Danf́ Der $\mathfrak{A r b e i t}$ won Bremer Mijifonaren

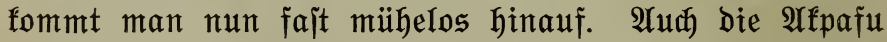
bauen ihre Wohnhäuler in berjelben $\mathfrak{A r t}$ wie ihre $\mathfrak{N a d}=$ barn, die Santrofofier, und überall zwijđen ben Säujern und an ben Grenzen ber Stadt itehen einzeln und gruppen= weije bie mit bem Strohhut zugededten Reisbehälter ber

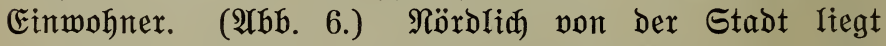
auf einer aniteigenden Stelle bes Gebirgsfamms bie Mi $\mathfrak{M}=$ fionsftation. Shr gegenüber, etwas hinter ber Stelle, von wo aus bie Stabt aufgenommen wurbe, iteht ein eigentüm=

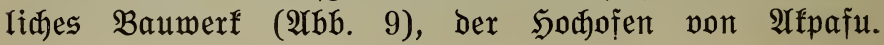


अu( ex hat ein flaches Darb wie die พohnhäu= jer der Stadt, und über jeiner Münbung ijt ein fleines Strohdä凸lein exridtet. Dex Dien hat einen iebr biufen sehmmanter, in welchem jeit = Iicheinige $3 \mathfrak{u g}=$ löber ange= bradt [ind. Nicht nux die äuß̃ere form des Diens jelbit ijt jehr veriate = den von den öfen, die wir ipäter in $\mathfrak{B} a=$ nyeli fennen lernen werben. Die Santrofofi $=$

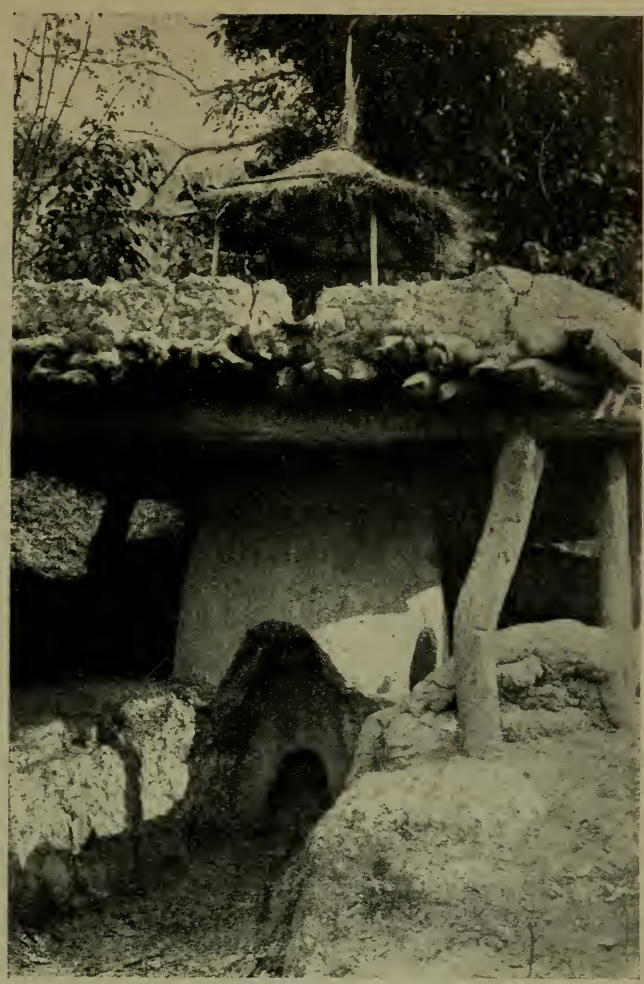

$\mathfrak{l b b}$. 9. Fochofen in Hkpafu.

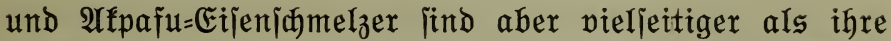
rollegen in Banyeli. Sie jømelzen nidht nur das Eijen, jombern fite jđmieben es aud gleid, und zwar barf bas nux mit von innen jelbit angefertigten eijernen Reulen ge= jळehen. Eijenjamelzen und Eijenjळmieden jind mit einer Reiłe uralter Gebräuđ̆e umgeben, und Meijter und Gejellen jind Durদ eine jorgf̈̈ltig gehütete Jnnung verbunden.

Bom Garten bes Mifítonshaules aus hat man eine

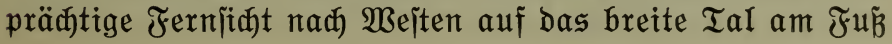


bes Bergzuges, auf dem Alfpafu liegt, und auf bie Berge

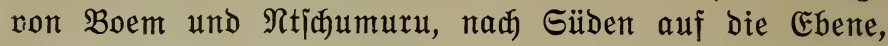
ïber weldhe wir won $\mathfrak{A}$ medidgowe her gereift waren, und bie

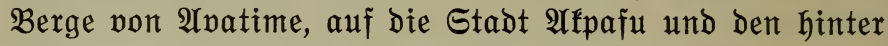
ihr iteil aufiteigenden, etwa 250 Meter höheren fegel= förmigen Berg, an weldyem die Biehherbe Der Station weibet. Răh Diten breite Täler und Das Togogebirge, fern im Sïbweiten bie Fortiegunt ber Bergfette, auf weldyer

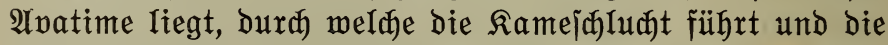

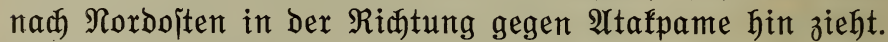

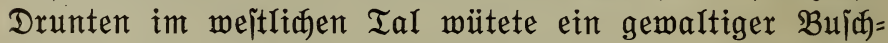
brand. Man hörte Das $\mathfrak{B r a f l e l n}$ Der Flammen und bas (5e= fnatter ber beritenden Grashalme. Die erhibte \&uft trug die perfohlten Blätter von Gras und Sträuthern bis zu uns herauf. Dieje Brände werben zum Ieil burd fleijøgierige Jäger angezündet, bie bann ben Brandherd umitellen und

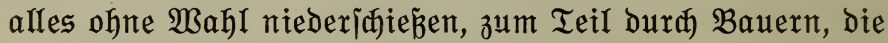
auf bieje Weije ihr feld vorbereiten. Nidgt mux zahlloje junge Bögel fallen joldfen Bränden zum Dpfer, jondern aud) eine Menge junges $\mathfrak{B i l}$.

Bei joldyen Gelegenheiten werben oft ganz junge 2 nti Iopen gefangen, bie zwar אraft genug haben, bem Feuer zu entrinnen, aber niđgt iđnell genug jind, Den Jägern ju ent= Iaufen. Bor brei Jahren war ein joldjes Tierdjen ben Mij= fitonaren in $\mathfrak{A} \mathfrak{k} p \mathfrak{j} \mathfrak{u}$ gebradyt worden. Sie hatten es gró̉ gezogen, und Das Tierdhen, eine weiblidhe Sditrrantilope,

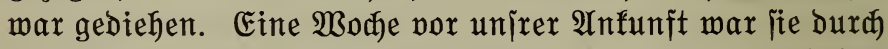
bie offen gebliebene Tür ihres Geheges entflohen, und der Jammer barob war jehr gró̉. Drei Tage ipäter itellte jiđ aber bas Tier bei $\mathfrak{R a h t ~ w i e b e r ~ e i n ~ u n d ~ i p a z i e r t e ~ w i l l i g ~}$ in lein Gehege.

Bon $\mathfrak{A} \mathfrak{x a f \mathfrak { u }}$ hätten wir mun einen ganz ordentridfen

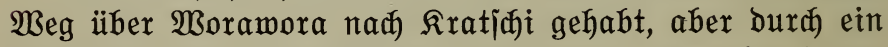
Mípperitändnis glaubten wir, unjer Beg gehe über Tapa. Der $\mathfrak{B e g}$ Dorthin führt Durd eine $\mathfrak{A} \mathfrak{z} a \mathfrak{h} \mathfrak{I}$ Dörfer, in benen 
Leute mohnen, die unjern Stämmen auf ber Golofiuite ver= wandt find und aud Tichi iprechen. Die Basler Mifiton hat fie früher jahrelang bedient, und barum war die Freube ber Chrijten in Gyeajefang und Boramora groź, als wir bei innen zu furzem Grü abitiegen. OIte Patienten famen, um für ihre Seilung Danf abzuitatten. Leider ijt in biejen Dörfern jabn viele Jahre die Shlaffranfheit heimifa. Die von Der Rranfheit Ergriffenen find indes alle in Dem Sa)laffranfendorf bei Mijahöhe untergebrađt.

Bohl hatten wix gehört, dá̉ dex Meg von Worawora nach Tapa (đ) limm jei, aber er übertraf unjere Befür(t)= tungen bei weitem. 3war führte ex zuerit gax frieblich ourch

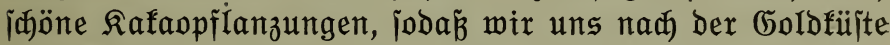
3urüctnerjegt fühlten, aber bald änderte fith das Bild. Die Gegend wurbe unfruchtbarer, der Weg führte meite Etrecten über blože Jelien, die nođ die Sonnenhibe fräftig ausitrahlten, objhon die Sonne bereits eine Weile hinter

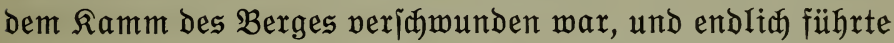
er über iteile Steimplatten bergan, jo iteil, da $\tilde{\beta}$ wir alle mehreremal zu Jall famen. Die Dunfelheit war zudem hereingebrohen, und nux die Blibe eines heraujatehenden Gemitters zeigten uns, wo unjere Fï̈̈e Salt finden fonnten.

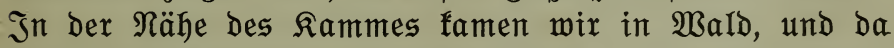
wurbe die Finjternis undurabringlich. Bon ben Reuten, die unjere Räber trugen, ging einer voraus und rief nach dem nahen Iapa hinüber, der Säuptling möge Laternen jđicfen, ba brei Europäer auf Dem Wege jeien. Nað furzer 3eit wurben orei Laternen gebradt, und nun ging's burch eine furze, aber fajt jenfredte Jelsidluat, ein jogenanntes Ramin, hinunter und in Das ganz nahe gelegene Dorf. Drei Europäex auf einmal einziehen zu jehen, war ein jeltenes

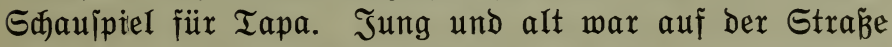
und folgte uns ins Säuptlingsgehöft, wo wir uns voritellten und unjern Danf für die po willfommenen Saternen $a \mathfrak{b}=$

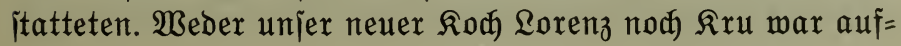


getaudt, und wo uniere Mosfitonege waren, Das wuß̈te natürlich niemand; aber in bem fleinen S(fultaus, bas $\jmath^{u}=$ gleid) als Kapelle bient, fanden wir 2 Interfunft. Der Lebrex, ein $\mathfrak{A}$ ngejtellter Der Bremer Mifjition, tat jein Möglidjites. Die Lebrersfrau forbte uns ein Radteflen pon Jams und einer etwas jehr abgelagert iđmed́enden 2 ntilopenfeule; jogar Tee braute fie uns. Den Mangel an Tellern, E $\mathfrak{E}_{\tilde{B}}=$ geräten und Tafien eriegten wir mit gutem $\mathfrak{5 u m o r}$ auf per= ifiedenite Beije. Nachdem wir aud nod) (belegenheit ge= habt hatten, die Chrijten zu begrïß̈en, ifnen den 3wed unjrer Reije auseinanderzulegen und eine furze, von Serzen

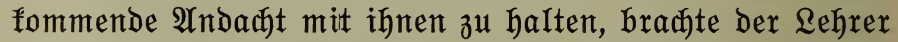
unjere Betten, in Geitalt eines Brettes für ben läntgiten von uns, einter Leiter für ben zweitlängiten und eines ver $=$ fradten Felobettes für den Rleinjten unter uns. Diesmal

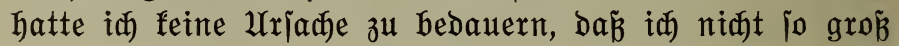
bin wie meine beiden Gefährten.

Frïh morgens - wir waren alle merfwürdig friih munter, wozu wohl bie "Betten" ihren Teil bazu bei= getragen hatten - verabifiedeten wir uns won unjern freundidien Wirten und itiegen aus biejem Feljentejt her= unter, auf Begen, bie Dem geitrigen $\mathscr{A}$ uffitieg ebenbürtig

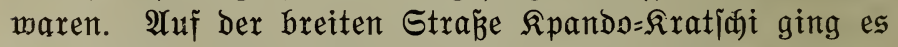
bann beffer. Wir freuten uns, bie Räber wieber beniizen 孔u föntten. Wix hatten es aud nötig, benn nod lagen

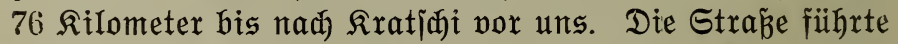
Durd Gegenden, die immer mehr Den Charafter Iichter

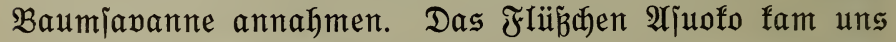
iehr gelegen; fein flares, über Quarz= uno braunes 2 (d)at=

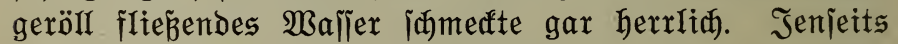

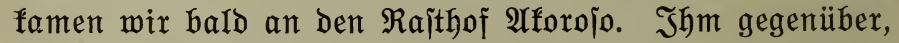
jenjeits Der Straß̉e, liegt Das Grab eines braven Deutīhen, bes meiland Dr. phil. Emil Rüiter, ber hier in ein= jamer Gavanne fein Leben im Dienite Iogos ausge= haudt hat. 


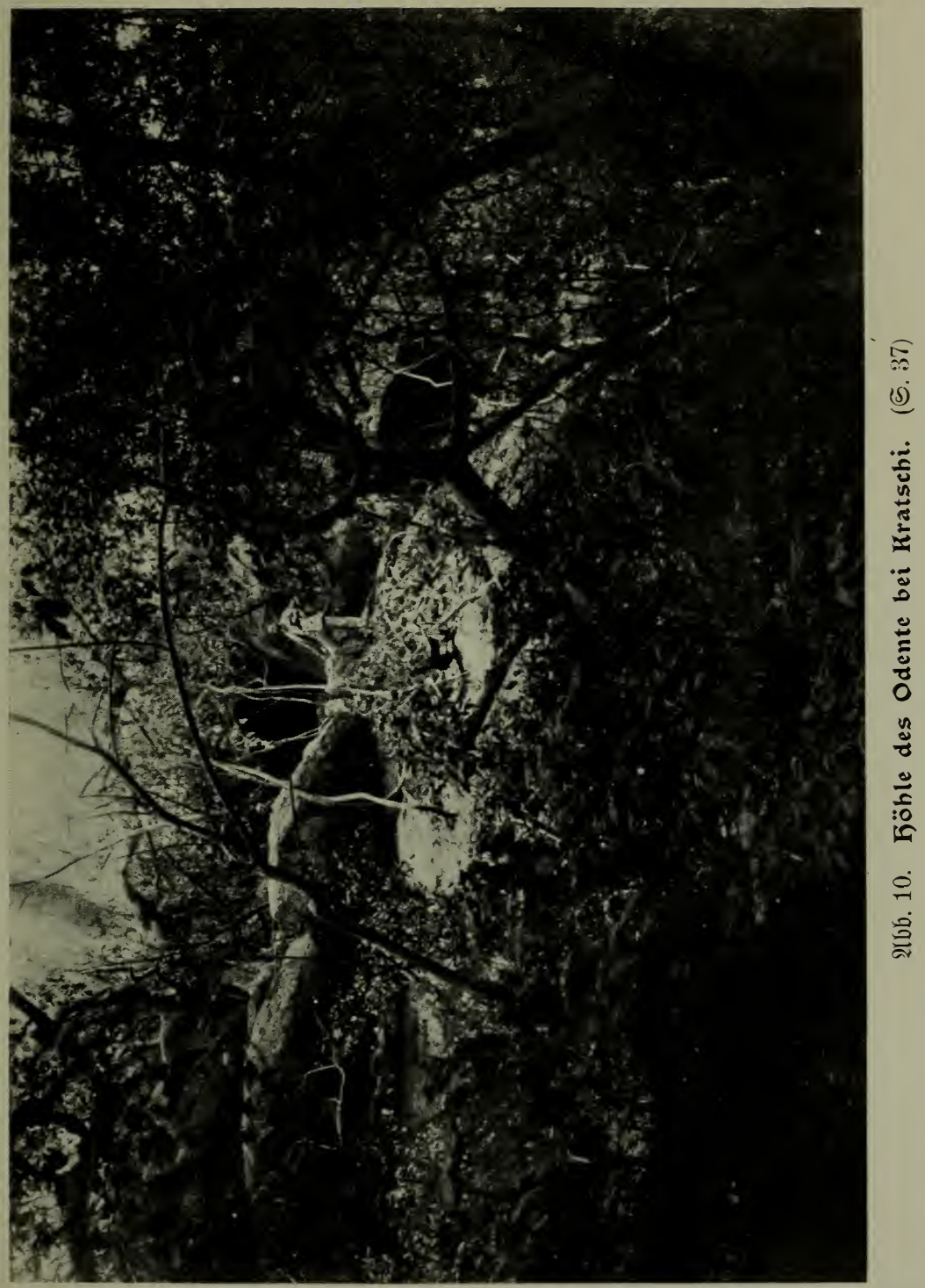



Immer unfrudtbarer und öber wirb die Gegend. Grok̉e Dunfelgraue Jelien liegen oft völlig îlädhenhafit neben Der Straß̉e und itrahlen die in ihnen aufgeipeidyerte Eomnen= hize aus. Das Gras der Gavanne ij̄t bürr ober auf groźe Stredfen hin abgebrannt. Mübe und buritig famen wir nad Ipajo. Gofort verjammelte fiø fait die gejamte Bemohner= ¡đaft um uns. Man brađte uns herrliches Bafler aus Dem nahen Bolta, und wir freuten uns, mit ben Ijøi fpreden= Den Einwohnern traulia verfebren ju fönnen. Es find meijt fräftige Leute, die mit Mühe Dem Boden ihren Unter = halt abringen; unter ifnen Iernten wix einen Säger fennen, Der fich, jogar an Elefanten und Römen gewagt hat. Wie fonnten wix anders, als ifnen etwas von Gottes Riebe, die uns glüalia und fröhlid madht, zu jagen! Wix hatten an ifnen aufmerfiame 3uhörer und injeden als Jreunde von= einander. Nað 50 Rilometer Jahrt famen wir nađ Dtijo,

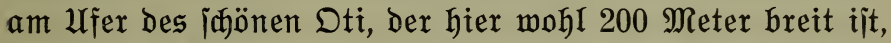
und dellen flares, tiefes Wailer zwijđen etwa jects Meter hohen Ufern faum merflich dahinfließ̈t. Im Rajthaus rubten wix ein wenig. Eine Regerfrau fodte uns einen herrlichen J゙lubfitich mit Jams.

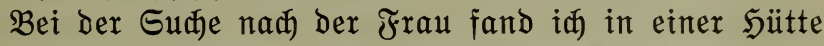

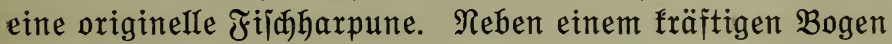

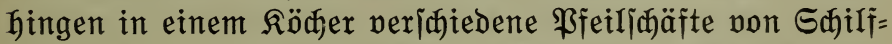
rohr; in einem Davon iterfte ein fonijøes Stüa Sol in diejem eine mit itarfen Widerhafen verjehene Pfeil= ipize. Eine itarfe Sanur ging von biejer Spize aus und

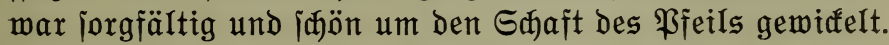

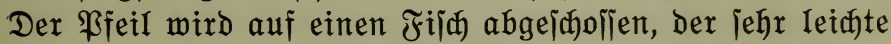

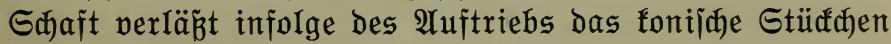
Solz, in welaem die Saxpune itedt, und bringt jo bie Sanur an bie Dberfläßhe, wo fie eingeholt und bamit ber Jij̄ heraufgezogen merden fann.

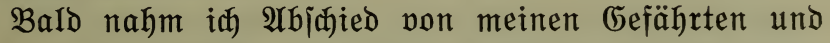
wollte in Rratiðt für uns Quartier beitellen, ba wir unjere 
Infunft nidgt hatten anmelden fönnen. Die Sike und Trofenheit jegten mir aber gewaltig $\mathfrak{u}$, und als id jiem= lich eridjöpft ben von ber liebenollen Miffitonsfrau in $\mathfrak{A}=$ pafu mir mitgegebenen Proviant verzehren wollte, über= fielen mid eine Menge fleiner Bienen, jegten fitd mix in bie Ohren, bie $\mathfrak{A}$ ugen, bie $\mathfrak{b a a r e}$ und wo jonit nod Plab vor=

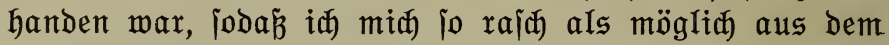
Etaube madhen muß̈te. Die Irof́enheit hatte hier ganz ungewöhnlihe Grabe erreidt. Einige Rilometer vor bem.

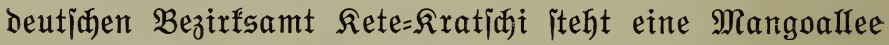
Der Strá̉e entlang. Biele Blätter waren Durđ bie Irodfen= Feit abgefallen, und bieje zeriprangen in viele Stüffe, wo fie unter meinen Fú ober unter Das Rab famen, mit einem.

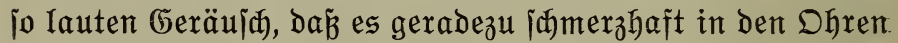
empfunden wurbe. Wiederholt bemerfte id fleine $\mathfrak{B i n d}=$ wirbel, Durch bie trodfene Blätter aus den an bie Straß̉e: angrenzenden $\mathfrak{B f l a n z u n g e n ~ h o d ~ i n ~ b i e ~} \mathfrak{L}$ uft binaufgetragen. murben. Beim 2 nitó̉en aneinander und an bie Stämmán. ber Bäume murbe ein Gefnatter perurjaht wie bei einem. Grasbrand, went die Glieber Der Grashalme burah die Sige beriten. Der bamalige Bezirfsleiter nahm midh mit groß̈er Freundlidfeit auf und Iub uns ein, feine Gääte zu jein. Exr

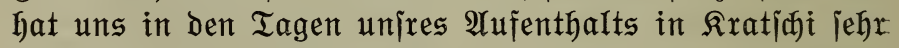
gró̉e Dienite geleijtet; nicht nux haben wir jeine (5ajt= freundianaft geniésen bürfen, jonbern ex hat uns aud mit Trägern für unjere Gadhen perjorgt und fie mit einer idneidigen $\mathfrak{A n j p r a c h e ~ z u x ~ r e c h t e n ~ 3 e i t ~ a u f ~ b e n ~}$ Beg ge= bradt.

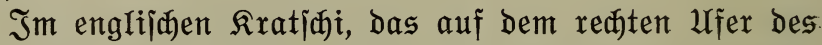
Bolta liegt, wurbe uns von Raufmann $\mathfrak{S u t t e r}$ und bem eng= Iijhen Regierungsfommi îar jehr viel Freundichleit ex= wiejen. Im Sauje bes lebtern fonnten wir audi die aus. veridiedenen Gebieten der Golofiijte hieher gezogenen. Chrijten unierex Gemeinden am Sonntag um uns ber= jammeln und mit ihnen Gottesdienit halten. So iehr wir. 


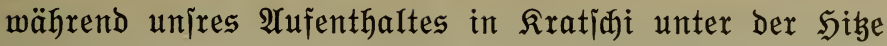
zu leiben hatten, jo freundich waren bie Tage für uns. Uniere Iraglaiten waren furz vor uns auf Dem Wajiermeg den Bolta heraũ angefommen und muß̈ten nun zum Ieil umgepadft merden. Unjere Räber maḑten uns Sorgen, bent ein Ruftið)laud nad dem andern wurbe an ber Stelle, wo er zujammengejegt war, unbicht.

Was হratiat weit und breit berühmt gemađt hat, ijt die Gottheit $\mathfrak{D} d$ e $n$ te. Früher wohnte fie in einer Söhle bei bem Dorf Rate auf Der Gold füite; fie murbe aber bort von vorwigigen Leuten baburd beleidigt, ba $\tilde{\beta}$ fie unver= jehens fie aus ihrer Söhle hervorzogen. Bei ber Gelegen= heit jă man, bã bie Gottheit ein Menjă jei, bem eine hier

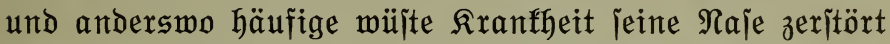

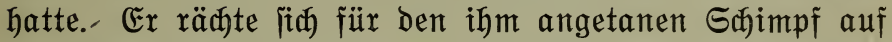
jeine Weije und floh dann nah Rratiði. Seine Madt und

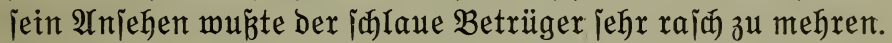
Er iđrecte niळt por Giftmorden und andern Greueltaten zurüßf, bis ifn endid die Regierung ergreifen und er=

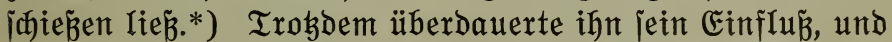
jegt noch itehen in jehr vielen Dörfern ber Goldfüite bis nach $\mathfrak{X}$ jante hinein und in vielen Dörfern in Togo Arbleger biejer Gottheit in Gejtalt von fegelförmigen Lebmbaufen, unter Denen nidst felten die Gebeille eines bei jeiner Er= riøtung bargebrađten Menjđenopfers liegen. Der Bezirfs= leiter max fo freunolich, uns auf einem Dienitgang, ben ex zu der Göhle, in welder die Gottheit wohnen foll, zu madhen hatte, mitzunehmen. Der $\mathfrak{B e g}$ zu ihr führt auf Dem linfen Ufer bes Bolta einer Fluß̈terraile entlang, etwa einen Rilo= meter fluß̧abmärts. In ben bort itehenden Galeriemald ijt eine breite Straß̉e gehauen. Das Borb der Flub́terralje ijt von mäđtigen grauen Greisfelien gebildet, die regellos

*) Siehe Traftat: „Der Fretijđ Ddente." (Mifítionsbua)= hanblung $\mathfrak{B a j e l}$.) 
ïbereinamber aufgejđichtet die 15 Meter hohe, Ianomärts gelegene Wand ber Flüterrafle bilden.

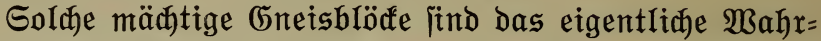
jeiden won Rratidi. Mit ibren abgeidliffenen formen marhen fie Den Eindrud non riejenhaftem Flügejdiebe. Durd eine breite $\mathfrak{A}$ nhäufung biejer felsmaflen itaut jiđ ber Bolta etwa zwei Rilometer oberbalb Rratiad, bildet Dort eine leeartige Ermeiterung und zwängt bann leine Bafler in vielen fleinen $\mathfrak{B a f l e x} e$ fällen und Stromiantellen

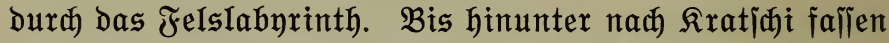
Felsblörfe den Lauf bes flulfes ein und liegen zu beiben Seiten bis weit ins Rand hinein. Sie bilden bie Ruft=

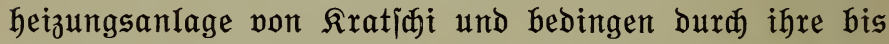
tief in bie Radht hinein fortbauernde $\mathfrak{A}$ usftrahlung ber tags= über aufgenommenen Sonnenwärme bie bejtändig hohe Temperatur von Rratidi. Das Sindernis der Sdjiffahrt Durd bieje Feljen ijt auf ber englifiden Seite burdh eine iehr bejheiden ausjehende Eingeleijebahn bis zu einem ge= wiflen (5rad überwunden.

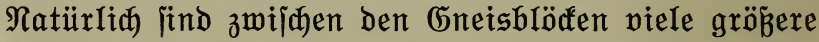
ober fleinere S̈̈̆hlen und ipaltartige 3wi jagenräume. Ein jolder 3 wijøenraum, ber ben Borteil breier $\mathfrak{A}$ usführungs= gänge hat, einen landeinmärts und zwei fluṕpärts, wurde von bem ¡đIauen Fetijđpriejter als ßohnung des Jetijđes exflärt. Die Bejđaffenheit diejes Raums und jeiner $3 \mathfrak{u}=$ gänge bot bie Mögliłfeit, jeberzeit geheimnisvoll zu er=

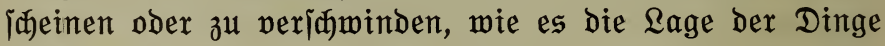
erforberte. Der eine breite Zugang flǘpwärts war mit Steinen und Lebm bis auf einen iamalen Spalt oben $\mathfrak{u}=$ gemauert, und vor bieje Mauer war ein weí̈es, baum= wollenes Iud gehängt. Der zweite, flup̉märts gelegene, iehr nerbefte Eingang war frei. Beim Betreten bes iđmaren,

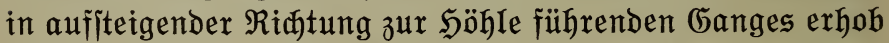

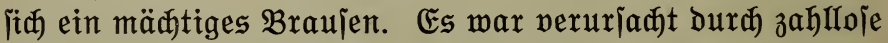
groß̉e Fledermäule, bie in ber Ş̈̈hle und im engen Gang 
geiðlafen hatten und mun bas Beite juaten. In ber Şöhle jelbit lagen einige Saufen leerer Shnapsfiajan, ein paar rojtige eijerne Exellen, wie fie von ben eingeborenen $\mathfrak{A} u s=$ rufern gebraudit werben. In einer Shale lagen zugebedt ein paar ßnołen eines jungen ßavians. Der Ianbeinmärts gelegene 3ugang ījt Dura den auf Der Söhle liegenden

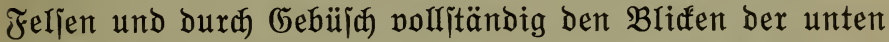
auf ber Flubterrafie Stehenden entzogen. Es ijt fajt un= glaublid, wie die Iajđenipielerfünite bes Dontepriejters und jeiner Gehilfen in einem joldhen Umfang die Bevölfe=

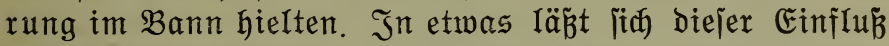

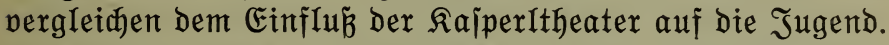

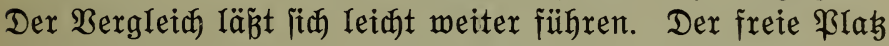

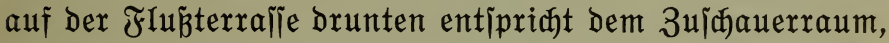
ber Jels vor ber Söhle ber Bühne, die Sö̆le jelbit und ihre geheimen Eingänge Dem geheimnisvollen Jnnern eines jolanen Iheaters. Der grojartigen, wilben Realität diejes Theaters entipricht die graule Birflidfeit der vom ßriejter ber Gottheit im Ramen bes Jetijøes begangenen Morbe und (5reuel. Gott jei Danf, dá̉ diejes entjeblidhe Theater von

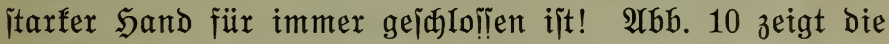
Söhle; in Der Mitte zwijhen meinen beiben auf dem Jeljen itehenden Gefährten befindet fiđ Der vermauerte breite Ein= gang, ređts von bem in ganzer Figur fichtbaren Miffitonar Groh führt ber geheime Weg von vorn in bie Söhle. Das

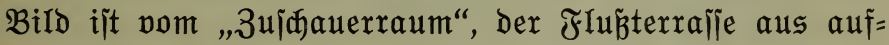
genommen.

Die ausgedehnten $\mathfrak{x u g h o l z p f l a n z u n g e n ~ i n ~ b e r ~ \Re a ̈ h e ~ d e s ~}$ Bezirfsamtes hatten jehr unter dex Size und groz̉en Irodfen= heit gelitten, jo die jü̈nen Mangoalleen, welde den Eträ́en entlang gepflanzt maren, und es erforberte beitän= bige Wadjamfeit, um fie vox plöblich ausbred)enden (5ras: bränden zu jđüzen. Es war zwar ein breiter Streifen auzer= halb Der Pflanzungen pon Gras befreit, aber troboem mar es porgefommen, dá̉ eine Teaf́pilanzung Durá Flugfeuer 
eines nahen Grasbrandes werheert worden war; jogar bie bedeutende Drtianaft Rete fam während urires Aufenthalts in $\mathfrak{x}$ ratijhi in Gefahr, in flammen aujaugehen. Die vom

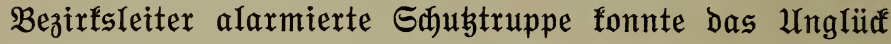
mit Mïhe abwenden.

\section{Bon Rratidi nad Jendi.}

$\mathfrak{A} m$ 8. Februar exifhienen bie Träger für unjere Gadjen. Der Bezirfsteiter hatte fite für uns gütigit requirieren Iaflen,

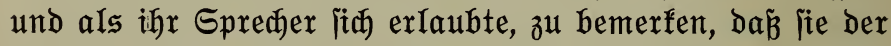

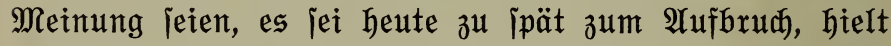
unjer freundianer Gajtgeber eine io ianeibige beutiðe $\mathfrak{A} n=$ iprache an jie, báz alle Bedenfen jofort veritummten und bie Reute ianellitens ihre Traglajten auf bie Röpie nahmen

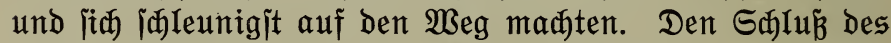

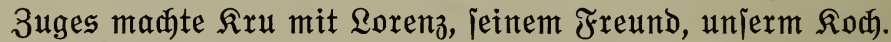

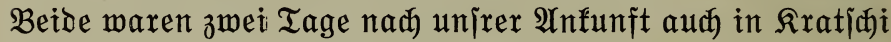
eingetroffen, und objđon mir Lorenz auf meine Frage, wie

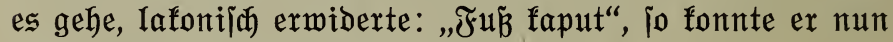

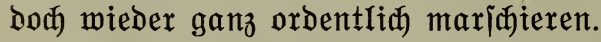

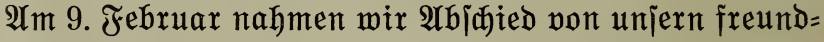
Iidhen (5ajtgebern, und nun fing unjere eigentridje Reije an. Es war ein herrlider Morgen, an bem wix vom Bezirfís= amt weg auf Der ¡đjönen Strä̉e burdh Rete und bann ins Land hineinfuhren. Sehr häufig begegneten uns fleine Karawanen, Treiber mit Iajttragenden Ejeln. Siebzehn Rilometer vom Bezinfsamt famen wir nad) Tariajo, nad) weitern 28 Rilometern nad $\mathfrak{K}$ wajifo. Die Ėinwohner find Iinj iprechende, aljo den Goldfiütenegern vermandte Stämme. Kmadjifo hei ob ber Name auf ben größten Teil ber Einmohner nidgt übel pafien würbe, wenigitens jahen bie Dörfer und Säujer ganz barnach aus. Die Gegend war nidgt mehr io aus= gebörrt, wie um Kratida herum, es fehlten aud bie ihlimmen Sibejpeidher, jene grauen Eneisfeljen, die uns 


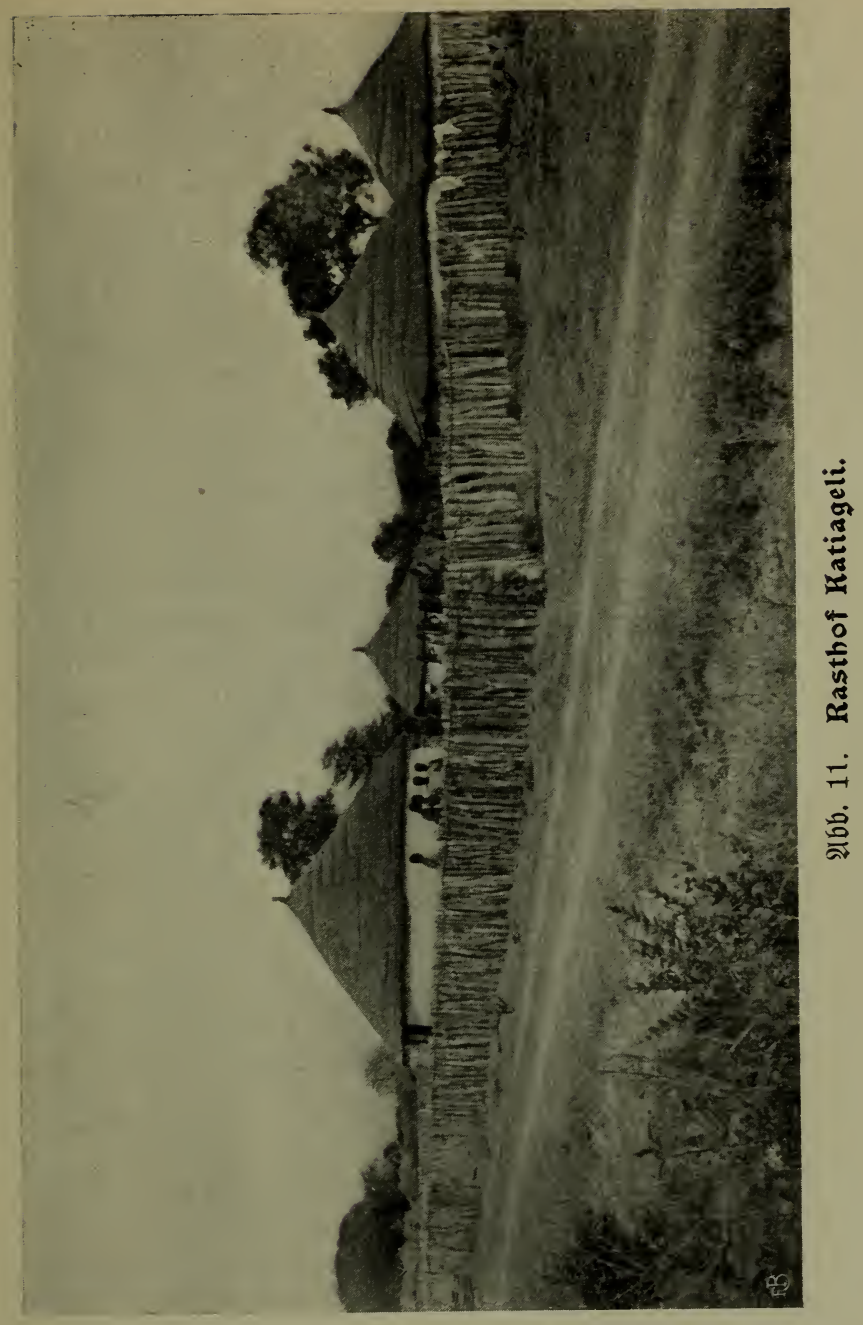


jo viel überflüilige Wärme abgegeben hatten. In ber Baumjavante zu beiden Seiten ber Strá̉e fing es an zu iproflen und zu grünen. Ein nieorigex Baum erfreute uns bejonders mit idjönen hellvioletten, in Rijpen itehenden, zarten, glodenförmigen Blüten mit herrlidem Simbeerouft.

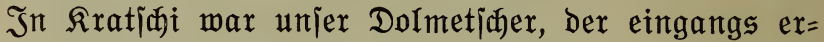
wähnte Raterhijt Sefu Ramiener, von Rumaje fommend, zu uns geitożen. Sein Fahrrad jollte uns gleid) aus einer

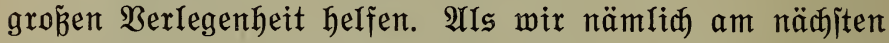
Morgen wohlgemut in bie im Friiglidyt erjtrahlende $\mathbb{L} a n d=$

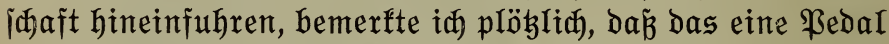
meines Rades jidh gelofert hatte. Der jofort angeitellte

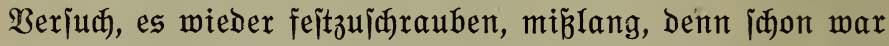
bas Geminde jehr ihadhaft geworden. Ulm basjelbe nidat

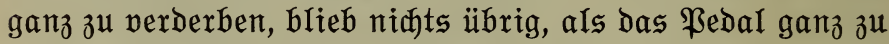
entfernen und ju hoffen, da $\mathfrak{B}$ es gelinge, in Bimbila ober bod in Sendi Galolierwerf́zeuge zu finden, mitteljt deren es gelingen möđte, Den Gdyaden zu bejeitigen. Bis Dorthin muk̈te iđ baher unjers braven Dolmetiders Rab brauden. Rur mit einem $\mathfrak{B e d a l}$ zu fahren, ging wegen bes Freilaujs

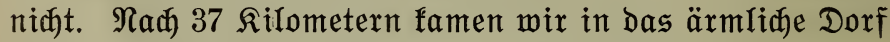
Ratiageli, bei bem ein iehr netter $\Re a j$ thof iteht, in weldhem wir. ganz gut aufgehoben waren.

Jeder in Iogo Reijende wird $\mathfrak{U}$ ra ache haben, das

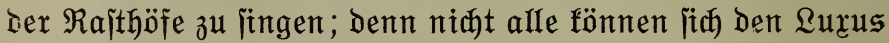
erlauber, ein 3elt mitzufiüren. 2Nbb. 11 zeigt den Raithof in Ratiageli, und nebenitehender Grundriß̈ mag jum $\mathfrak{B e r}=$ itändnis des Bildes etwas beitragen. Der Sof iit mit einem joliben 3aun won eingerammten $\mathfrak{P f a ̈ h l e n ~ e i n = ~}$ gefriedigt; vorn beim Eingang von Der Strä̉e her iteht bie groß̉e Rundদütte für Den Reijenden, den Seiten entlang

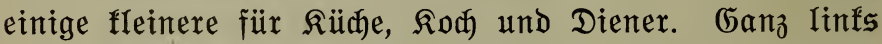
im Bild fieht man eine $\mathfrak{A} \mathfrak{z} a \mathfrak{h l}$ fräftiger $\mathfrak{B o h l e n ~ a m ~ Z a u n ~}$ aufgebaut; iie jind für Reparatur ber Brüafen auf ber nähjitliegenden Streffe bejtimmt. Dieje Rajthöfe find von 


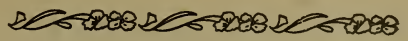

Den Şäuptringen Dex Dörfer ou exbauen und $\mathfrak{u}$ unter $=$ halten; aud für bie Bebür $\tilde{f}=$ nilīe der Reijenden haben die Säuptlinge gegen ange= meijene Entichäbigung $\mathfrak{u}$ jor gen. Die Runbhütten bieten reichlichen Raum. Weil aber das Da⿱ die Mauern nidt gegen die Beitrahlung Dura die Gonne jđübt, ermärmen itø die Mauern beträdtrich und Galten die Temperatux

Rasthof.

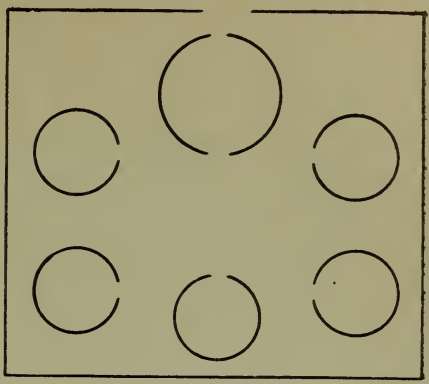

Ibb. 12.

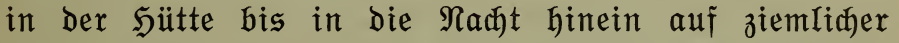

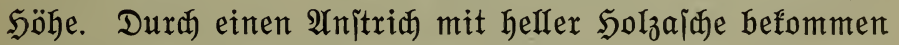
die Sütten ein rectit freundiches $\mathfrak{A}$ usjehen.

Bon Rratjhi an ijt bas হand jehr eben, weber über= iareitet man Berge, noch find melde in ber Nähe. Die

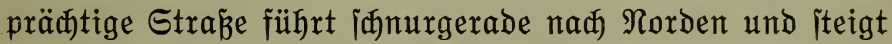
nux $\ddot{u}$ ber menige meterhohe Bodenerhebungen, bie mehrere Rilometer auseinander liegen. Dementiprediend zeigt itch

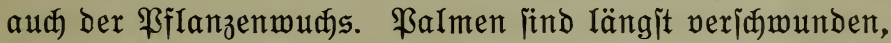

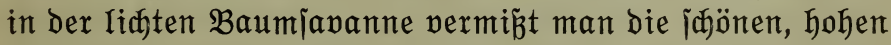
Riejenbäume der jüblich gelegenen Gebiete, Der Baummuds erinnert an benjenigen in Europa in liatem Raubwald pon $20=$ bis 30jährigen Eiøen. $\mathfrak{A} n$ joldhe Bäume exinnern bejon= bers die immer häufiger werbenden ভđibutterbäume. J⿹re Jrühte in Dex Größ̉e von fleiten Üpfeln bejtehen aus einer

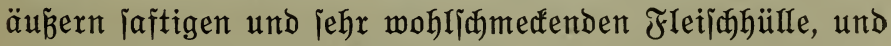
einem Rern von etwa Dattelgrö̈e, aus meldem bura 3er=

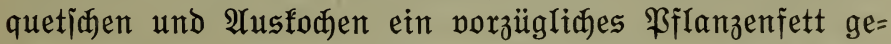
wonnen wirb. Ein anderex, ebenjo gejđägter Baum, bie Barfia afrifana, der Damadamabaum wirb immer zahl=

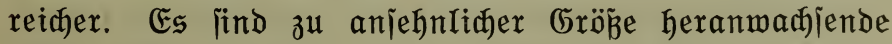
¡đöne Bäume mit paarig gefiederten Blättern. Die 
Blüten itellen rote RugeIn von 4-6 cm Durchmefier bar. Sie find gebildet Durd einen didffolbigen Blüten= boden, auf weldaem unzählige, fleine, rote Blüten in feinen Epirallinien itehen. Dieje roten $\mathfrak{R}$ ugeln hängen an 20 bis $25 \mathrm{~cm}$ langen berben Stielen. Die Frühte find $20-30 \mathrm{~cm}$ Iange Sdgoten; bieje enthalten fleine, bohnenförmige Rerne, bie in eine intenfity gelbe marfähnlide Malle eingebettet jitrd. Bon ber Rinde bes Baumes und bejonders aus ben

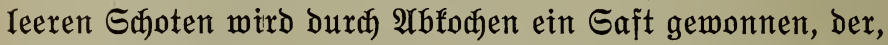

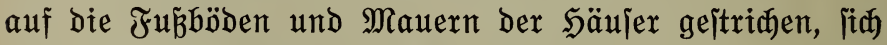
innig mit bem Rehm verbindet und ing hart und itaubfrei

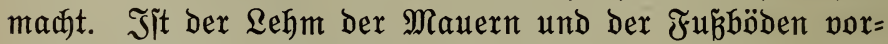
her jorgfältig geglättet worben, io befommt er burd einen joldjen $\mathfrak{A n j t r i d}$ etwas wie eine $\mathfrak{B o l i t u r}$. Diejem Saft ver= Danfen bie Dörfer und Raithöfe Der nörditanen Gebiete ihr

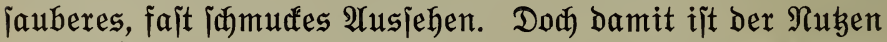
ber Barfia noch nidjt eridjöpft. Das gelbe Marf der Schoten wirb getrodfnet, in $\mathfrak{y o l}_{3}$ möriern gejtoken und bildet dann ein jehr feines, gelbes $\mathfrak{B u l v e r , ~ D a s ~ a n ~ G a f r a n ~ e r i n n e r t ~ u n d ~}$

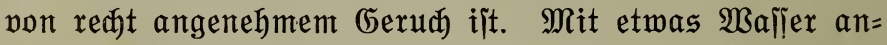
gerührt bildet es eine jebr beliebte, geiunde Bolfsnahrung. Die Rerne ber Gdoten endidi werden mit einigen andern Pfianzenitofien, Deren Serfunft id nidyt feititellen fonnte, ju braunen fladen oder $\mathfrak{R} u g e l n$ geformt und als iehr ge=

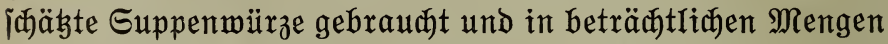
an bie jüblinger mohnenden Gtämme verfauft. Ein Neger fennt nidfts Göheres als eine mit biejem Stoff, Dem Dawa= bawa, veriebte Guppe. Europäijđem (5eidmad dürfte der 3ujał meniger behagen.

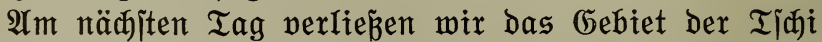

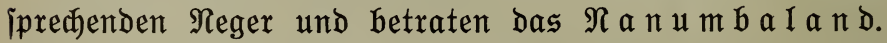
Das erite Ranumbadorf an ber Straß̉e hei

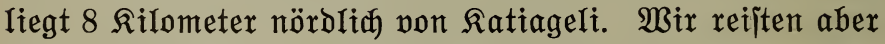
nod) 21 Rilometer weiter bis zum nä̋jiten $\mathfrak{R a j t h o f ~ i n ~} \mathfrak{W u}=$ Iendjui. 
Di e $\mathfrak{R}$ a $\mathfrak{u} \mathfrak{m} \mathfrak{a}$ find bas exite $\mathfrak{B o l f}$, mit bem wix uns $3 \mathfrak{u}$ bejääftigen haben im Blif auf eine unter ifnen $\mathfrak{u}$ eröffnende Miffion. Shr Gebiet reid)t von Rpandae im

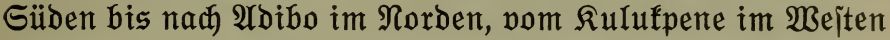
bis zum Dti im Diten. Der fleine Stamm zählt annähernd 20000 Menjøen. Sie find mit den nörblið pon ifnen mohnenden Dagomba (ridtiger: Dagbamba) jehr nahe ver= manot; ihre Eprache ift ein Dialeft Des Dagbane, der Sprache der Dagomba. Die Sauptitadt ihres Stammes ijt $\mathfrak{B} \mathfrak{i} \mathbf{m} \mathfrak{b} \mathfrak{I} \mathfrak{a}$.

Die Männer tragen aus berbem einheimijøem Baum= wollitoff verfertigte, hembenartige Leibröre, die bis in die

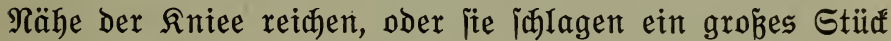
einheimijøen oder eingeführten Baummollitoffs um den Rörper und über bie linfe Srulter. Frauen tragen joldie Tüher über bie Brult oder ben Leib gejalungen. Niat jelten fieht man die weiten Beinfleiber und Leibröre, wie ite die mohammedanijøen S్ auja und Fula tragen.

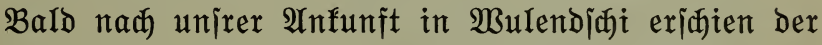
Stellvertreter Des Säuptlings mit zahlreichem Gefolge. Er bejhenfte uns mit einem S్bun und vielen Jamswurzeln. Wix madten gleich nawher unjern Gegenbejuch und fanden Den Säuptling lelbit in ber Eingangshütte zu jeinem Gehöft auf einem erhöhten ßlab zwijhen mäׁtigen, mit Leder überzogenen నifien mit untergejđlagenen Beinen am Boden

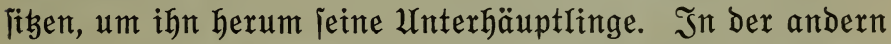
Sälfte der jehr geräumigen Runbhütte jtand jein ßjerb, mit einer (Slơfe am Shals, gemäd) lich furz gerdnittene Salme von Gorgum fauend. Das Säuptlingsgehöft in $\mathfrak{W u =}$

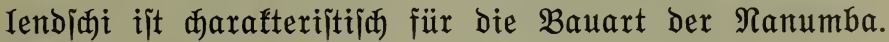
( $\mathfrak{A b b} .13$ und 14.)

Die Eingangsöffinung zur groß̈en Run๖hütte, in welđer wix den Gäuptling trajen, ijt jauber in Lebm modelliert und mit Dawadawa gut getränft. Solange der Lebm der Einfailung nod weich mar, hat man allerlei Ğberben von 


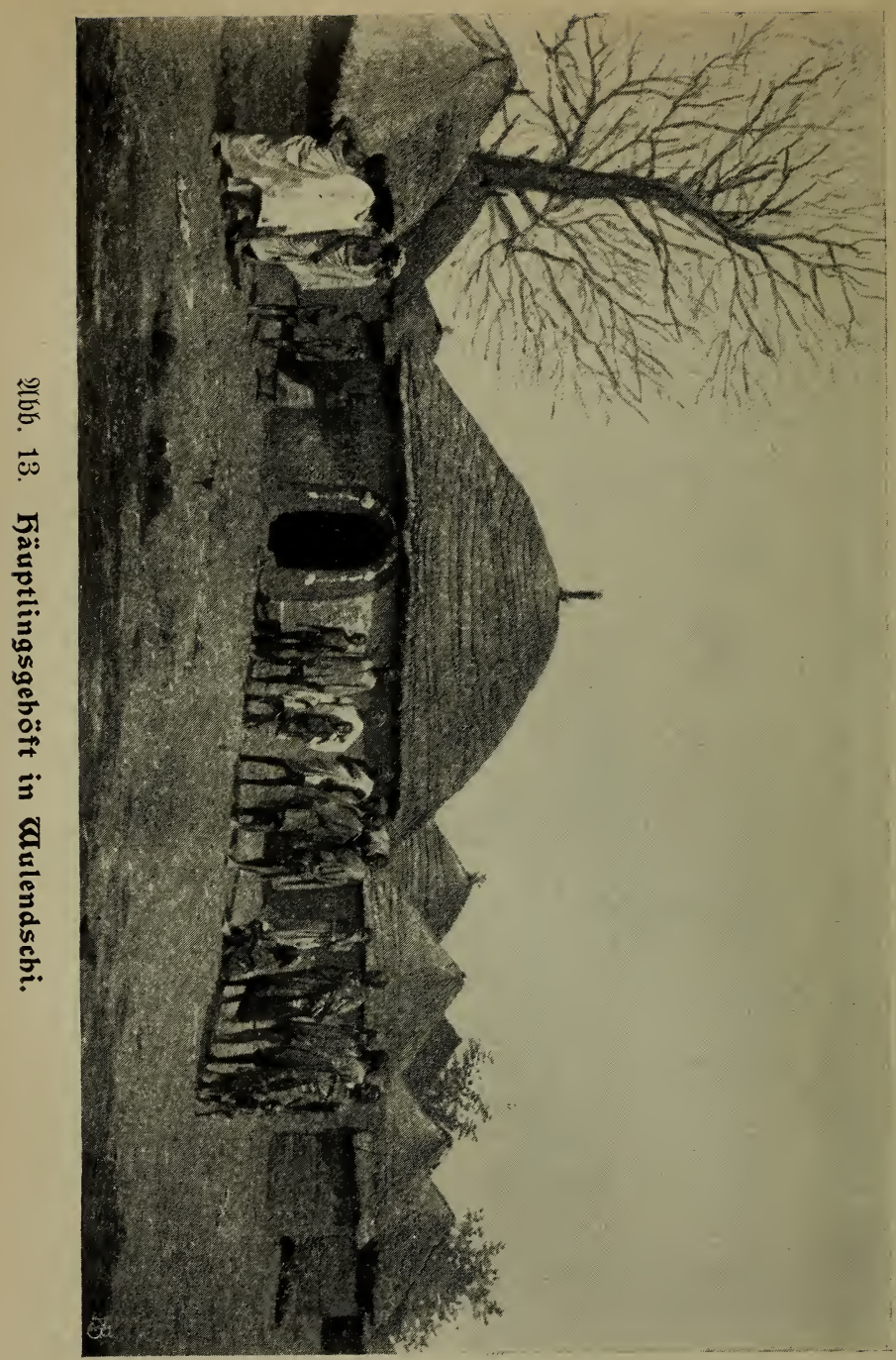


Tellern und Iafien barein gedrüut, und zwar in redgt

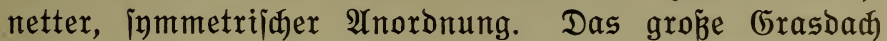
trägt in einigen auf ber Spize angebradten 3weigen ein

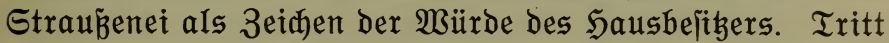

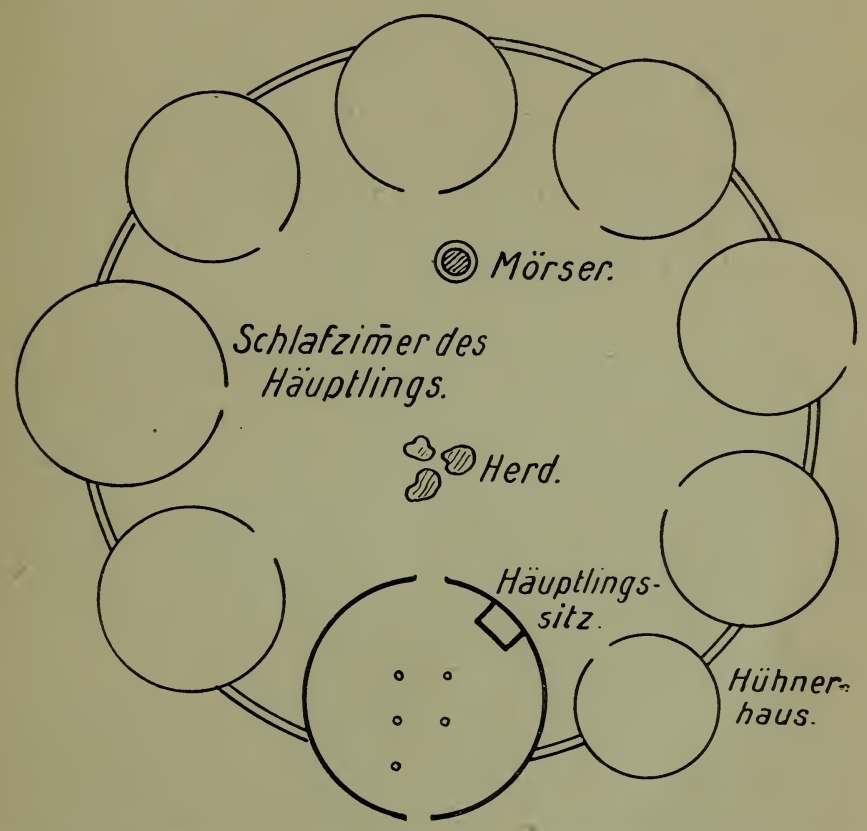

26bb. 14. Grundriss des Ђäuptlingsgehöftes in æaulendschi.

man Dur(h Die Der Eingangsöffinung entgegengejegte D̈ff = nung ber Shütte in ben innern Sof, jo fieht man im $\mathfrak{R}$ reis weitere Rumbhütten, die Durd eine Ringmauer mit ber groß̉en Eingangshütte verbunden find. Âle dieje Siutten haben nur eine Türöffnung in ben $\mathfrak{S}$ of, nur eine Sütte hat eine joldje nad) auken. Feniteröfinungen find nidjt an= gebradt. Sm Sof iteht ein hölzerner Mörjer und Iiegen 
ein paar Steine, bie ben Sherb voritellen. Ähnlid, nur etwas bejøeibener, find die Gehöfte der Ranumba überalf gebaut.

Die Därber werben mit einer jiemlid̆ feinen Grasart gebedt. Das Gras wird in grop̈en BündeIn in bie Dörfer gebradyt und hier mit Gilfe von Strohbändern in fleinen Büjdeldyen zu Iangen Streifen georonet; dieje Streifen werben bann in mehrfachen Lagen auf bas Dadgeriijt von Etangen gelegt, Die auf einem fräftigen, im 3entrum ber Sütte in bie Erde eingerammten $\mathfrak{P f a h l}$ befeitigt werden,

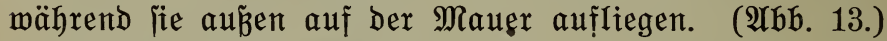
Jit bie Sütte jehr gró̉, jo werben die Dadjparren auf ein won vier und mehr itarfen $\mathfrak{B}$ tählen getragenes Gerïit aufgelegt.

Gđjon hier bemerft man, dá̉ der Mohammedanismus

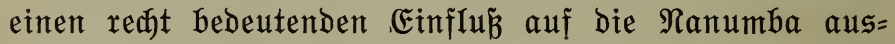
geübt hat. Der Imam von $\mathfrak{B u l e n d j h i ~ b e j u d t e ~ u n s . ~ W B i r ~}$ waren überrajht über jein inmales, intelligentes (bejidht und jein gerabezu feines Benehmen. Unns bie Moldee zu zeigen lebnte er aber höflid $\mathfrak{a} \mathfrak{b}$, ba fie fid wohl in wenig vorteilhaftem 3 uitand befinden modyte; Dagegen idjidte er uns bie beiten Stüdfe eines frifh geinIadyteten Sdiafes als (5eidhent.

$-\mathscr{A} u f$ einem freien $\mathfrak{B l a g}$ in Bulendidit iteht ein an= nähernd zylindrijđer, hohler Lehmbau von Mannshöhe. Unten ift eine fleine D̈finung, in meldher nod Irdhe Iag; in etwas mehr als halber Söhe war eine $\mathfrak{A}$ rt $\mathfrak{R o j t}$ angebradt. Wir lié̉en uns jagen, Dá̉ das einer der öffentlichen D̈fen iei, worin bie Rerne der Sdhibutterbäume ausgefod)t und jo bie Gdibutter gemonnen merbe.

$\mathfrak{u}$ un unere Einlabung hin famen etlidge Einmohner, $\mathfrak{u m}$ Mittel gegen ihre $\mathfrak{R} r a n f h e i t e n ~ z \mathfrak{u}$ exhalter. $\mathfrak{A} \mathfrak{u} \mathfrak{k} e r$ einigen Tuberfulölen und Snphilitijøen fielen bie zahl= reichen an dronijđer Bindehautentzündung Leidenden auf.

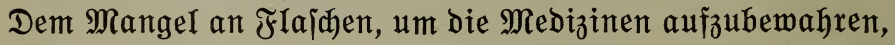

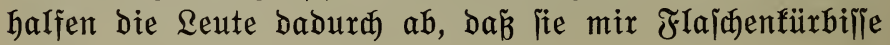




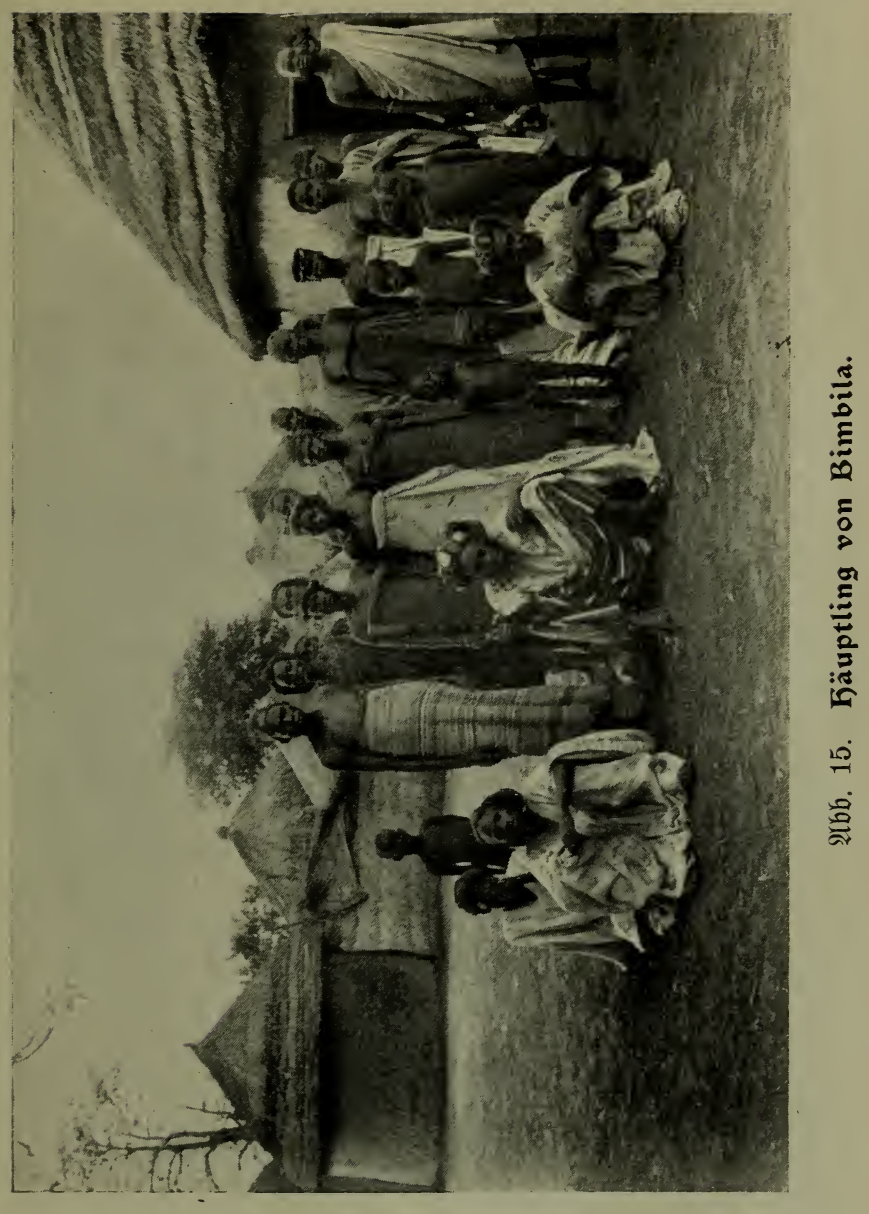




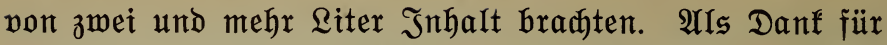
empfangene Medizin iaiffte uns ein Batient eine groß̉e

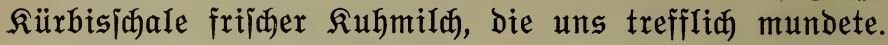
Biele Nanumba haben fleine Serben von Rinbvieh, aber es fehlt nod viel, bis fie eine rationelle Biehzudt zu betreiben

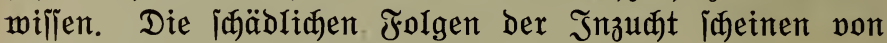
ifnen now nicht genügend exfannt zu jein.

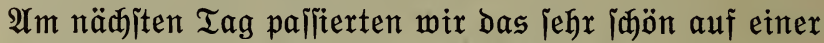
etmas höhern Bodenwelle gelegene Rafpaneli. Słhon von

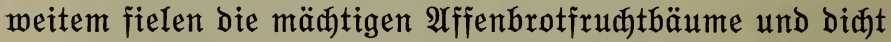
belaubten Săattenbäume auf. Lebtere itehen auf ber Strá̉e, und auf Den zahIreichen, vom Stamm ausgehenden Wurzeln jiłen abends die Bemohner. Die Wurzeln haben Davon eine eigentlidxe ßolitux angenommen. Es ijt eine ber vielen Ficusarten, die überall in Ifrifa als Sদ̆atten= bäume jebr beliebt find.

Elf Rilometer weiter gegen Norben exreidten wix die Sauptitadt des Ranumbalandes $\mathfrak{B} i \mathrm{~m} \mathfrak{b}$ i $\mathfrak{l} a$. Sie liegt auf einem Şügel und zählt etma 600 Sütten in fieben ver= iøiedenen Stadteilen. Die ziemlich zahlreidhe Mohamme= banergemeinde wohnt in einem bejondern Stadteil $z^{u}=$ jammen. Die Stadt mag etma 3000 Einmohner zählen.

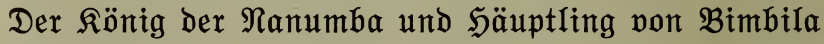
ijt ein freunblicher alter Mann ( $\mathfrak{H b}$. 15). Das Bild zeigt inn auf einem mit Leber bezogenen Riflen jïgend. In jeiner Redyten hält ex Den Rönigs[tab, linf́s und redts von iłm jïzen einige jeiner Unterfäuptlinge. Yrlle brei tragen die bei Den Dagomba und నanumba gebräuðlichen, über= mäßjig Iangen Müisen von Baummollitoff. Sie find bejest mit einer $\mathfrak{A n z a h l ~ r e c t e d i g e r ~} \mathfrak{A}$ mulette; einige $\mathfrak{A}$ mulette itecten in Rapieln, die aus getriebenem Silber gearbeitet find. Sinter bem Säuptling jtehen eine $\mathfrak{A n z a h l ~ l e i n e r ~}$ Frauen und Rinder. Ex hat eine ganze $\mathfrak{A n z a h l}$ Frauen, und weil jede Jrau im Gehöft ihres Mannes eine eigene

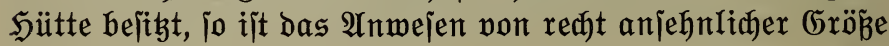




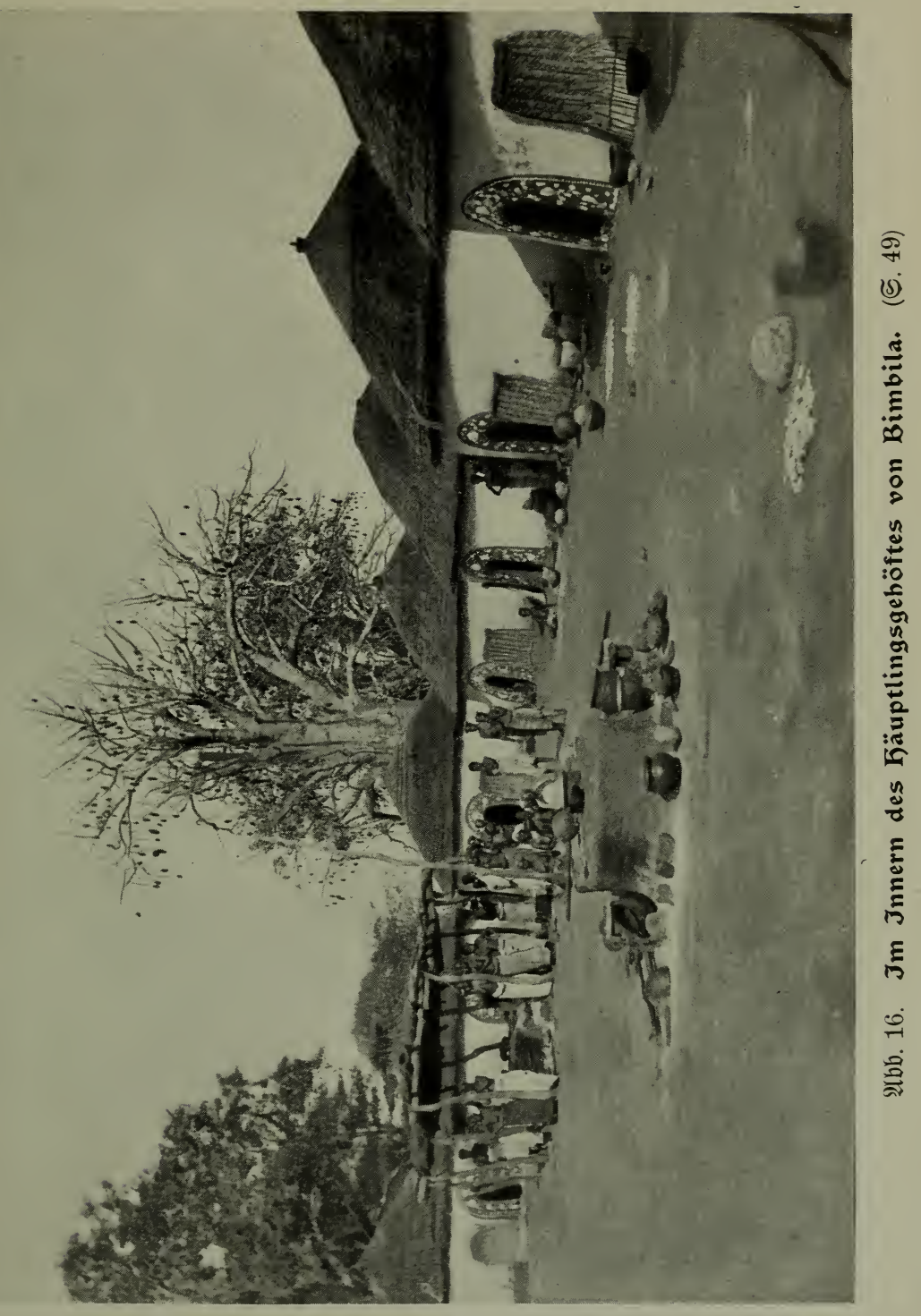





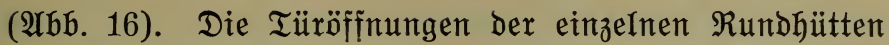
find iehr reid und redt geidmadivoll mit ganzen Iellern und Ielleriðerben verziert. Reben ben Türöff̈nungen Iehnen an ben Mauern bie aus Gras geflodtenen Berialüilje Der D̈ff=

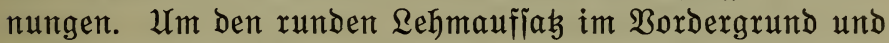
unter bem Sdattendach Iinfs im Bild find bie Rodjitellen angebradt. Der fahle Baum im Sintergrund mit ben her=

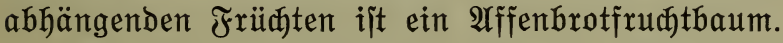

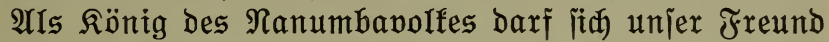

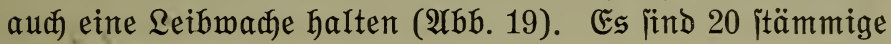
Ranumba, mit langen Steiniðloźffinten bewaffnet und in iehr mannigfaltiger $\mathfrak{U}$ niform. Nidgt alle genié̈en ben ¿urus von Beinfleidern, bagegen jind alle bie veridjiedenen Rleidungsptïfe mit $\mathfrak{A}$ muletten bidgt bejegt. Es find bie bem Unfundigen als fleine Patrontäjđdjen exidheinenden brei=

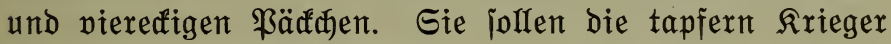
hieb= und iđukjeit madjen.

Im mohammedanijhen Stabtteil iteht die Moichee

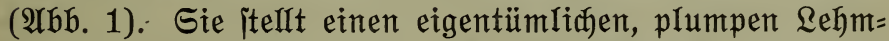

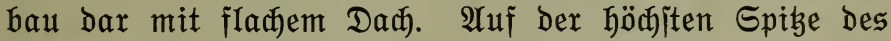

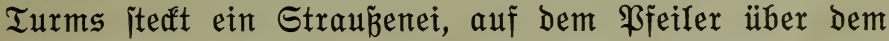
niebrigen Eingang frinolerweije eine Ieere Weinflajhe. Ein Photograph fönnte ben Innenraum ber Moínee am hell= liđten Tag als Dunfelfammer benüber.

Jeden Tag won 12 $\mathfrak{u h r}$ mittags bis nadjmittags 3 $\mathfrak{u h r}$ wird auf bem Den Marfträrm begleitet ein junger Mann mit unab= läjifigem Getrommel. Es wurben verfauft: 2 Eier für $1 \mathfrak{B f g}$., 25 Pfund Sorgum (Rijpenhirie) für 20 Pfg. ujw. Es wurben ferner veridjiedene Arten Bohnen, Straud $=$ erbjen, Rolbenhirje, Seife aus Potaidhe und Erjifutter, einheimijđer Tabaf und andere $\mathfrak{B a r e n}$ auf ben Marft ge= bradt. Es herridte ein jehr lebhaftes Treiben.

Mitten auf Dem Marftplał iteht ein gemaltiger $\mathfrak{\Omega} a$ pof́l a m. Der Kapofbaum ift jehr nahe mit bem überall 
auf ber Goldfiüte vorfommenden Seibenbaummollbaum ver= wandt. Betbe Bäume tragen ungefähr $20 \mathrm{~cm}$ Iange ipindel= förmige fruthtfapieln, bie in ber Mitte einen Durdymefler von ungefähr $6 \mathrm{~cm}$ haben. Die Fruatfapieln beiber Bäume

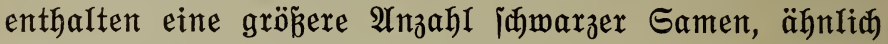
den Samenförnern der Baummolle. Sie find eingehüllt in eine Menge feiner, Ianger, feibenglänzender, fitbergrauer Saare. Während nun bie Frudtfapieln bes Seibenbaum= mollbaums bei Der Reife auf Dem Baume aufipringen, foda Dex Wind die Seidenbaummolle nadh allen Ridtungen ent= führen fann, bleiben bie Jruhtfapieln bes Rapofbaums gejd)Ioflen und fallen nad wollendeter Reife ab. Die Seiden= baummolle geht barum z̆um größ̈ten Teil perloren, während bie Rapofwolle mühelos gejammelt und gewonnen werben fann. Wenn nun aud beide Fajern zu ipröbe find, als da man baraus Stoffe weben fönnte, io find fie bod jehr ge= iăägt aIs Politermaterial. Rapof jelbjt hat eine Zufunft

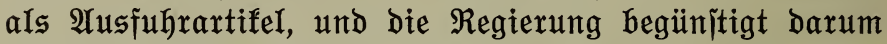

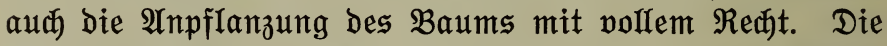
Bäume wadjien jehr raja und jint mit bem mageriten Boben

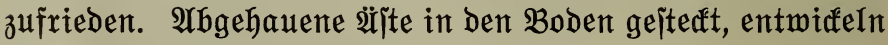
(t⿱亠䒑) jogar zu tabellojen Bäumen.

YUf unjere freundidge Einlabung hin famen eine $\mathfrak{A} n=$

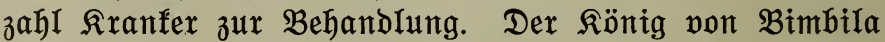
feIbjt litt an ber hier fo häufigen wronijaden Bindehaut= erfranfung. Die $\mathfrak{U}$ riache der $\mathfrak{R}$ ranfheit wird einerjeits der viele Staub jein, den die Winde dort mit fith führen, andererieits wohl aud ber Raud ihrer Jeueritellen in ben Runbhütten, ber mux iðwer einen $\mathfrak{2}$ usweg findet, benn Jenjter find ein unbefannter $\mathfrak{L u r u s , ~ u n d ~ b i e ~ m e i j t e n ~} \mathfrak{y}$ ütten haben nux eine Eingangstür. Der $\Re$ önig nahm bie an= gebotene Mẻbizin mit Danf an und iđjufte uns als Gegen= geirjenf einen Sammel, der won Sorenz mit Freuben in Empfang genommen wurbe, und er vermodite jogar auf bas immer traurige (befidt unjres $\mathfrak{s}$ u einen zufriedenen, fajt 
fröhlidyen $3 \mathfrak{u g}$ zu zaubern. Jedenfalls haben fï die beiden

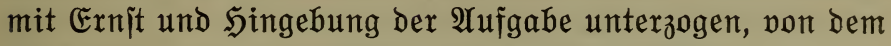
Tier niabts auf ben näbjiten Iag übrig ju Iafien.

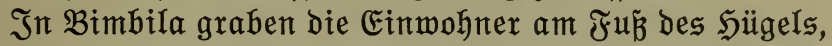
aũ welchem bie Stadt iteht, zwei Meter tiefe Gruben und gewinnen io ganz annebmbares Irinfwaller trog ber $b a=$

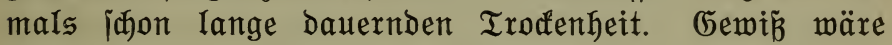
gutes Grunowalfer leidjt zu erbohren.

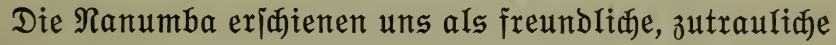
Qeute. Sie würden gern jehen, wenn bei ifnen bie Mifjion angefangen wiurde. Jedenfalls fann niemand jagen, es jei hiezu noch zu früh.

Dex günitige Eindruaf, ben uns bie Ranumba von $\mathfrak{R} a$ tiageli und Bimbila madyten, wurbe am näbjiten Tag nod neritärft, als wir in bem elf Rilometer norbnorbmeitlid gelegenen iøönen Dorf $\mathfrak{B u j u g a ~ a b j t i e g e n , ~ u m ~ b i e ~ R e u t e ~ z u ~}$ begrï̈ßn. Der furze Bejud in jenem Dorf bei ben freund= lidgen Reuten mit offinten (Gejutgtern wirb uns itets in an=

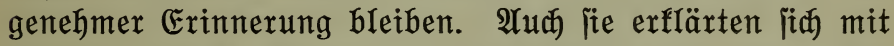
Freuben bereit, Mififinare aufaunehmen, und baten uns, boc ja bald ju fommen.

Depojena und Raganya, bie beiben weitern Dörfer, find flein und ärmlidf. In lebterm Dorf madten wir $\Re a j t$, 42 ßilometer von Bimbila entfernt. Der Şäuptling er=

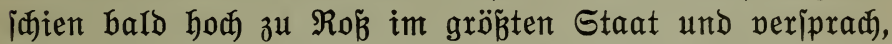
für uniere Bedürfnifle zu jorgen. Er zeigte uns bann auf

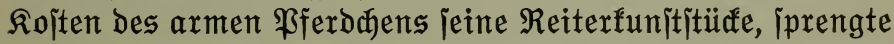

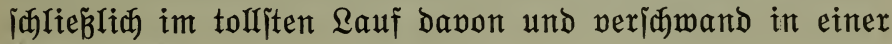
Staubmolfe.

$\mathfrak{A m}$ näafiten Tage, Dem 14. F̌bruar, verlief: :n wir bas Land ber Namumba und betraten bas ber $D$ a g o m $\mathfrak{b} a$ (riøtiger: Dagbamba, wie ihon bemerft). Im eriten Dorf,

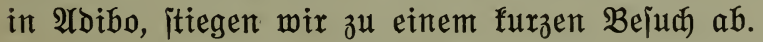

Die Dagomba bildeten einit ein jiemlia mäßtiges Reid mit ber Sauptitadt $\mathfrak{S}$ en $b i$. S(fon babura, bá ber 
größ̄ere Teil bes Landes (Dagbong) unter englijae Dber= hoheit fam und nur ber fleinere Teil Deutið $=$ Togo zugeteilt

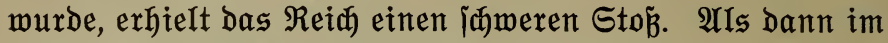

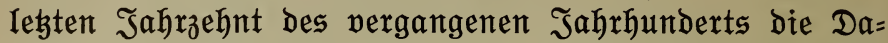

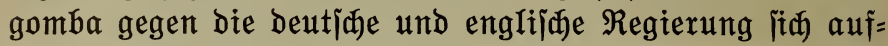
lehnten und won Den Deutiðen bei Bumbalaga, von ben

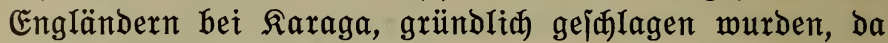
war bie alte Serrlidfeit, bie jid bejonders in unaufförlidgen Raubzügen und Stammesfebden fumb tat, für alle 3eiten bahin. Dá̉ bamals eine Sandvoll beutj̄er Goldaten mehrere taujend Dagomba io gründid bejtegten, brad iłren alten $\mathrm{Stol}_{3}$.

Auf Deutichem Gebiet wohnen zwijđen bem Dti und ber Beitgrenze in rund 7000 Siutten 14000 Dagomba, Iaut einer 3ählung Durd Sauptmann Mellin. UUngefähr 10000 Da= gomba wohnen nod öjtlid vom Dti in Sanjugu und $\mathfrak{R a f}=$ pali.

Jn ber Bauart ihrer Säuler und in iłrer Rleibung

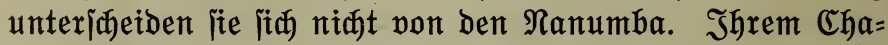

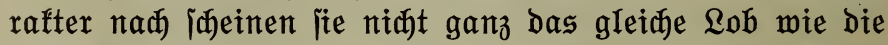

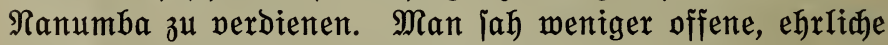

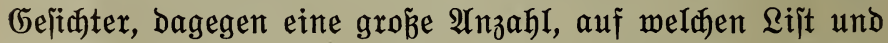

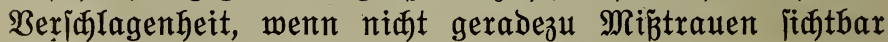
war.

YDibo liegt auf einem Shägel, ber einen ungewöhnlid freien Bliff nad Dit und Beit geitattet. Bei flarem Better joll man won bort aus bie Berge won Banyeli lehen fönnen. Benn uns aud dieje unjiłbtbar blieben, jo jahen wir bod gegen Dîten weit in bie fajt unbewohnten Ebenen zu beiben Seiten bes Dti, gegen Beiten bis in englijhes Gebiet hin= ein. Ardibo ijt ein redft itattliches Dorf; bedeutend grö̈̈er aber ît Bumbalaga, bas zu beiden Seiten ber Straß̉e in mehreren Stabteilen liegt. Sier iahen wir aud wieder mit Freuben bie eriten Fäaherpalmen. Es fiel uns auf,

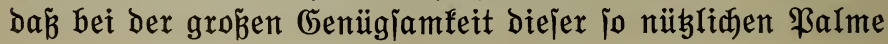


ihre Anpflanzung in Togo nidgt mit mehr Nadjorud ge= fördert wird. Bei bem Mangel an Bauforz wären bie ¡đönen, gexaben Balfen, bie man jehr leidjt burdy Spaltung Der Stämme gewinnen fann, jehr wertwoll. Erit weit im Rorben trafen wix bann wieber größ̈ere Bejtände ber herr= Iidjen Bäume an.

Je mehr wir uns Sendi näherten, beito meniger brad) Iiegendes Sand trafen wir. Die Sirjefelder waren vor furzer Zeit alle abgeerntet worben. Nur Gin und wieber [ă man nod groß̈e Saufen ber braunen Rijpen von Durrha, einer Rijpenhirje; Damit belabene Frauen und Kinder

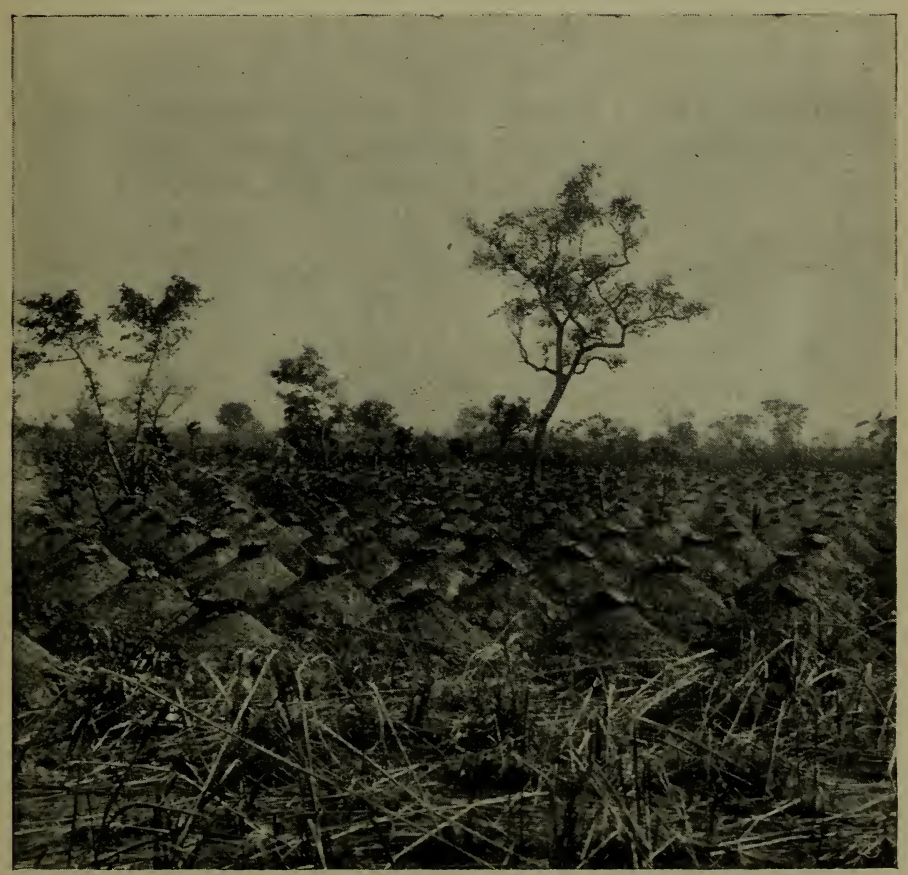

Ifbb. 17. Jamsfeld frisch bestellt. 
widhen furhtfam von ber Strá̉e, als jie uns auf ben blin= fenden Räbern daherfommen jahen. Die Lanbja jaft jah baher etmas herbitlich aus. Die Jamsfelder aber waren frija bejtellt und zeugten won Dem Fleí̈ Der Dagomba. Da war fein jold wüjtes Durdeinander von halb und ganz

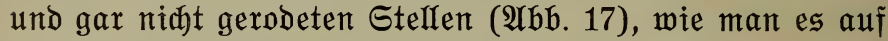

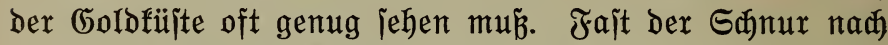
waren die jaubern fegelf̈̈rmigen, $60-80 \mathrm{~cm}$ hohen Erd= baufen auf groz̉en Jläđhen aufgeworfen. In ifrem Intern bargen jie das Saatitüa, und oben brauf lagen ein Büichel Blätter und eine Erojholle. Es ijt eine fleine, aber aus= gezeidnet jamedfende Jamsart, die von Ranumba und Da= gomba auf dieje Weije angebaut wird.

Die Entfernung von Laganna bis Jenbi beträgt 31 Rilometer. Ş̧on von weitem exfennt man die Rage und bie bebeutende $\mathfrak{A}$ usdehnung ber Stadt auf Dem flađhen Sügel an ben mähtigen Irffenbrotfrudtbäumen, die bort itehen. Im Ial jübmärts von Jendi und ben ganzen $\mathfrak{U}$ bhang bes Sügels hinauf Dehnen jith die ßrflanzungen Der Station aus. Wenn auদ die ßrfanzen unter ber Troftenheit gelitten hatten, jo war bas bod nidt der Fall in bem Má̃ wie in

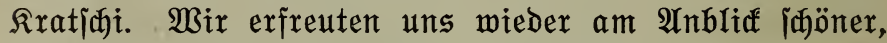
Dunfelgrïner D̈Ipalmen, vielveriprechender $\mathfrak{A}$ nanas= und Bananenpflanzungen und groß̉er Bejtände von Rapof, Doum, Mahagoni, Teaf, ßapao und andern Nubłölzern.

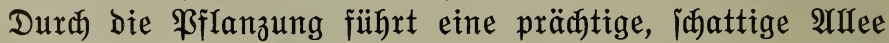
ben Sügel hinauf zur Station. Sie freuzt die groß̉e Rara= manenitrá̉e, die von Bajari naá Salaga führt, bann fommt man auf Den groźzen, freien ßlał weitriđ won ber Station. Die Station zeigte fich bei unjrer $\mathfrak{A n f u n f t}$ nidht gerabe jehr vorteilfaft ( $\mathfrak{A b}$. 18), denn bas Sauptgebäube jollte ein neues (5rasdach befommen und jă baher etmas ruinenhaft aus. Sinfs bawon iteht bie mit Wellblec gebefte Wohnung des Stationsleiters. Leider itehen beide Gebäude mit ifren Sängsfronten nă Dit und Weit jehr ungünjtig. Die inten= 
iive Beitrahlung ber (be= bäube, bie (itđ) aus joldjer Lage ergibt, madyt (it) jehr unangenehm bemerf́ar; zudem ift die $\mathfrak{B}$ hhung Des $\mathfrak{B e z}$ irfíleiters ređt niebrig, und barum emp= findet man bie von bem Bellblech aufgenommene Bärme jẹ̆ auforingliđ). Linfs bavon ragen zwei einjame fä̈herpalmen em= por. $\mathfrak{A} \mathfrak{n}$ ifrem $\widetilde{F} u \tilde{b}$ liegen bie Gräber von bem im Januar diejes $\mathfrak{J a h r e s}$ geitorbenen Bezirfisleiter Sauptmann Mellin und eines vor zwölf Jahren bier geitorbenen Stations= aijiitenten. Es war für uns ein tiefer Sđmerz, am Grabe Sauptmann Mellins itehen zu mïlijen, den wix fo jebr hoffiten in Mangu nod ju jehen. Etwas mehr im Bordergrund liegt ein Bavillon, in welchem die 3ollabfertigung vor fitc geht. Tägriḑ bietet (ita) auf jenem $\mathfrak{P l a b}$ ein gar bewegtes Bild, wenn die Rarawanen von ober nad) Galaga abgefertigt merben.

Der Stationsleiter emp= fing uns mit groß̉er Freund=

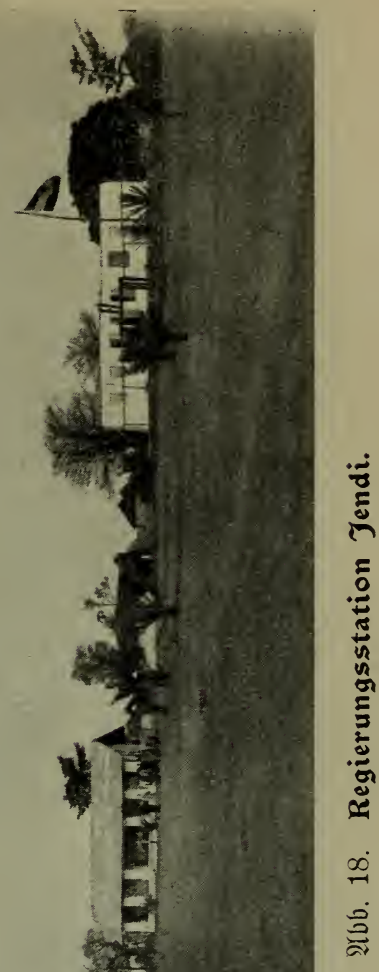




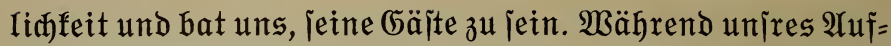
enthalts in Sendi find wir mit größster Freundridfeit pon ihm beherbergt worben, und wir find i⿹m bafür und für viele wertoolle Dienite zu grö̉em Danf perpflidhtet. Wir bejudten mit ihm Sauptmann Mellins Grab und hielten eine furze, von Serzen fommende $\mathfrak{A n d a d g t , ~ i n ~ w e l d e r ~ w i r ~}$ mit $\mathfrak{B e h m u t ~ b e s ~ v o r t r e f f i t a n e n ~ M a n n e s ~ g e d a d t e n , ~ b e r ~ j o ~}$ viel für bie Rolonie geleijtet hat, und Der Durd fein warmes Serz und leine Geredtigfeit und Milde bas Bertrauen und bie Riebe der Bölferiøaften bes Mangubejirfs in jeltenem Má̉e gewonnen hatte. Einen Bemeis von ber $\mathfrak{A}($ tutung, in welder Sauptmann Mellin itand, exhielten wir in jenen Tagen. Es fam eine $\mathfrak{A b o r o m u n g}$ bes Säuptlings von Gan= tile, fünf gemehrtragende Soldaten und ihr $\mathfrak{A}$ nführer,

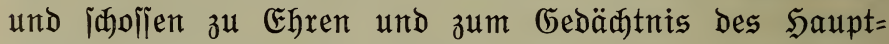
manns ihre Gewehre breimal über feinem Grabe ab. Das Grab liegt am $\mathfrak{F} u \tilde{B}$ einter männlidjen und einer weib= lidhen Fäderpalme. Legtere war mit gewaltigen Irauben ber Dunfelgelben, fopfgrö̈en Frühte beladen, ein Sinnbilo Des treuen und vortreffichen Mannes, Defien Arbeit Frü̈bte tragen wirb bis in ferre 3eiten. Bom (5rab idweift ber Bliff nađ Rorben, Dîten und Bejten über eine weite Ébene, bie fïh, nux ganz ipärlid mit Bäumen beitanden, bis an bie Berge von Moab eritreatt. Siiböitlich von ber Station liegt ber Stadtteil won Sendi, in weldyem der Rönig ber Dagomba wohnt. Er ijt ein bebauernswerter Mant. Niðht nux i it jein Reid) zerjallen, pondern er jelbjt ijt eine Ruine.

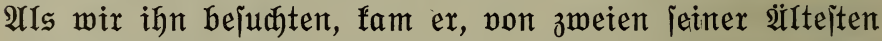
geitübt, höbjit mühjan aus jeinem Gehöft gewanft. Dhne Silfe fonnte er ïd weder jegen nod exheben. Sein Gejidnt war entitellt burd jareffidje (5eidnüre, ex jelbjt ein Bild bes Sammers. Boll Mitleid bat id ifn, Dod) meine Mittel

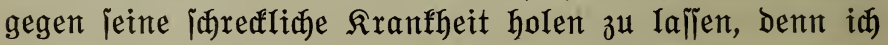

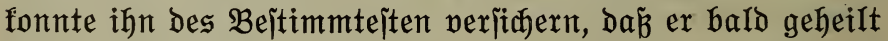
jein werde. Leider verjømähte er bas und lié̉ trob meiner 


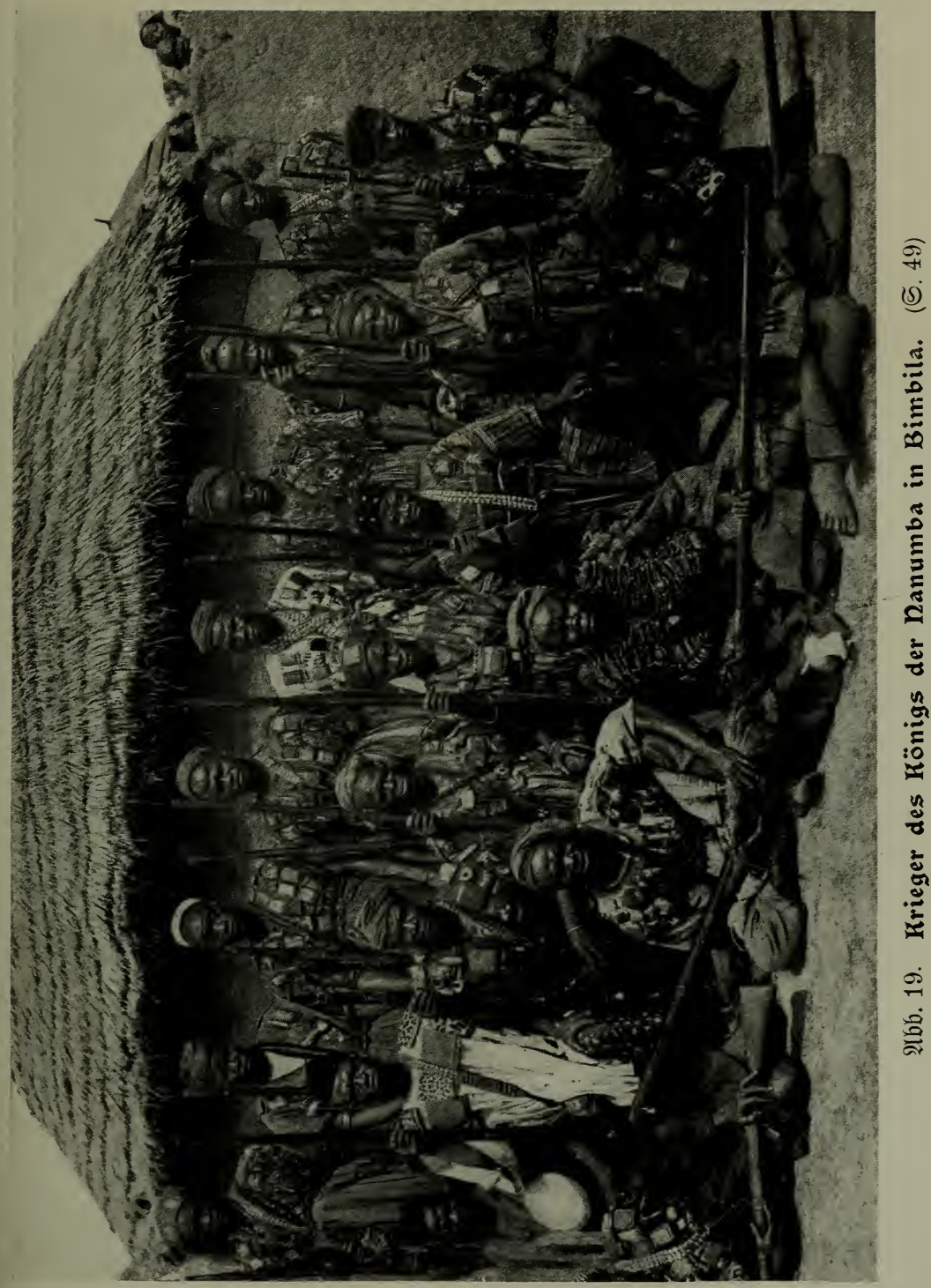



wieberholten Bitten bie ihm als Geidenf angebotenen Me= bizinen nidjt holen. Wie er, jo handelten aud jeine $\mathfrak{U n t}_{\mathrm{n}} \mathrm{r}=$

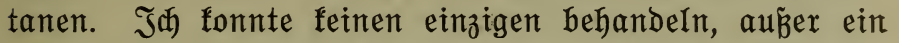
paar Goldaten und Goldatenfrauen, bie mid ber Stations= leiter bat in Behandlung zu nehmen.

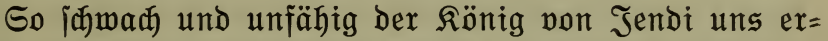

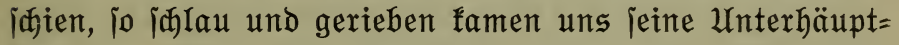
linge vor ( $\mathfrak{A b \mathfrak { b }}$ 20). Sie itellten eine wahre Blütenleje von đarafterifitiçen Dagombamännern bar. Der fleine Mann in Der Mitte, Der in ber Rechten jeine mit zwei $\mathfrak{A} m u=$ Ietten verzierte Dagombamübe trägt, mährend jeine Sinfe itđ mit einigen $\mathfrak{A}$ muletten, die $i \mathfrak{h m}$ am $\mathfrak{S a l s}$ bängen, zu

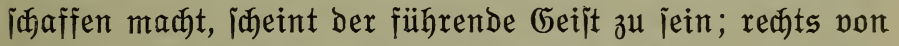

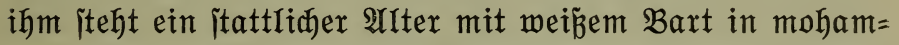
medanijher Rleibung, wahriøeinlid Der zweite im Range. (Das geriijtartige Baumerf mit bem (5rasbad) im Sinter = grund iit bie meteorologijace Station.)

Jeben Radymittag fommen bie burdreijenden Rara= wanen zum Zoll auf bie Station. In langem Zug fommt juerit ber Sarawanenführer und jeine Frauen, bann Iajten= tragende E్fer mit ihren Führern. Nidht jelten figt auf bem Rǚfen eines (Graudjens itolz ein 5 ahn und betradytet fid bie Gegend won jeinem erhabenen Standpunft aus mit Sidjerheit und $\mathfrak{B u ̈ r d e . ~} \mathfrak{A} u \mathfrak{f}$ einem idgönen $\mathfrak{P}$ ferd jitgt in

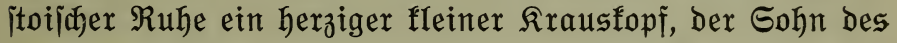
Rarawanenführers, in zierlidem Sattel, jorglid mit Tühern feitgebunden, ben fleinen Fez auf bem Bollhaar.

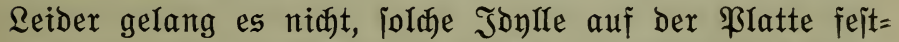
zuhalten, weil bie Gonne im Rürfen ber Gejellida aft itand.

Weitrid von der Station liegen nod) werjhiedene Stadt= teile von Jendi. Einer berjelben ijt won ber zahlreiden, etwa 1000 Seelen zählenden Mohammedanergemeinde be= wohnt. Der Imam berjelben madte uns aber feinen befiern Eindruat als bie jehr verfallene Mojdee jelbit, bie nidjt viel anders ausiah als ein wiijter Saufe $\mathfrak{L} e \mathfrak{h m}$ mit ein 
paar zerzauiten Strohmijøen barauf. Nidts bejto meniger

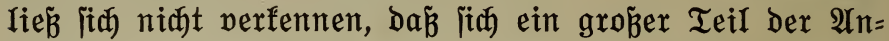
gejehenen und Intelligenten unter ben Dagomba von Jendi bem Mohammedanismus zugemandt hat, ähnlid wie in Bimbila und den andern bedeutenderen Drtjøaften bes $\mathfrak{N a =}$ numba = und Dagombalandes, die wix bisher gejeben hatten.

Sn dex গähe bes mohammedanijaen Stadtteils ijt ber Marft mit ben vielen Unterfunftshütten für bie ßaxa= wanen. Der Marft ijt ein geräumiger ßlab, herrlich be=

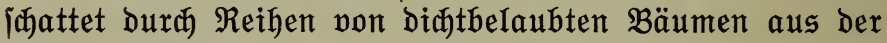
Familie Der Feigen. Dukende pon $\mathfrak{A}$ asgeiexn juaten ihre

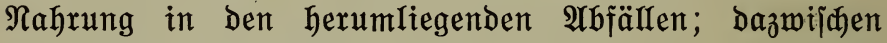
trieben fï ganze frïge wilber Tauben herum. Lajtträger jahen naদ, ob die Rolaniilie, aus benen ihre Rajten meijt beitanden, aud nod feudt genug für die Reije bes nähiten Tages jeien. Dieje Rolanïile, die aus Den Maldgebieten ber Golbfïite mafienhaft ausgeführt werben, bilden, je weiter man nach Norben fommt, eine um fo wertwollere

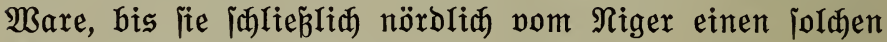

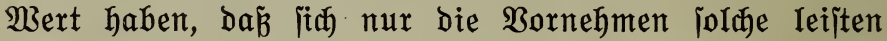
fönnen. Es find jhön rote, derbe Rerne, pon der Größ̉e von Roß̈faitanien (Gippocaitanus), die fich in zwei bis vier Teile trennen Iafien. Das rote, an ber $\mathfrak{L u f t}$ rajh braun werbende Fleijळ berjelben wirb gefaut und ijt barum von jo hohem Wert, weil es dem Rauenden jehr groźe Stra= pazen zu madyen erlaubt, ohne dá̉ er bas Bebürfnis năh Speije und Iranf jehr empfindet. Die Raramanenleute be= haupten, dá̉ ein Iräger mit einigen Rolanüịlen einen ganzen Iag jeine Lajt tragen fönne, ohne gezwungen zu lein, Speije oder Tranf zu fich zu nehmen. Dies ijt mohl itarf ïbertrieben, zumal da Die Raramanen nur furze Iage= märjhe von etwa 20 Rilometern zu maden pflegen. Etwas mirb aber mohl an ber Saদje jein. Der Gejamad der Nüilfe, die zu fauen ein gutes Gebí̈ erforbert, ijt herb und für eimen europäijðen Gaumen niðht angenehm. Es liegt in 


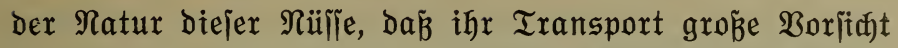
erforbert, wenn fie nidbt auf ben monatelangen Reijen Edhaden leiben jollen. Sie werben in jorgfültig mit groß̉en Blättern ausgelegte Tragförbe verpaưt und bie Blätter inmer von 3eit $\mathfrak{u}$ 3eit angejeudtet. .

Reben joldyen Lajtträgern itanden eine Menge Lajtejel, bie gar behaglid ifre Mahlzeit hielten, die aus fräftigem Eorghum, ber roten und weipen Rijpenhirie Ifriffas be: itamb. Ein Lajtträger fođte fith über eittem Strohfeuerben in einem $\mathfrak{2}$ bुugsgraben lein bejheidenes Mahl won Sirje, etwas Fleijh und Gdifutter in eitrem iđwarzen Töpfinen. Lebtere hatte ex von einem ber leidt geidürzten Mäbdhen gefauft, Die graziös einen $\mathfrak{5 o l z h t e l l e r ~ a u j ~ b e r ~ e i n e n ~} \mathfrak{S a n d}=$ flädse tragend, Durd bie Rarawanenleute gingen und bie Sdibutter zum Rauf anboten, indem fie mit zum Teil reøt angenehmer Stimme Iaut und gezogen riefen: Maji, Maji! Die Unterfunftshütten für bie Träger und Treiber find fleine, aus Sirjejtengeln erbaute Runbhütten, bie in langen Reihen hinter Dem Marftplab itehen und ben Leuten ge= nügent Sđjub vor Rälte und Rälie bieten.

Jn Bimbila hatte iđ vergeblid nad einem Edflofier oder Sd)mied gejudt, mit befien Silfe mir es hätte gelingen fönten, mein Fahrrab wieder in Stand zu itellen. Ébenjo vergeblich war mein Sudhen in Jenbi nach einem joldyen Rïnitler. Ałber ber Stationsleiter eridjien als Retter in ber $\mathfrak{R o t}$ mit einter alten Eägefeile. Mit Silfe diejes nüb=

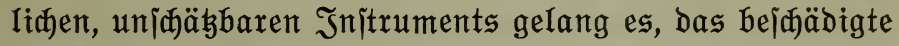
Geminde zum Teil wieder aujauriaten, zum Teil nadju= feilen, und nadbem dieje $\mathfrak{A r b e i t ~ m i t ~ S i n g e b u n g ~ u n d ~ L i e b e ~}$

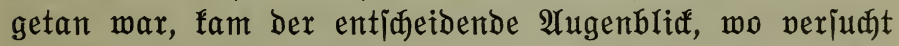
wurbe, bas unbraudbar gemorbene ßebal wieber in bie Kurbel zu jarauben. Jeber half mit Rat und Iat, mit

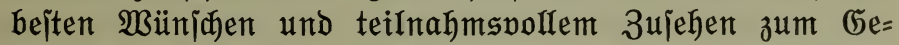
lingen ber $\mathfrak{A}$ rbeit. Wie viel hing bod bavon ab, ob bas Gewinde fallen und bas Bedal wieber gebraudisfähig 
wärde! Gelang bas Berf niđt, Dann itand mir bevor, bie ganze übrige Reife zu $\mathfrak{P}$ ferd madhen zu muilfen und in= folgedelfen vielfach won meinen Gefährten getrennt $\mathfrak{z u}^{\mathfrak{u}}$ reijen.

Mit größ̈ter Borjið̧t wurbe bas Berf begonnen, mit ganz fleinen Teirlitüfen einer $\mathfrak{U}$ mbrehung; mit gleid. $=$ mäpigem Druaf von oben wurbe bas verlebte Geminde in bas nod gut erhaltene hineingepreßßst. Weldae allgemeine Freude war es, als bies gelang, bas Geminde fith immer tiefer in bie Rurbel hineinarbeitete und endidi das Bebal

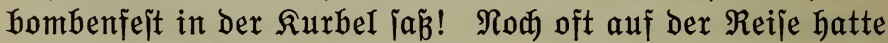
id allen Grund, Danfbar bes freundidien Stationsleiters von Sendi und feiner alten Sägefeile zu gedenfen, wenn trob der häufigen Stöß̈e, welda das ßedal nođ̆ aushalten muß̉te, bas (Gewinde unbemeglid fejt jigen blieb und wohl aud bleiben wird, bis das Rad überhaupt ausgebient hat. Jendi exfürlt bie Bebingungen zur $\mathfrak{A n l a g e ~ e i n e r ~} \mathfrak{M i} i=$ fionsftation in befriedigender Beife. Es ift ein widtiger, annähernd zentral gelegener, volfreidger Drt. Freilid wird man, was lebtern \$unft anbetrifft, etwas bejheiden in eirem jo bünn benölferten Lande, wie es bas nörbliche Iogo ift. 3ubem ideinen bie Dagomba vielfach bem Sandel nadbugehen, und barum find bie Stäbte oft redt menjđen= Ieer. Blab zum $\mathfrak{B a u}$ einer Miffitonsftation gibt's in Jendi

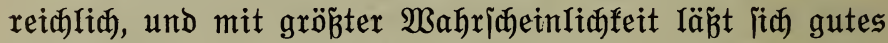
Grundwaller in niat jehr grop̉er Tiefe erbohren. Bon Malaria î́t Sendi allerbings jo wentg frei wie irgend ein Drt in ber Nähe. Sebenfalls bringt die Miffitonstätigfeit unter ben jebr zeritreut wohnenden Dagomba und $\mathfrak{R a n u m b a}$ eine jehr anjtrengende Reijetätigfeit mit fid . Die jđönen Straß̉en, bie von Jendi nach Rorben und Sïden, nach Diten und Beiten ausgehen, werben bieje Tätigfeit in unjøäbs= barer Weije erleidtern, um jo mehr, aIs jonit in ber Regen= zeit groß̉e Stref́en $\mathfrak{L a n d e s}$ in Seen und Sümpfe verwandelt

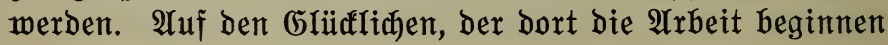




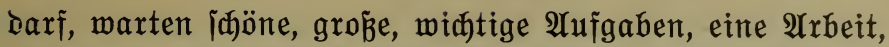
in ber man mit $\mathfrak{L}$ uit bie ganze Rraft und Leijtungsfähigfeit einjegen fann, wenn einmal die Ghwierigfeit der Sprache überwunden jein wirb. Dagbane iaseint uns feine der jebr faner exlernbaren Sprađen zu jein.

\section{Bon Jendi nå̆ Tamale.}

Rahbem wir einen anjehnliden Teil bes unter beutjaer Serrichaft lebenden Dagombavolfs gejeyen hatten, galt es, Den unter englijøer Regiexung lebenden, ungleiđ grö̈ern Ieil зu jeh̆en. Es leben nämliđ̆ nux 6-7\% Der Dagomba in Togo, die übrigen $93-94 \%$ find in ber englifachen (5old= fiijtenfolonie. Will man aljo bas Dagombavolf mififionieren, jo barf man niđht an dem im englijøen Gebiet lebenden

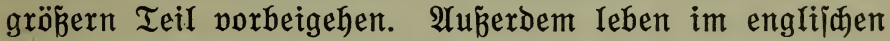
Gebiet noa jwei mit den Dagomba jehr nahe vermandte, menn aud fleinere Bölfer, die Mampruji und die Tampruit, bie mit ber Spradje Der Dagomba, dem Dagbane, bearbeitet werben fönnen. Im beutjøen Gebiet hätten wix etwa 20000 Ranumba und 14000 Dagomba, aljo ein rect fleines

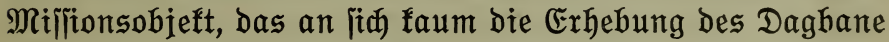

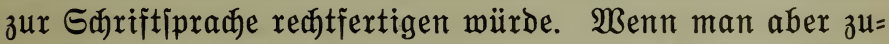
gleid die Dagomba, Mampruji und Tampruji im englijøen

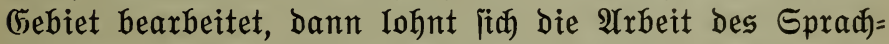
itudiums und ber Druf ber Büđer ganz anders. Allerbings find im englijđen Gebiet nod feine Bolfszählungen vor= genommen morben; wir find barum bei ben angegebenen

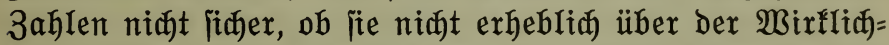
feit bleiben (unter berielben find fite jebenfalls nid)t bei ber ïberall herriđenden Iendenz in ähnliden Berbältniflen). Jür ben Bezirf Mangu= Jenbi hat ber verjtorbene Saupt= mann Mellin eine Şüttenzählung Durageführt, die mit ziem= Iiđer Siđherheit die Einmohnerzahl jenes Bezinfs feitjtellen läß̈t. Demnă find unzweifelhaft obige $93-94 \%$ injojern 


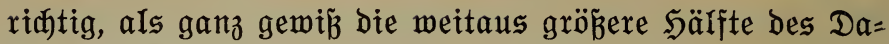
gombavolfs im engliføen bebiet $\mathfrak{u}$ treffen ijt. In einem Rreis, beflen Rabius 30 Rilometer lang iit, und in beflen Mittelpunft Tamale liegt, leben naর্ unirer S(häłung alfein etwa 40000 Dagomba.

$\mathfrak{A} m$ 14. Februar waren wir in Jendi angefommen.

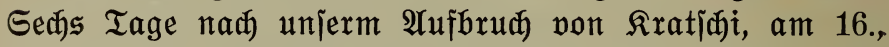
wandten wix uns mun nad Weiten, nahmen âbjaied von unjerm freundrichen Gajtgeber und fuhren auf ber Rara=

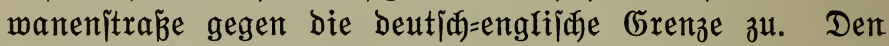

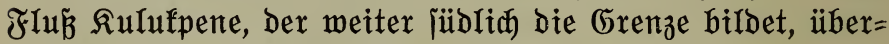
idritten wir trodfenen Fuß̉es. Ân jener Stelle war jein Lauf Durch eine Gandanhäufung unterbrodgen. 3wölf $\Re i l n=$ meter von Jendi erreidten wir bie lebte auf beutinem (5e= biet liegende Dagombaortidaft, Sambu. $\mathfrak{A} m$ Eingang in bas Dorf meldete in itrammer Saltung Der Soldat, Den ber Stationsleiter Sonntag mit uniern Trägern abgejđicft

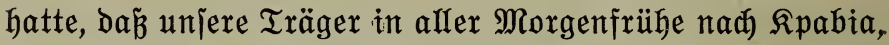
unjerm heutigen Reijeziel, aufgebroden jeien. Dex Sta = tionsleiter hatte uns nämlid in freundlidjiter Weije für Träger gejorgt, bie uniere Lajten bis Tamale zul tragent hatten.

. Es war nidłt $\mathfrak{j} \mathfrak{u}$ verfennen,

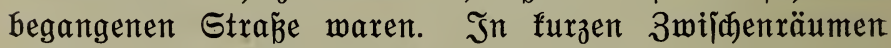
zogen an uns größ̈ere boex fleinere ßarawanen von Trägern und $\mathfrak{L a j t e j e l n ~ m i t ~ i h r e n ~ T r e i b e r n ~ v o r i ̈ b e r . ~ E i n m a l ~ i p r e n g t e ~}$ aud ein vornebmer Saulahändler an uns vorbei; vor iłm im Gattel já̉ jein fleiner Sohn, beibe in weiten, wallenden Gemändern. Gonit war bie Gegend menidhenleer. Bolle 21 Rilometer trafen wix auf feine menifhlidge $\mathfrak{B o h n u n g}$ wohl aber auf Spuren zahlreidhen Bildes, bejonders von Syänen und $\mathfrak{A n t i l o p e n . ~ D e r ~} \mathfrak{B e g}$ führte weedjelnd bald

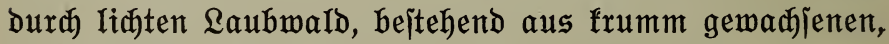
10-15 Meter hohen Bäumen, Dann wieder über Ebenen, bie von ber Gonne burdghlüht waren, und auf benen teils 
Das vermelfte gelbe Gras nod itand, oder aber idon $a \mathfrak{b}=$ gebrannt war. Mand) diejer Ebenen ließ̉en unjđwer ex= fennen, dá̉ fie in Dex Regenzeit groje Sümpfe ober aud Seen bilden. Niðt felten fübrte ber Weg ïber groje Strefen fläßhenhaft liegenben, geringwertigen Eijenerz= fels. Bom Ramm der niebrigen Sügel fahen wix in ein öbes, Duritiges Land hinaus, in meite, pom Grasbrand verfohlte Ebenen und auf unfrudtbare Sügel mit ipär=

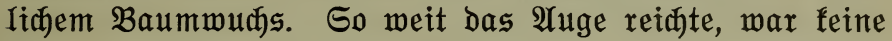
Spur menjळliðer Wohnungen ober menjळliðex Tätigfeit 3u erblidfen. Endich famen wir an ein paar armjelige Beiler, und nach 39 Rilometer Fahrt nach Rpabia. Der Drt hat barum einige Bebeutung, dá̉ er an ber Straß̉e Sendi=Salaga und ber Strá̉e liegt, bie von Salaga über Raraga naç Gambaga führt, der alten Militäritraß̉e dex Engländer. Diđht beim Dorf liegt ber orbentlich unter= haltene Ra|thof, in bem wix abjtiegen. Unmittelbar neben Dem Rajthof wixd Marft abgebalten, und während jeitter ganzen Dauer begleitete, wie gewohnt, ein Sändlex das Marftgejarei mit unaufhörlichem Getrommel. Seine Irommel hat die form einer Sanduhr. Die Erniure, die von einem Trommelfell zum andern geipannt find, fönnen, Da bie Trommel unter bem $\mathfrak{A}$ m getragen wirb, burd einen Druf bes $\mathfrak{A}$ rms gegen ben Leib itraffer geipannt werben; Daburah mixb der Ton ber Irommel höher. Wenn aud auf dieje Weije zwei verjøieden hohe Töne hervorgebraht merben fönnen, fo bleibt eben bod das Getrommel für euro= päifhe Dhren und Nexven fein Genuß̈, wenn ohne Unter= bređung Dasfelbe furze Signal brei Stunden lang mit lang= jam iteigender Begeijterung und niat nachlajiender $\mathfrak{R}$ raft jo laut getrommelt wirb, dá̉ es den nidjt unbedeutenden Marftlärm übertönt.

அuळ in Rpabia beiteht eine zahlreiche Mohammedaner= gemeinde; ifre Mojace aber ijt, ähnlia der in Jendi, feine Gehenswïrdigfeit. 
Rings um Rpabia liegen eine jiemlidbe 3ahl fleiner Dörfer und Beiler. Einer Davon trägt Den auffallenden

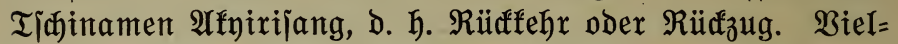
leidt, Dá̉ einmal ein Seerhaufen ber 2rjanteer bis bieher vororang und Durd bie Troitlo[itgfeit Der Gegend veranlä̧t murbe, umăfehren. Spabia jamt ben barumber liegen= Den Drtiळaften mag etwa 2000 Einwohner zählen.

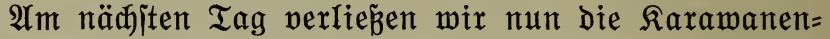

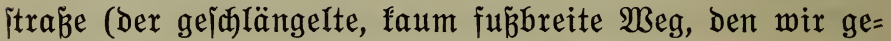
gangen waren, werbient freilid) nid)t ben itolzen Ramen), und reijten in weitnorbwejticher Ridtung weiter auf Reger= pfaben, bei weldhen man allerbings nux als Endergebnis jagen fonnte, in weldher Ridtung fie fübren, wenn man alle bie unzä̆ligen Windungen und Rrümmungen aboierte oder jubtrahierte und dann bas Mittel jog.

Eine gute Strecfe weit war ber $\mathfrak{B e g}$ won ben $\mathfrak{A} n=$ wohnern etwas gereinigt, und zwar in ber uns non ber Goldfiijte ber befannten Weile. Die Leute itellen fid Dabei

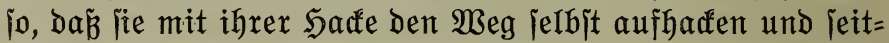
wärts aufwerfen. Es entiteht baburd eitre mit jeber $\mathfrak{B e g}=$ reinigung (iં pertiefende Rinte, Die bann vom Regenwaffer aufgefüllt wird, Das barin itehen bleibt und den Weg ver=

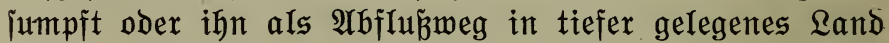
wähIt. Regenwalier madhte uns allerbings in jenter 3eit feine Sdywierigfeiten, Denn alles war gänz̧lid ausgedorrt; bagegen lag tiefer Sand auf groz̉en Streften und erínerte unjer Fortfommen jehr. $\mathfrak{R u r}$ in jehr weiten Irbjtänden famen wir an fleinen Beilern von 2-6 Sïtten vorbei; in einem, namens TIđhofu, Das aus brei Gehöften bejtand, bejalofien wir zu übernadten. Mein Dagombawortiðab reidte gerade jo weit, Den Leuten flar zu machen, was wir

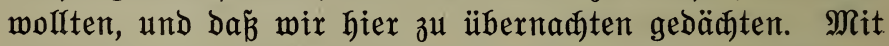
groß̉er Bereitmilligfeit periprad ein altes, runzliges Männ=

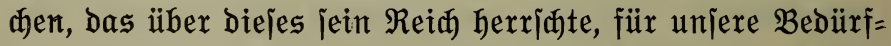
nifle zu forgen. Was in Den Gehöften anwejend war, veriah 


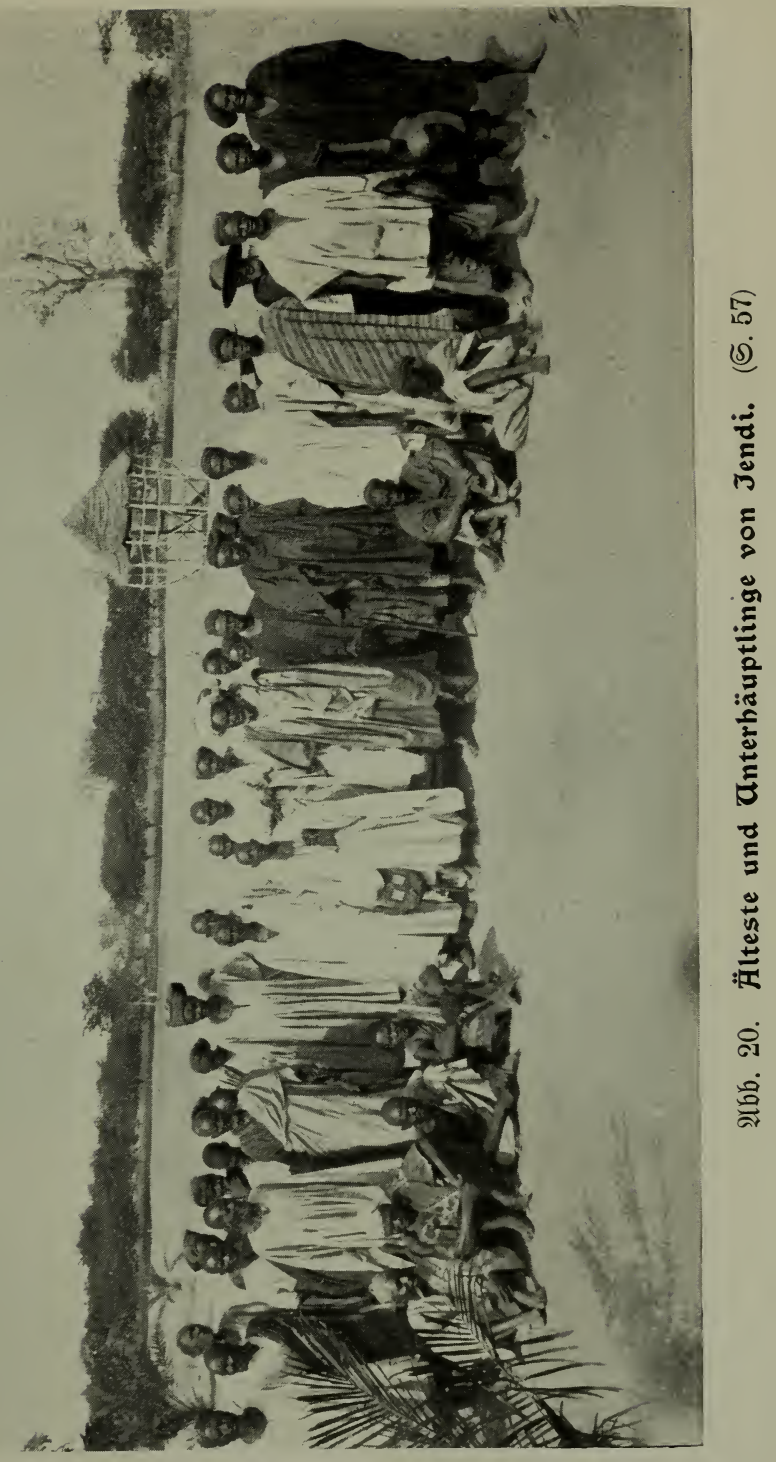





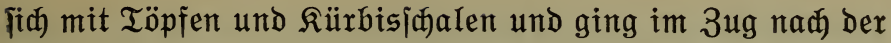
nahen Wafieritelle. Das Männdhen jelbjt bradhte uns ein Suhn und viele Samswurzeln als (5ejđenf́. Ratürlid war

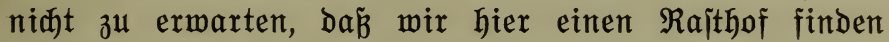
würben. Wix ¡đflugen barum unier Lager im Sdjatten

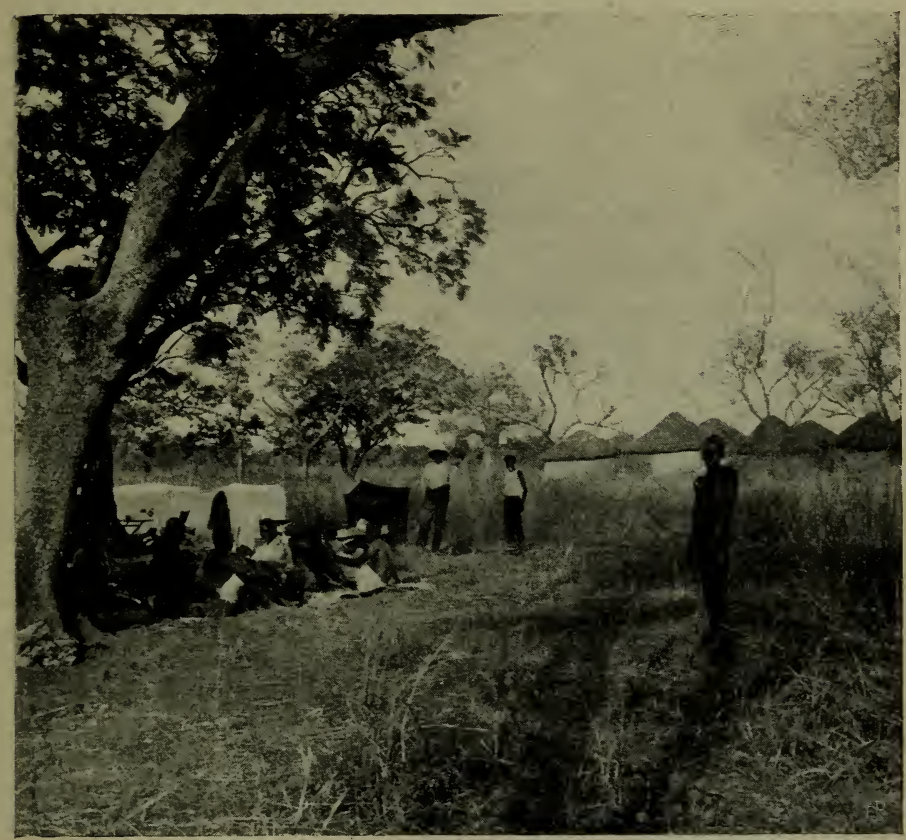

Mbb. 21. Kager in Cschoku.

eines grożen Dawabawabaums, einer Barfia, auf ( $\mathfrak{A b \mathfrak { b } . ~ 2 1 ) , ~ u n d ~ a I s ~ u n i e r e ~ I r a ̈ g e r ~ f a m e n , ~ e n t w i t f e l t e ~ f i ̉ ~ e i n ~}$ ganz fröhlides Lagerleben. Bald erhielt id Bejuđ. Das

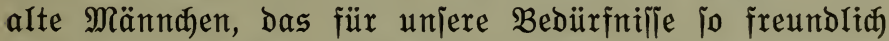
gejorgt hatte, fam ju mir und bat mid, nad jeinen $\mathfrak{A} u g e n$

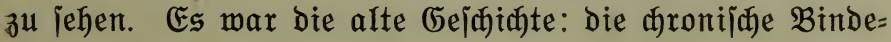


hautentzündung, bie zu S(frumpfung bes obern Libes ge= führt hatte, jodá nun bie Bimpern auf der Sornhaut rieben und eine bichte Trübung Derjelben hernorgerufen.

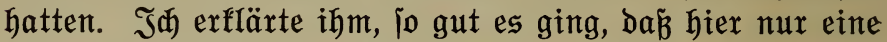
fleine Dperation helfen fönne, und fiehe da, bas Männdben. willigte jofort ein. Mein Feldituhl war ber Dperations= ituhl und bie unbegrenzte Beite mein Dperationszimmer.

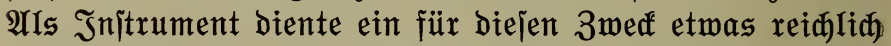
groß̉es Bijtouri. Der Wadfere hielt ausgezeidnet itand,

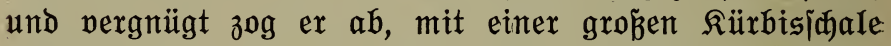
voll Medizin zux weitern Behandlung ber $\mathfrak{A}$ ugen veriehen. Bald bradbte er mir einen nod ältern, febr gebredichen Mann und bat midf, aud ihn in Behandung ou nehmen. Das war nun ein wenigex ausfidstsoller fall. Dem armen Manne fehlte nidgts; er hatte nur mit feinen wohl 80 Jahren offenbar lange genug gelebt. Seine Drgane waren alle in Dromung, aber abgenubt. Sa jagte ihm Das io gut es ging. Er läßhelte halb vergnïgt, halb ungläubig Dazu und bat um Medizin. Ja, wenn id jo ein Mittel gehabt hätte, das altersidwache Männlein und Beiblein wieder jung und elajtilø madhen fönnte! Go ein Mittel gibt es. eben weder im fulturfranfen Europa, nod in Der afrifani= finen $\mathfrak{B i}$ ilonis, in ber wix uns befanden; trobsem befam bas. Männdhen auh eine Rürbisfhale voll Mebizin, bie wohl nidht befiere und nidht idjedtere Dienite getan hat als eins. ber vielen für iđweres (5eld an ben Mann gebradten euro= päijßhen und amerifanijøen Geheimmittel.

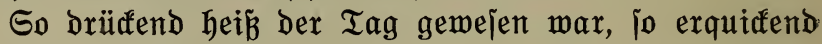

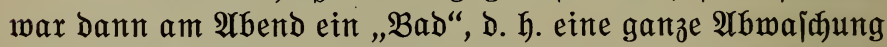

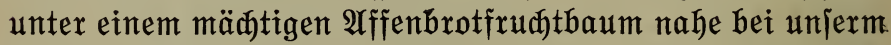

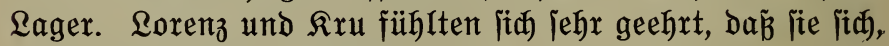
mit unjerer einzigen $\mathfrak{B a f f e}$, bie wir mit uns führten, eintem Buldmelier, D. h. einer Sippe bemaffnet, neben bem Felobett bes einen unter uns, ber unliebjamen Bejud in ber Radt. fürhtete, niederIafien durften. Beder Löme nod Leopard, 
nod) irgend ein anderes Tier magte es jedod, fold furcht= barer (Gejahx zu trogen und uns nädtlidermeile zu bejuđen.

Es muxbe bej̧lofien, am näßjiten Iag bis Tamale 3u fahren, eine Streffe, die unjere Iräger in zmei Iagen

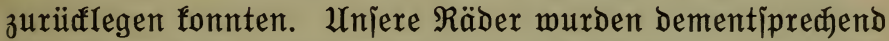
bepaăt, und wix gönnten Den Irägern bie ganze, ungeitörte

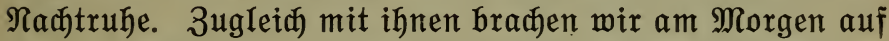
und verabidiebeten uns von ben braven Reuten bes Weilers. In unzähligen Winbungen führte ber Beg Dura lichte Baum[avanne, ïber Ȩenen und Diđ̆tere Wäldan. Es fieht eigenartig aus, wenn man etwas vorausgefahren ijt und auf bie Nađfommenden martet. Der hinter bem eriten Seranfommende iđeint dabei hin und her zu pendeln; bald ijt er zux Rẹten, bald zux Linfen Des Boranfahrenden, meil jozulagen feine gerabe Streffe auf Dem ganzen Weg vorfommt. Niðt jelten waren die unvermuteten Rurven

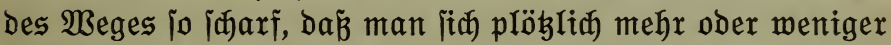

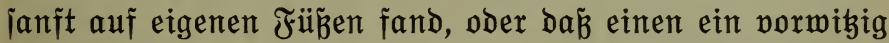
über den झfad hängender 3weig unjanjt jejthielt, menn der

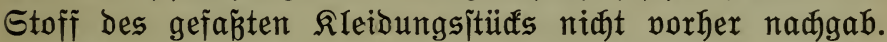
Erît nach 24 Rilometern exreidten wix bas exite Dorf Tof́u. Es bejteht aus etwa 30 Gehöften. Die Einmohner waren

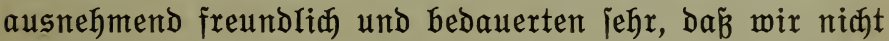
bei 旸en übernałten wollten. Beinahe wäre hier einem meiner Gef̈ährten ein reøtes Minggejđił begegnet. $\mathfrak{U}$ Is ex an einer auß̉erhalb bes Dorfes weibenden Rub porbeifahren mollte, iđ)lug dieje aus, traf das Rad meines Freundes und

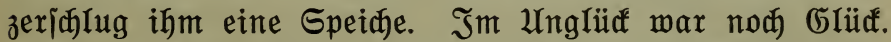
Sätte $\mathfrak{i} \mathfrak{x}$ Suf meinen Freund jelbit oder ben Rahmen bes Rabes getroffen, jo hätte leiđht ein jđwerer Sđaden an= geriđtet werben fönnen.

Unjere Träger jollten hier übernađten und am näđjiten Iag in Tamale wieber zu uns itožen. Wir verabjøiebeten uns baher pon ben freundidjen Leuten. Sie haben bann unjere Träger mit gró̉er (5ajtfreundjøaft aufgenommen und 


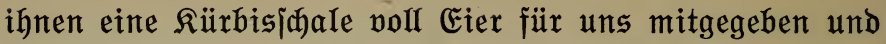
uns Durd fie nodhmals jagen Iaflen, wie fie bebauerten, bå̉ wir nidgt bei ifnen ïbernadteten. 23 Rilometer hatten

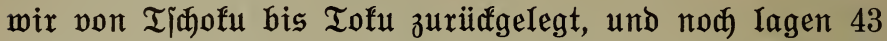
zwijhen uns und Tamale. Etwa 12 Rilometer vor Tamale trafen wix ein bebeutenderes Dorf Go. Es liegt auf einem ¡đönen Sü̈gel und beiteht aus 50-60 Gehöften. Neun Rilo= meter weiter famen wir endida auf bie breite, iđöne Strá̉e, bie von Tamale nad Salaga fïhrt, und ba hatten uniere Durd bie engen, (đ)ledten, frummen Bege peruriadten Leiben vorläufig ein Ende. Die Strá̉e führt an zwei größ̈ern Dörfern vorbei und dant einen flachen Shügel bin= $\mathfrak{a} \mathfrak{u} \mathfrak{n} \mathfrak{n a d} \mathfrak{I} \mathfrak{a} \mathfrak{m} \mathfrak{a} \mathfrak{I} e$.

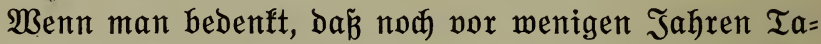
male nur als fleiner Beiler beitand, io muß̉ man beim $\mathfrak{A} n=$

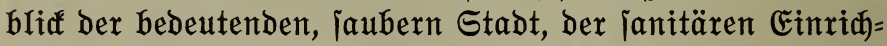
tungen und ber groß̈en, joliben Stationsgebäude ber Energie ber engIi

Die Stadt Tamale madjt idjon non meitem einen red)t

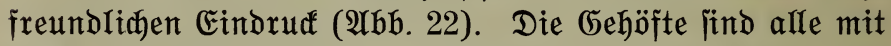

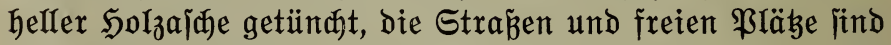
jehr jauber gehalten, und an ben Grenzen ber Stabt find eine $\mathfrak{A n z a h l ~ w o n ~}$ Rehrridhtwerbrennungsöfen in Betrieb. Dieje jind jehr einfach, aber zwedtoienlid in ber Beife ge= baut, dá̉ in form won Quadern behauene Eijenfonglo= meratblöfe in einem Rreife von $3-4$ Meter Durdamefier etwa 1,5 Meter hoch aufgebaut [ind, joda zwilden Den Quabern eindringen fann. Die Einwohner find angemiejen, allen ihren Rehrribt in bieje D̈fen zu werfen. Tag und Radyt brenten bieje D̈fen und bejeitigen auf bieje Beife eine grop̉e Menge Unrat. Ein Rahteil haftet aller= bings Der Einriđhtung an, ber iid uns zu veriđjiebenen Malen, als wix in ber Stadt herumgingen, redht unan=

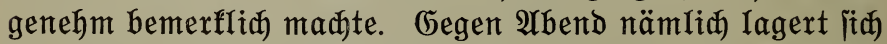
Der übelriechende Raud ber D̈fen in mehr ober weniger 


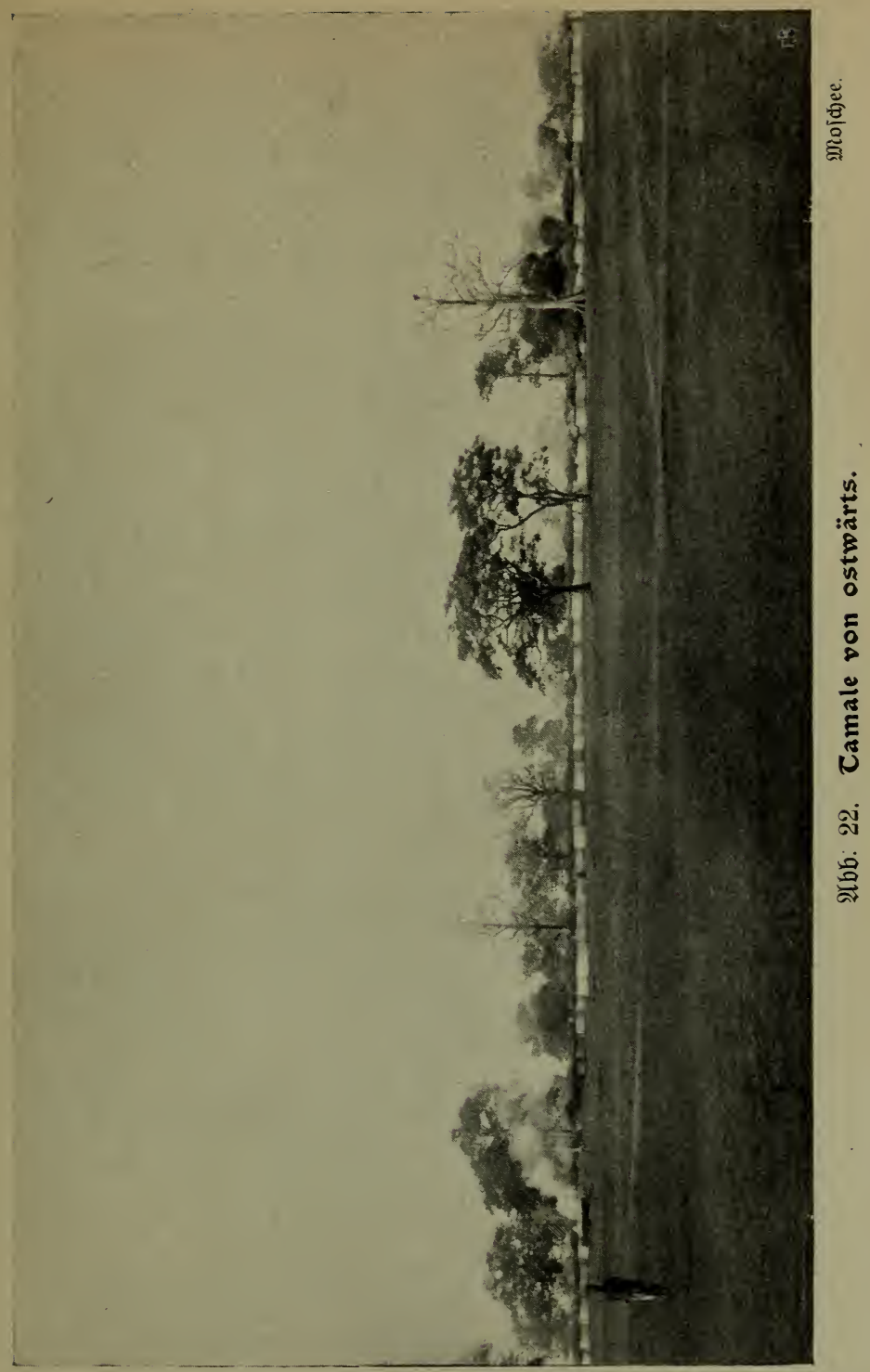


bidten Gdwaden ïber bem Boden und verdirbt einem bie Freube an ber jonjt io reinen \&uft. Rechts auf bem Stabt= bild jieht man die Mojøee der zahlreidhen Mohammedaner= gemeinde, die etwas befler in Stand gehalten ijt als jonjt in vielen Stäbten. $\mathfrak{A} \mathfrak{u} \mathfrak{f}$ ben adyt, Das Gebäube überragenden Spizen der Lehmauffäbe itedfen als Sd)mữ die gewohnten Strauḱpeneier.

Das exite Gebäude der englijhen ßRegierungsitation, bas wir zu jehen befamen, ijt das Gdhulfaus. Es ijt ein etwa 12 Meter Ianger und 5 Meter breiter einjtöđiger $\mathfrak{B a u}$ von ¡ab̈n behauenen Ganbiteinen. Ein früherex $\mathfrak{A} n=$ geitellter unjerer Miffion hält barin mit einer muntern

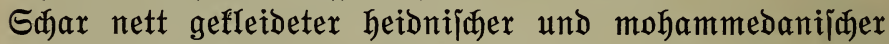
Rnaben Sibule. Ifle andern Stationsgebäude find eben= falls aus behauenen Ganditeinen aufgefïhrt, madjen einen joliben Eindrud und zeugen von jehr reidflid aufgemendeten Gelomitteln. Der Gđhule am nädhiten itehen bie Säujer für die Waffenvorräte, Den Büđjenmađher, die Bauholzporräte und ein grof̉er Sdareiner = und Bauhandwerferiđuppen; ferner bas Gefängnis und bas Pojt= und Telegraphenhaus mit Daran angebauter, halboffener Geridhtshalle.

500 Meter öjtlid liegen bie Bohnungen Der Regie $=$ rungsbeamten, ebenfalls jolibe Sanditeinbanten, bie aber zum Sduł wor ber Sije und in Der Regenzeit vor ben ge= waltigen Regengïlien ïberall mit Sdhindelverialägen ver=

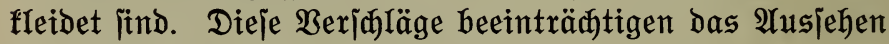
ber Şäujer jehr und madjen bie 3immer recht bunfel.

$\mathfrak{A m}$ unbefriebigenditen ift für ben $\mathfrak{A} \mathfrak{r}_{3} \mathrm{t}$, bie $\mathfrak{A}$ pothefe und bie Kranfen gejorgt, bod foll aud hierin balo Bandel geiđaffen merben. Einitmeilen ijt für die 2 pothefe und bas Spredizimmer nur eine niebrige, mit Gras bededte Lehmbütte vorhanden.

Etwa 2 凡ilometer öitlid von ben Dienitwohnungen ber Angeitellten hat ber leiber vor unjerer $\mathfrak{A}$ nfunft veritorbene Rejibent Colonel Watheritone ein impojantes Gebäude auf $=$ 


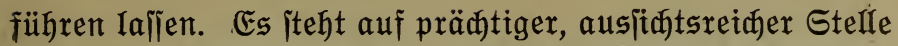
und fieht fajt aus wie ein behäbiges Landhaus in England. Auf Der $\mathfrak{B e j t f e i t e ~ f e h l e n ~ b i e ~ g e w o h n t e n ~ B e r a n d e n , ~ u n d ~ d i e ~}$ freie Front bes Saules ilt den Strahlen ber Radmittags= jonne idublos ausgejegt. Jedenfalls ijt bas Saus ein 3eugnis Dawon, ba $\tilde{\beta}$ England mit Der Berwilligung von Gelomitteln nidgt fargt.

Sehr zierlidi und jauber ijt bie Riederlafilung für bie Golbaten angelegt. Es find lauter Gehöfte von je vier Runbhütten, in weldjen immer zwei Soldaten mit ihren Frauen wohnen. Sinnurgerabe, etwa 7 Meter breite

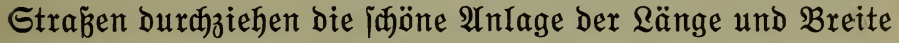

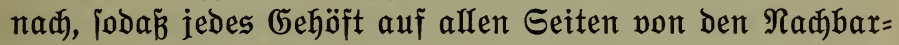
gehöften Durd bie Strä̧enbreite getrennt ijt. Zurzeit be= itand die $\mathfrak{A}$ nlage aus fünf Reihen won je jedgs Gehöften.

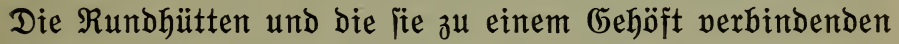
Mauern find mit heller Solzajae jauber geitriden.

Tamale ijt Sauptijy ber englijhen Regierung ber jog.

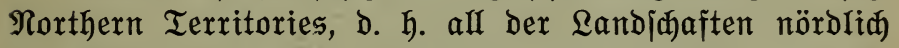
von $\mathfrak{A}[a n t e$ bis an bie Rorogrenze ber Rolonie. Sier ijt Darum ber Dberfommiflar itationiert, und inm jur Geite itehen nod ein Rommiliar, ein Sauptmann ïber bie Sduly= und Polizeitruppe, ein $\mathfrak{A} \mathfrak{r}^{t} \mathrm{t}$ und ein Bauleiter. Leiber war bei unjerm Bejud in Tamale ber Dberfommiliar auf einer Dienjtreife abwejend. In jeiner Stelle wurben wir nom Sommiliar, ber mit jeiner Frau anmejend war, mit groß̈er Freundidfeit aufgenommen und beherbergt.

Die Sđubtruppe zähIte bamals nahe an 200 Mann. Eine $\mathfrak{A n z a h l ~ w o n ~ i h n e n ~ i j t ~ v o r z u ̈ g l i d ~ b e r i t t e n . ~ S i e ~ t r a g e n ~}$ furze blaue $\mathfrak{B a f f e n r o ̈ f e , ~ f u r z e ~ B e i n f l e i d e r ~ u n d ~ w o l l e n e ~}$ Binde um bie Unteridjenfel, als Ropfbedecfung in Tamale

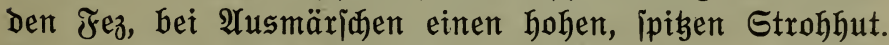
Sie find mit Senry=Martini=仿arabinern $7 \mathrm{~mm}$ Kaliber hemaffinet. Man befommt von i็nen Den Einorud einer

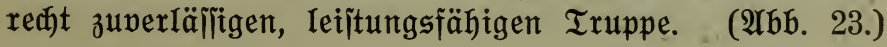




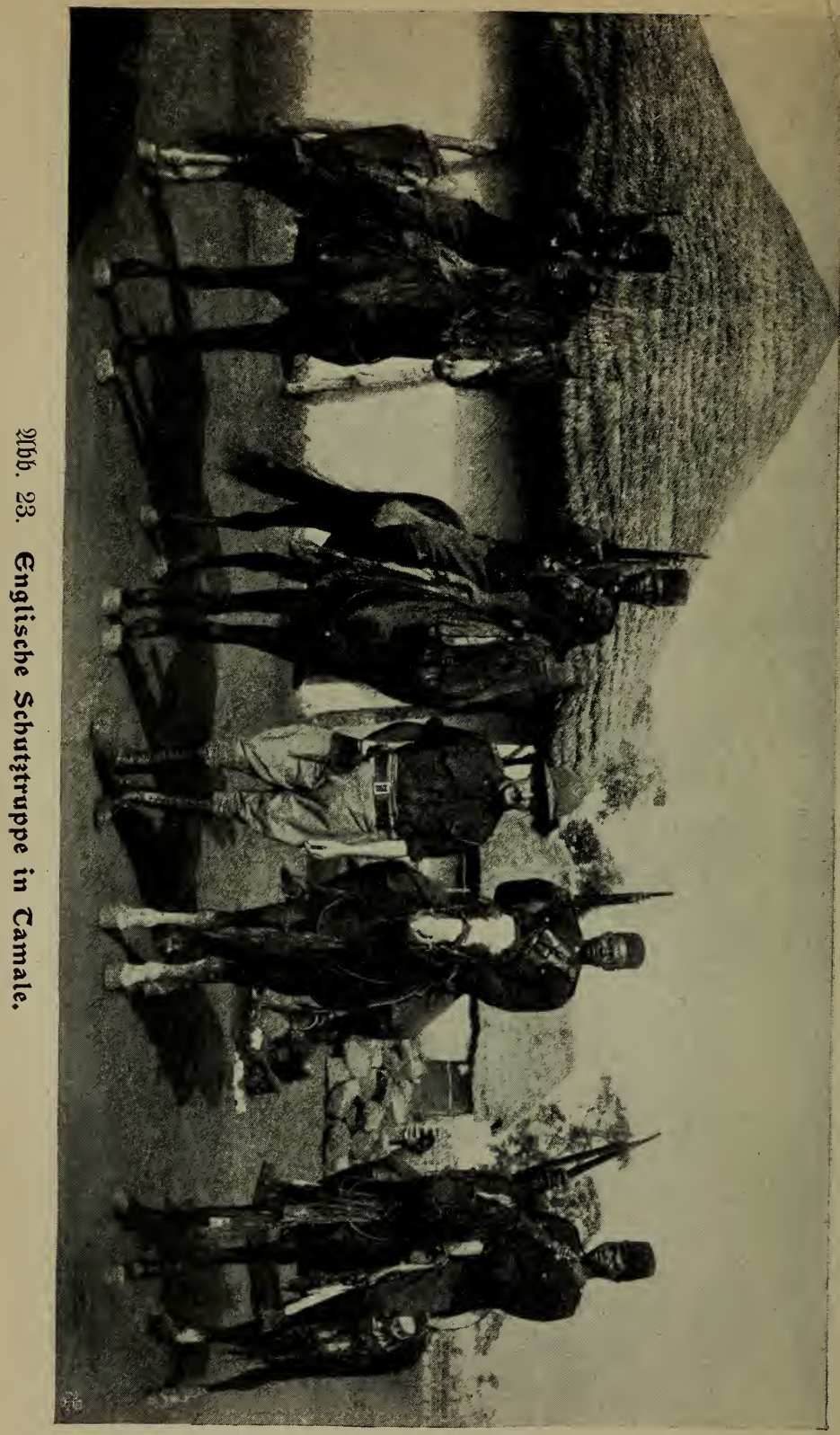




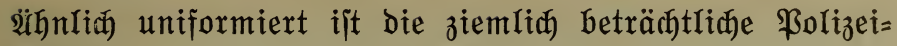
tıuppe.

$\mathfrak{A m}$ Gïbabhang bes breiten Shügelzuges, auf deflen Rücfen Tamale liegt, ijt jehr gutes Grumbmalier erbohrt morben. Strafgefangene perjorgen jeden Morgen die fämt=

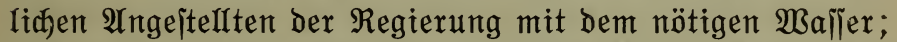
auch einem groß̈en Teil der Stadtbeö̈lferung fommt die Bohltat zu itatten.

Es ijt bie ausgeiprod)ene $\mathfrak{U}$ [id Sandel nach Tamale ju jiehen. 3u diejem 3wed werben Ereite Strä̧en nach ben bebeutenderen Sandelsitäbten ge: haut, bejonders foll bas in ungejunder Lage befindicte Daboya jenjeits bes Bolta jeinen Rang als wiðtiger Sandelsplał verlieren. Won Tamale führt jest jøon eine ¡đnurgerabe, gut unterhaltene Strá̉e an den Bolta nach Dem Tamaleport genannten פeghi. Bis Dorthin ijt aud in

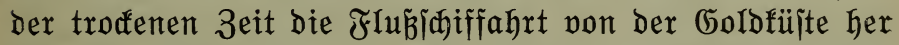
mögliđ. Waren von ber Rüite fönnen zu verhältnismäbig billigem ßreis bis Dorthin und bann mit Wagen auf ber

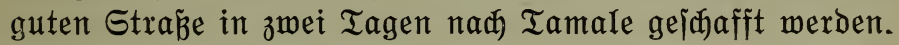
Db Daburd alle Rahteile, die in ber Lage von Iamale begründet find, aufgehoben werben fönnen, wirb die $3 \mathfrak{u}=$ funft lehren. Die groß̉e Entfernung pon Der billigen und

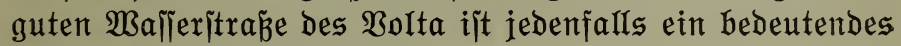
Sindernis für die Entwiallung Tamales.

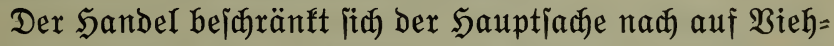

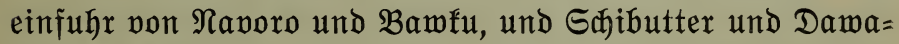
bawa von $\mathfrak{B a}$ und Sorrha her. Die Biehtransporte leiden oft jehr infolge der Iletjejtiche, modurch die Iiere mit einer iehr jølimmen Irypanojomenfranfheit angejtedt merden. $20 \%$ Berluit bis nach Rumaje ijt now ein redt geringer; oft nerlieren die Sändler bis $3 \mathfrak{u} 80 \%$ ifrer Tiere. Es find haupt|ächlich Budfelrinder mit oft pradtwollem Gehörn, groß̉e Søafe, beren Wibder ein fajt magredt abjtehendes, ¡ॅön gewundenes Gehörn tragen, und zwei 3iegenraflen, 
Die eine, die befante $3 \mathfrak{w e r g} a$ iege, und bie andere won etwas höherem, ¡đIanferem $\mathfrak{B a u}$ und lebhafterer färbung. Erit wenn eine Eijenbahn gebaut jein wird, ijt baran $\mathfrak{u}$ Denfen, dá⿱㇒ diejex Sandel gewinnbringend wirb, indem mux badurd bie (Gejahr ber Infeftion mit Irypanojomen vermindert werden fann, es jei benn, Dá man Mittel finde, die jhlimme friege auszurotten. Grhibutter hat wohl eine 3ufunft als $\mathfrak{A}$ usfuhrartifel, bod find bie Mengen nod zu

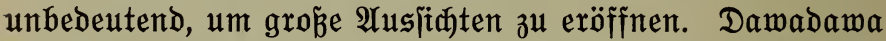
fommt nur für ben Inlandhandel in Betrad)t. Die Sörner= frïbte, zwei Sirjearten: eine Rijpenhixje, die Durrha oder Sorghum, und bie Rolbenhirje, Das ßenijetum, werben einjtweilen nođ nidgt in grö̈ßern Mengen angepflanzt. Die Rauffraft Der Bewohner Der nördrichen Gebiete ijt, weil nod) feine $\mathfrak{A} \mathfrak{u} \mathfrak{1} \mathfrak{u} \mathfrak{x} \mathfrak{r}$ bejteht, jehr gering und wird je weiter gegen Norben, um jo geringer. Die Biehjud iteht bei ben Dagomba erit in Den $\mathfrak{A} n$ fängen. Einige Gegenden find wegen maflenhaftem Borfommen won Tetjeffiegen beriid = tigt, io bejonders bas oben erwähnte Daboya.

Bährend Baulteine fạt überall mühelos gemonnen werben fönnen und in vorzüglidher Beidaffenheit zutage

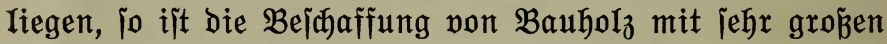
Sdyierigfeiten verbunden. In ben lidten Baumianannen braudren die Bäume nidht wie im Urmald Iange Stämme, um zum Lidft zu gelangen; bie Trodenheit und geringe Sumus[đidgt erlaubt bie Bildung geraber Stämme auđ nidjt. So ind Bretter, bie ben bejachenjten $\mathfrak{A}$ nforberungen gereøt $t$ werben, ein lehr teurer $\mathfrak{A r t i f e l}$. Türen, Bretter= böben und Möbel in jenen Gegenden find bent aud von läßjerlidh armieliger Bejđaffenheit. Türen beuten oft nur die Crenze eines 3immers an und exfüflen feinen andern, innen eigentlid zufommenden 3 werf; jedenfalls idü̈ben fie in feiner Weije bavor, bá man .pon auß̉en gejehen wirb. Rommoden und Sđränfe bieten Dem Eindringen von Staub und Inieften feinerlei Ğbierigf́eiten. In den Brettern 
medjeIn Stellen mit diḑtem und Iofferem Gefüge ab, die Fajern Des Solzes ziehen in allen mögliđben Riðtungen längs und quer burd bas Brett, jobá̉ es fiđ in unbereden=

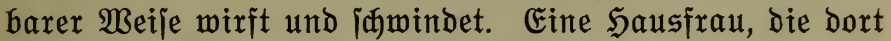
iđalten und walten joll, wird aljo gut tun, ihre Erwar tungen in bezug auf Mobiliar bej̧eiden zu geitalten.

Tamale weilit etwa 6000 Einmohner auf; die Moham= medanergemetnde foll annähernd 1000 Seelen zählen.

$E_{s}$ itehen eine ganze $\mathfrak{A} \mathfrak{z} \mathfrak{a h l}$ jrüherer Miffions=

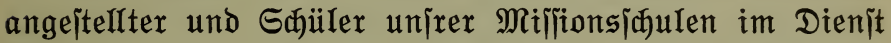
ber Regierung in Tamale. Bir hatten gehört, Dá̉ fie fitch

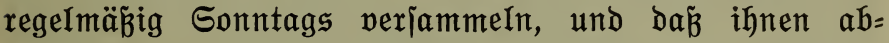
weajelnd von benen unter ihnen, die früher als Ratedijten gebient haben, Gottesdienit gehalten merbe. Sie hatten jogar im Borjahr eine Gammlung veranjaltet und ihrex Seimatgemeinde Den Ertrag, 180 Marf́, als Beitrag jum Miffionsfejtopfer gejuidut. Es war uns baher eine groß̉e Freube, als es uns möglid wurbe, an bem Sonntag, den wix in Tamale zubrahten, die Chrijten um uns $\mathfrak{u}$ ver= jammeIn. Bon Den Bertretern der Regierung murbe uns bereitmillig Das Grulhaus zur Berfügung geitellt. Der Raum fültte fïh mit nahezu 70 ßerionen, zum größ̈ten Teil Chriften von Der Golbfiilte, zum fleinern Teil heib= nijøe Sandwerfer von der Rüite, die jđon in mehrfađe Berührung mit Dex Miffiton gefommen waren. Es war eine

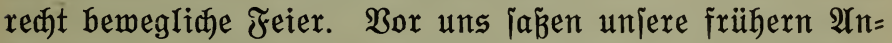

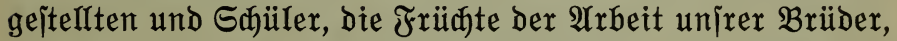
die zum Teil in ber Seimat als Snvaliben now leben, zum Teil zux Ruhe eingegangen find. Beim Gejang Der lieben, vertrauten Rixhenlieber fonnte einen jळon Danf und Freube übermannen. Die fleine Gemeinde hat uns das Bort mit Berlangen und Beritänonis abgenommen. Es hat fin ein neues Band der Liebe und Gemeinjaaft zwijøen uns und diejem alleinjtehenden Säuflein unjrer Chrijten gefnüpft. İ rührender Weije fam dies dann zum $\mathfrak{A}$ usdrud, 


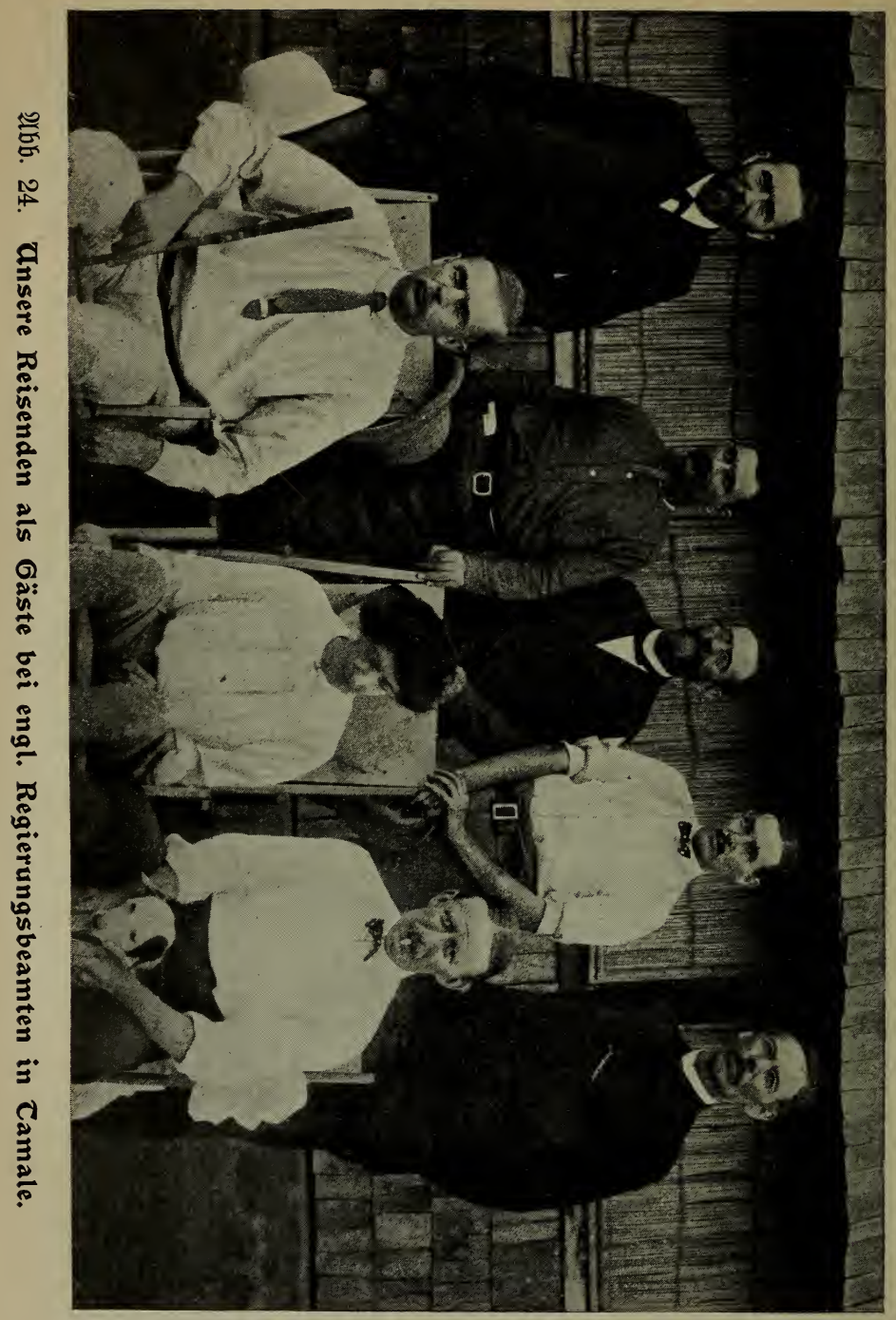


als fite ben Iag unirer $\mathfrak{A b r e i j e ~ e r f u b r e n . ~ D a ~ h a b e n ~ f i e ~ u n s ~}$

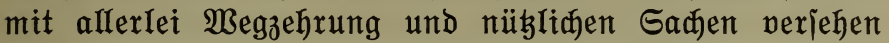
und haben es [iં etwas foiten Iaflen. Wir hörten aud mit

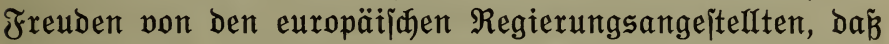
ite die volle 3ufriedenheit ifrer Borgejegten erworben haben und zum Teil jehr gejøäbte Mitarbeiter gemorben itito.

Am 18. Februar maren wix in Tamale eingetroffen und hatten unjern Frauen auf der (Goldfiujte telegraphija

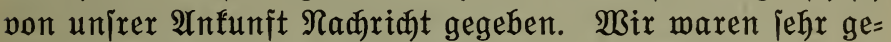

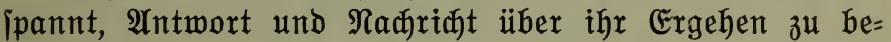
fommen. Unjer Warten war aber vergeblich. Erit am 4. März exreiđte uns die exjehnte $\mathfrak{A}$ thtwort in Gambaga. Die Ielegraphenbeamten jind eben hier zu Lande jehr un= zuperlälifige Sherren, und wix find jola)e Berzögerungen tele= graphijäer Meloungen längit gewohnt.

$\mathfrak{U}$ 22. Jebruar brachen wix von Tamale auf, und zwar wollten wix, bevor wir naw Gambaga reijten, die Land= ¡かaft mejtich von Iamale bejuchen, ba wix gehört hatten, dá̉ bort die Benölferung diater jei als jonjtmo. Wir nahmen baher die Strä̌e, die von Tamale nađ̆ Daboya und Wa= Rorrha führt. Sie war bamals neu angelegt, aller = bings ohne Steinunterbau, jodá̉ fie in ber Regenzeit jehr bald bejhäbigt jein wird. Uns ermöglidte fie in ber herr jhenden Irodenheit ein jẹr bequemes, rajđes Bormärts= fommen. Wix fuhren 27 Rilometer bis nach dem jiemlið bedeutenden Dorfe Tolon. Dá̉ die Gegend dichter benölfert ijt als bie ganze leit Rratiळi zurürfgelegte Streffe, zeigte

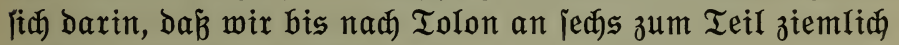
grö̈en Dörfern vorbeifamen.

Die Regierungsbeamten in Tamale maren fo freund: Iiđ, uns Iräger зu bejorgen; überhaupt haben fie uns in jeder Weije aufs freundichjte mit Rat und Iat gedient, aber als ber $\mathfrak{A}$ ufbrud erfolgen jollte, ba waren eben feine Iräger vorhanben. Die Serren veripradjen, fobalo als 


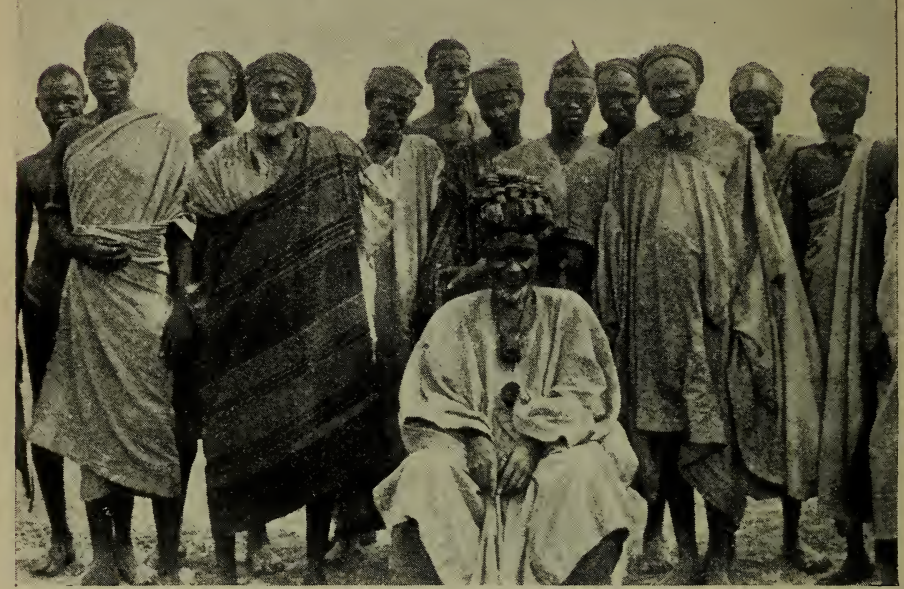

2łbb. 25. Fäuptling und Gefolge zu Besuch in Colon.

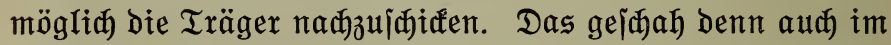
Saufe bes Bormittags, bođ muß̈ten wir natürlich lange

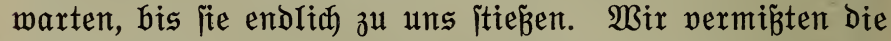
¡đneibige Rede Des Regierungsbeamten, die Damals in Rratjai jo raja Reben in bie Sache gebradt hatte.

Das Randiðaftsbild mejtich won Tamale ijt ganz das gleithe wie im Diten. Breite, flache Täler weajeln mit gleichartig und bewegt itđ in übergängen von liđater Baum=

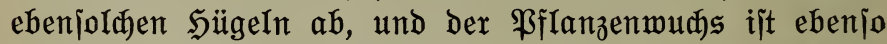
javanne zu offener Grasiteppe. Der Boden ijt, entipreanend ber biđteren Bevölferung, rewt intenjin mit den beiben Sixjearten und Jams bebaut.

In Tolon fanden wix ein gutes Rajthaus, und faum waren wir Dort, fo madyte uns der ältejte Sohn des Säupt= 


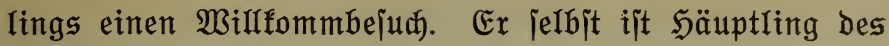

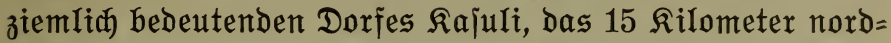
mejtrid von Tolon liegt. Der Säuptling jandte uns burd ifn einen Sammel und 50 Eier zum (5ejđenf nebjt einer Menge Jams. Wir lié̉en iłm beîtens danfen und melden,

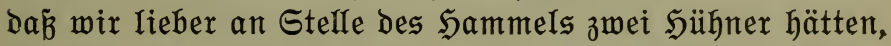
ba wir nur wenige Träger mit uns brärthten. (Sleiđa wurden nod zwei $\mathfrak{5}$ ïhner gebracht und uns mitgeteilt, ba Der Säuptling ben Sammel unter feinen $\mathfrak{U}$ mitänden wieder

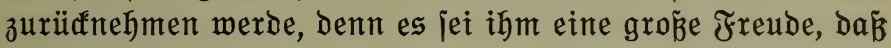
wir gefommen jeien. Wir baten bann, bod wenigitens bie Sü̈ner wieber antehmen zu wollen; nad langen Berhand= lungen nahm ber Gejandte ein $\mathfrak{H u h n}$ wieder zurüd, bradte bann aber eine zweite אürbisfdale voll Eier als Gejhenf.

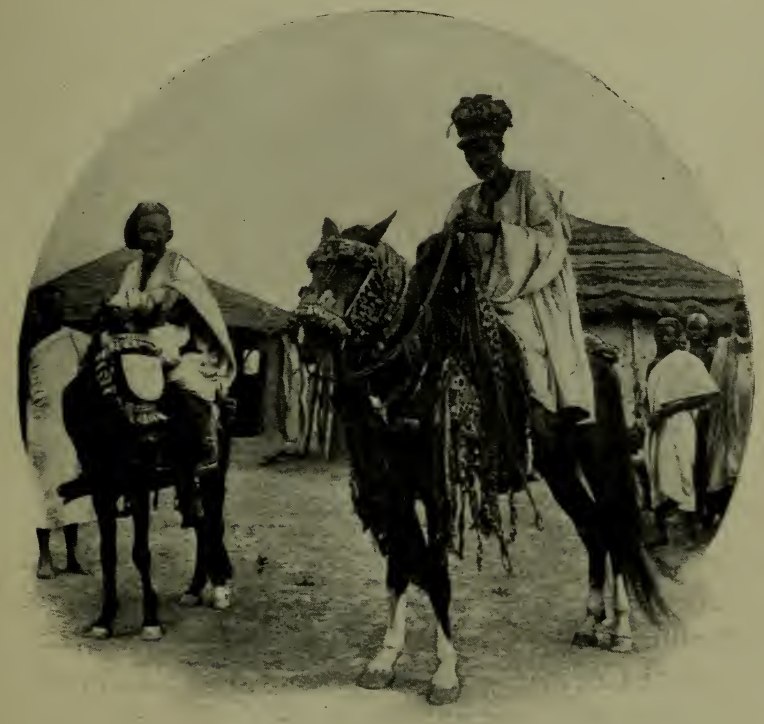

Abb. 26. Fäuptling von Colon und Kasuli. 
Der Sohn Des Şäuptlings, Der uns bieje Gejhenfe über=

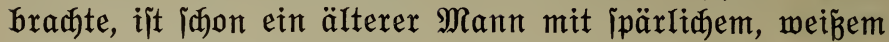
Rinnbart und freundridem, offenem Gefidft. Er trug Das

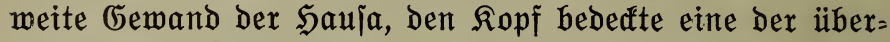
mä̈̈̇g hohen Dagombamüben, an welder eine Menge $\mathfrak{A} m \mathfrak{u}=$

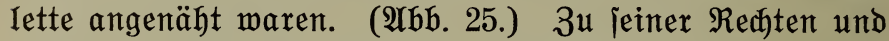
Linfen itanden zwei gutmütig breinfaauende ïlteite, und

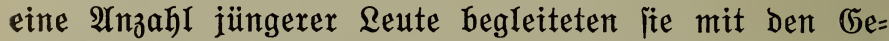
iđgenfen. Wix bejucten darauf Den Şäuptling und jeinen

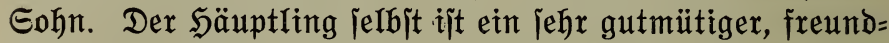

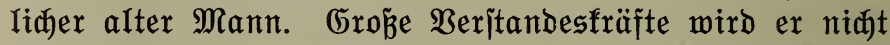
bejigen; bafür hat er aber ein jehr vertrauenerwedfendes Bejen und trob jeiner etwas unterjegten Geitalt ein ganz mürbenolles Benehmen. (Gleid) nadbem wir von bem $\mathfrak{B} e=$ juch wieder im $\mathfrak{R a j t h o f ~ a n g e l a n g t ~ w a r e n , ~ f a m ~ b e r ~ S ̧ a ̈ u p t = ~}$

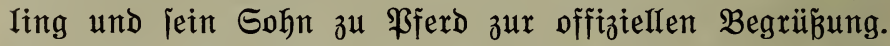
Sie hatten jich jelbjt und ihre Bferbe aufs inönjte aus= geitattet. Der Söuptling ritt ein fleines Tier, bas auj ber Stirn eine groß̉e Silberplatte mit allerlei eingelalagenen Jiguren trug. $\mathfrak{A}$ üer diejer ßiatte war der 3aum bes \$ferddens mit einer Menge eijerner und mefifingener Glöd" wen und anderex Berzierungen verjehen. Sein Sohn ritt einen gró̈en, etwas plumpen Rappen, der nod̆ mehr mit Zierat, (5ehängen, Fellitreifen und $\mathfrak{A}$ muletten behängt war,

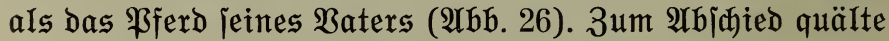
bann ber Gohn jeinen Rappen zu allen möglidjen Sprüngen, um uns feine Sattelfẹtigfeit vor $\mathfrak{A} \mathfrak{u g e n}$ zu führen.

Tolon madte uns einen jehr guten Eindrudf. Die Ein= wohner waren ausnahmslos jehr freundlid und zutraulid. überall jah man freundidide (Gejithter. Das Dorf mag etwa

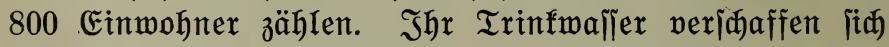
bie Einmohner in einfadjiter, wenn aud nidgt einmandfreier Beije babura, Dá jie irgendwo im Dori 2-3 Meter tiefe Löher graben. In joldher Tiefe itop̉en fie, wie es ideint,

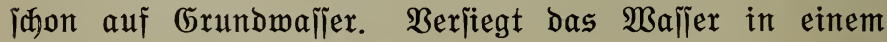




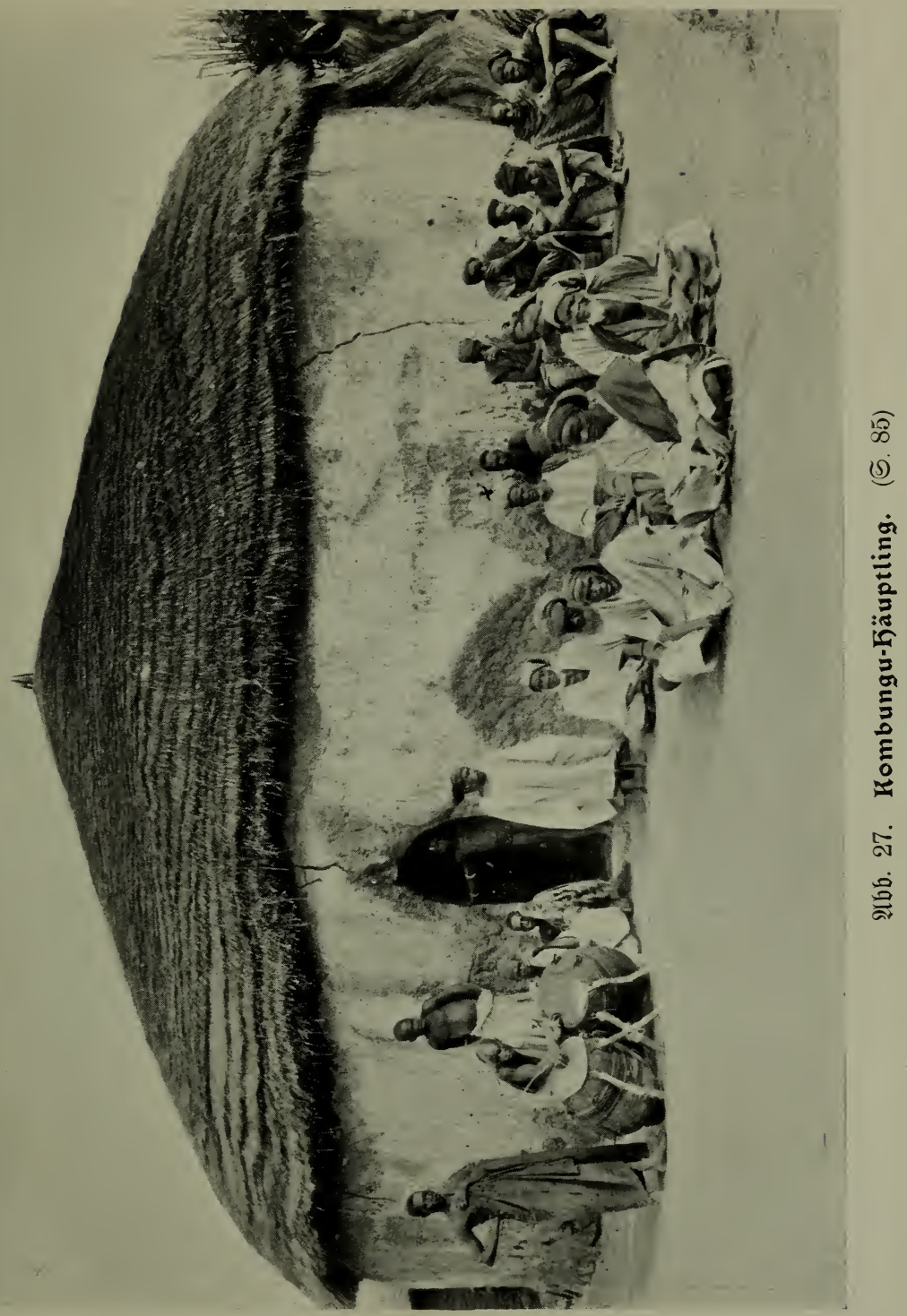



joldyen Lod, io wird ganz nahe baneben ein anderes ge= graben, während das alte als hehrriatablagerungsitelle benugt wird. über bie etwas verengte D̈ffinung ber Gruben werben ein ober zwei bïnne Baumitämmđjen gelegt, um zu verhindern, dá̉ Meniđen ober Tiere Gineinfalfen.

$\mathfrak{A} u$ h in Iolon bejteht eine fleine Mohammedaner= gemeinde; ein Malam unterridtet ein paar Jungen im Rejen. In allererjter Morgenfrühe meâte uns ber $\Re u f$ bes Muezzin, und won weitem hörte man bie lauten Stimmen Der intelligenten Jungen und ihres Lehrers. Er liejt mit ingender Stimme eine Gure bes Roran por, und fie wieder= holen bielelbe im gletaen Ionfall.

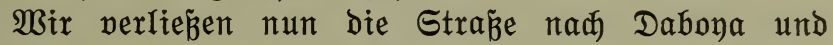
wandten uns mehr norbweitlich; unjer 3iel war $\mathfrak{L}$ umbungu. Edjon nach 8 నilometern famen wix burd ein nettes Dorf, namens $\mathfrak{V}_{\mathfrak{o}}$ (tiefes o wie hoffen). Ëin $\mathfrak{A}$ usä̈ziger ohne Finger und 3ehen itreáte mir unbefangen bie veritümmelte Sand jum (5rü hin. Wie jehnen wir und bas Bolf bie 3eit herbei, in welder bieje $\mathfrak{U r m e n}$ in $\mathfrak{X}$ inlen untergebradjt und nidgt nur verpflegt, fondern aud ifoliert werben! Bis jegt ijt auf ber Gorbfüite nod nidhts für fie geidehen. Sdjon 5 Rilometer weiter trafen wir wieber ein Dorf

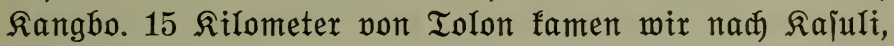
Dem Dorf, über meldes unier Freund von Tolon Säuptling ijt. Sajult ijt nahezu jo groß́ wie Tolon. Der Şäuptling traf bald nad) uns bort ein, während wir idjon weiter gefahren waren. Er gab Dann unjern Trägern Ėer und eine $\mathfrak{A} n \mathfrak{z} a \mathfrak{l}$ fleine 3 itronen als (bejhenf für uns mit und verjah fie unentgeltitid mit Speije. Die 3itronen waren

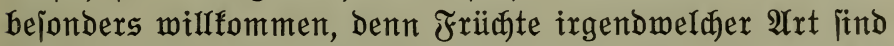
im Dagombaland eine groß̉e Geltenteit. Nur Papaya, bie jogenannten Baummelonen, werden ipärlid̄ angepflanzt.

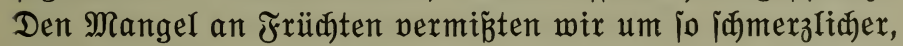

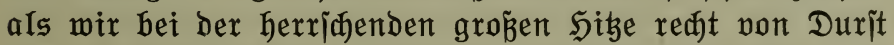
geplagt murben und zur Stillung besfelben nur leidten Iee

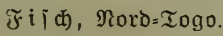


tranfen. Da idmeate benn berielbe mit einem $3 \mathfrak{u}$ aja von ein paar Tropfen 3itronenjaft jehr viel angenehmer und

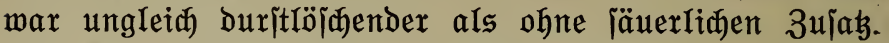
Wix famen nody burd zwei Dörfer, bis wix nad einer längern, unfruđtbaren Strecfe unier 3iel erreidten. Der Rarte nach erwarteten wir $\mathfrak{L}$ ungbungu ober $\mathfrak{L}$ umbungu als aniehnliche Stadt zu finden und waren jehr enttäujht. Das Dorf bejteht aus ein paar armjerigen Gehöften und ift jebr ¡đ̆muzig. Der Şäuptling war abwejend, und da natürlid, fein Rajthof vorhanden war, wurde uns das Gehöft bes Säuptlings als Quartier eingeräumt. Dieje Einräumung war bald gejđehen. Das Gehöft itand leer, und nachdem die grof̉e Eingangshütte ein wentg ausgefehrt war, zogen wir ein und teilten fie mit einem groß̉en Flug Tauben, be=

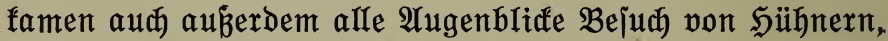
Ziegen und groß̉en und fleinen Dagombajungen, bie auf $=$ fallend oft dort etwas verloren zu haben idienen. Die Nähe

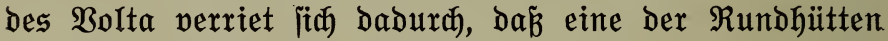
im engen Gehöft ein gewaltiges Shienbein eines $\tilde{I} \mathfrak{l u} \tilde{z}=$

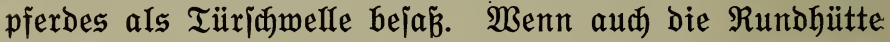
Des Şäuptlings einen Durdmefler von 12 Metern hatte, fo zog bod die Mehrzahl von uns vor, im freien zul $\mathfrak{u}$ ber $=$ nađhten, Denn der Sängermettitreit Der Taubenmänndhen. hörte aud in ber Radht nidht auf.

$\mathfrak{A} m$ nädjiten Morgen wandten wir uns nad Diten und

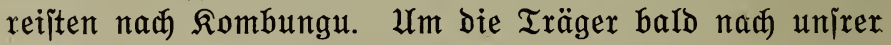
Infunft bort zu haben, fertigten wix jie morgens um 3 $\mathfrak{u h r}$ $\mathfrak{a b}$. Nadhdem wix 10 Rilometer zurüdgelegt hatten, fam. Tibung, ein ziemtid bedeutendes Dorf, in Sidt. Da fanden wix unjere Träger auf ihren Traglajten jïgend, vor ihnen. eine grö́e Berjammlung ber Einwohner, und in beren Mitte

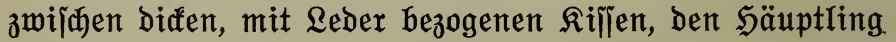

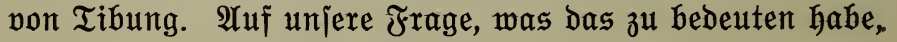
jagte uns ber Begleitsmann unirer Träger, ber Säuptling von Tibung wolle uns ein- Gejhenf überreiden. Nadher 
itellte es fị aber hexaus, bá̧ ex franf war und von mix behandelt zu werden münjate; ex habe barum die Iräger warten Iallen, weil ex nicht wille, welaher von ihnen bie Medizinen trage. Der Säuptling, ein hagerer, jebr franf ausjehendex Mann, exhob fich mühjam und itellte fï mix

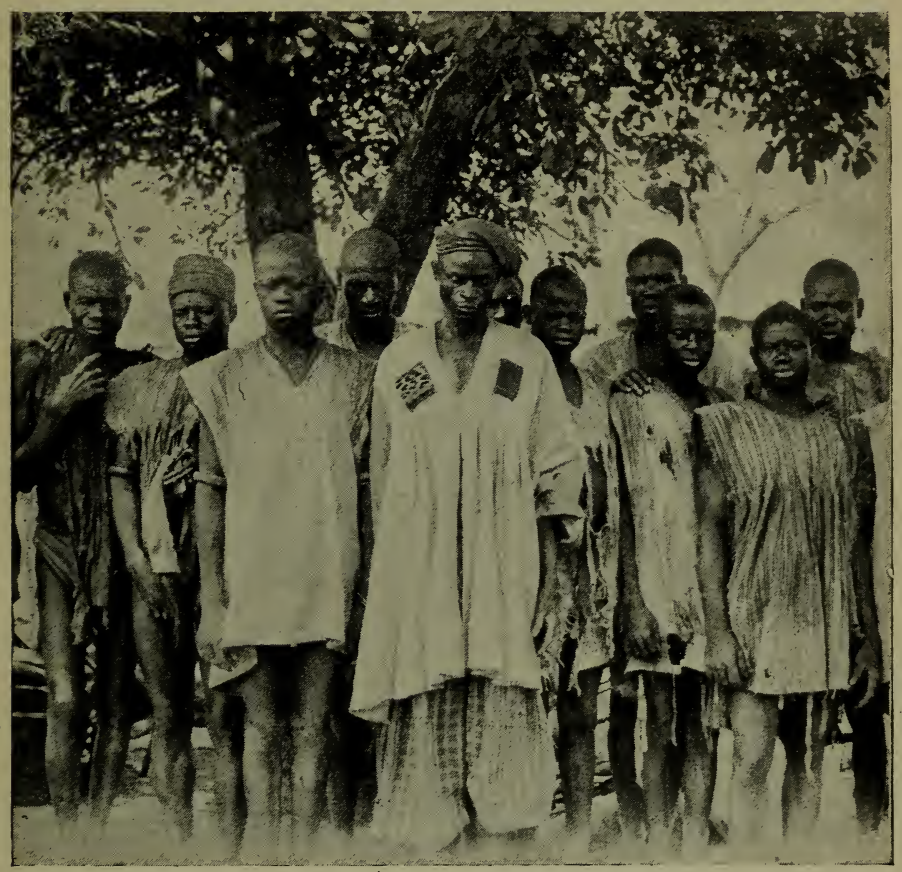

2lbb. 28. Savelugu mit unsern Crägern von Camale.

vor. Ex litt an einer \&ungenentzünoung mit beoroblicher

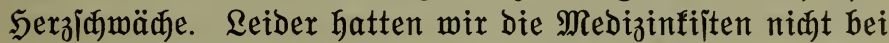
uns, und fo follte ein Bote mit uns nad Gavelugu gehen und Dort bie nötigen Mittel in Empfang neymen. Drei Iage nach her itellte fich Denn ber Bote Dort ein, und wix hoffen, 
Dá̉ er mit ben Mitteln niajt zu ipät gefommen ijt. Der

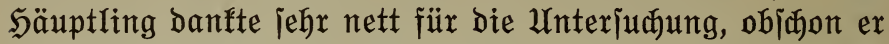
natürlid betrübt wax, nidgt gleidh bie Mittel befommen zu fönnen, und iđenfte uns zwei iđöne Sühner und eine Menge Eier.

Die Regierungsbeamten in Tamale hatten in freumb=

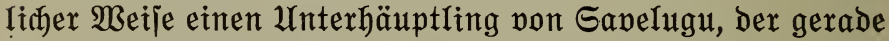
in Tamale anmejend war, bamit beauftragt, unjere Träger

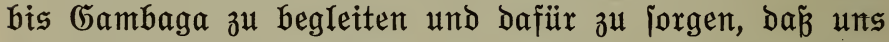

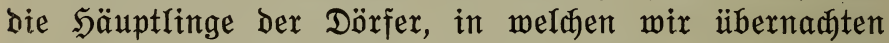

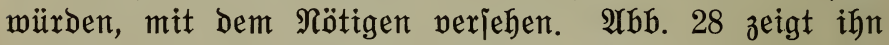
inmitten ber Träger mit weï̈em Leibrof und weiten Bein= fleibern; auf ber Brujt trägt er zwei auf ben Leibroứ genähte $\mathfrak{A m u l e t t e , ~ v o n ~ b e n e n ~ D a s ~ r e d y t e ~ m i t ~ R e o p a r d e n f e l l ~}$

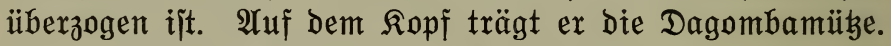
Ein jo ergebenes (bejidyt ex aud auf bem Bild madht, wir fennen ifn beller; benn wir haben alfe $\mathfrak{U}$ rajadje zu glauben,

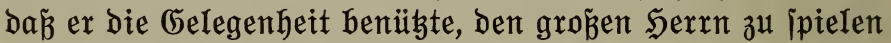

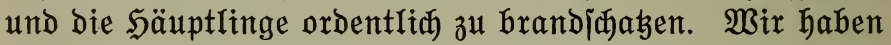
inm denn aud hierïber ein ßribatiffimum gelejen und hoffer, da

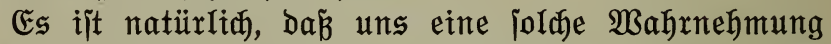
hödjit peinlich war, bođ war nidhts zu ändern. UYnter den Berhältnifien, unter benen wix reiften, braudten wix einen joldhen Begleiter für unjere Träger.

Die Bege von Iolon hex, bis wir auf bie groṕe, nadh Gambaga führende Strä̉e famen, waren wieder io, da

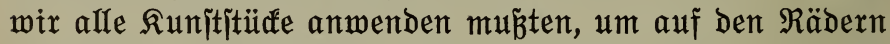
zu bleiben. 3wei Dörfer, Sano und $\mathfrak{B}$ uba, famben wir nod in ebenex Gegend, bann wurbe die Landjichaft etwas hüge=

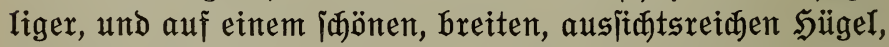
36 Rilometer von $\mathfrak{L u m b u n g u , ~ t r a f e n ~ w i x ~ b a s ~ b e d e u t e n d e ~}$ Dorf Earangbalo. Das Dorf hat wenigitens 1000 Ein= wohner und wohl an bie 300 Gehöfte in veridjedenen (5ruppen. 
Nur 2 Rilometer weiter liegt $\mathfrak{R}$ o m $\mathfrak{b} \mathfrak{u} \mathfrak{g}$ u. Der $\Re a i t=$ hof liegt nahezu im Mittelpunft ber Stadt. Ringsherum ind, in Entfernung von 300-500 Meter, bie verifhiedenen

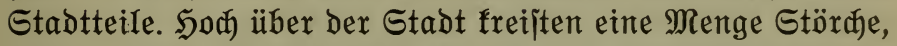
andere jä̌en auf ben hohen $\mathfrak{K a p o f}=$ und Feigenbäumen, wo ïe niften. Den $\mathfrak{b a ̈ u p t r i n g , ~ e i n e n ~ w u ̈ r b e n o l l e n , ~ g e m e l l e n e n ~}$ Serrn, fanden wir vor bem Eingang leines Gehöftes, um ihn her jeine ültejten, neben ber Türe jein zwerghafter Diener, ber bejtändig ein mefïngenes Beften in ber Rähe

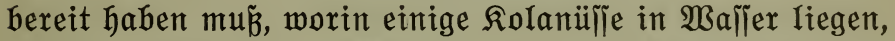
weldye bie Majeität zu fauen geruht. Linfs non ber Ein= gangsöffinung befand fich ber Trommler mit zwei burch

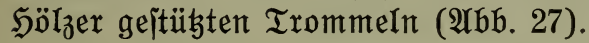

Der Şäuptring erlaubte uns, einen (Gang Durd fein (5e= höft zu madhen. Es beîteht, auß̌er Der groß̈en Ëingangs= hütte, aus niđht weniger als 31, jum Teil red geräumigen Rundদütten, und in Der Mitte biejes Iabyrinthartigen Ge= wimmels erhebt fïh ein eigentümlides Baumerf im Stil

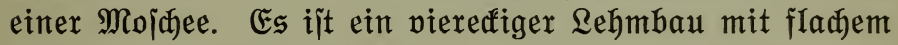
Dach und gewaltig bidfen Mauern, Der bem Säuptling als

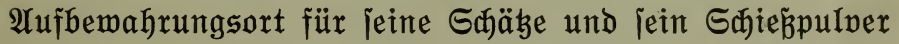
bient. Bon lebterem hatte ex in ben früheren unjitheren 3eiten immer einen grojen Borrat Dort vermahrt. Bon bem fladjen Dad, ju weldjem man mit Silfe einer von Lebm gebauten iđiefen Ebene hinaufflettern fann, über=

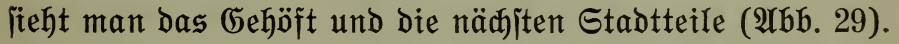
Die näßjit gelegenen Däaher Iaflen bie $\mathfrak{A}$ rt und Weije, wie fie gebefat werben, erfennen. Rehts im Bild ijt eine Rund= hütte mit bejonders verzierter Türöffnung zu erfennen. Die Berzierung beiteht aus Telleriøerben und haupt|äd)(id) aus Stüđen von Rürbisโdalen, die mojaifähnlid in ben Lehm ber Türöffnung hineingebrüatt murben. Sinfs im Bild fieht man ein paar Rundhütten im Bau. Zuerit werben. bie Mauern volfitändig aufgebaut, und exit nadhyer bie Eingangsöffinung Gineingejđnitten und barauf modelfiert, 


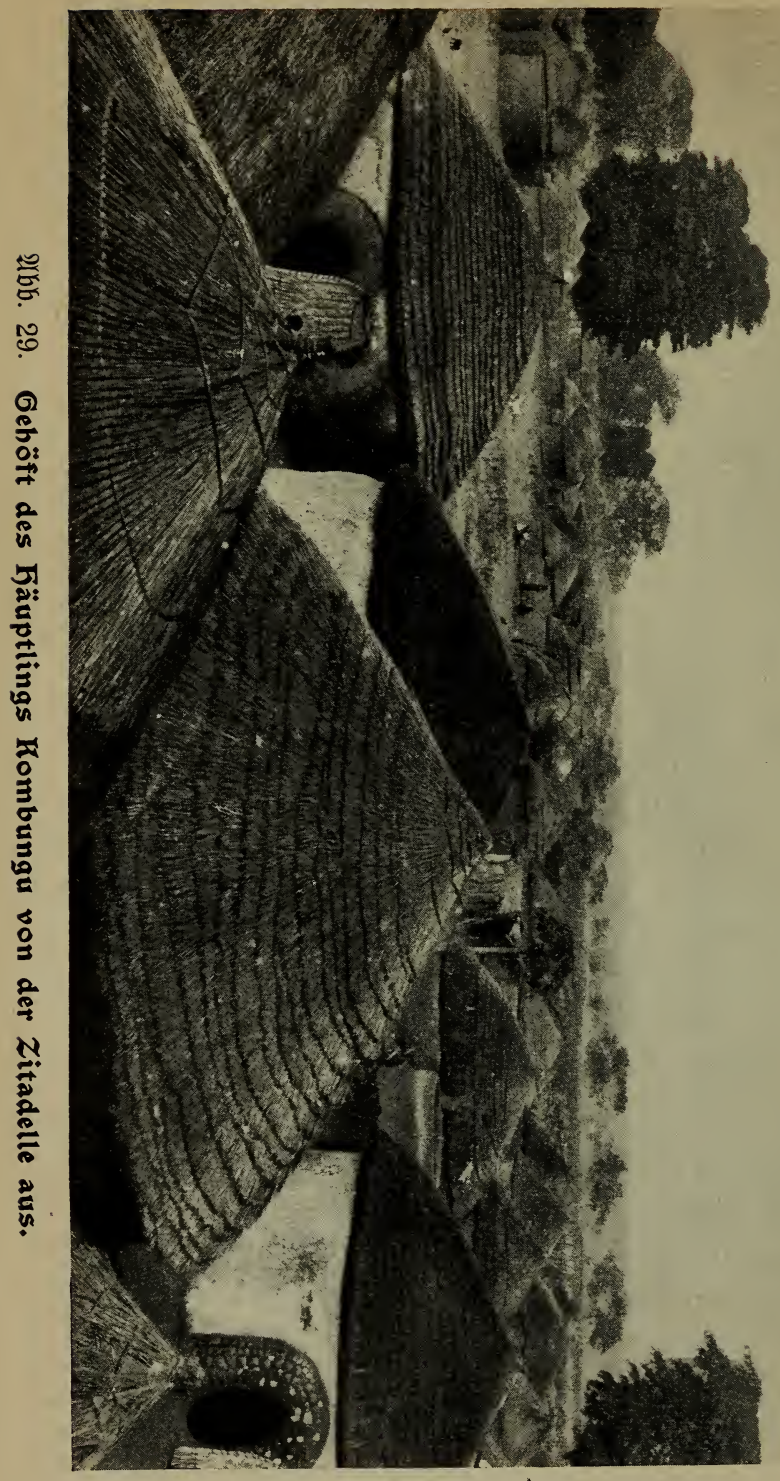


mobei bann bie Berzierungen angebradt werben. $\mathfrak{A} u f$ ben freien ßlägen um bie (5ehöfte wiro überall Tabaf gepflanzt.

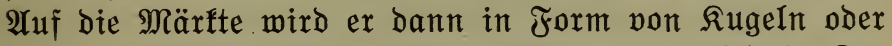
Diffen, ipindelförmigen Rollen gebrađt. Es wird in $D a=$ gomba viel gejđmupft uno gefaut, weniger geraudit.

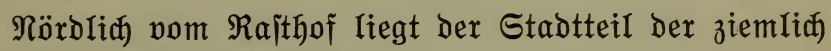
3ahIreidjen Mohammedanergemeinde. Reben ber ärmlidjen Moidee iteht eine iaböne Dattelpalme. Shat wohl ein Meffa= pilger ben hern, aus weldhem fie erwachien iit, fern aus bem Rorben ober Rordoiten gebradt? Der größ̈te Stadtteil liegt jüböptrił vom Rajthof. Rombungu hat wahriðeinlid 8-10000 Einwohner; viele won ifnen ideinen Durd Sandelsgejøäf̆te auswärts zu jein.

Beim früheiten Morgengrauen jahen wir eine ganze Sdiar Rindex mit brennenden Grasfacteln zwijđen ben Stabtteilen hin und her rennen. Sie madten Jagb auf eine fleine $\mathfrak{A r t}$ Sajen, bie in grojer $3 a \mathfrak{h l}$ bort vorzufommen idheinen; ite werben vom f̧euerijhein geblendet und fallen Dann ben wilden, Ieiđtffü̈̈̇gen Rindern zur Beute.

$\mathfrak{A} m$ näßjiten Tag gelangten wir nad Gavelugu. Der Dorthin führende Beg war jehr iđledht, wohl Der iđlimmite auf Der ganzen Reije. Er ijt zwar jehr viel begangen, aber überall mit tiefem Sand bebeft. Der uriprünglidje Beg ilt febr tief ausgetreten, und jo find neben ifm eine ganze Inzahl \$arallelwege entitanden, won denen man alle

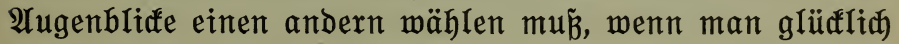
Durbffommen will.

Die Entfernung von Rombungu bis Savelugu beträgt nur 15,3 Rilometer; wir waren aber jehr mïde, als wir endida gegen Mittag in Gavelugu anfamen. Sa $\mathfrak{v}$ e $\mathfrak{I} \mathfrak{u} \mathfrak{g} \mathfrak{u}$ liegt an ber Straß̉e von Tamale nađ (5ambaga. Die Stadt iit in einem nad) Weiten offenen Bogen gebaut und bejteht aus einem verhäItnismäß̈ig ¡đmalen Streifen von Gehöiten von etwa 2 Rilometer $2 a ̈ n g e$. Die Gehöfte find in größ̉ern 


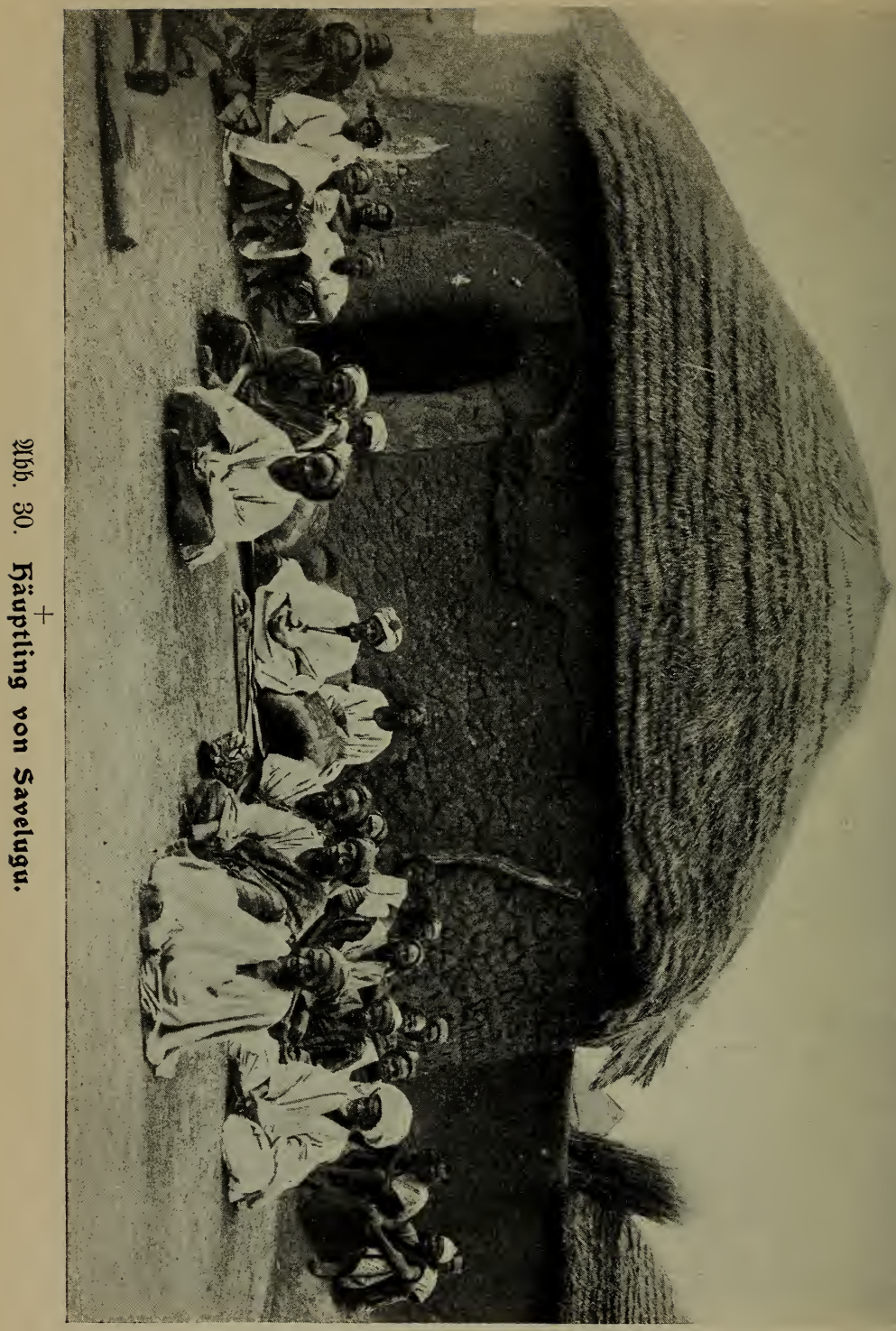


(5ruppen zujammengebaut, und zwijøen ben einzelnen Gruppen find jđöne, freie ßläge und breite Straß̌en.

Der Dberfäuptling von Gavelugu max abwejend; mix bejułten baher jeinen Stellvertreter. Ex empfing uns im

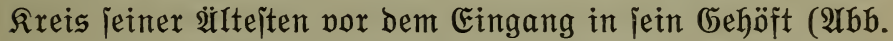
30). Er trug Mohammedanerfleidung, auf jeinem weiß̈en Iurban war ein $\mathfrak{A}$ mulett befejtigt, zu jeinen beiben Seiten

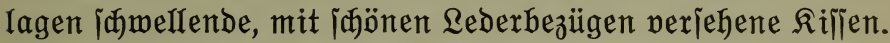
Ex ijt ein jehr veritändig und freundrich ausjehender Mann. Seine grof̉e Runbhütte zeigt allerbings Spuxen von $\mathfrak{B e r}=$ fall, indem von ber Eingangsöfinung die Sälfte der Leদ̆m= verfleibung weggebrochen ijt. Der nörblichite Teil ber Stadt, und zwar ein jehr anjehnlidjer Teil, ijt pon den Dagomba, die Mohammedaner gemorden find, bemohnt. Der innen voritehende Smam ijt ein jehr inmpathijøer, hagerer Mann, mit ehrwürdigem, weiß̈em Bart und fait vornehmem Bejen.

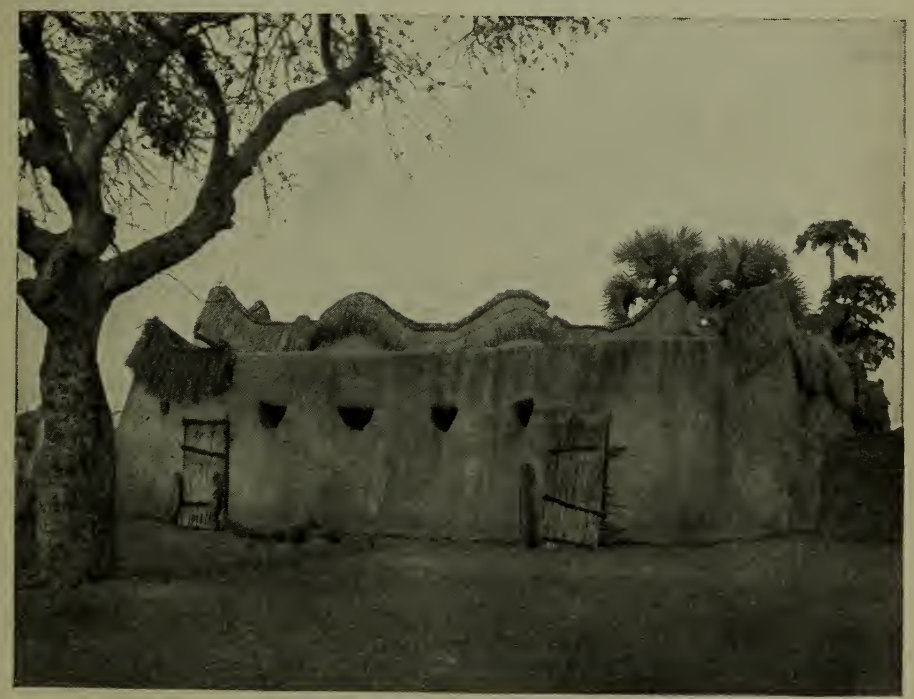

Abb. 31. Moschee in Savelugu. 
Er exlaubte mix freundid, die Moldee, die neben jeinem

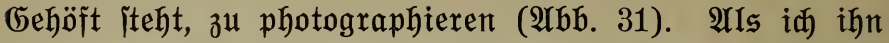
bat, mix babei als würdige Staffage zu itehen, Iehnte ex bas jehr höflid a a und jandte mix burd feinen Dienter ein

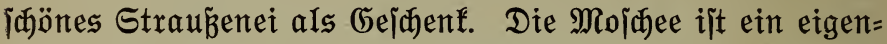
artiges Baumerf. 3wei Eingänge fü̆ren in einen Sof, von wo aus man bann in bas Intere gelangt. Die Mauern iind Durd Strohgefledyt vor ben Einwirfungen Des Regens jorglid) geiduizt, und ein paar Straupeneier jieren bie höbjten Erhebungen Der Lebmmauern.

Bei einem Gang Durd bie Stadt hörte id won weitem ben eintönigen Singiang einer mohammedanijaen Shule. Ja fand fie in einer bunfeln Runbhïtte. Der alte Lehrer,

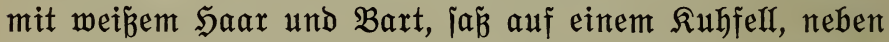
iłm zwei junge Männer. Der Lehrer hatte ein iđönes, altes Manuffript Des Roran in Saula mit arabijanen Lettern

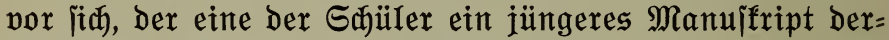

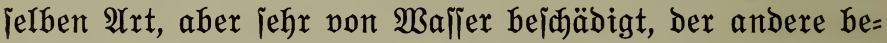
half fid mit einer hölzernen Tafel, auf ber bie gelejente Stelle mit groben 3ügen gejđrieben war. Etwas zögernd fam auf meine Bitte ber $\mathfrak{A}$ Ite mit jeinen Sdjülern aus ber

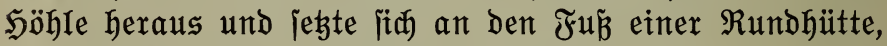
wo id bann $\mathfrak{A b \mathfrak { b }} 32$ aufnehmen fonnte.

Sn Savelugu bot ein junger Dagomba, namens $\mathfrak{M u} \mathfrak{a}$,

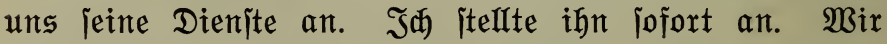

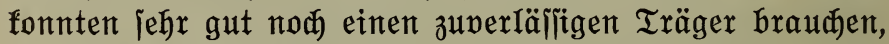
und mir follte er jpäter nod) in meiner $\mathfrak{A}$ rbeit behilflich jein. Er hat fí dent aud unjere ganze 3ufriedenheit erworben; was man inm anvertraute, Das bejorgte ex jeberzeit jo gut er irgend fonnte (i. $\mathfrak{A} \mathfrak{b b} .3$ S. 7).

In Sanelugu brohte unirer Reije eine exnitlidue 1 Unter= brechung. Bei einem ber Reijenden itellte fith eine auf ben exiten Blid recht bedrohlidge Störung ber Gejundheit ein,

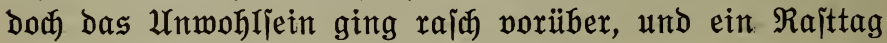
bradte alles wieder Ieiblid ins (beleile. Es eriajien aber 


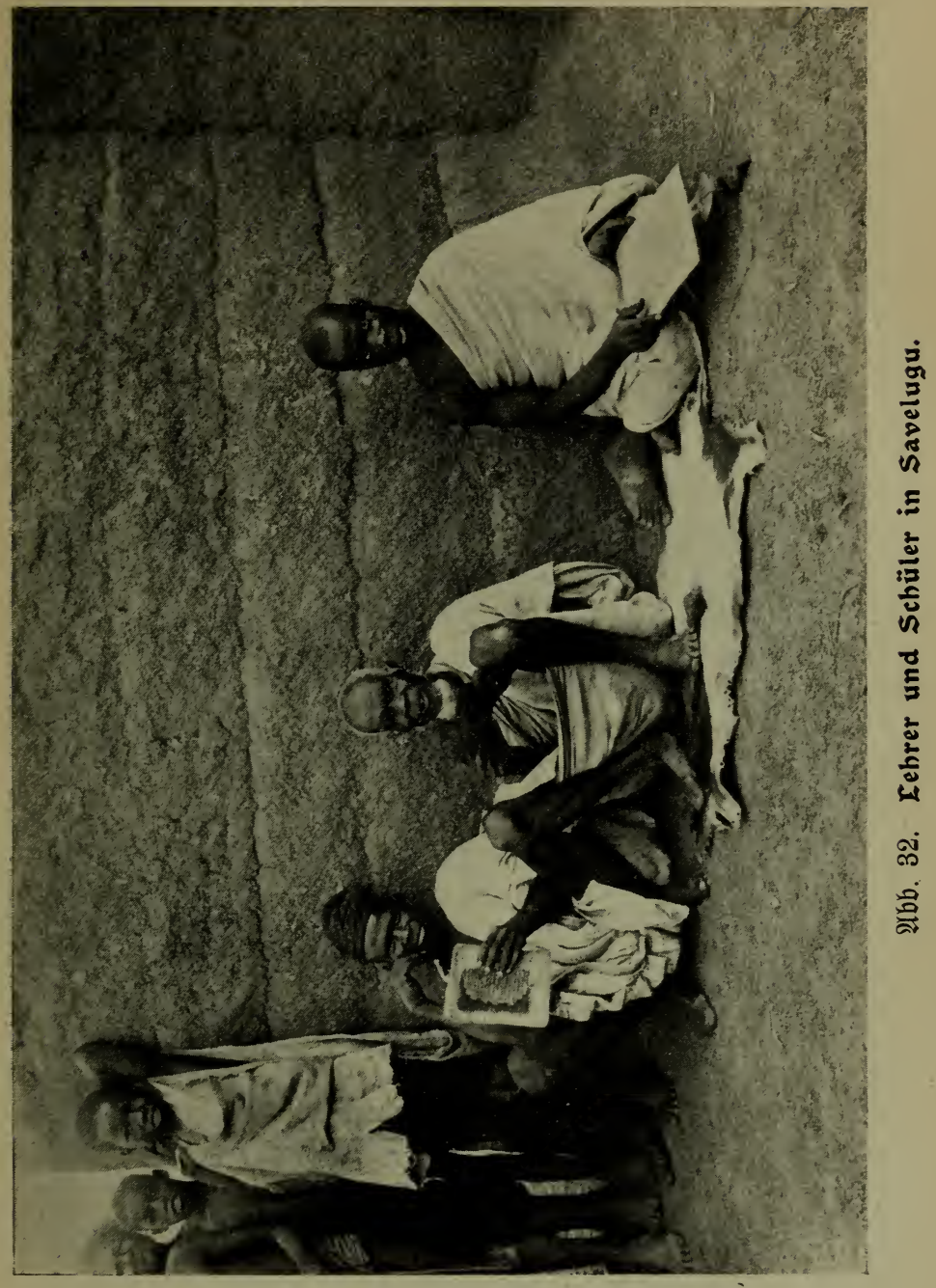


geraten, bie anjtrengende Reije nach Raraga aufaugeben

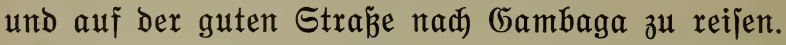

$\mathfrak{A m}$ 27. Februar brachen wix auf und reiften norb= wärts. Es wurbe uns flar, Dáz wir bei ber Reije über

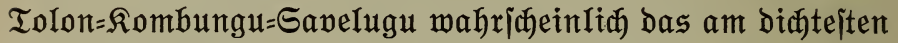
bemohnte Gebiet ber Dagomba gejehen hatten. Eine fünf= tige Dagombamiffion mïßzte bort in jener Gegend ifren Sauptits haben, fo weit es fith um bie im englifanen (Gebiet wohnenden Teile bes $\mathfrak{B o l f s}$ handelt. In einem $\mathfrak{R}$ reis von

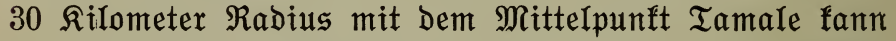
man eitren jehr groß̌en \$rozentjał des ganzen Dagomba= volfes erreidfen. 3" Pferd fann man fajt mïhelos in bie

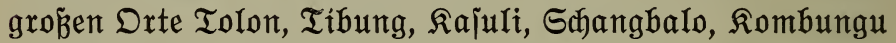
und Savelugu gelangen und io eine iđöne, ausfintsreiche, energijđe Miffionstätigfeit eröffnen. Das Bejtehen won grö́en, einflǘreiden Mohammedanergemeinden wirb neue Aufgaben und jehr ianierige Fragen bringen, es wirb groß̈e Aniprïde an Den Taft und bie Weisheit Der Miffionare itelfen, aber es wird fiđ bort ein herrliches Feld ber Tätig= feit eröffrnen für Männer, die ihre ganze Perjon und alle inre Fähigfeiten in Gottes Dienjt itellen wollen und beren Lebensaufgabe barin bejteht, Gottes Biflen $\mathfrak{u}$ tun.

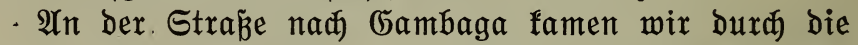
fleinen Dörfer Tamale, 8 Silometer von Sapelugu, uno Tung, weitere 2 Rilometer nad Norben. Die Dörfer ideinen im Ëntitehen begriffen $\mathfrak{u}$ jein. Die neu angelegte, breite Etraß̉e mit ihrem iteigenden Berfehr Iodft bie Reute aus ber Ungebung zur $\mathfrak{A}$ njied lung an ihr. Tung liegt jehr iđjön auf

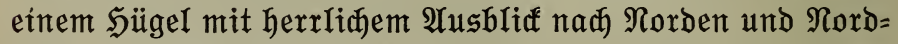

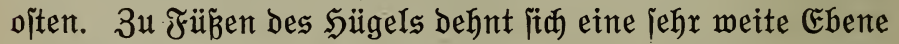

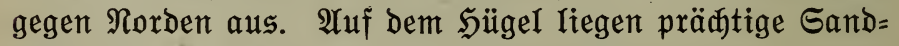
iteine, die io, wie fie find, aIs Baulteine vermendet werben

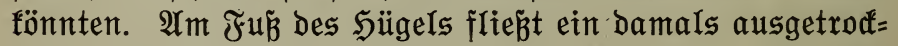
neter Bađ̆, ber aber bas Gelände weithin verjumpft. Beiterhin war bie neue Straß̈e nod nidht gebaut ober nur 
Dura eine Ridhtung in Der Baumjananne angebeutet. Wir fuhren Darum grop̉e Strecten auf Der alten, jehr aus= gelaufenen Strä̉e. 24 Rilometer von Gavelugu famen wix

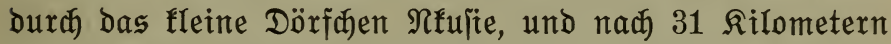
Iangten wir in Diari, unjerm Rajtort für Den Iag, an. Bor Diari liegt die Raramanjerei. Sie itellt nahezu ben Gipjel ber Bejđeidenheit Dar. An Den Grenzen eines von Gras und (5ebüiø gereinigten Plabes find 1,5 Meter hohe Gras= bütten gebaut, zu welnen fleine \&öøer 3ugang bieten. Auf Dem freien \$lab werden bie Tiere der Rarawanen an Bflöfe angebunden, während die Mannjळaft in bie Gras=

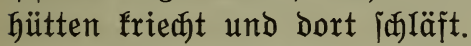

In Diari erwartete uns eine groże überrajđung. Wir

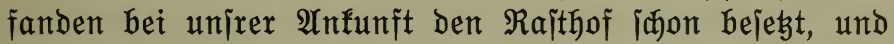
zwar von zwei franzöjif gubugu burদ englij̄es Gebiet reijten, um mit Dem Gou= verneur der Goldfuijte und dem von Togo zu unterhandeIn.

Sie räumten uns mit der größ̈ten Riebenswärdigfeit die eine der grö̈̈ern Rundhütten ein und baten uns, ihre (5äjte zu jein. $\mathfrak{A n}$ der gajtlichen Tafel der Sorren entipann

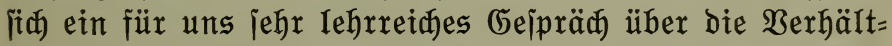

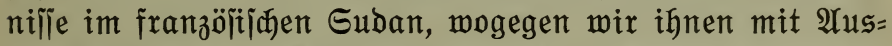
funft über die Goldfüite bienen fonnten. OUuf unjere Frage,

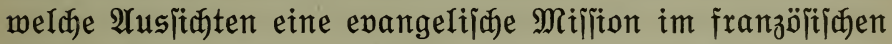
Suban haben würde, erflärte uns der ältere der Sherren,

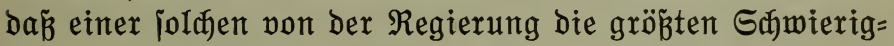
feiten entgegeniteḩen mürben. Es mar offenbar nur die Söflichfeit, die $i \mathfrak{h}$ verbot, rund heraus ju jagen: Eine

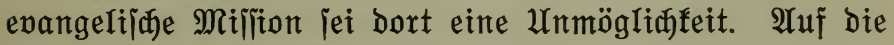
Frage, warum Denn Den weib̆en Bätern erlaubt jei, zu mij= finteren, teilte er uns mit, Dá̉ die Regierung alle Eđulen

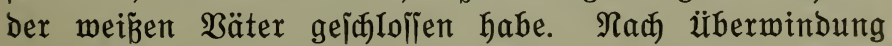

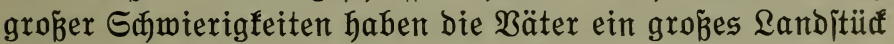

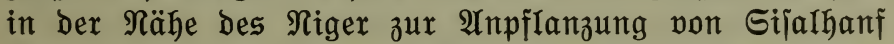

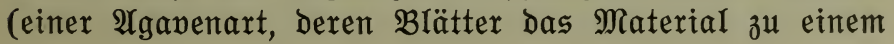


jehr geidä̈bten $\mathfrak{B a j t}$ liefern) befommen. Das jei nun bie

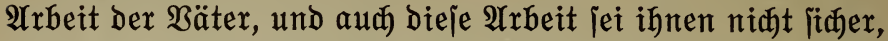

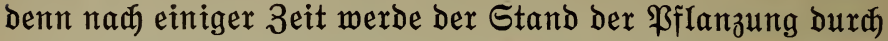
Regierungsbeamte bejidtigt, und wenn bie \$fflanzung nidft befriebige, werbe fie ben Bätern won ber Regierung ohne weiteres abgenommen. Den Einmand, Dáa bođ bie Regie= rung Danfbar fein follte, wenn bie Miflifonare der Regierung

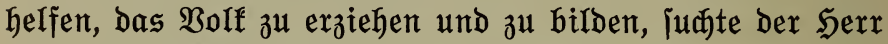

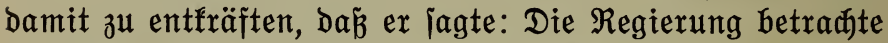
die Erziehung und Sdhulung Der $\mathfrak{B o ̈ l f e r}$ als ihre alleinige Pfitat. Sie geidehe im franzöjifiden Suban burd die $R e=$ gierungsbeamten. Bei ber $\mathfrak{A n f u n f t}$ eines Beamten in einem Dorf verjammle fith bie Ėinwohneriđaft um inn, und er vermittle iłnen in (5ejpräd)sform biejenigen Renntnilie,

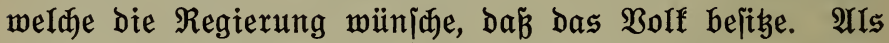

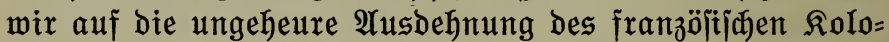

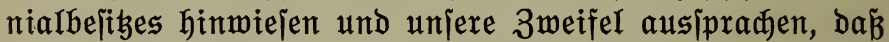
bies ganze Gebiet in ber angebeuteten Beife Durd die $\Re e=$ gierungsbeamten genügend beeinflǚt werben fönne, ex=

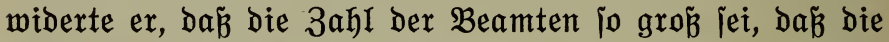

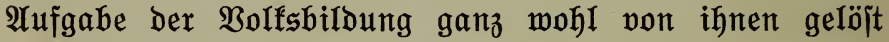
werben förnte.

- Gind bieje Mitteilungen wirflid ridtig, und wix haben feinen Grund Daran zu zweifeln, indem der „Administrateur des Colonies françaises" einen iiberaus vertrauenerwedfen= Den Eindruaf madte, fo wirb nod einige Zeit vergehen, bis die weiten Gebiete im Rorben ber Goldfiijte und Togo Dem Enangelium geöffnet werden. Das Bewuátiein aber, ठẩ bie 3eit unfehlbar fommen mus, in melder dieje, jegt nod io fejt verifhlofienen Türen Durd hödjte Sand geöffnet werben, ob Menidjen verjudien fie geidholfen zu halten ober

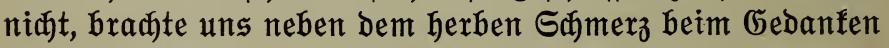
an bie Taulende, benen jebt nod bas emige sidjt nidbt Ieudten fann, bod aud zum Bemuß̄tjein, wie ohnmähtig bie

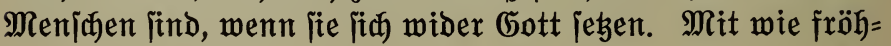




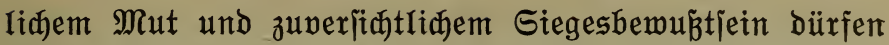
aber aud bie Rinder bes Sörajten bas Rommen Geines Reiches ermarten trob des Widerjtands ber Menichen!

$\mathfrak{A m}$ nädjiten Morgen bejtiegen bie beiben Serren in aller Frühe i⿹re prädtigen Pferbe und ritten nad Süben; wir wandten uns wieder nađ) Norben, unjerm näbjiten Ziel Rafita entgegen. $\mathfrak{A} u \mathfrak{f}$ biejer Strede begegneten wir einer Menge Rarawanen vor Rajtejeln. Es jind jierlidae, idjanfe Tierden won hellem bis Dunfelm (Grau, mit furzen Saaren und einem Dunfeln Strich über ben Rüifen; jelten begegnet man braunen und nod jeltener ihwarzen EEjeln. Mit ihren flugen, ¡đ̆warzen $\mathfrak{A}$ ugen jahen fie uns gar fragend an, went wir ihnen auf unjern Majđinen, bergleidjen ifnen nod nie vorgefommen war, näher famen. Die meilten trippelten ruhig, wenn aud etwas bejorgt an uns vorbei, andere aber bradten bas nicht über jīch. Sie legten ihre Iangen Dhren

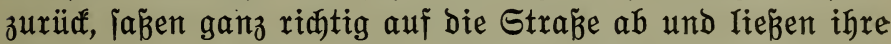
Lajt, zwei an ihren Seiten hängende Rörbe, nad) hinten gleiten, halfen wohl aud mit S(füitteIn nad) und prangen bann Ios und lebig von der Straß̉e jeitwärts. So brollig ein jitzender EEjel, Der fith jeiner Lait auf joldje Beife ent=

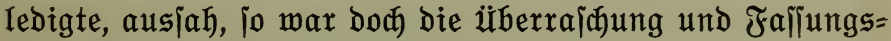

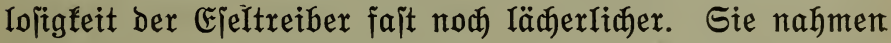
bie Sadje nadh geidehener Tat aud won ber fomijanen Seite,

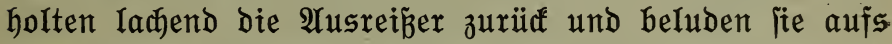

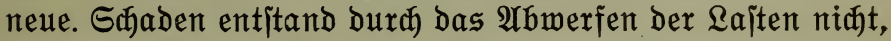
Denn ber Inhalt der నörbe bejtand aus unzerbred)lichen Baren, meift aus Rörnerfrüdten.

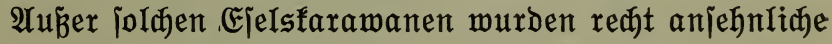
Serden (Gro $\tilde{B}=$ und Rleinvieh jïbwärts an uns vorbei=

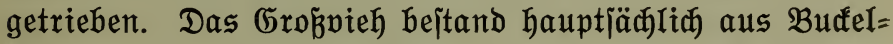

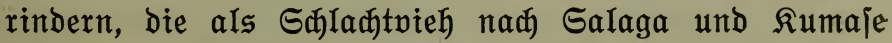
fommen. 3ur 3udt eignet fith bieje Rinoviehrafie in ber jïblidjeren Gegend nidft redyt, wie uns aud ipäter von ben beutichen Beamten, bie ber Frage groß̈es Interefle entgegen= 
bringen, bejtätigt wurbe. Das gleidye gilt won ber Rafle ber

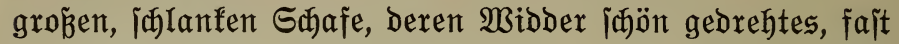
wagredht abitehendes Gehörn tragen. Die Gegend, Dura die bie Strápe führt, wird immer menfanenleerer.

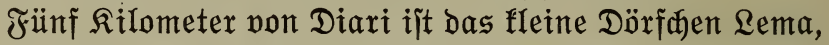
9 Rilometer weiter $\mathfrak{B i e g u , ~ e i n ~ e b e n t o ~ a ̈ r m l i d y e s ~ D o ̈ r f u d e n ~ i n ~}$ ber $\mathfrak{R a ̈ h e ~ e i n e s ~ i t e i n i g e n ~ S h u ̈ g e l s ~ g e l e g e n . ~ B o n ~ h i e r ~ f u ̈ h r t ~}$ ein Beg Durd menidenleere Einöbe hinüber nađ Raraga. Unier Dagombabiener Muja ijt pon Raraga gebürtig und jagte uns, Dáb bei weitem nidgt fo viel Reute Dort in jenter

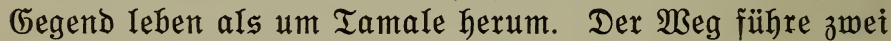
Tagereijen weit burd fajt gänzlił unbemohnte Gegenden.

Benn wix aud oft idhledtes Waffer befamen, jo

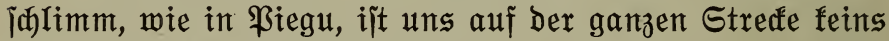
mehr vorgefommen. Wix fanden zwei $\mathfrak{s}$ aben in einer

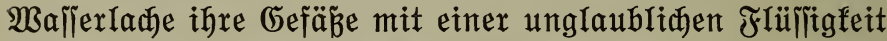

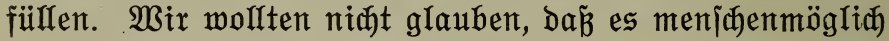

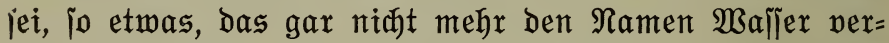

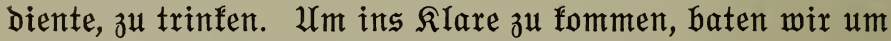
etwas gutes Waffer, worauf bie armen Bürjđdnen uns ge=

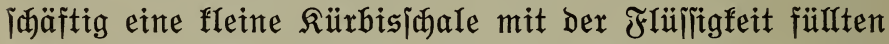
und jum Trinfen bradten. Mit herałidfem Bedauern für die armen Reute banften wir ifnen für ihre Mühe und zogen weiter. 28 Rilometer von Diari famen wix an ein Drittes Dörfanen Difiga und bann nach weitern 8 Rilo=

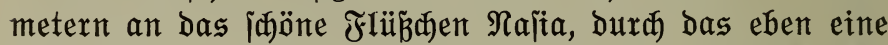

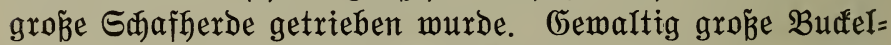
odjen mit pradtoollem (5ehörn famen uns von ber andern Seite Des Frïß̧̈nens entgegen. 3wei Rilometer weiter famen wir an bas Dorf $\mathfrak{N a j i a ~ m i t ~ e i n e m ~ o r b e n t l i d i d e n ~}$

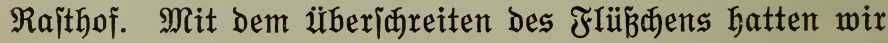
bas Gebiet ber Dagomba verIafien, Denn bas Dorf Rajia ijt von Mampruji bewohnt.

Die $\mathfrak{M} \mathfrak{a} \mathfrak{m} \mathfrak{x} \mathfrak{u} \mathfrak{i} \mathfrak{i}$ jind ein fleiner Bolfsptamm, ber

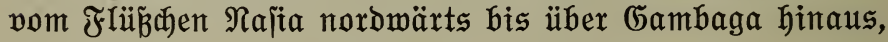




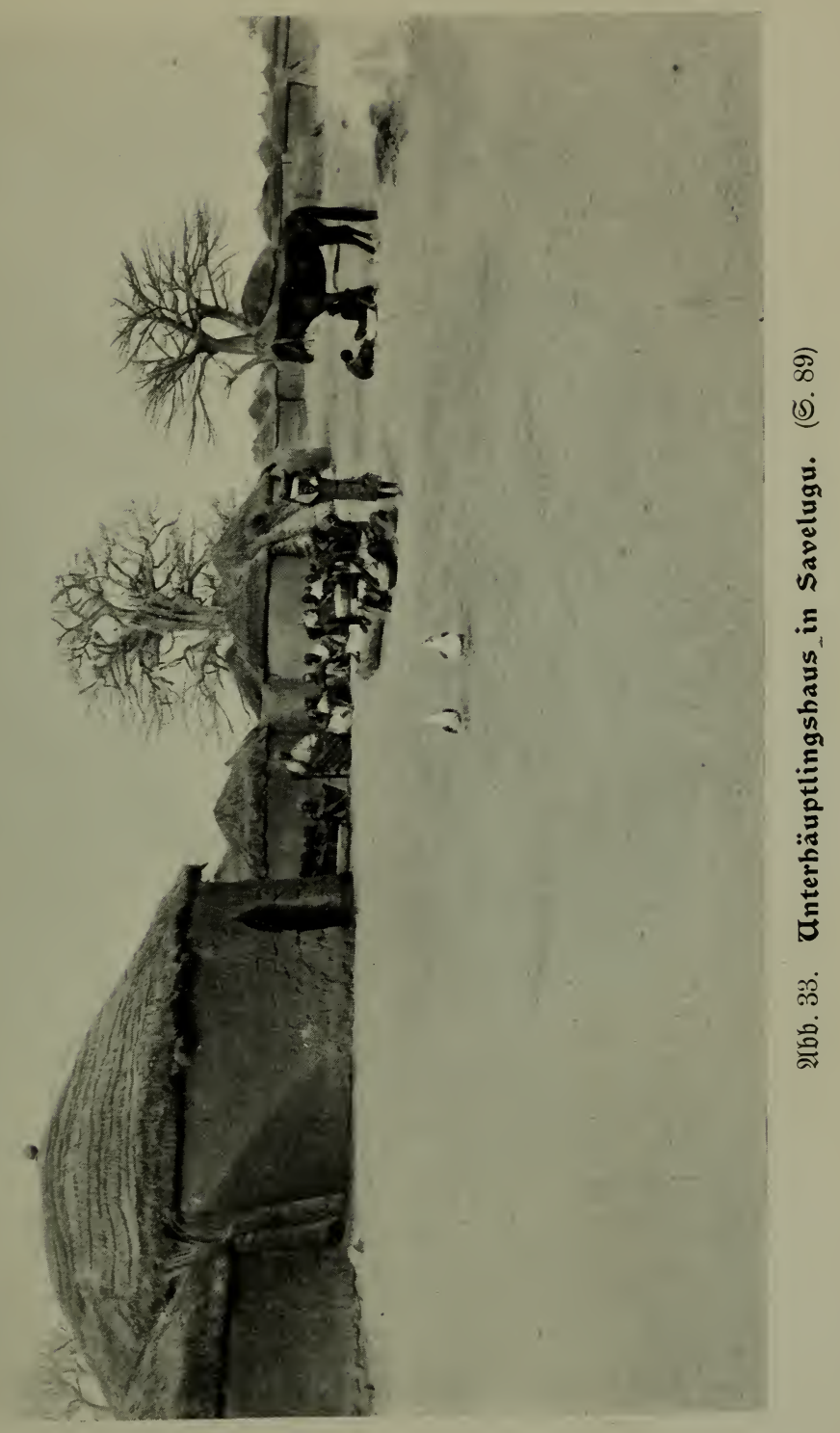





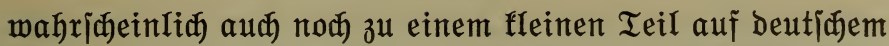
Gebiet mohnt. Der Stamm mag vielleidt 15000 Menjan zählen. Die Dörfer der Mampruji und Tampruji find flein;

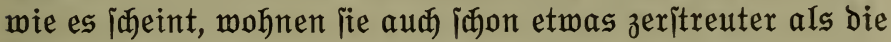
Dagomba. Sie iprechen einen Dialeft des Dagbane und find unirer Beobadtung naদ ganz gut mit Der Eprache Der Da= gomba zu erreichen. Es ijt ein im ganzen fräftiger Meniđen=

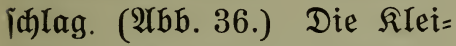
Dung ijt bürftiger als bie ber Dagomba. $\mathfrak{U}$ s Stammes= zeichen jheinen jie einen Ian= gen Tätowierjanitt pon ber Mitte der Iinfen Rajenjeite nach Dem Iinfen Unterfiefer= winfel zu tragen. Während die Dagomba gern auf Dem Sheitel einen Streifen Saare bis in ben Naden itehen Iafien, baben viele Mampruji und Tampruji zwei rundriche $\mathfrak{I} n=$ jeIn von Gaaren auf bem

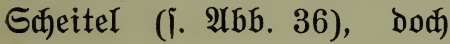
joeint jolde Saartradyt nidt ben Wert pon Stammeszeichen зu দaben und meদr eine $\mathfrak{A} \mathfrak{x t}$

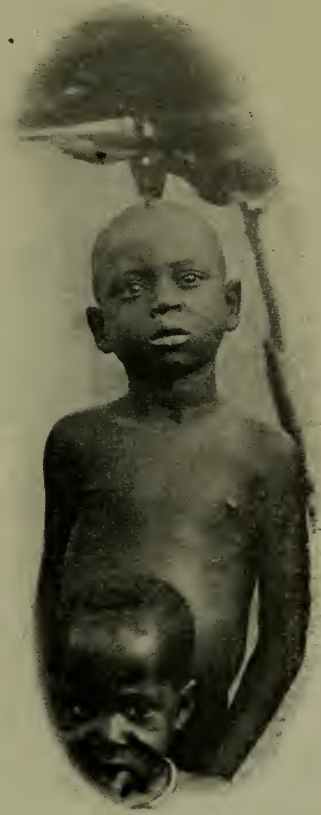

Mobejache zu lein. Die Rleibung fehlt bei Rinbern ganz, erwadjene Männer tragen eine $\mathfrak{A}$ rt Babehojen oder aud ein fleines Jell, bas an einer Lenden= iđnux befeitigt wixb. Ropfbededungen jahen wix-nid)t häufig. Der Säuptling von నajia trug eine Dagomba= müke mit einigen $\mathfrak{A m u l e t t e n ~ D a r a n , ~ a m ~ D a u m e n ~ b e r ~ r e d t e n ~}$ Sand einen fehr biffen Ring von Silber und an einer 


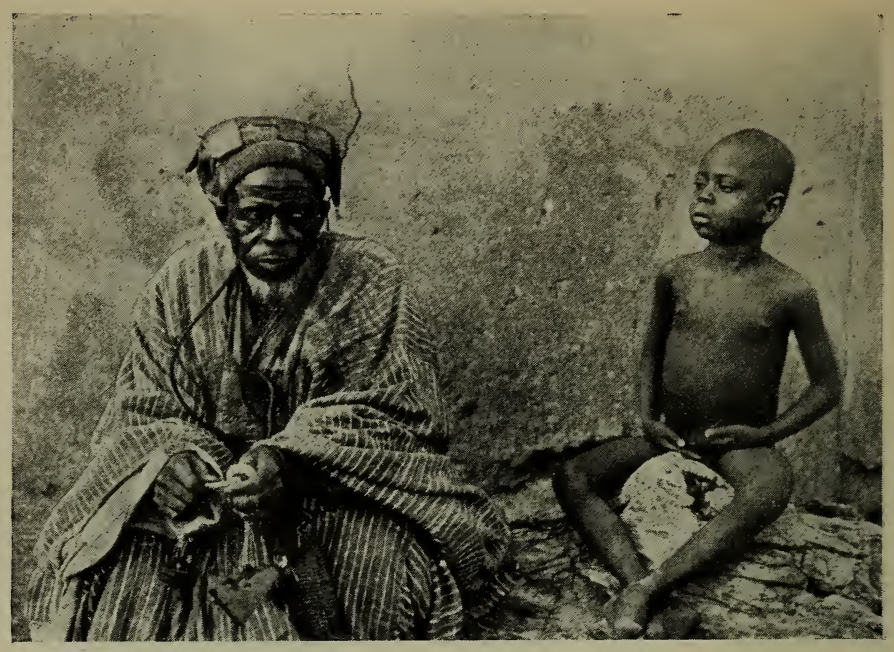

2Ybb. 35. Gäuptling von Rasia und sein Jüngster.

filbernen Rette ein runbes und ein Dreiectiges 2 mulett, bas ex, wohl zum Słhug gegen den jalimmen Einflub, der jeiner Meinung nad won ber photographijhen Ramera aus= ging, wor fith hinfielt. ( $\mathfrak{U b \mathfrak { b } . ~ 3 5 . ) ~}$

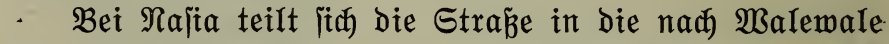

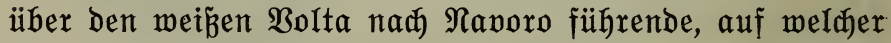
die groß̉en Biehtransporte herunterfommen, und in die. bireft nad, Norben über (5ambaga naদ̆ Baufu (Bamfu) gehende. Sebtere ijt lange niat jo begangen wie eritere. Wix gingen auf ber Straß̃e năh Gambaga. Wegen Man= gels an 3eit muß̈ten wir es uns verjagen, Balewale und

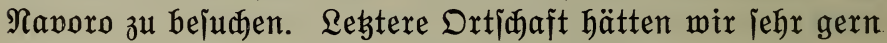
bejuðt, um die dort von den weiben Bätern angefangene. Arbeit fenmen zu Iernen.

Während der exiten 24 Rilometer auf ber Strá̉e nach Gambaga trafen wix feine menjఝ) liche Nieberlafiung, wohl aber viele Spuren von Bild. Eine Sherde ßaviane rannte 
mit übermütigen Sprüngen vor uns über Den $\mathfrak{B e g}$; einer bavon iprang auf einen niebrigen $\mathfrak{B a u m}$, jegte jith auf einen ait und lebnte fich bequem an ben frummen Stamm. Bon

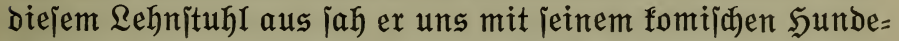
gejīt zu und mujterte unjere Räber, frabte fich babei behaglich an jeinem Bauch und fprang bann finunter und jagte in tollen Sprüngen feinen (5efährten nach. Bon 3eit 3u 3eit taudte noch ber eine ober andere Ropf aus bem hohen Gras auf, bis fie verjamanden. Elefantenipuren

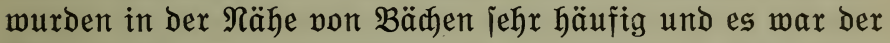

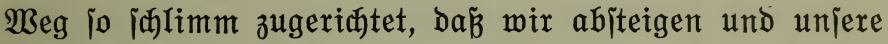
Räber über die grożen, oft $30 \mathrm{~cm}$ tiefen, runden \&öׁer fiihren muß̈ten, welăe die mähtigen Tiere in bem weidhen Dehm der Strá̉e getreten hatten. Brüuen gab es auf ber Streffe nidht, und man mußjte jehen, wie man über die brei Bäׁx, die Den Weg freuzten, hinüberfam. ßaragu, bas erite

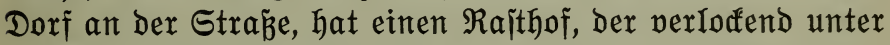
mähtigen Damadamabäumen gelegen uns zux Rait einlud; wir wollten aber weiter. Das nädjite Dorf Boyeni, 32 Rilo=

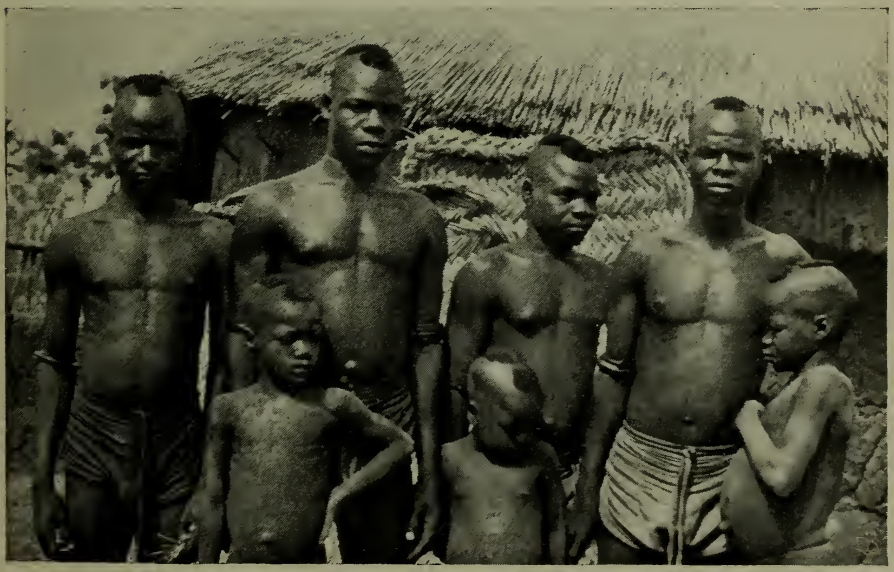

2Kb. 36. Camprusi. 
meter von शajia entfernt, wähIten wix um unjrex Irägex willen als Rajtitation. Ein ganz netter Raithof Iag an Dex Straßje, und faum waren wir abgejtiegen, fo fam eirig ein artes Männđen gelaufen, die Sarfe über der Sđulter,

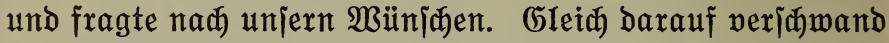

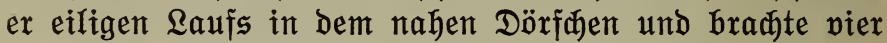

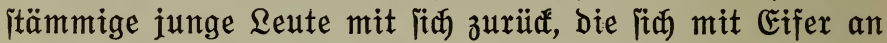
die Reinigung bes Ra|thofs madten und Jeuerholz her= trugen, während einige BübЂen mit Rürbisfஞalen voll

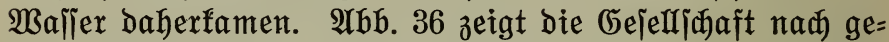
tanex Männđen, bas uns zuexit empfangen hatte. Wix exfuhren, dấ es der Şäuptling pon Boneni lei.

Bei einemt Gang Duxch bas Dörf́nen fand ith einen auf bem Duxhidnitt rechtedigen, gegen $30 \mathrm{~cm}$ Iangen, glatten Sanditein von jehr grożer Särte und feinem Rorn. Wix ex=

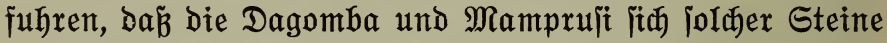
3um BügeIn Der jamalen Streifen Baummollitoff bebienen,

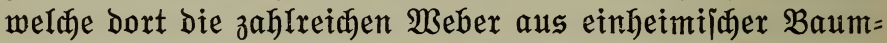
molle heritellen. Dieje etma $6-8 \mathrm{~cm}$ breiten Streifen

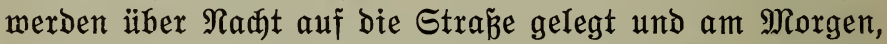
menn fie taufeudt find, mit folden Steinen falt gebïgelt. Die Einmohner gehören Dem fleinen Stamm der Iam= pruji an.

Die Gehöfte marhten nixt gerabe einen hervorragend

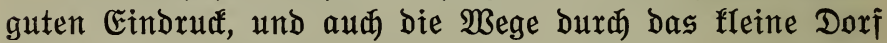
waren reht unjauber. Bejuche in ben Geböften jtellten wix baxum nach Dem exiten Berjud ein, weil bex weibliche Ieil Der Bevölferung, joweit ex nidht verheiratet max, volljtändig

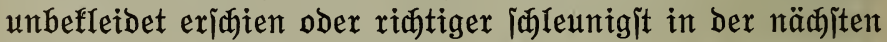

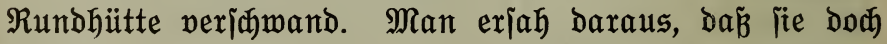

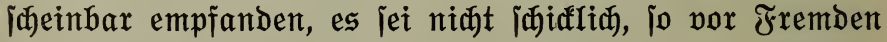
ou exjeinen. Das ijt bod als ein S(fritt in bex Ridtung zu jittjamer Befleibung anzuerfennen.

In ber Nähe des Dorfes hörte iđ̆ fröhliche Männer= 
und Rinderitimmen. Ș ging ifnen nad und fam in ein

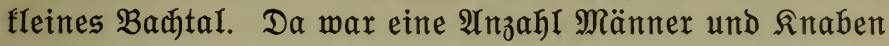
eifrig bejđäftigt, \&ijđe zu fangen. Sie hatten bas Bädiein abgedämmt, famen nun von oben her im $\mathfrak{B a}$ aller gewatet

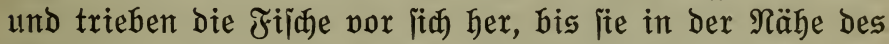
Dammes angelangt, burd einen zweiten, raja auf= gemorfenen Damm bie Filide am Entfommen hindern fonnten. $\mathfrak{R u n}$ Iajen fie mit grö̈̈ter Geelenruhe einen Fija nach Dem andern aus bem Sđllamnt und Wailer aũ und warfen fie in eine fladje (5rube, bie mit ein paar 3 weigen

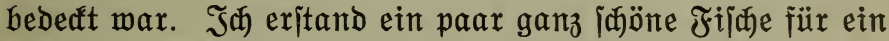
Billiges und fonnte bamit meine Gefährten überrajhen in einer Gegend, wo fonjt faum jemand an bie Möglidfeit ge=

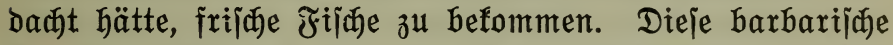

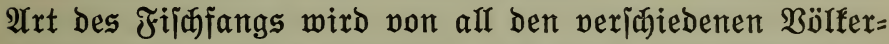
iđaften weit umber betrieben, und es ijt nur wunderbar,

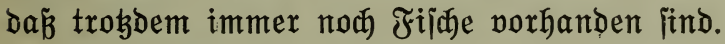

$\mathfrak{A} m$ nädjiten Iag famen wix auf verwahrlojten Begen nad Dem Dörfachen Lingbiji ober, wie es bie Saula nennen, Maibindiga (b. h. Säger ober Sđhübe). Rings um bas Dorf ijt Tabaf angepflanzt. Der Rubitall bes Dorfes ijt ređt originell. Es ijt eine groß́e Runbhütte, Deren Mauern aus itarfen Baumitämmanen beitehen, bie in ben Boben ein= gerammt fint. Das grof́e (Grasdad trägt auf Der Spize eine Rehmfappe, in welnem ein prächtiges Antilopengehörn eingela fien i itt.

Bon Lingbifi an wirb ber Weg ¡đmaler. Während er bisher Durdh flaches Land über weite, mit feinem Gras be= madjiene Ebenen und Dura liate Wälder geführt hatte, fing er nun an hügelig und je länger je jandiger zu werben.

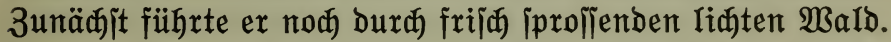
Es war eine eigentümlid)e S(jönheit ber Gegend, und wir fühlten uns in einen heimatlidgen $\mathfrak{L a u b w a l d}$ jur frühlings: zeit verjebt. Freilid fehlten bie liebliden Blumen, und bei ber $\mathfrak{A}$ ufnahme eines Bildes überfielen mid) Sunderte von 


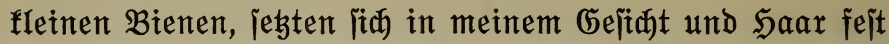
und nötigten midh, iđfleunig|t mein $\Re a d$ zu bejteigen und meinen Gefährten nadbujagen, die iđgon einen guten $\mathfrak{B o r}=$ iprung wor mix hatter. Shre Spuren waren in bem jan= bigen Wege Ieidgt $3 \mathfrak{u}$ erfenten.

Nă weitern 6 Rilometern famen wir an bas jehr ärm= lidje Dorf Bofu. Die Gegend wurbe immer hägeliger. überafl liegt ein weidfer, leidft verwitternder grauer Sand= itein in breiten, flachen Sdyidften zutage; er gift bas $\mathfrak{M a}=$ terial zu dem oft mehr als fnöd)eltiefen Gand, Der ben Weg bedeaft und Das Fortfommen jehr erjđmert. Entiprediend biejer Gejteinsart ift bie Gegend unfrutbtbar und offenbar

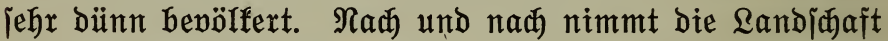
bas Gepräge einer $\mathfrak{y}$ odjebene an. über bieje 5 odyebene ziehen von Siìmejt nadh Rorboit niebrige, 30-40 Meter

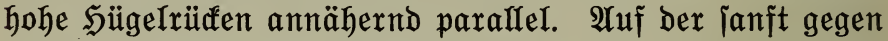
Norben aniteigenden Sodjebene liegt, 29,5 Rilometer von Boyeni, 153 Rilometer von Tamale, die redt bedeutende Stadt Gambaga.

(5 a m $\mathfrak{b} \mathfrak{a} \mathfrak{g} \mathfrak{a}$ hat ungefähr 8000 Einwohner; Davon find ein ziemlid bedeutender Teil Mohammedaner. Der Imam jajien uns ein etwas undulbjamer 5 err zu jein, wenigitens

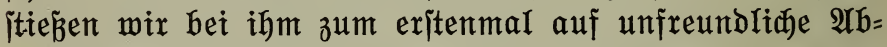
weijung, als wir ign baten, uns zu erlauben, won bem

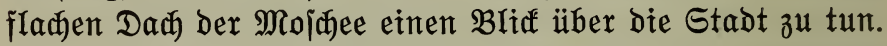
Auđ jonjt war bie Saltung ber Bevölferung nid)t erfreulid; bejonders aufbringlið, gerabezu frech benahmen fïh jüngere Leute beiberlei (Gejhled ts, joba nehmen ber Benölferung einiger Drtífaften auf ber jüb= lichen Golbfiijte exinnert wurben. Die Regierungsitation beitebt aus einigen nidgt gerabe anjehnlidjen Lebmbäulern mit weit herunterhängenden Grasbädhern, bie etwas ver= wahrlojt exidienen. Der Eindrud wurde nod badurd ver=

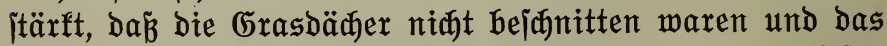
(5ras ber Bebachung unorbentlid in langen, regellojen 
Strähnen, herunterhing. Der Raum, in weldem Der Dort itationierte $\mathfrak{A r}_{3}$ t jeine Rranfen empfängt, ijt von bebrüđen= Der Enge.

Leiber wax gerabe ein höherer Dffiziex ber Sđus= truppe mit biejer abwejend auf einer Strafexpedition gegen einen Stamm Der $\Re$ ujẩ oder, wie jie bie Engländer nenten, Dex Fraf́ra; ebenjo war dex Rommifjar auf einer Dienitreije. Wix wurben aber pon bem dort itationierten $\mathfrak{A}$ rat jehr freunblid aufgenommen, und man wies uns in einem ber Regierungshäuler Quartier an. $\mathfrak{A} u \tilde{B} e r$ dem Regierungs= argt war nod) die Gemahlin bes Rommifíars und ein Saupt= mann ber Sđubtruppe anmejend, ber furz vorber von ber Expedition gegen die হu[aji zurïłgefommen mar. Die Ber= anlâfung zu bem $3 \mathfrak{u g}$ gegen jenen Stamm war ein viel= facher Mord, ben er fith hatte zu Sdulden fommen Iajien. Es wax ein Säuptling mit jeiner ganzen Jamilie auf grau= jame Beije umgebraht morben, und itatt dá̉ bie Mörder ausgeliefert wurben, nahm ber Stamm eitte brohende Sal=

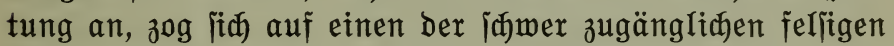
Sügel zurüđ und ridtete fiđ Dort zux Berteibigung ein. Es war barum nötig, mit Waffengewalt gegen ihn vorzugehen. Uus ben ErzähIungen Des Şauptmanns war zu entnehmen,

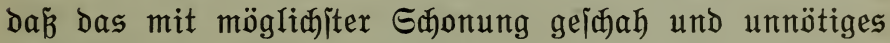
Blutwergieß̃en itreng vermieben wurbe, wenn aud ber

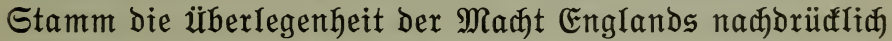

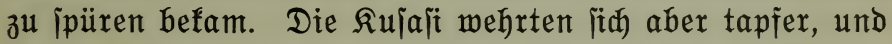
es ijt veritändliđ), warum früher ber gefür(htete Sflaven=

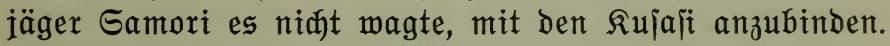

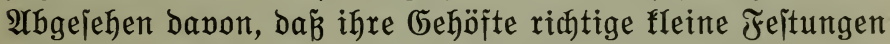
find, haben fie die Gewohnheit, bei $\mathfrak{A n n a ̈ h e r u n g ~ u ̈ b e r l e g e n e r ~}$

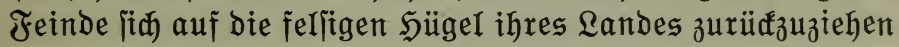
und pon bort aus ben anrüafenden Jeind mit pergifteten

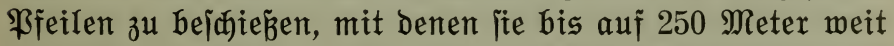

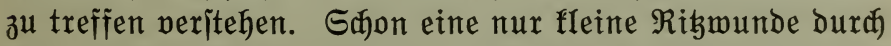

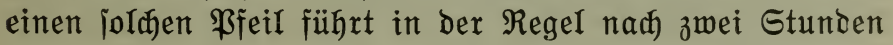


den Tod des Getroffenen an Sherzlähmung herbei. $3 u$ Pfeilgift perwenden die Reute die Gamen von Gtrophantus hifpibus. Sie idheinen bieje mit now andern pilanzlichen und tierijanen Stoffen zu einem biofen Extraft einzufochen und bamit bie $\mathfrak{B}$ feilipizen zu bejtreidjen.

$\mathfrak{U}_{\mathfrak{u} \mathfrak{d})}$ in Gambaga trafen wix eine fleine $\mathfrak{A} \mathfrak{z} \mathfrak{z} \mathfrak{h} \mathfrak{l}$ won Chriften aus unjern Gemeinden an ber Goldfïjte. Wir juchten bie Bande der Gemeinjøaft neu zu fnüpjen und freuten uns, Dá̉ es aud ihnen ein Bedürfnis war, bies zu tun. Wir jangen miteinander uniere trauten Lieber und redeten über Geiftlidges und Beltrides, won ifrem Leben hier in ber Frembe und won ihren Bolfsgenofien und Ge= meindegliedern iłrer Seimat. Während unires $\mathscr{\text { Wufenthalts }}$ fodten ifre Frauen wieberholt für uns bie Randesjpeijen ihrer Seimat, und zu unjrer 2rbreife verjahen fie uns nod mit Mundworrat, ber uns bann jehr willfommen war, als wix in Gegenden famen, wo fein Jams mehr gebaut wirb.

Menn Gambaga je eine Miffinsfitation werden jollte, io wirb bie Benölferung Der Stabt bejondere $\mathfrak{A n f o r b e r u n g e n ~}$ $\mathfrak{a n}$ ben Iaft, die Geduld - und Weisheit Des Miffitonars itellen. $\mathfrak{A b g e j e h e n ~ w o n ~ b e r ~ j e h r ~ g r o ́ ̈ e n ~ M o h a m m e d a n e r = ~}$ gemeinde, liegt die Edwierigfeit in bem nidgt jehr an= genehmen Charafter Der Stabtbenölferung. Wegen Iräger=

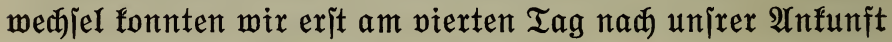
non (5ambaga aufbrechen. Die Berzögerung hatte aber bas Gute, bá wir gerabe now bas jo jehnjü̈tig ermartete Tele = gramm von Den Unirigen in Empfang nehmen fonnten.

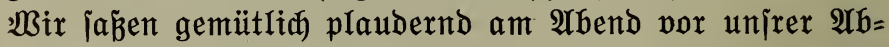
retie in ber "Dffiziersmefle", b. h. unter freiem Simmel und unterhielten uns $\ddot{u} b e r$ gemeinjame Befannte. Salie $\tilde{b}=$ lidb waren wir aud auf bas politijhe Gebiet hiniiber = gefommen, Da fam ein Bübden bahergelaufen und trug in einem Siriejtengel won fingerdife, Deffen oberites Gried ge= ipalten war, einen groß̈en Briefumiahlag an uns abrefifert. Das iit bie $\mathfrak{A r t}$ und Beije, wie von Gambaga Briefe be= 


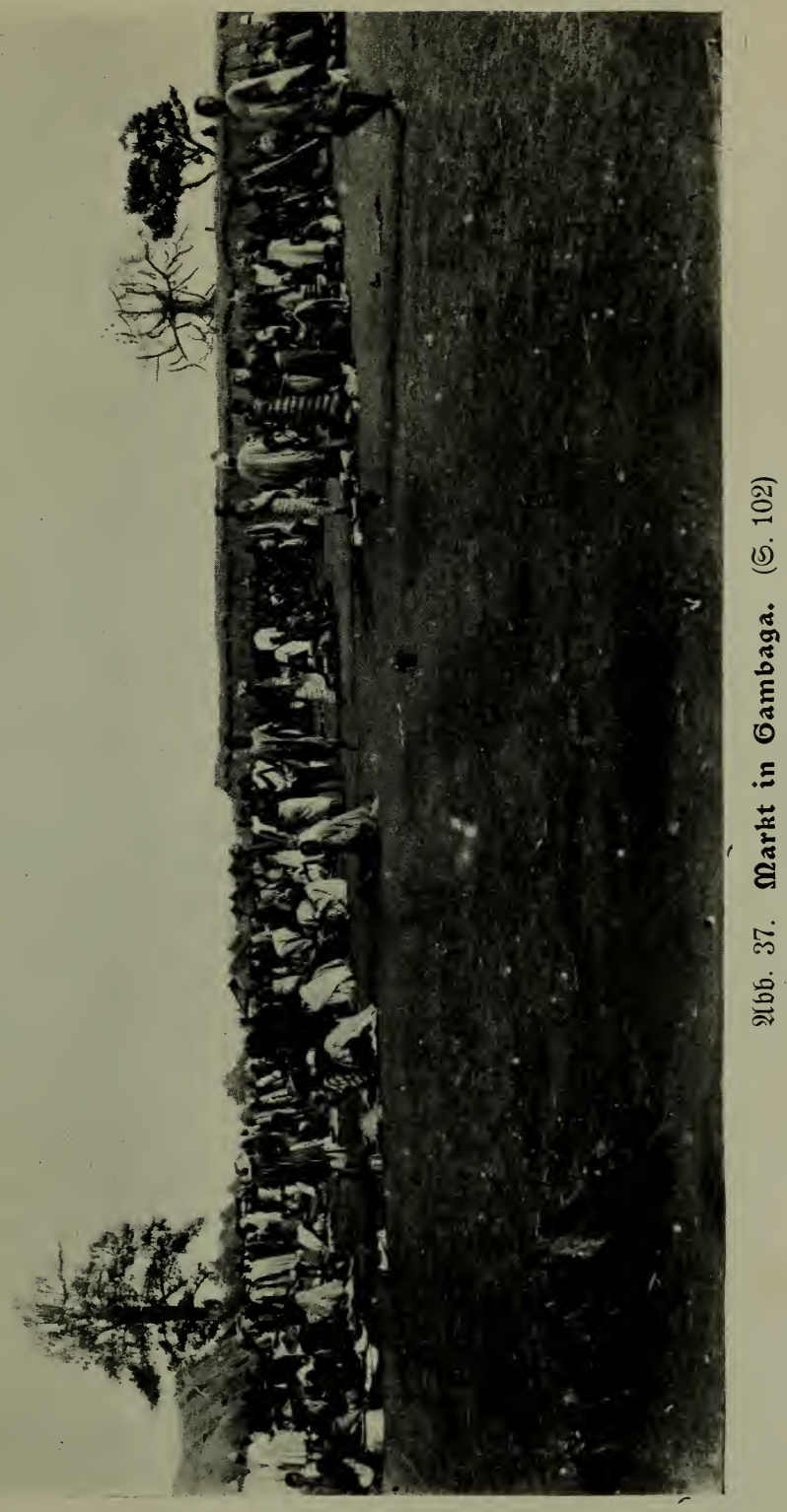



fördert werben. Ein Iunge bef́ommt Durd Bermittlung Des Säuptlings in einem jolden Siriejtengel bie $\mathfrak{P o j t}$ ex be= waffnet fitđ mit $\mathfrak{B f e i l}$ und Bogen und läuft ins näafite Dorf́, Dort jorgt ber Säuptling Dafür, dá̉ einer jeiner Untertanen ben Brief in berjelben $\mathfrak{B e i j e}$ in bas weiter bem Beitimmungsort ber Genoung zu gelegene Dorf beförbert und io weiter.

Unjere Freude war gró̉, als aus dem groß̉en Briej=

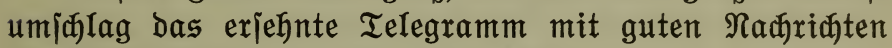
von ben $\mathfrak{U n j}$ rigen zum $\mathfrak{B}$ orjळein fam.

\section{Bon (Gambaga bis zur Deutiðen Grenze.}

Wenn Gambaga iđon Den Charafter einer trägt (bie Stabt liegt 450 Meter ïber Dem Meer), fo tritt bies auf bem Bege nad Norben von (5ambaga aus nod mehr in Erideinung. İn zwei Badtälern herridte nođ) jiemlid frijđes Grïn. Ein iđöner Baum trat in ben Tälern bejonders häufig auf, Der über und über mit jđjönen, weiß̈en Blïten bebeeft war, wahrijeinlid eine Caejalpinie; jonjt aber hatte bie Randjaaft einen unwirtliden $3 \mathfrak{u g}$. überall waren graue Sanditeinfeljen, won Wind und Regen tief angenagt, zu erbličen. Die freien Sodffä̋hen zeigten Gpuren

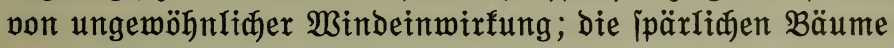
waren verfrüppelt und zerzaujt. Dennow herridte eine hohe Temperatur. Die Binde, bie über bie Sodjebenen itreichen, führen bie über bem blop̉en Boden ermärmte \&uft mit jidf. Ein paar ganz ärmlidje Dörfaden liegen am Wege, bis bann

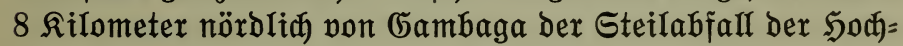
ebene erreidyt wird, über ben ber Weg hinabführt auf bie endlole Ebene, bie mit unbebeutenden Unterbreefungen bis an ben Niger reidft.

Ein weiter $\mathfrak{A}$ usblif tut jiđ vor bem Reijenden auf, ber auf ber Stelle iteht, an ber bie Sondebene jäh ins Tal bes weißßen Bolta abfällt. Bis an ben fernen Sorizont wedjieln 
Grasiteppen und lidte Baumiavannen miteinander ab. Es ijt ein groß̉artiges, aber bïiteres (Gemälde. Die unge= heure Ébene trägt Den Stempel Der Einöbe und Unfrudat= barfeit. Nur ein Band reidern Pflanzenmudjes jieht fita von Dit nadh Weit am Fun bes Berges hin. Es ijt bies ber Galeriemald ju beiben Seiten bes weiß́en Bolta, Der vom Juß bes öftlith pom Wege gelegenen, ebenjo iteil abfallen= Den Sïgels als breites Silberband heraufglänzt.

Eine Rarawante mit Rajtejeln, groß̉en Sdiajen, und einem $\mathfrak{P f e r d}$ itieg gerabe Den halsbrechend iteilen $\mathfrak{B e g}$ aus ber Ëbene herauf. Die Rajtejel trippelten hurtig und ofne Zeidjen von Ermiibung ïber bie iteilen Feljen herauf, bie Ğaje aber feudten jømer, und einige von ifnen erreidten nur mit Mühe die $\mathfrak{b o ̈ h e . ~} \Im$ n 20 Minuten waren wir unten auf ber Ebene angelangt, und nadh wenigen Rilometern erreidten wix bas $\mathfrak{U}$ fer bes weí̈en $\mathfrak{B}$ olta.

Jenjeits lag ein armjeliges Gehöft, biesjeits wax eine

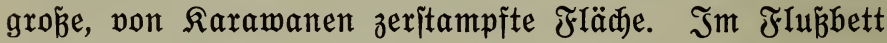
lag ber uns befannte graue, weide Ganditein, teils flächen=

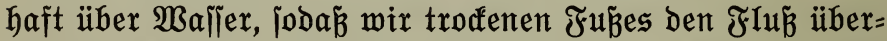
jareiten fonnten, teils bildete er unzählige fleine Injeln. In Der Feljenbarre, ïber bie wix jđritten, hatte das itrö= mende $\mathfrak{B a f l e r}$ bie wunderlidjiten Formen und Kanäle ge=

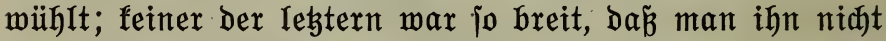
நätte mühelos ïberiđreiten fönnen. Der Befitzer Des $\mathfrak{b e}=$ höftes am rebten 2 ffer reidte uns herrliches $\mathfrak{B a f l e r}$ aus

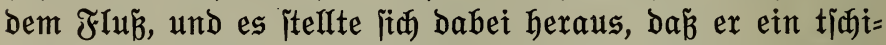

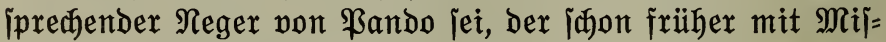
finnaren unjerer Gejelljafift in Berïhrung gefommen war.

Wix waren mit Dem überiđreiten Des weiken $\mathfrak{B}$ olta in das Land der Rujafi ober Jrafra (nacft Serumlaufende),

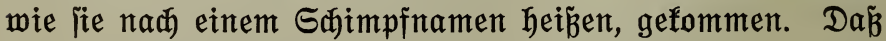
ihnen ber Rame Frafra mit einem gewillen Rerbt beigelegt wirb, jałen wix iđon beim übergang über ben weißjen Bolta.

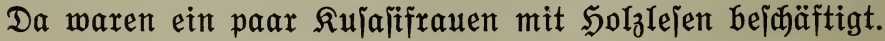


Gie hatten an Stelle pon Rleibern zwei Büjđhel Blätter

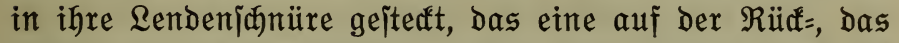
andere auf ber Borberjeite. Shon biejer traurige $\mathfrak{A n b r i f}$ und was wir jonjt nod won den $\mathfrak{R}$ ujaji jahen, wef́te unjer herzliajites Mitleid mit bem armen, verađteten $\mathfrak{B} o \mathfrak{l}$, bas in bejtändiger furdht vor Meniđen und Geijern lebt. Wie zahlreid bas $\mathfrak{B o l f}$ ijt, entzieht fiđ unirer S(jäbung, ba wir mux einen fleinen Teil ihres Landes gejehen haben. Sie wohnen zu beiden Seiten bes weí̉en und roten Bolta bis über die beutiche Grenze hinüber. Es ijt jehr iđwer, fid

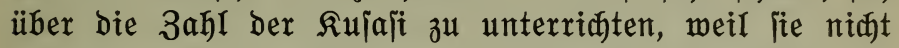
in Dörfern beieinander wohnen, jondern in Gehöften, bie auf weite Streffen hin zeritreut liegen.

Eine furze Strede fuhren wir auf ber in jefr jofledtem

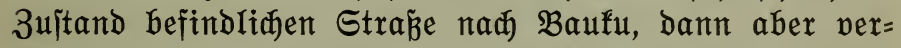

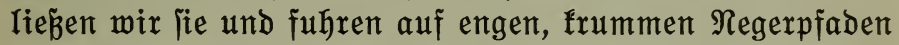
nad) Diter. Bald famen wir an bas exite Rujafigehöit. Ein alter, blinber Mann humpelte aus jeiner elenden $\Re u n d=$ hütte und zeigte uns ben $\mathfrak{B}$ eg zu ben nä̋hiten Gehöpten. In

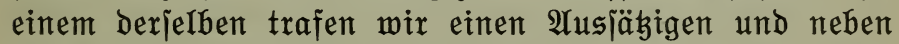

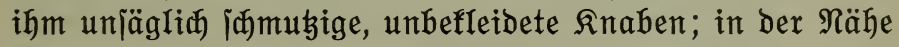
bavon, unter ber Eingangsöffnung, befanden fï̆ ifre eben= falls völlig unbefleibeten Mütter. Die BIattbiil

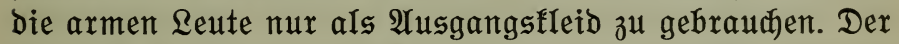
ebenfalls vollitändig unbefleidete $\mathfrak{B a t e r}$ Der ßnaben iđnibte

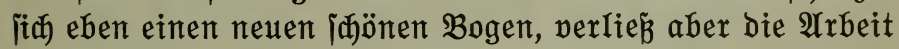
bereitwillig, als wix ifn baten, uns ben $\mathfrak{B e g}$ zu zeigen. Eilig lief er vor uns her und führte uns zu bem Gehöft bes Säuptlings. Mit vielen Worten wurben wir biejem von unjerm Begleiter übergeben, und mit ebenjovielen, offen= bar jehr freundriden $\mathfrak{B}$ orten nahm uns ber Säuptling in Empfang. (5leid Darauf lief biejer eilig bavon und bradte einen grö̉en Solzteller mit heipen, in Sditbutter gefodten Flaben won Sirjemehl, und in einem irbenen Srjilffeldien eine itark mit $\mathfrak{B f e f f e r}$ gemürzte $B$ rühe, zu der er uns einlud. 
Jah fojtete von Den Fladen und fand fie fehr iamarthaft, fonnte aber meine Begleiter nidjt zum 3ugreifen bewegen.

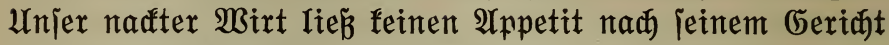

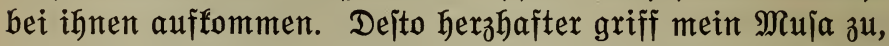
und wir wunderten uns über feinen unheimlidjen 2 ppetit;

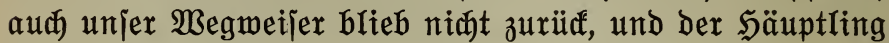

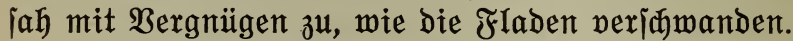

Bei den Dagomba und Mampruji hatten wir nur ganz ferten bie uns von ber Golbfiilte her wohlbefannten Zeidfen Des Gözendienites gejehen. Etwa in einer \$flanzung jahen wix an einer Sđ̆mux aufgehängte, mit Febern geipiate,

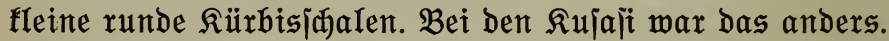
Reben Dem Eingang in bie Gehöfte fanden wir immer einen fegelförmigen ober ähnlid geformten, etwa meterhohen Lehmbau, auf beflen hörhite Spige eine Rürbisfinale ge= ftïlpt war, unter ber eine Menge Sühnerfedern hervorjahen. In ben $\mathfrak{B a ̈ n d e n ~ d e r ~ \Re u n b h u ̈ t t e n ~ h i n g e n ~ S d ) a ̈ b e l ~ v o n ~}$ allerlei Tieren, Sdnüre mit Raurimujheln bejebt, Pflanzenfajerbüiøel und bergleidfen.

Der $\mathfrak{S a ̈ u p t l i n g ~ g a b ~ u n s ~ e i n e n ~ j u n g e n , ~ p r a ̈ d t i g ~ g e b a u t e n ~}$

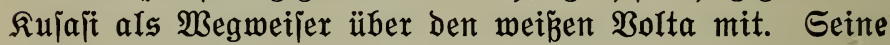
ganze Rleibung bejtand in einer bünten Lendenidnux. Mandher Rünitler bätte jeine Freube gebabt an bem Spiel ber-fraftwoll entroidelten Musfeln, unter ber idofolade: braunen, fajt jđwarzen, jammtnen Saut, wie ex vor uns her eilte, während wir fo Iangiam als möglid binter ígm herfuhren.

Gegen Mittag famen wix wieber an ben weïßen $\mathfrak{B}$ olta und itiegen Das iteile, hohe Ulfer hinunter auf einte tiefer gelegene, 伍male frlupterralie, bie biđt mit Tabaf bepflanzt war. Eine Streffe weit ging es auf biejer flǘabmärts und Dann iteil hinab in ben $\mathcal{F} \mathfrak{I} \mathfrak{b}$, Der Giex etwa 100 Meter breit war, in weldjem aber eine Sanbbanf Iag, auf bie wix leidyt hinüber gelangen fonnten. Sierin war uns nun ber אulafijüngling überlegen. Ex braudete fid nidht exit feiner 
Rleider z̆u entledigen wie wir; ১afür trug ex uns bie Räber Ginüber, und wix patjđten hinterbrein bis über bie Süften im Wailer. Die Strömung war faum bemerfbar, bie Sonne itand nahezu ienfredyt, und das $\mathfrak{W a}$ aler war fait wärmer als bie Rujt. Dex Berjud, ein Bad im flü zu

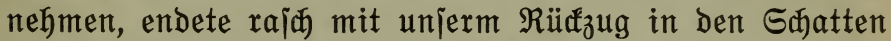
Des Galeriemaldes an jeinem linfen $\mathfrak{U}$ fer, dent won einer Ěrquifung fonnte bei ber Temperatur des Waflers und ber gewaltigen Gonnenfige nidgt bie Rebe jein.

Als wix auf bem hohen linfen $\mathfrak{U}$ fer im Silatten ber

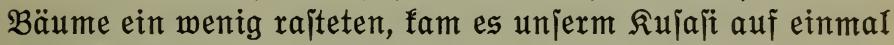

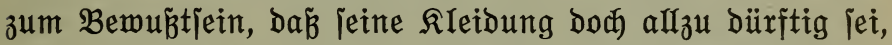

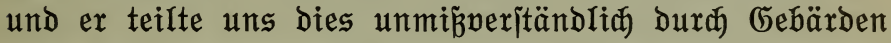
mit. Einer won uns gab ifm barum ein weiß̄es Sandtudh, bas ex gerade bei jiđ̆ hatte. Seine ¡đwarzen $\mathfrak{A}$ ugen glänzten beim $\mathfrak{A n b l i f f}$ Des Tübleins, und hoderfreut probierte er es an. Leiber reidte es nidht ganz herum. Er war offenbar iehr in Berlegenheit, wie ex es am vorteilhafteiten ver= wenden fönnte. Zuerjt legte er es jo um, dá ex hinten be=

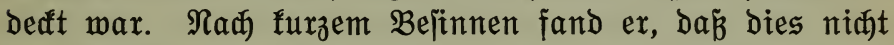
das Riđtige jei, und probierte es jo, da war. Dod aud bies befriebigte ifn niat. Plöblid leudtete es in jeinem Gejidt auf. Er hatte bie inwierige Frage glänzend gelöit. Triumphierend fnüpite ex bas Tud auf Der Geite, jodá̉ nur ber jeitlidje Teil bes Dberidentels un= bebeatt blieb. Năb biejem Erfolg faltete er bas Tud pro= fitliđ ¡đjön zulammen, zog einen graujđwarzen, zweifinger= breiten Streifen Zeug unter jeiner Yabjel hervor und benugte Den als Berftagsfleibung. Dann zeigte ex uns

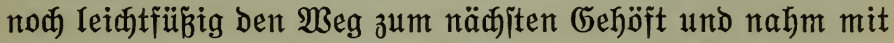

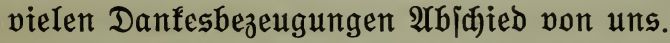

Der $\mathfrak{B e g}$ führte Durch eine jefr anders geitaltete Gegend als wir bisher gezogen waren. Redts von uns, im Sïben, fahen wir ben Steilabfall ber Sodjebene, über bie wir heute von Gambaga her gefommen waren. ütber bieje 
Sodhebene ziehen annähernd paraflele S̈̈̆hnzüge von Gïd= weit nad Rorbojt. 3wijanen ihnen liegen jeiđte Iäler von

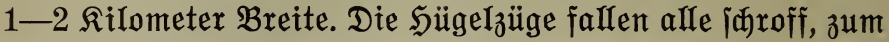

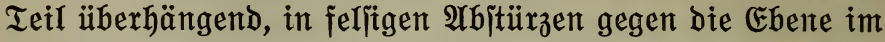

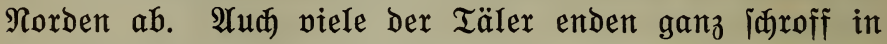
ber gleidhen Linie mit den S్̈ügeln, joda brud befommt, bie Sodhebene jei burd Baflerwirfung

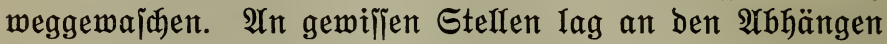
Mergelificfer, und oben zog fid etwas wie eine Bafler = itandstinie in ber Söhe bes plöglid) aufförenden Tals an

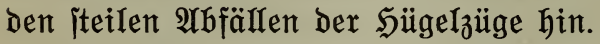

Die EEbene, über bie Der ßeg führte, iłt von Bädhen

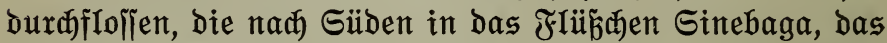

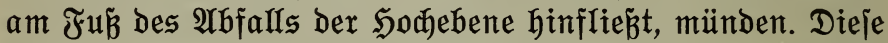

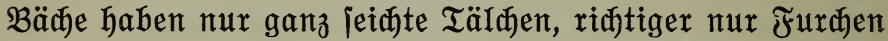
in bie Ebene gezogen, joba man ben Einorud hat, man jei auf einem Boden, auf Dem friésende Gewäller exit in jüngiter 3eit an ber Geländebiloung gearbeitet baben. Jebenfalls ift bie Gegend geologija jehr interefiant, und wir be= bauerten, niøgt bie nötigen Fadffenntnifie zu befitgen, bie uns erlaubt hätten, aus ber auffallenden Bildung bes

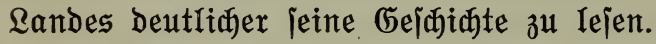

17 Kilometer wom eriten übergang über ben weiß̈en Bolta famen wir an unjer heutiges Ziel Sinebaga. Der Dortige Säuptring war abwejend, und wir glaubten iđjon, im Freien ïbernađten zu mïlien. Der Şäuptling baut jitð ein neues (5ehöft, bas nod) ganz bie Rujajtбauart zeigt, von ber wix hier einige ganz bezeidnende $\mathfrak{P r o b e n}$ jahen.

थIs wix uns eben zur $\Re a j t$ unter einem Sdubbach ein=

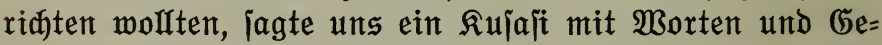
bärben, baß ein Rajthof in Sinebaga jei, und ridgtig, einen Rilometer jübmärts trafen wir auf Den idjöniten Rajthof, Der uns auf ber ganzen Reije vorgefommen ijt. Eine $120 \mathrm{~cm}$ hohe Mauer umgab im నreis einen $50 f$ von nahezu 50 Meter Durdmeller. $\mathfrak{A} m$ ber Mauer mehr Fejtigfeit zu 


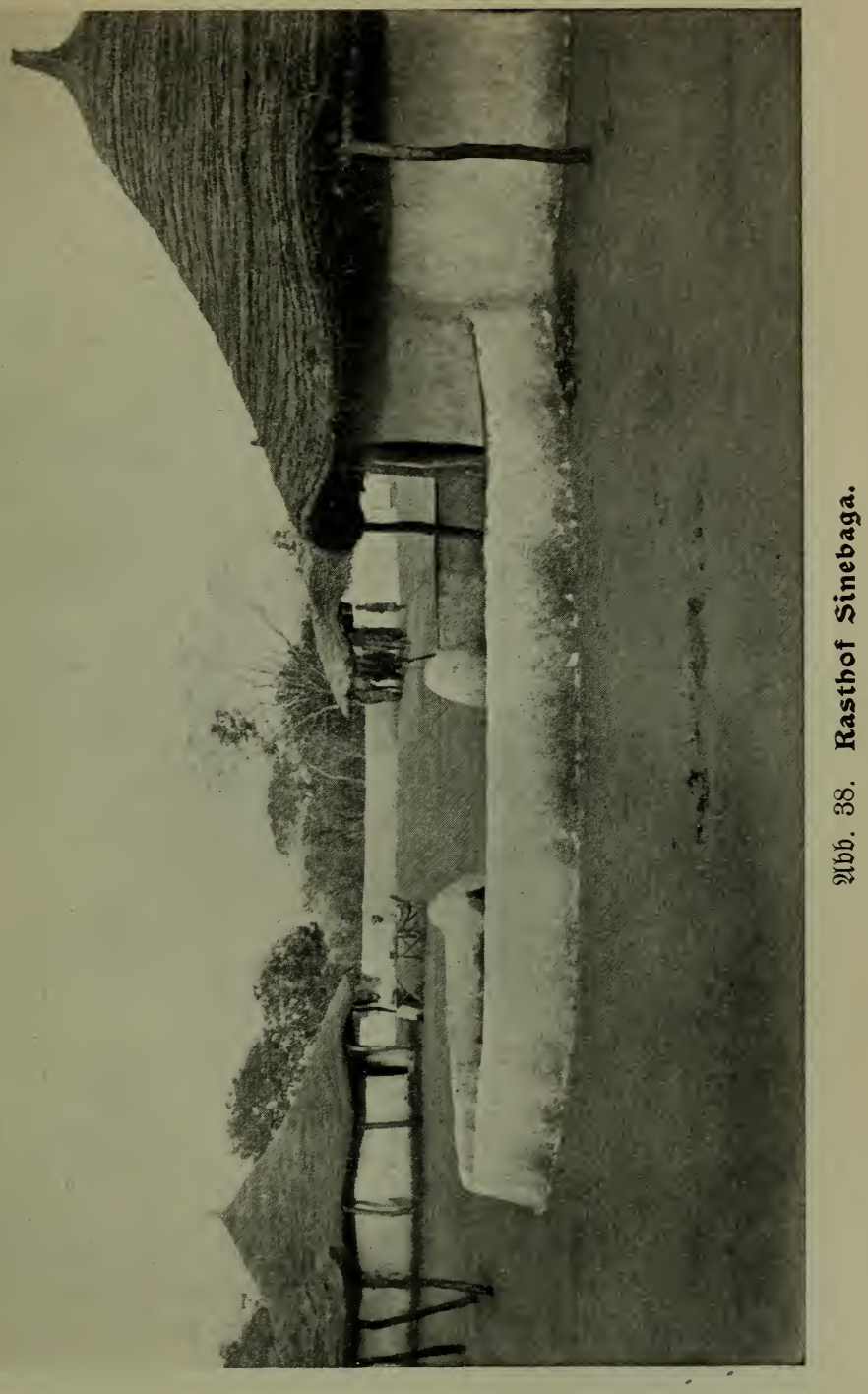


geben, ijt fie alle 2 Meter mit Beritärfungen in Regelform verjehen. Im Sof jind zwei ganz hervorragend jäöne Rund= hütten aufgeführt, bie burd einen mit (5ras gedefften Gang miteinander verbunden find. $3 \mathfrak{u}$ ben Sü̈tten führen zwei (5änge, bie mit $50 \mathrm{~cm}$ hohen Mäuerđen eingefá̉ fitnd. Die Dächer find mit Gras gedecft, und um ju verhindern, dá man burch herabjallenden Staub und bergleidjen be= läptigt werbe, find nod iđöne, von Siriejtengeln hergeitellte Matten Darunter angebract. $\mathfrak{I} m$ Sof befinden (id nod)

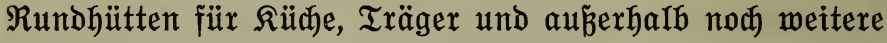
vier zur $\mathfrak{U n t e r b r i n g u n g ~ D e r ~ T r a ̈ g e r ~ u n d ~ e i n e s ~} \mathfrak{P}$ ferbes. Das Ganze, $\mathfrak{U}$ mãa hütten, ijt jehr porgfältig geglättet und mit Dawa= bawajaft behandelt. Die Mauern find now überdies mit

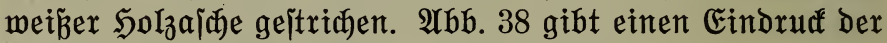
fleiß̄igen $\mathfrak{A} \mathfrak{x b e i t}$ ber Reute von Sinebaga.

Bix waren nun im Lanbe ber $\mathfrak{K u} a j i$, und hätten uns nid)t uniere Freunde in (5ambaga mit Maisbrot reid) weriehen, jo hätten wix uns eben bod zu Speijen aus Sirie weritehen müllen. Erit in Sanjanne Mangu wirb wieber

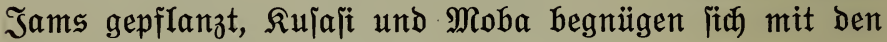
beiden Sirjearten Sorghum und Benijetum.

\section{Bon ber englijad=dentiden Grenze bis Samjanne Mangu.}

2Tm 6. März bradjen wir auf und fuhren ber beutjøen

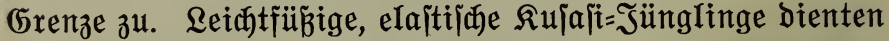

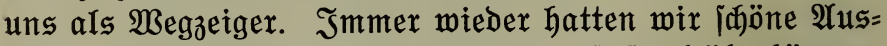
bliđfe gegen Gïben auf bie jenfređten, oft itarf überhängen=

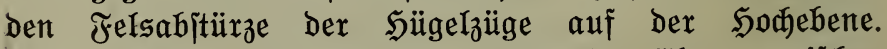
Die frudtbaren, oft ganz leiðt anjteigenden Ebenen zwijøen

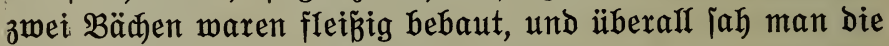
zeritreuten Gehöfte. Standen irgendmo brei ober vier Ge= höfte nahe beijammen, io waren bejto grö̈bere Strecten 


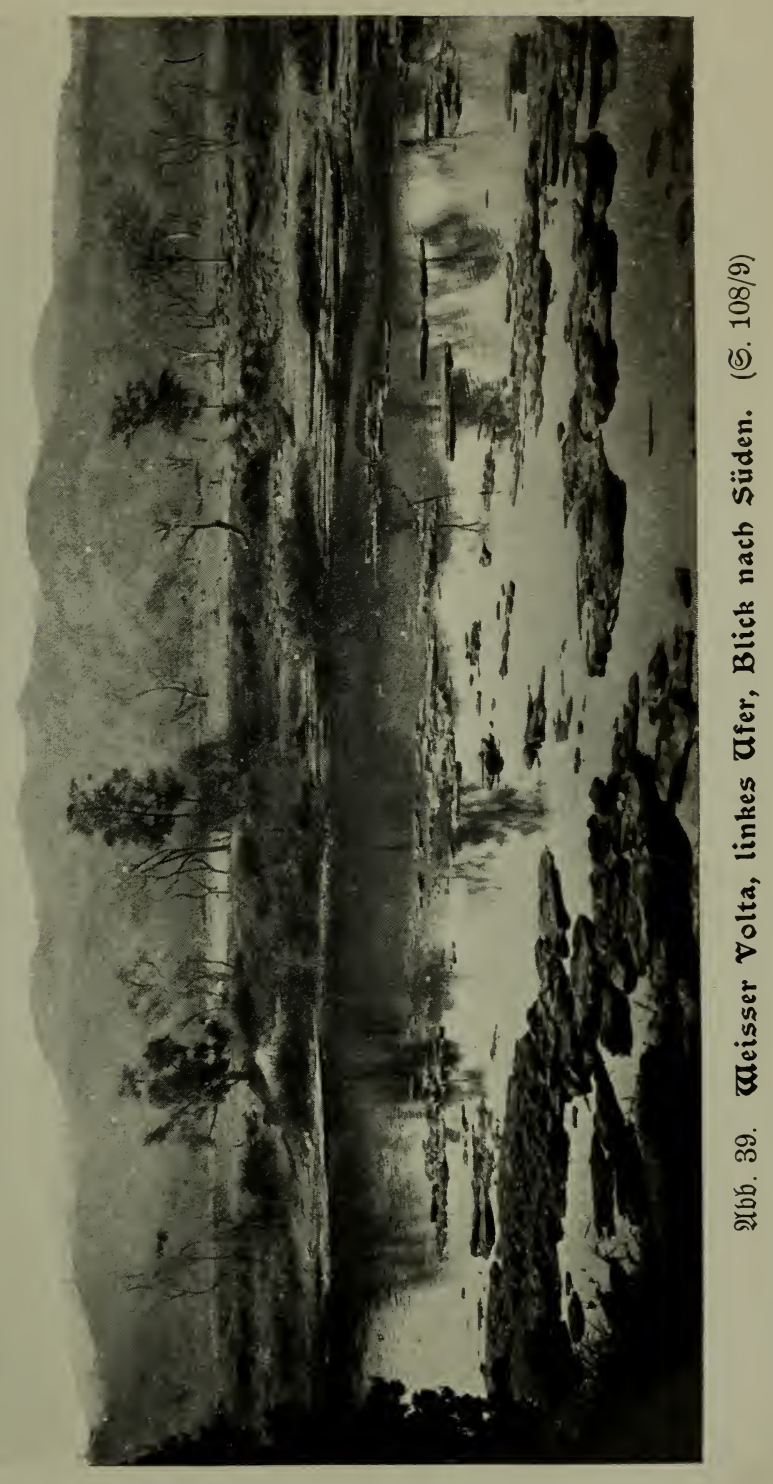



wieder ohne irgend ein Gehöft. Die Dörfer nehmen barum

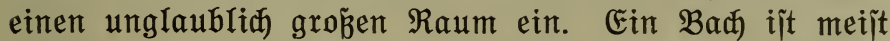
die Grenze; wie weit dem Bach entlang aber ein Dorf fith

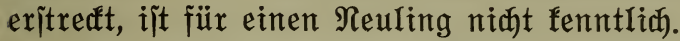

Bo wix auf unjern Räbern exj̧ienen, jølüpften Frauen und Rinder wie Murmeltierdinen janelritens ourd

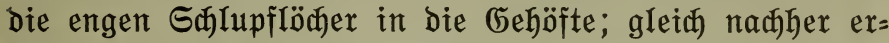

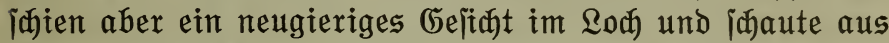

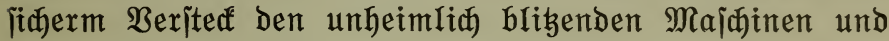
ben fremben Menjøen zu. Die Gehöfte zeigen niøt mehr den Charafter der నujajţaumerfe. Die Quermauern Dura die Gehöfte fangen an $3 \mathfrak{u}$ fehlen, und wo wir abjtiegen, um bie hie und ba fĭ verjammelnben Männergruppen $z \mathfrak{u}$ grüß̈en, hörten wir die unreinen Diphtongen und bas tiefe o, jowie viele Gutturale. Im exiten Dorf Loare mohnen iðon Moba. Eine $\mathfrak{A n z a h l ~ j u n g e r ~ M a ̈ n n e r ~ b e z e u g t e n ~ i h r e ~}$ Freube an, unjern Räbern, dá̉ fie luitig vor uns her=

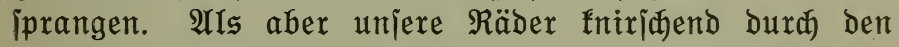
groben Gand fuhren, ba itoben ite in hellem Edreden auj alle Seiten auseinander; nur ber Wegweijer, der die Sache iajon fannte, Iahte fie Iuitig aus, und bald itimmte bie ganze Gejelliðaft ein, und ber Gryedfen war vergellen.

Im näßjten Dorf Giej̣ famen bie ältern Männer alle= jamt zu einem Gehört, an bem mix vorbeizufahren hatten. Wix itiegen ab und jöhittelten ifnen die Sand. Sie itanden

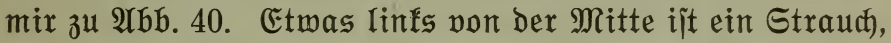
an Dem eine Menge von Dingen hängen, bie auf Den Geijter= Dienit Bezug haben. Reben bem Unterfiefer eines jungen

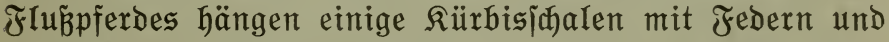
vertrodfnetem Blut von Sühnern; redts im Bild neben

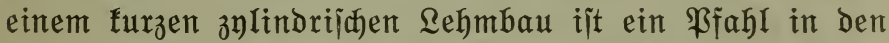
Boden gerammt mit einer breiteiligen Gabel. In diejer Gabel liegt aud ingend ein mit bem Geijterbienit zujammen= hängender Stein.

Unter ben Umitehenden erfannte iđ gleich einen Rol=

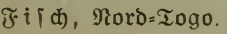




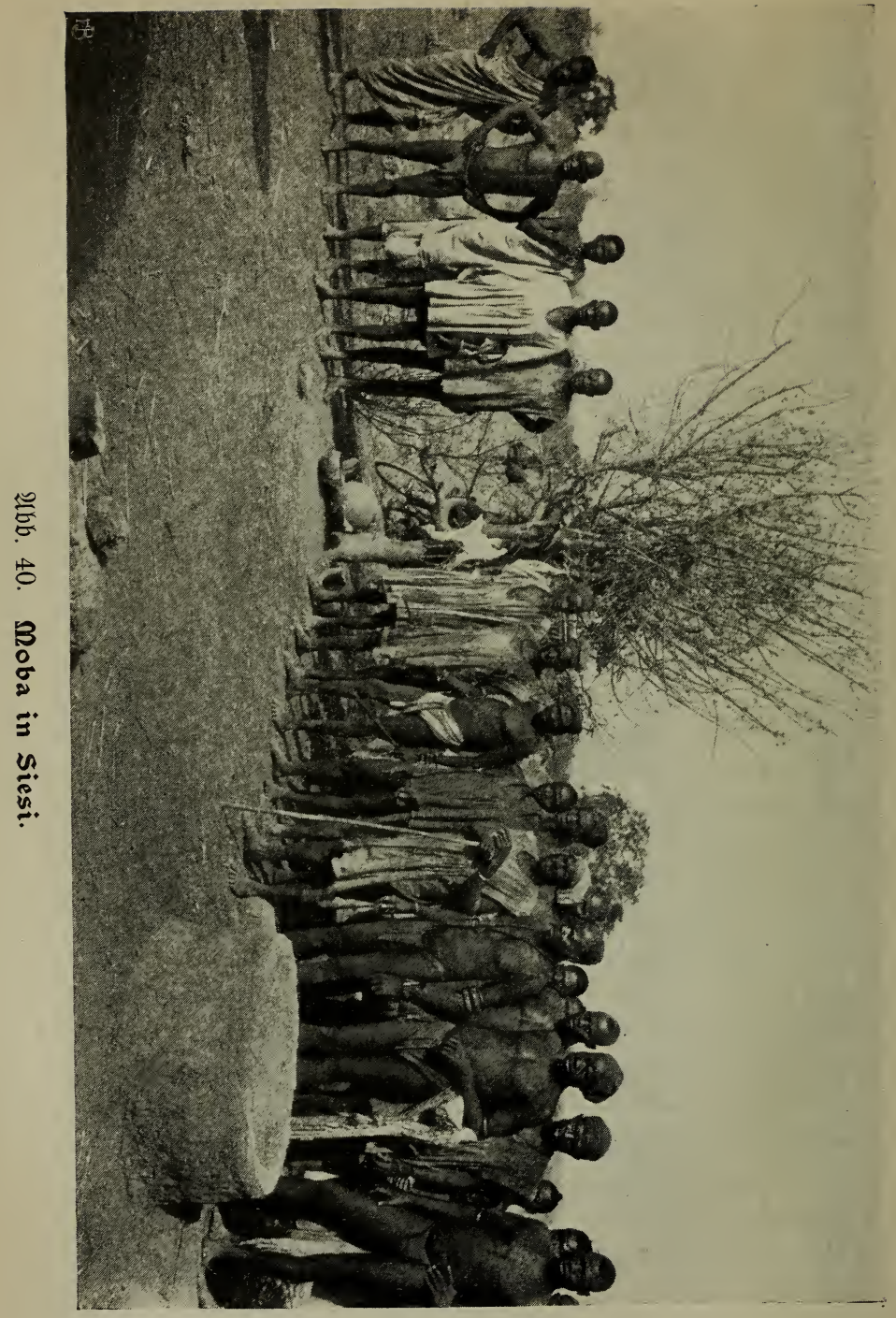


legen. Er hatte jeine Initrumente auf Der Brujt hängen. Sie bejtanden aus ein paar Mefiern und einem pinzetten= artigen $\mathfrak{I}$ mitrument. $\mathfrak{A} n$ ben $\mathfrak{A} r m e n$ trug er fräftige, aus Solz gefertigte Ringe, an ben Sandgelenfen Sdjüre mit Leoparbenzähnen, jonjt aber litt er nidht an überfluß von Rleidungsitüưen.

Die Moba find zum gropenen Teil jefr leidenjđaftlide Rauder. Die meijten tragen ifre $\mathfrak{B j e i f e}$ nebjt einer $\mathfrak{P o r}=$ tion Tabaf an einer Gdnur über ber linfen Sdulter. Die Frauen jind fajt ebenjo eifrige Raudher wie bie Männer.

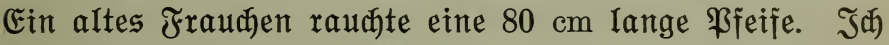
bat fie, mir bieje Pfeife fäuflich abzutreten. Sie willigte ein, als fie aber jah, wie id den nod nidyt geraudaten Tabaf ausjüütten wollte, bat jie midh jehr, ihx ben zu überlaljen.

Es tat uns leid, Dá̉ wir mit ben freundridgen zutrau= lichen Reuten niđgt reden fonten und uns auf freundidide Bliđ̌e und Mienen bejđränfen muß̈ten. Sändebrud zur $\mathfrak{B e}=$

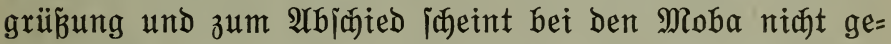
bräudlid zu jein, wohl aber ein janftes, oft wiederholtes $3 \mathfrak{u}=$ jammenidjlagen der im red)ten Binfel zueinander gehaltenen

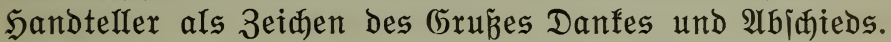

Die Bebardung Der Şäujer ijt bei ben Moba anders als bei ben bisher auf Der Reije berïhrten Stämmen. über bas gewöhnliðbe Solzgerippe bes Darbes werben 3-4 Meter lange Sirjeltengel bidht nebeneinander gelegt. Man läß̆t fie weit über bie Mauern herausitehen und ianeidet fie bann

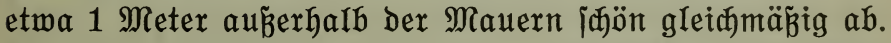
Das (5rasdach läß̈t fie etwa $80 \mathrm{~cm}$ unbeded̆t. Die Däßher iehen infolge bavon eigentümlid, ausgefranjt, aber niđt un=

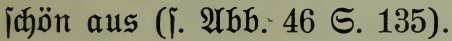

Wir paffierten die Grenze, die mit eitrem iđanarz= angeitridenen, zugeipigten $\mathfrak{B f a h l}$ mitten im lidaten, nieb= rigen Gehölz gefennzeidnet wax, und famen bald in unjern eriten Rajtort auf Deutiajem Boden, nady Punfpariene, 14 Rilometer von Sinebaga. 
Sdion von weitem jahen wir bie rote Dienjtmübe des Soldaten, Den ber Bejirfísleiter von \$arpart uns von Gan= janne Mangu aus entgegengejhidt hatte. Der Goldat war nidht mü̈̈ig gemeien. Er hatte uns Durd bie Leute von Punfpariente zwei jøöne Grashïtten unter einer präđtigen Barfia bauen Iaffen. Gerabe famen in Iangem 3ug Frauen

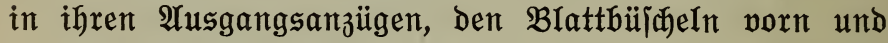
Ginten, mit $\mathfrak{W a} \mid$ ertöpfen auf Dem Ropf Daher, Dann eine

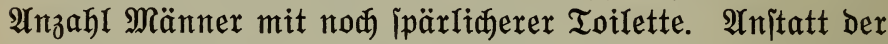

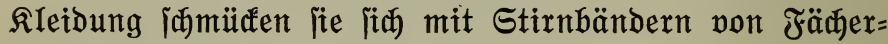
palmen, bie fie jebr nett $\mathfrak{j u}$ flechten verjtehen. Sn Den mit jehr groß̈en Qößhern veriehenen Dhrläppdyen iteden bei jungen Leuten oft fingerbidfe, $20 \mathrm{~cm}$ Iange, hellgelbe Sirje= itengel; ein älterer $\mathfrak{M a n n}$ trug in jeinem linfen $\mathrm{Dhr}=$ läppdhen nidbt wenigex als 14 Mefíingringe, im redten jogar 18 , in zweien, etwas grö̈pern Ringen, hingen nod je orei fleinere. $\mathfrak{A m}$ Sals und an ben Siüften tragen bie Mänter Sdnüre ober Raurimuidheln, über Dem Elfbogengelent oft biffe, hölzerne Ringe, an ben Shandgelenfen und über Dem Sprunggelenf́ breite Bänder von Fä̆herpalmblättern, Shre \$reifen, die fie, wie gejagt, auf der Seite oder auf dem Rülfen tragen, haben gebrannte Röpfe von rotem Ton; Das Rohr be= iteht aus Bambus oder fonft einem $\mathfrak{J o l}_{3}$; ein Geflügelfnodhen, Der jauber geiđabt ijt, bient gewöhnlid als Munditüax. Die Rohre fint meift mit einfaden eingerigten Stridmultern nett perziert. Arn Gtelle ber in Europa beliebten Quajten hängen bie Moba ein paar $\mathfrak{K a u r i m u j h e l n ~ a n ~ b i e ~ R o h r e . ~}$ Einer verband bas Sdjöne mit Dem Räblidjen und hatte einen eifernen $\mathfrak{P f e i f e n r a ̈ u m e r ~ a n ~ j e i n ~ n e t t ~ v e r z i e r t e s ~} \mathfrak{B j e i f}=$ dhen gehängt. Älttere Männer tragen oft an einer Sđjnur über bie Sibultern bas Fefl einer Antilope oder eines Sđjafes auf Dem Rüúen.

Yuffallend viele Moba leiden an dronifaer Entzü̈t= Dung Der Bindehaut Der $\mathfrak{H}$ ugen und ihren Folgezultänden. Der Säuptring von $\mathfrak{B u n f p a r i e n e , ~ e i n ~ a l t e s , ~ b u ̈ r f t i g e s ~ M a ̈ n n = ~}$ 
Ђen, fam zu mir und zeigte mix jeine $\mathfrak{A} u g e n$. Die Bimpern bes obern Ribes rieben auf Der Sornhaut beiber $\mathfrak{A}$ ugen und hatten Dabura eine iळleichende Entzündung berjelben her= vorgerujen. Das ijt die häufigite Folge diejer cronijäen Bindehautentzündung. 3ux Bejeitigung bes Leibens iळIug idf ifm eine fleine Dperation vor. Er ging Darauf ein. Geine Befleidung beitand aus einem hinten über ben Rüfen herab̧ängenden 3iegenfell, baneben hatte ex noch als Deçe

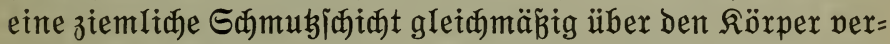
teilt. Der Jeldituhl, Der als Dperationsituhl Diente, muñte

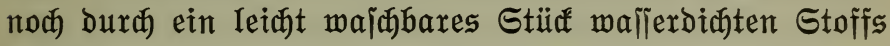
geidüut werben. Bis bas Dperationsfeld ordentlich rein war, bauerte es ein Weilhen, und es fonnten einem dabei 3meifel an Der Wajळedtheit der Sautjarbe bes guten Mannes aufiteigen. Bon 3eichen übermältigender Danf= barfeit nađ Dex Dperation fann iđ̆ niđt beriđten, Denn dazu ¡đmerzte die Dperation zu jehr, aber nađher wird ex iळon die günitige Wirfung bes Eingriff́s zu ipüren be=

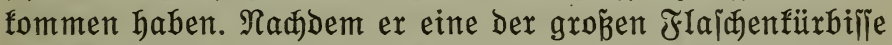

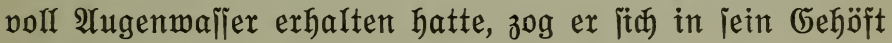
วurüứ

Es mar ein munderjøöner Yrbend. Die Gehöfte lagen itill und friedrich über die weite Ebene bin zerjtreut; im Sïben glänzte eine đđroffe, zum Teil überhängende Jels= mand im Riđt Der untergehenden Gonne.

Recht leib tat es uns, am nädjten Morgen ßunfpariene mit jeinen frieblichen, Jutrauliḑen Einmohnern verlafien

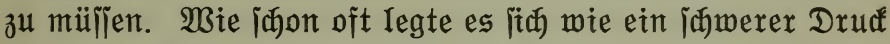
auf uns, dá̉ wir ben Leuten, bie für uns gearbeitet hatten und uns vertrauend entgegengefommen waren, jo gar nidjts bieten und ifnen pon ben wunderbaren Iaten Gottes zu unjerm Seil niđhts jagen fonnten. Es ijt ein herbes Ding,

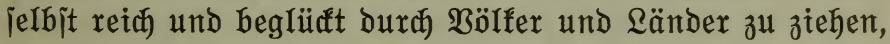
ohne von diejem Reichtum und Glüu mitteilen zu fönnen, mo jo viel jđreiende $\mathfrak{A}$ rmut und das ganze Leben exfüllende 
Ingit und innere $\mathfrak{U n r u h e}$ ijt. Bon biejer $\mathfrak{A} n g$ it zeugten bie Unmafien von Sajugmitteln gegen erzürnte Geijter, und bie Spuren biejer 2Angit jint für ben, ber in ben Gejidtern

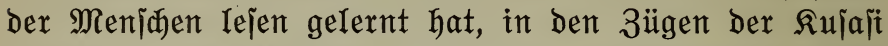
und Moba unverfennbar. Se länger, je bringender wurbe bie Bitte unirer Serzen: Dein Reid fomme! Die 3eit hat dies Berlangen niđht abgeichwädt. Die armen, nadften

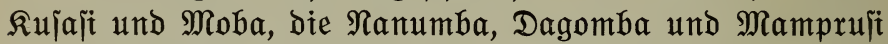
und bie ipäter zu erwähnenden Ronfomba itehen bittend vor uns, und bitten aud bith, lieber Sejer: bete aud bu für die Bölfer, beren Bilder an bir vorüberziehen und tue

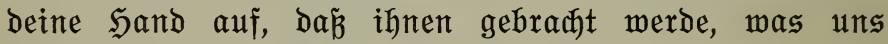
Menifhen allein glüuflid und reid madyt.

UIIs nörolidajten $\mathfrak{B u n f t}$ unjrex Reije hatten wir Dan= bugu gemählt und wollten biejes 3iel in zwei Tagen er=

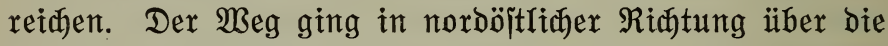
Ebene, bie von 3eit an Zeit Durh Die jeifte Rinne eines Badhes unterbroden war. Unfrud thare Streden weed jelten $\mathfrak{a b}$ mit mohlbebauten Stellen. $\mathfrak{B}_{0}$ frudtharer Boden war, ba war aud ein Dorf ju treffen, b. h. von bem Dorf jah man immer nur gerade bie paar Gehöfte, bie in ber Nähe bes

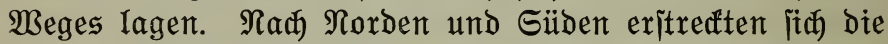
Dörfer mohl nod filometermeit. $\mathfrak{A} u f$ einer Stredfe pon 31 Rilometern famen wir burd neun Dörfer: Durd Ret, Goatere, Rangfangviga, Sanfus, (5umbare, Suluboar), Ruluvigu, Bofam und julebt burd Lodugu.

Das jefr weit zeritreute Dorf liegt am $\mathfrak{F u}$ eines etwa

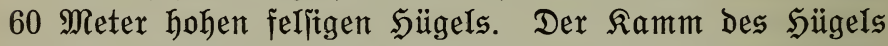
ijt von gewaltigen, wild Durdheinander und ïbereinander geworienen Felien gebildet, von benen mandie mehr als 40 Rubifmeter gró̉ jind. Unter und zwijhen biejen Feljen

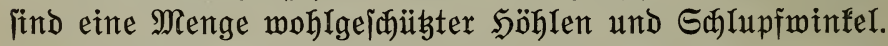
Jegt haujen Darin groß̉e Bölfer von ßerlhühnern und anderes (betier; in ben unfichern 3eiten vor ber Bejits= ergreifung Durch bie Deutijhen bienten bieje Ieidgt $\mathfrak{u}$ ver= 
teibigenden, vor Wind und Regen gejđübten Söhlen den Eingeborenen als 3uffudytsort vor ifren Feinden. Mandie

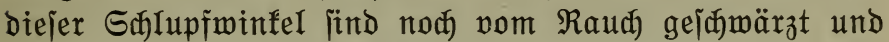
perraten burch allerlei überrejte, bá̉ jie vor niat jehr Ianger 3eit bemohnt maren. überall triffft man auf Spuren bes Geijterdienites, der wohl auf jenen Sügeln bejonders gepflegt wirb. Bon einem auf bem hödjten \$unft bes

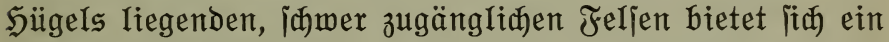
reizendes Randjđaftsbill. 3u Fü̈̈en bes Sügels liegen auf Der Ebene zeritreut die jaubern Gehöfte Der Einmohner; außjerhalb derjelben erbliłt man, einzeln ober ju jweien, die Sirjeppeidherden, fleine Runbhütten mit ber Tente ba= vor, einem runden, geebreten und mit Damadama behan= Delten ßlas. Dazmijhen ziehen freuz und quer die jamalen Wege von Gehöft zu Gehöft und in bie benahbarten Dörfer hinüber. Leiber war bas liebliđbe Bild beeinträdtigt Dura die herbitlidye Landjhaft: Die Felder maren abgeerntet und alles (brün verborrt. Wie herrlich mú es hier jein, wenn die Sirjefelder in frijhes Grün gefleibet find, wenn die Bäche frié̉en und alles fĭ der heranreifenden Ernte freut! So weit Das $\mathfrak{A}$ uge reidte, jah man überall zeritreute (5e= höfte. Man befommt den Einoru氏, das Land jei nahezu jo bicht bewohnt, als es jeiner Ertragfähigfeit nađ zu er= nähren vermag.

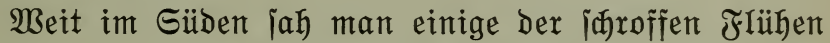
bex bort abjallenden Sodjebene. Noఝ Iange genofien wix ben intimen Reiz Des eigenartigen হandjđaftsbilbes, und gax manderlei Gedanfen bewegten uns. Wie oft modte wohl in frühern 3eiten auf diejer freien Warte ein Moba ge= itanden jein und bejorgt und angitnolf ausgejđaut haben nach ben 3eichen eines herannahenden feindichen Seeres! Wie oft werben die Rauhjäulen und Flammen ber brennen= den Gehöfte den Weg der Jeinde fenntlid gemađt haben, und von welchen blutigen Rämpfen fönnten mohl die Jeljen erzählen, unter denen die geängiteten Leute ihre 3ufrucht ge= 
jưt hatten! Unter einer iđattigen, groß̈en Tamarinde hatten bie Qeute von Lobugu uns zwei Grashütten gebaut, und ein bort itationierter $\mathfrak{B o l i z i}$ iłt, ber Sogn bes Säupt=

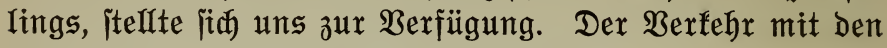
Einwohnern war Der Denf́bar freundicfite.

$\mathfrak{A m}$ närhiten Tage reijten wir weiter über $\mathfrak{B o j a c h , ~}$

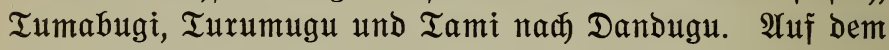
Weg freuzten wir ein bedeutenderes Badtal; in Der fid

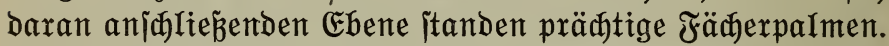
Wir trafen dieje herrlibe $\mathfrak{B a l m e n a r t ~ h a ̈ u f i g ~ i n ~ d e x ~ N a ̈ h e ~}$ ber Bärhe. Die gropen, gelben früdte merben won alt und jung in Moab gern gegellen. Sie fentren eben bie

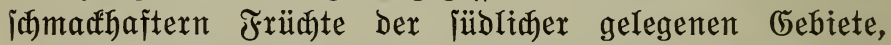
die $\mathfrak{B a p a y a ~ ( B a u m m e l o n e n ) , ~ D i e ~ I n a n a s , ~ M a n g o , ~ D r a n g e n , ~}$ (5uajaven noch nidft.

Die Moba treiben ein menig $\mathfrak{B i e h z u d t , ~ b o d ~ j o , ~ b a ́ ~ f i e ~}$ nitht jelbit bie Sherben weiben und bejorgen. Sie bingen

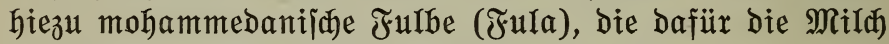
ber Sherbe und bie Sälfte ber Rälber erhalten.

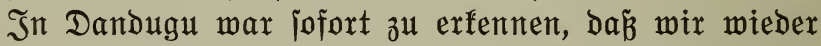
einen andern Bolfsitamm vor uns hatten. Zwar zieren jīh bie jungen Männer in ähnlidber Meife, wie die Moba= jünglinge mit Stirnbändern und Retten von Glasperlen

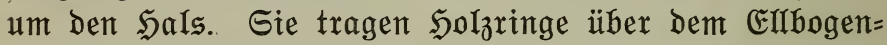
gelenf und Melitingringe am Sandogelent, aber fie fleiden (ith viel belier. Meifitens tragen bie Mänter Leibröđfe von jelbitgefertigten Gemeben; nur bie Frauen fitto aud bet ihnen nidbt beller befleidet. Es find $\mathfrak{b} \mathfrak{a} \mathfrak{x} \mathfrak{m} \mathfrak{a}$, bie bier wohnen; Der größzte Ieil won ihnen ineint aber jenjeits ber beutichen (5renze in franzöjijhem Gebiet zu leben. J⿹re Spradhe if́t mit ber Spradhe der Moba nahe vermandt.

Der Säuptring von Dandugu trug bei jeinem Bejud bei uns, und als wir ihm den Bejud exwiberten, ein weí̉ und iahmax geitreiftes weites (Gemand und einen Turban, auf weldyem ein paar $\mathfrak{A}$ mulette angebrad)t waren. Er ijt ein 
alter, gutmütig ausfehender Mann. Es fam uns vor, als ob bie (5urma nicht fo offen und vertraulid wären, wie die Rujaj und Moba. Ein freundliaer Blif und ein freund=

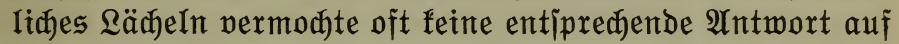
ben etwas finjtern (Gejidtern hervorzurufen. Es ijt aber

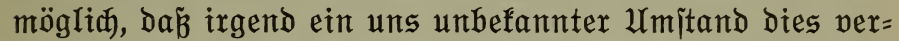
urjact hat. Die Bauart ber Gehöfte und ber Dörfer ijt ganz diejelbe wie in Moab. In Der Eingangshütte Des Ge= höftes Des Säuptrings itand ein 2,5 Meter hoher urnen= förmiger Behälter für ausgedrojaene Sirje. Bom Dad

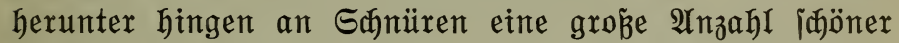
Epeere, mit ihren breiten Spizen nach oben, und Durah

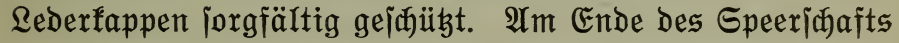
waren iðön gejđmiebete, vierfantige Spizen angebrađt; bieje waren freigelafien und bienten wohl bazu, den Gpeer in ben Boden zu iteffen, ohne dá̉ die Shneide dabei Shaden

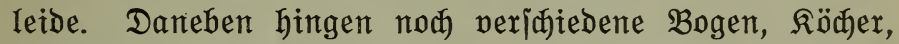

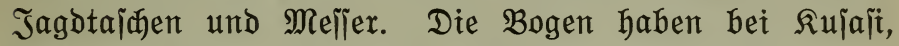
Moba und Gurma Gebren von Bambus, bei den Dagomba, నanumba, Mampruji und Ronfomba Sebren von gebrebten

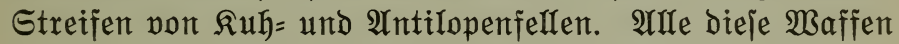
waren reichlich mit $\mathfrak{A}$ muletten behangen und alles io

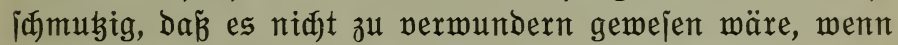
Die ganze Bej历erung bis auf die Eijenteile von Mäujen verzehrt worben wäre. Sn Der riđtigen Erwägung, dá̉ fiđ jo etwas jutragen fönnte, waren die Webrgehänge vor

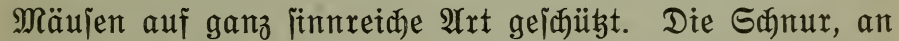

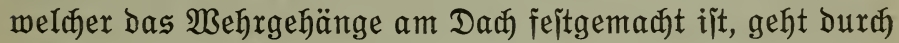

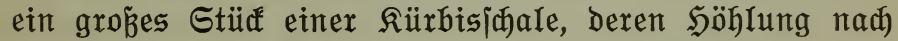
unten fiteht. Dura einen Rnoten in ber Ganur ijt dieje Ћürbisicale über dem Wehrgehänge feitgehalten. So fönnen Mäuje zwar an Der Sֲnur auf und ab flettern, aber es ijt ihnen niat möglid, an bie barunter hängenden Sachen zu gelangen.

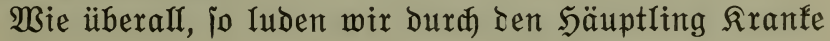




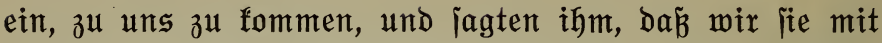
Freuben unentgeltlid behandeln würden. Der Beideid, ben wir tags zunor in Sodugu erhalten hatten, wurde uns aud heute zu teil: Es jeien feine Rranfe unter ifner. Das wiederholte fïch won nun an regelmäßig und wir bachten an

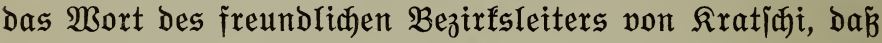
es idwer halten werbe, నranfe zur Behanolung zu be= fommen, weil bie Ingit, nadh dem Sdhlaffxanfendorf ge= idifft $\mathfrak{u}$ werden, den Reuten allzu jehr in bie Glieber ge=

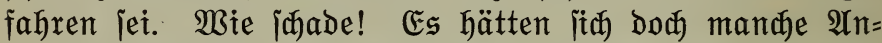
fnüpfungspunfte aus freundlidger äratlither Tätigfeit ex= geben, und barauf mußsten wir nun verzidjten.

über bie $3 \mathfrak{a h l}$ ber im beutinen Gebiet wohnenden (5urma gift eine 3ählung Dura ben veritorbenen Saupt=

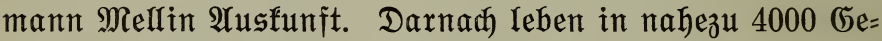
höften $40000 \quad \mathfrak{b} \mathfrak{u} \mathfrak{x} \mathfrak{m} \mathfrak{a}$; $\mathfrak{M}$ oba gehöfte murben nahezu 6000 gezählt mit 61000 Einwohnern; $\mathfrak{K} \mathfrak{u}\{\mathfrak{a}\{\mathfrak{i}$ in 1250 (be= höften 13000.

(5urma und Moba fömren jedenfalls mit einer Sprache bebient werden, ob aber bie $\mathfrak{R} u \mathfrak{a}$ ât eher mit Dagomba als mit (5urma, bas wirb erjt die Zufunft Iehren. Die Zahlen zeigen, bá̉ bie nörolidaen Gebiete von Togo verhältnis=

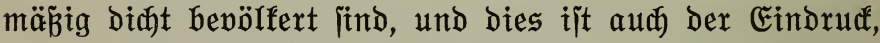
ben ber Reijende befommt. Ganz bejombers machen bie $\mathfrak{B e r}=$ bältnifle des gebirgigen Ieils won Moab, ben wir bald iđjildern werben, Den Eindrud eittes Landes, Das unter ben jegt herriøenden אulturverhältniffen nur nođ mit Mühe die Bevölferung ernähren fann.

Mohammedanijhen Einfluß bemerft man bei Den $\mathfrak{R}=$ iafi, Moba und Gurma nidyt. Die einzigen Mohammedaner unter ifnen find bie Sirten; es find bies, wie finon erwähnt, Fula oder Fulbe, won benen, wie es fijeint, feine \$ropa= ganda getrieben wirb, womit allerbings nidht gejagt ijt, bá es fid in Wirflidffeit jo verhält; benn zu einer ridhtigen $\mathfrak{B} e=$ urteilung ber Berhältniflie war bie Zeit, bie uns zu Cebote 
itand, viel zu furz. Dazu fam unjere Unfenntnis der Epraden, modura unjere Beobadtungen jebr exjøert waren.

Wie oft hatten wir alle $\mathfrak{U}$ raache, im itillen ben Bezirts:

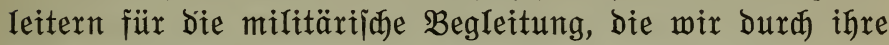
Güte exhielten, danfbar zu jein. Es maren immer aus= gejuat tühtige Leute, und fie haben uns jehr groß̉e Dienite geleijtet. Satten wir an irgend etwas Mangel, jo jorgten jie, Dá̉ wir Das Nötige geliefert exhielten. Sie jorgten aud bafür, dá̉ die Träger beteinander blieben. Man fonnte fiđ Durhaus auf fie perlafien. Es war uns zwar anfangs nixht ganz angenehm, in militärijøer Begleitung reijen

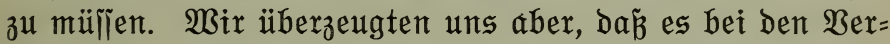
hältnilien, unter benen mir die Reije zu madhen genötigt waren, und ohne Renntnis ber Sprađhe bas einzig riatige war, und unjere Danfbarfeit dafür murbe immer auf= ridytiger und herzlidyer. Die beiden Soldaten, bie uns Sherr von ßarpart zur Berfügung itellte, waren über alles erhaben.

Wir brachen mit fait mehmütigen Gefühlen am 9. Mä̀ auf und fuhren jübwärts. Die eine Sälfte der jळönen Reije lag bamit hinter uns. Unjer 3iel war Dapong, 16 凡ilo= meter jüböitlich von Dandugu. Der Meg führt fajt aus=

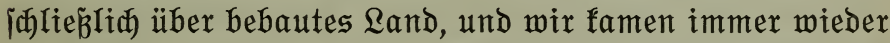
an Gehöften vorbei. Urnjere $\mathfrak{A n f u n f t ~ m a x ~ f u ̈ r ~ d i e ~ z a h I r e i c h ~}$ (aIs "Shlachtvieh", wie wir hörten) gehaltenen Sunde immer eine etmas aufregende Sache. Sie famen rubelmeije, wütend bellend dahergerannt, liefen abex immer mit 3eidnen ber Furat Davon, wenn fie nahe genug herangefommen waren.

Siex fam uns in einigen (5ehöften ein neuer Samud

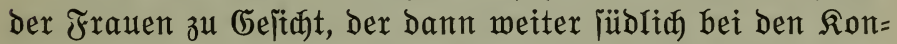
fombafrauen ganz allgemein mixd. J゙ jah bei einer Jrau

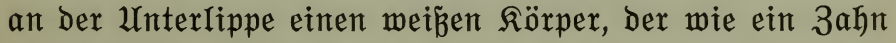
hervorragte. Ja dađte zuerit, der Frau jei wohl ein 3ahn auf $\mathfrak{A b m e g e ~ g e f o m m e n ~ u n d ~ D u r দ ~ d i e ~ L i p p e ~ h e r v o r g e m a n j e n . ~}$ 
Boll Mitgefühl faß̧te id den Rörper behutiam an, um wo=

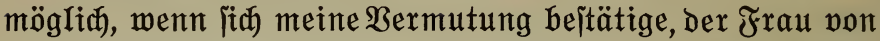
ber Entitellung zu helfen. Ş eritaunte aber nidt wenig, als mir ber permeintlidg perirrte $3 \mathfrak{a h n}$ in Den Fingern blieb.

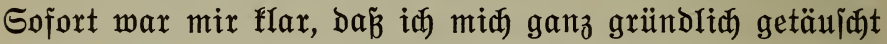
hatte. Bas mir als Berunjtaltung auffiel, bas war bei bem armen Beibe eine 3ierat. Der vermeintlidge 3ahn wax ein weiß̈ex, fegelförmig gelđliffener Stein, ber in ein

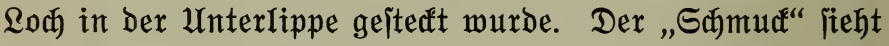
in ber Tat redgt eigenartig aus, und es würden woht now andere Leute als wix auf bie Meinung gefommen jein, bá es eine Berunitaltung jei. Wir jahen aber jpäter nod) andere Sađjen, bie uns eindrüatid den Sał ber alten Römer ins (5ebäbtnts riefen: de gustibus non est disputandum.

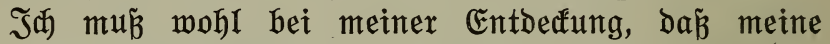
Diagnoje jo grundjalja war, ein recht exjtauntes Gejitht ge=

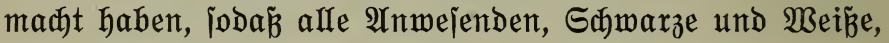

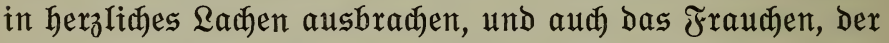
idf Den Stein (ळnellitens mit vielen Entiøuldigungen $\mathfrak{z}=$

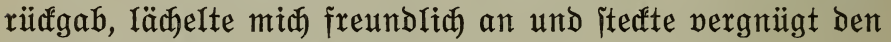
S(f)udf wieder an feinen Drt.

Rurz ehe wix Dapong erreţten, hörten wix won weitem taftmäß̈̈iges Rlopfen, das uns ganz an bas heimatlidhe Drejuen bes Getreides erinnerte. Bald jahen wix bent aud eine $\mathfrak{A} \mathfrak{n} \mathfrak{a} \mathfrak{h l}$ jüngerer und älterer $\mathfrak{L} e \mathfrak{t e}$, bie lange

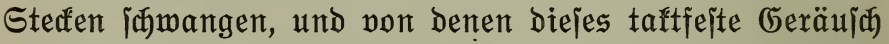
ausging. Wix fanden fie vor einem fleinen Runbhïttchen wirflich mit Drejळen won Rolbenfirje (Bentietum) be= ¡đäftigt. Sn Der fleinen, runden Siütte hatten fie die Ernte an Rorbenhirie untergebradt. Bor Dem Şäusdien wax ein runder $\mathfrak{P l a b}$ etwas ausgehöhlt und mit einem guten Rehmbelag veriehen, Dex hart geichlagen und mit $\mathfrak{D a}=$ mabawa behandelt eine vorzüglidhe Tenne abgab (2rbb. 41). Jeder ber Drejhenden war mit einem Blattitiel ber Fäđherpalme, Der für Den 3 weef etwas jugeridtet war, ver= 


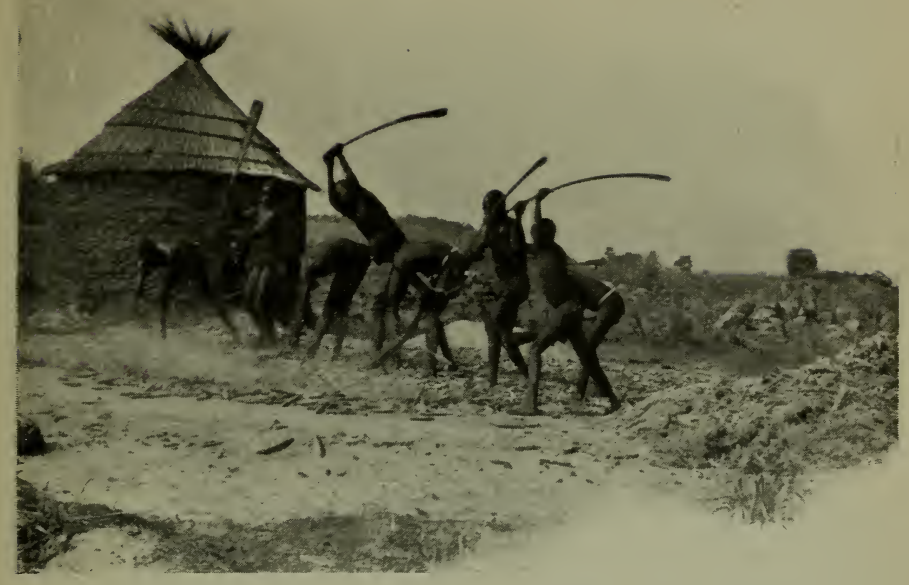

2(b6. 41. Dreschen von Kolbenbirse.

jehen, und damit orojøen ite mun im Iaft bie auf ber Tenne ausgebreiteten Rolben aus. Ein paar Jungen fehrten jobann mit Rimbenitüren die ausgebrojøene Sirje auj einen Şaufen und die leeren Rolben auf einen andern, während ein anderer in bas minzige Schlupflod bes Gpeidhers hineingefroden war und eine neue Lage Rolben Gerausjøaffte.

Rux nod eine furze Strede, und wir waren in Dapong. Der grof̉e Rajthof liegt am Ditabhang eines felifgen

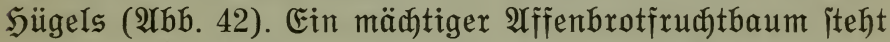

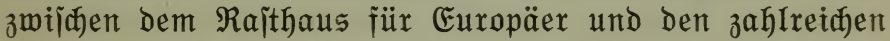
Runbhütten, in weldeit ein Goldat und etne ganze Rolonie mohammedanijaer Sändler wohnt. Unmittelbar hinter dem Rajthof exhebt fich Der Sügel, und von einer Felsplatte aus ijt Das Bild des Raithofs aufgenommen. Ditwärts jenft 
(iłd) Das Gelände zu einem breiten Tal, in weldhem zeritrent einige Gehöfte liegen.

Auf bem Sü̈gel über ber Station fanden wix eine groß̈e Fläade mit ausgepprodener Sdarattenbiloung. Das $\mathfrak{M a}=$ terial ijt weidjer, grauer Quarjianditein. SYuf ben Feljen wudfjen jefr itachelige Euphorbien, und unter ifnen lebten

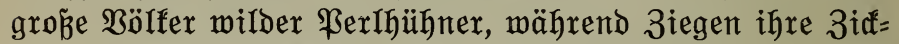
lein bort herumführten. Seden $\mathfrak{A}$ ugenblidf hörte man von irgendeiner Seite her das eigenfinnige Gemedter der fleinen Tiere, die bie Mutter aus den $\mathfrak{A}$ ugen verloren hatten.

Da wix hier in Moab feinen Jams befommen fonnten, io verjudften wix mit bem leidgt erfältlidfen Sirjemehl unjern Speijezettel etwas zu bereidern. Er hatte es jowiejo nötig, Denn unjere Rüde war jehr einförmig. Ein Berjuch, Sirjemebliuppe zu fochen, geriet herrlid, und aud der füx iolde Reuerungen am wenigiten Begeifterte fand ben $\mathfrak{b}_{e}=$ ¡đmad derielben jehr an Grünfernjuppe erinnernd. Weniger

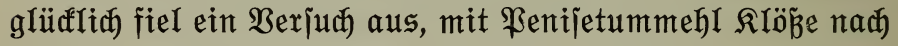

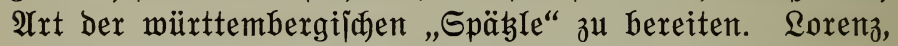
Der Rođ, madte zwar einen Ieig nadh bejtem Wiflen, aber ex fam uns ju troffen vor. Dann iønizelte ex mit viel Zeit= aufwand länglidłe, vierfantige Stǚfłen baraus und fodte

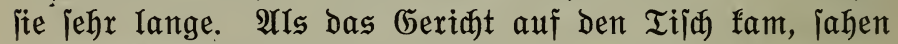
bie vierfantigen, $4-5 \mathrm{~cm}$ langen Dinger um fein 5 aar zarter aus als vor bem Rodhen und exinnerten lebhaft an groß̉e $\mathfrak{b o l}$ nägel, wie fie etwa von Sdhreinern gemadht und verwendet werben, um zwei Reijten im Binfel zulammen= zulezen. Mit vieliagender Miene enthielt fid benn aud ber Ronjernatine unter uns bes Genulfes biejes nagelneuen Geriats, und wir andern fanden bie "Sixiejpägle" aud reidglid hart und zähe. Damit endeten unjere Berjuðhe mit Sixjemehl, und wix überlafien es der fünftigen Mififions= frau, bie in Moab iđalten und walten wirb, weitere $\mathfrak{B e r}=$ juche anzuitellen. 


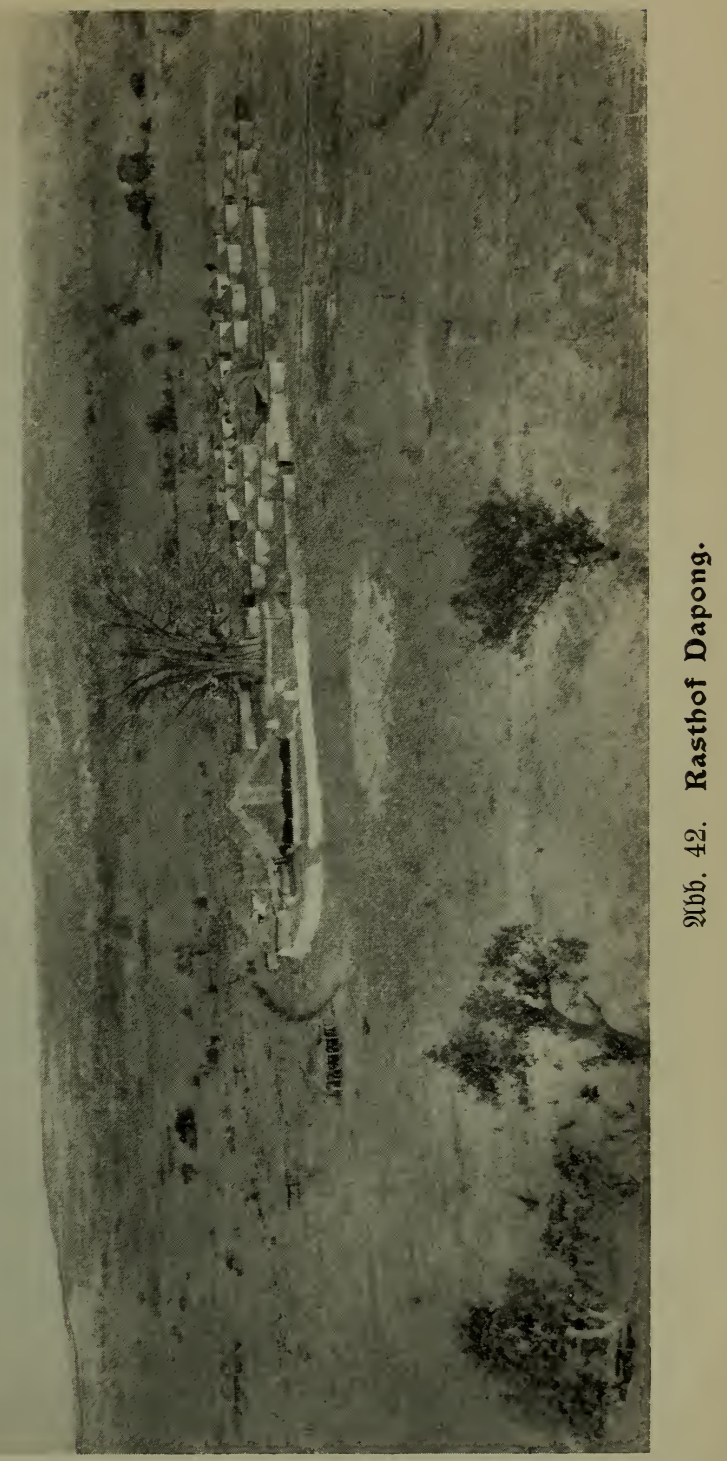


Im nädjten Tag zogen wir meiter jïðwärts, Dem Steil= abfall ber Sodjebene entgegen. Diejer hat an einer Stelle eine merfmürbige, breite Rüre, Durd bie man ebenen Fües nach $\mathfrak{B o g u}$ und Sanjanne Mangu gelangen fann. Wir zogen vor, Das öftlith von Bogu gelegene Bergland zu Durd)= jiehen und gingen über $\mathfrak{B a n a}$ nad Iongu. 13 Silometer

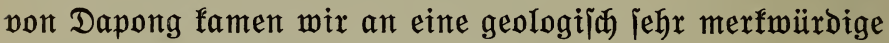
Stelle. Das Gelände fiel langiam năh Süden zu ab. Dex Beg nad $\mathfrak{B a n a}$ führte an eine lebr iteile Salde, die mit Mergeljaiefer bedecft war. Dieje iteile Salde won etma 70-80 Meter Söhe hinauf führt Der $\mathfrak{B e g}$ in bas Tal pon ßana.

Der itramme, freundidje Gohn Des Shäuptlings von ßana war uns weit entgegengeritten und begleitete uns bis an bie Mergelhalde. Sier famen uns eine $\mathfrak{A n} z \mathfrak{a} \mathfrak{l} \mathfrak{l}$ Leute von Bana herunter zu Silfe und jaboben und trugen unjere Räber mit groß̧er Bereitmilligfeit ben iteilen $\mathfrak{B}$ eg hinauf. Dben angelangt, veritärfte fiđd ber Eindrud ber eigen= artigen Formation des Eeländes. Das Tal hört ganz plöglid auf und fällt fajt jenfred

In bem furzen, ziemlich iteil anjteigenden Täldaen liegen bie Gehöfte der Reute von \$ana zeritreut. Spuren von Kunititnn fand man nidbt ielten. Die Berzierungen find mit einem ipijen Gegenjtand in Den Lehm gerigt und mit Rohle nadrgezogen. Wenn aud bie Gehöfte jehr flein waren, io waren fie boch jauber, und aud bie $\mathfrak{B e}=$ mohner madten einen jehr inmpathifhen Eindrud. Fait

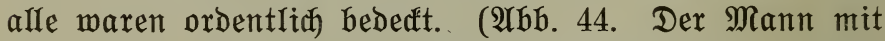
Dem grauen Bart in ber. Mitte ift Der Säuptling, hinter ihm iteht jein Gohn.)

In $\mathfrak{P a n a}$ iahen wir zum eritenmal, wie im gebirgigen Teil von Moab jebes einigermaß̈en vermenঠbare Land be= baut wirb. $\mathfrak{U} \mathrm{m}$ Plag $\mathfrak{z} \mathfrak{u}$ iparen und wohl audf, um bie Sirje vor $\Re$ atten zu fidhern, werden bie fleinen Sirjejpeidher auf Felsblöaten erbaut. Sier fanden wir wieder eine andere 


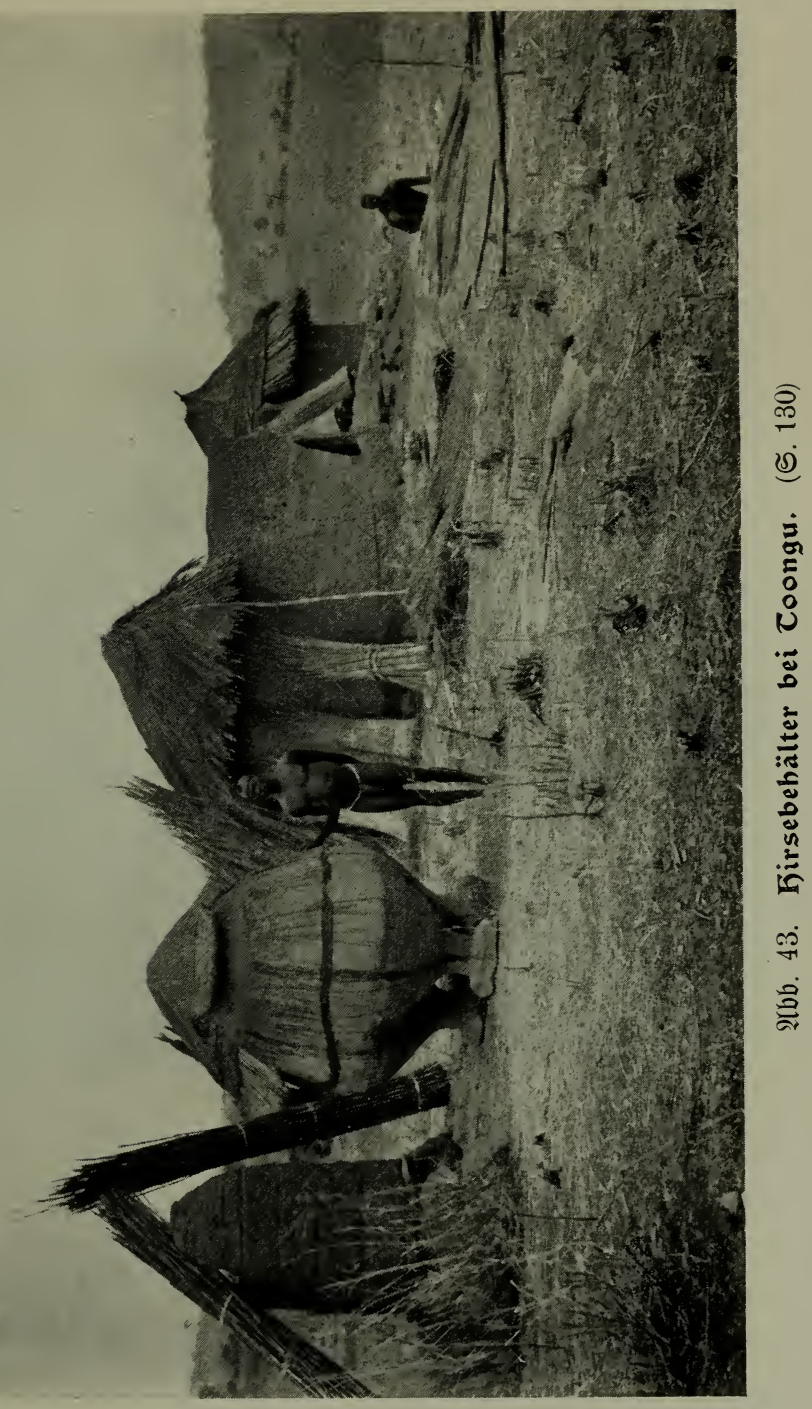





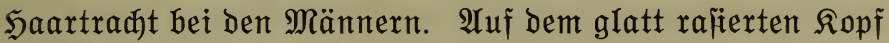
Ialien viele eine Iniel 5 aare ïber und hinter bem redten oder linfen Dhre itehen; andere rafieren bas Saar jo, Dá̉

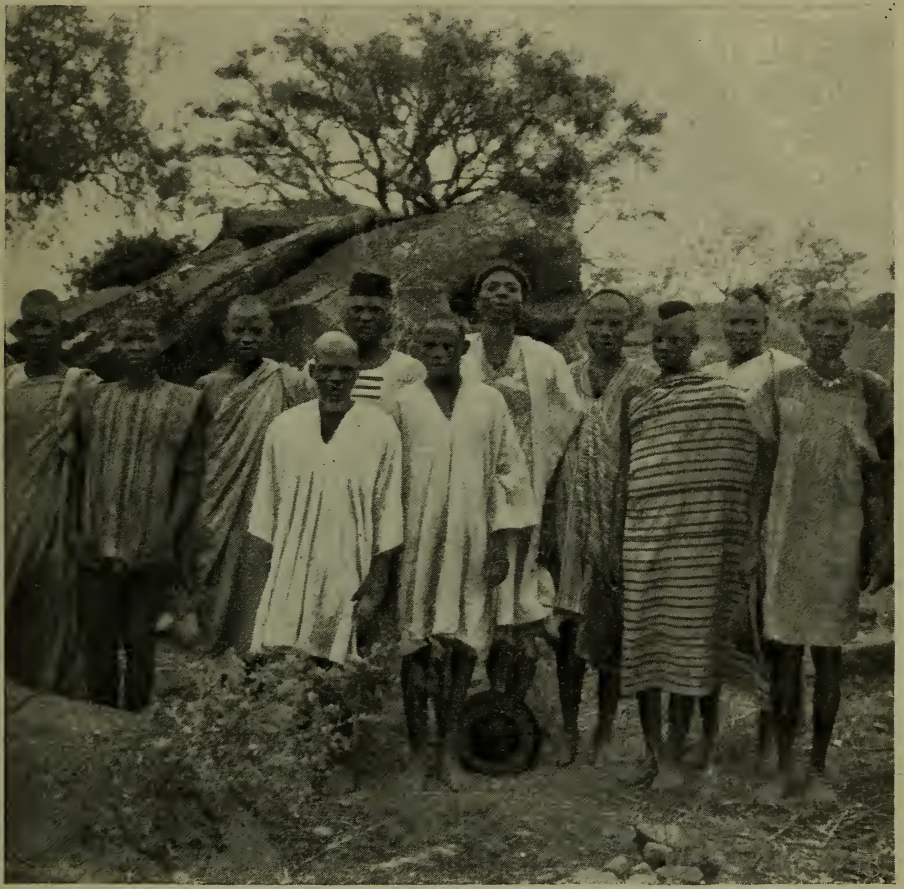

\{bb. 44. Einwohner von Pana.

ein breiter Streifen über bem Sđeitel unb Sinterfopf übrig= gelalien wird.

Jedermann wetteiferte, uns beim Transport unirer Räber behilffich zu jein. Sorgiam hoben Borausgehende Iole Steine aus dem $\mathfrak{B e g}$, bamit wir ober bie Räber ja nicht anjitieß̈en. Der Weg führte über eine Sodjebene, und bald 


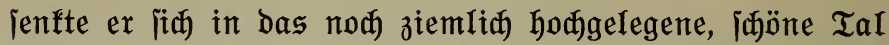
von Toongu (nad) bem eriten furzen o wie in Dfen fommt ein zweites längeres $\mathfrak{o}$ wie in offen). Einige Stellen bes Beges erinnern ganz an Gegenden in Den Borbergen bes Jura. Bürben itatt ber Gehöfte aus $\mathfrak{R u n d h u ̈ t t e n ~ B a u e r n = ~}$

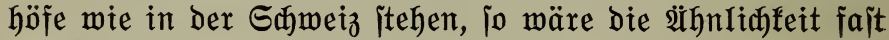
vollfommen.

Das Ial von Toongu iit reizend; es ijt etwa 2 Kilo= meter breit. 3u beiden Geiten begrenzen es 50-60 Meter hohe, iteile, felfige Sïgel. Gehöfte fitnd in groß̈er $3 a \mathfrak{h l}$ ïber das ganze Ial zeritreut. 3wij̄an ben Sügeln, bie bas Tal begrenzen, liegen fleine, ittlle Seitentäldhen, ïberall nette, iaubere Gehöfte. Sdjöne, hohe Fä̈herpalmen find im ganzen Ial fajt gleiđmäß̈ig verteilt und verleigen ber Lambīdaft einen eigenartigen $\Re e i z$.

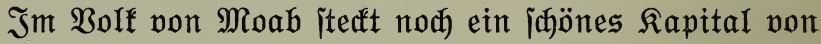
Geịilibeit und Rraft. Die Mobajünglinge find jum gröpten Teil wahre Bradytgeitalten. Wenn man ite io elaitiifh und itolz burd ifr Tal idreiten fiebt, auf ber Edhulter die als Baffe und $\mathfrak{B e r} \mathfrak{f}_{z}$ eug dienende $\mathfrak{H}$ affe ober Das Beil mit bem blinfenden, iđarjen Eijen, in ber redten Sand Pfeil und Bogen, um Stirn, Dber $=$ und 2 lnter= arme und über Dem Fußjgelenf breite, hellgelbe Bänder von Fäđerpalmblatt, jo Iadyt einem bas $\mathfrak{H e r}_{\mathfrak{z}}$ ïber dieje Bilder

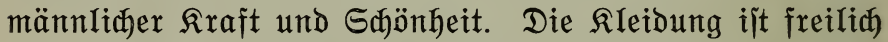
bas wenigite an ifnen, aber ihre wohlgepflegte, iđnarz= braune Saut bient als Deffe.

Ulles Land ijt aufs jorgfältigite angebaut, und bei jebem (5ehöft iteht benn aud mindejtens ein grö̈er, urnen= förmiger Sirrebehälter auf Drei Fü̈̈еn. Der eine, in

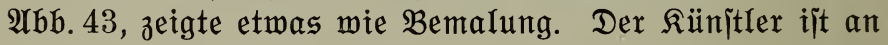
ber $\mathfrak{A}$ rbeit, bas zerfallene väterlidhe (5ehöft wieber in Stand zu leben und hat mit diejer $\mathfrak{U}$ rne Den $\mathfrak{A n f a n g}$ gemadt. Da= neben itehen Bündel von Sirjejtengeln für Das Dađ, und fein Bruder orbnet bas Gras zum Decfen bes Daches. 
Die Leute pon Ioongu erridteten uns unter zmei groß̈en Tamarinden unjere Grashütten, aber ber Berjuð, den Rranfen bes Ials Silfe zu bringen, falug wieder fehl. Uuđ mein $\mathfrak{A n e r b i e t e n , ~ M e d i z i n ~ u n e n t g e l t l i c ~ a b z u g e b e n , ~}$ murbe abgelehnt mit bem Bejđeid: Es gibt feine Rranfen hier.

Im näđjten Morgen zogen wix nad̆ unjerm legten Rajtplał bei ben Moba, nach) Bogu. (Der Ronjonant $g$ wird pon Den Moba meijt als (5uttural (Bod)u) aus= geiprodien.) Der Weg führte Durch ein furzes Geitental und Dann iteil über den felfigen $\mathfrak{U b h a n g ~ i n ~ b i e ~ S ̧ o ̈ h e . ~ D i e ~}$

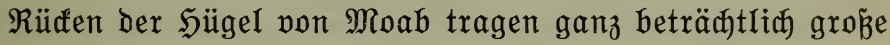

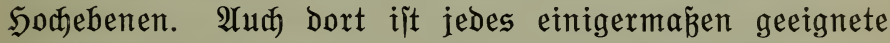
Stüđđgen Land bebaut, und man triff̈t überall, wenn aud in etwas meiterer Entjernung voneinander, Gehöfte.

Auf diejer Sochebene fanden roix auf flachen ober leidt geneigten Jelsplatten eigentümliche Biloungen, bie uns an die befannten Gletichermiiflen erinnerten. Es find an= nähernd runde $\mathfrak{D}$ ö Dft i it unterhalb der obern D̈ffnung Der Durđmeller grö̈̈er. Die \&öđer haben eine Tiefe von $60 \mathrm{~cm}$ bis nahezu ein Meter. Die Wandungen find rund, wie abgejđliffen. Bei

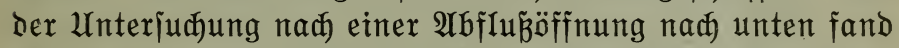
id in einem der Söळer eine fleine Gdildfröte, die, fobald fie herausgenommen mar, ¡đnellitens bas Weite judte, und baneben eine fleine, jøön gefledte Salange. Leider

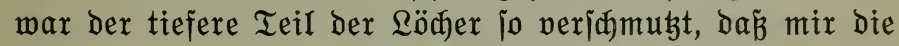
meitere Unterjud,ung beim Mangel an 3eit nidbt mehr

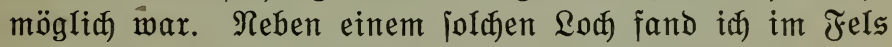
eine fait freisrunde Einjprengung von Eijenfonglomerat.

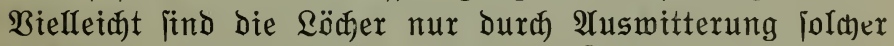
weicherer Einiprengungen entitanden. 3ur Entitebung

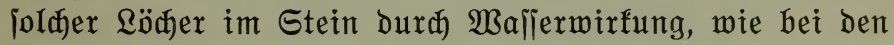
Gletjhermïhlen, fehlte jheinbar die Borbedingung, ein Strom von Wajier, der mit einiger Gemalt burd freijende 
Bewegung mit Sillfe von härtern Steinen foldhe Bildungen zuitambe bringen fann. Die Lage ber Felsplatten, in weldyen wir joldje Bildungen antrafen, war nidyt berart,

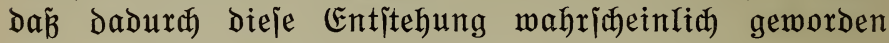
wäre.

Bon ber Sodbebene itiegen wir wieber in ein weites,

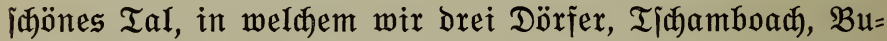
loch und 3 ung, antrafen, b. h. es waren im weiten Talfeflel eine Menge Gehöite zeritreut, und nur Einheimila fone fonten uns jagen, wo bie einzelnen Dörfer anfingen und auf= hörten.

Bei Dem Dorfe 3ung famen wix an etrer Begräbnis= itätte im freien felo norbei ( $\mathfrak{H b b}$. 45). Regellos Iagen auf fleinen Erohaufen irdene Töpfe, wie fie bie Moba zum Ballerholen benïgen. Wrlle hatten mehrere iðarfe, mit ben

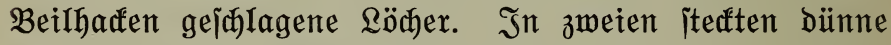
Baumitämmđjen. Bei einem Iopf war eine bünne Stein= platte in ben Boden gejtedt. Wix erfuhren, da bie Moba inre Toten fitzend begraben. $\mathfrak{A n}$ ber Stelle, wo ber Ropf ber Leidje unter bem Boben liegt, wirb ein folder Topf hin= gelegt und mit ber Beilhadfe einige \&örher hineingeid)lagen. Die Moba haben, wie wir hörten, die Boritellung, da

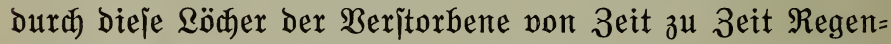
wajier zu trinfen befomme. Mit mebmütigen Gedanfen werließzen wir dies Iotenfeld. Sind nidyt wir baxan Safuld, Dá̉ Denen, die Da begraben liegen, bas herrliche, trojtreidje Enangelium nidyt verfündigt werden fonnte? In Gottes ewiger (5nade liegt freilid aud Irojt bei jolden Gebanfen, aber nun gilt es, bie 3eit zu benüben, jonjt werden bie itillen Totenfelder bex mun offen itebenden Sänder uns ïberlaut anflagen wegen unirer Bequemlidfeit und unires Rleinglaubens.

Bon 3ung führte der $\mathfrak{B e g}$ in ein furzes Geitental an iteilem, felfigem Sang hinauf wieder auf eine Sodebene, 


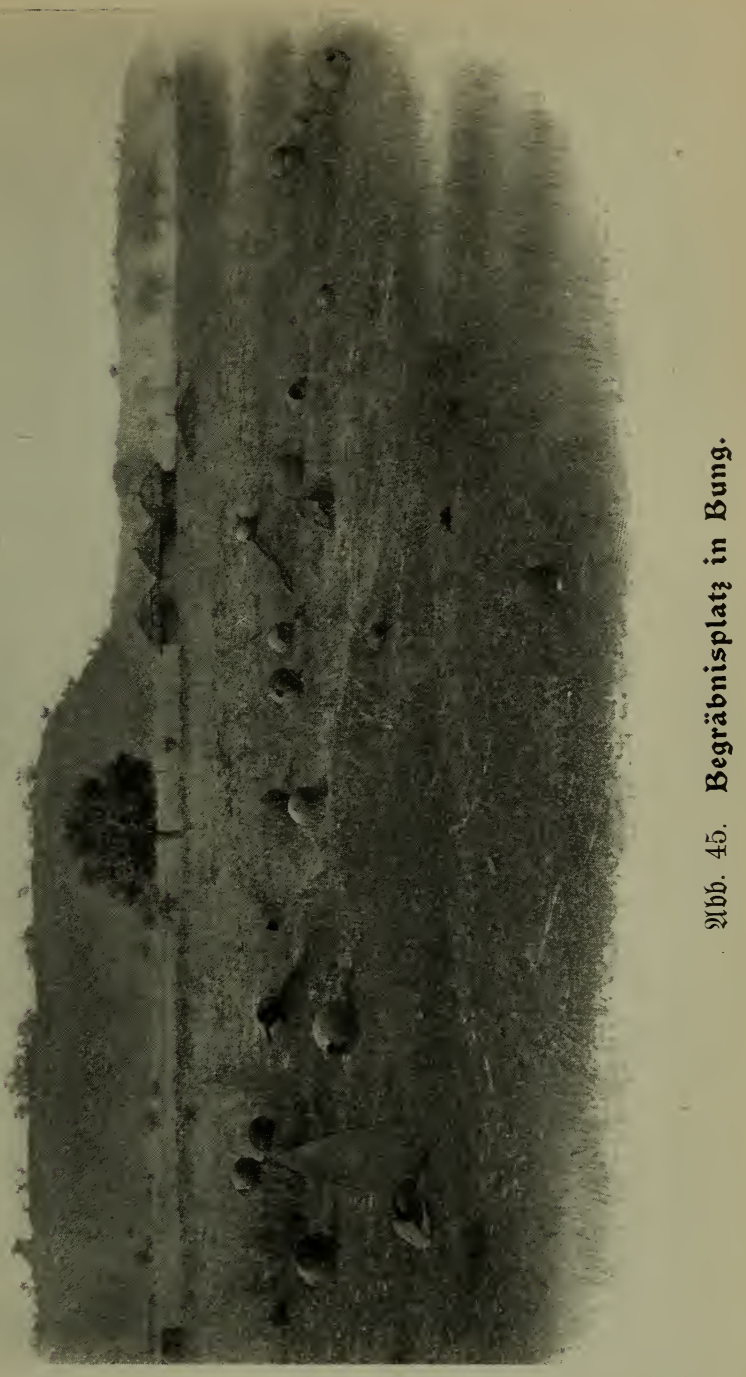


auf ber bie fehr zeritreuten (behöfte von Randod liegen; bann geht ber Beg hinunter in Das weite Tal von Bogu (Bod)u). Das Tal ijt itreçenweije mehr als 4 Rilometer breit; bei Bogu iit bie iđmalite Stelle, und ein gewaltiger, teilweije itarf ïberhängender frels won wohl 70-80 Meter Söhe ipringt ins $\mathfrak{I a l}$ vor. Bogu bejift ein jü̈nes, ge= räumiges $\mathfrak{R a}$ [thaus mitten in einer $\mathfrak{P f l a n z u n g}$ won Mango= bäumen und in weiterer $\mathfrak{U}$ mgebung won Färherpalmen, die gerabe anfingen, iłre eriten Blätter zu zeigen. Ein paar frijđgrüne Remoneniträudher (eine fleine 3itronenart) er= freuten uns bejonders als liebe alte Befannte pon ber Goldo= fuijte her. Der Şäuptling von Bogu itellte uns jeine Söhne, gemaltig musfulöle Jünglinge, zu etwaigen Dienitleijtungen zur Berfügung. Er ijt ein jehr intelfigenter, ausnehmend freundlider, angenebmer Mann. Saranfe befam ida aber aud bier nidyt zur Behandlung.

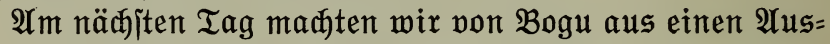
flug in bas weitlid bavon gelegene Bergland won Moab. $\mathfrak{A} \mathfrak{i f}$ iteilen, felfigen Begen ging es wieber auf eine $\mathfrak{W}$ od $=$ ebene hinauf. Die fladhen Sanditeine lagen in jo reidh=

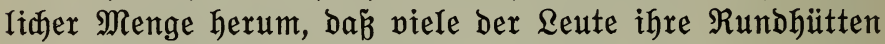
und Siriejpeidyer mit jolden Steinen itatt mit bem

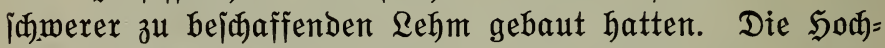
ebene ijt nadh Weiten nahezu 6 Rilometer lang. Dann führt Der $\mathfrak{B e g}$ wieder ins Ial. Da waren nun grö̈ere Etredfen ohne Gehöft. In Dem Dorf Siluboad raiteten wir unter einem breiten Jeigenbaum. (5anz in ber Rähe war ein jönnes, jehr jauber gebautes Gehöft. Es war eine leidfte $\mathfrak{Y}$ ufgabe, mid mit dem Sausbejiger anzu= freunden. Er führte mid in jeinem Gehöfte herum. Es ijt ein (ehr darafterijtijđes Mobabaumerf, Das aus jieben

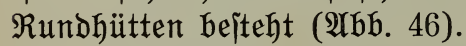

Dex $\mathfrak{A}$ usflug führte uns bis nad $\mathfrak{B a f o h o s , ~ e t w a ~} 12$ Silometer von $\mathfrak{B}$ ogu entfernt. Der Sä̈uptling von $\mathfrak{B a}=$ fohos nahm uns jehr freundidi auf, baute uns eine iđjöne 


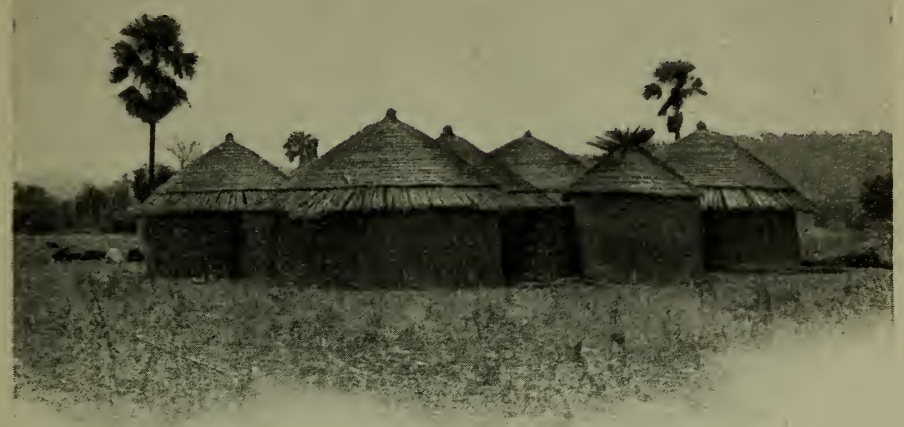

2(bb. 46. Gehöft in siluboach.

Grashütte und zeigte jeinen Gäjten jeine Frertigfeit im

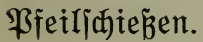

Ein furzer $\mathfrak{A}$ usflug brachte mixh nod an die Stelle, mo iich bas merfmürdige Tal von Bogu gegen Norben in die weite Ebene öffnet. Während bei Bogu bas Ial nur etma

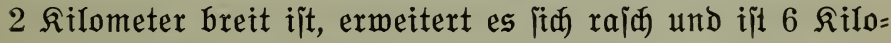
meter nördich pon Bogu, an ber Stelle, wo es in bie Ebene übergeht, reid)lich 6 rilometer breit. 3u beiden Seiten itehen wie gewaltige Bäßter jenfredte Jelswände auf Der Söhe ber S̆̈̈gel und iđauen meit hinaus in bie unabjebbare Ebene im Norben.

Dá̉ die Moba jebr gern rauden, merft man bald, wenn man unter ihnen weilt. Es fiebt gar gemütlich aus, menn die Männer baherfommen: auf der reaten Gđulter

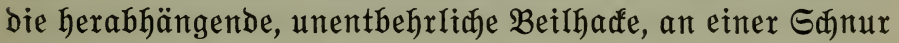
über ber Brult oder auf der Iinfen Sđulter die Iajhe mit Tabaf, auf Dem Rüđen ein flatterndes Shaffell als beinahe einziges $\Re$ leibungs|tüđ, im Mund eine $60-80 \mathrm{~cm}$ lange 
Pfeife, an ber gewaltig gejogen wirb, und wobei ber Samaudhende fajt bei jebem zmeiten Shritt eine Raud)= wolfe vor fiđ her bläpt.

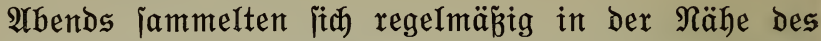
Rajthofes auf etlidhen Bäumen groß̉e Sđjaren won weiß̈en Reihern und flapperten ihx weithin hörbares Salaflied. Bei Tage liefen fie unter weibenden Gdhafen und Rindern herum und fingen ihnen bie Friegen weg.

Sebr interellant war es, wenn bie Jungmannidaft

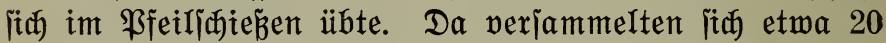

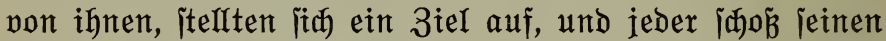
Pfeil barauf ab. Jeder Treffer gab zulautem Iubel $\mathfrak{A} \mathfrak{n}=$ Ia $\tilde{b}$. Solange wir unter ben Moba reijten, hörten wir nie wiijten Rađtlärm, weber Streit nod 3anf. Wir befamen

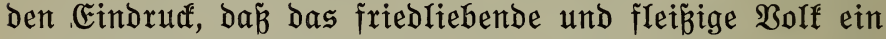
jiemlith ruhiges $\mathfrak{L e b e n}$ führt. Die $3 a \mathfrak{l}$ des Bolfes darf aber nicht mehx jehr wadjen, denn bas Land ijt nahe an ber Grenze leiner Leiftungsfäbigfeit. Freilid liegt im ebenen Teil won Moab, nördida bes Berglandes, nod

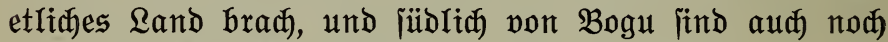
jehr grop̉e Etreften unbebaut; aber es expheint bei ben

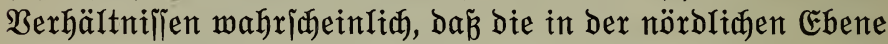
lebenden Moba ichon âsgewanderte find. Sie werben nidbt ohne Not ihr iøönes Bergland verlaflen haben, in weldjem fie aud por feindidien 2 ngriffen fitherer waren als in ber Ebene. Einer 9 uswanderung nad GïDen itand entgegen: exitens ber feindjelige Charafter ber bort moh= nenden Tiffofoji, bie aus riante itammen und mit jeber= mann in ewiger febde lebten, und wohl aud ber unfrudt= barere Boben ber junädyit jüblid gelegenen Ränderitreffen.

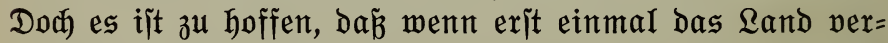
nünftiger bebaut wird, es nod längere Zeit aud eine nod) diđtere Bevölferung zu ernähren vermögen werbe. Es

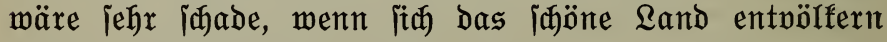
würbe. Die Bemïhungen dex Regierung, die Biehzuht zu 
heben, find aud im Interefie ber 3ufunft ber Moba von grö̈̈ter Biđtigfeit.

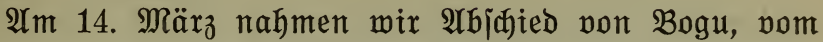
iajönen Lande Moab und bon ber uns lieb gewordenen Bevölferung. Dá̉ bođ bald bie Zeit fomme, in welder bie Boten bes ewigen Seils eintiehen in bies Rand, und Gottes wahres Sidht in jeiner Serrlidffeit aufgehen fann über bem Bolf, bas nod jegt im Finjtern wandelt!

Je mehr wir uns Sanjanne Mangu näherten, dejto öber wurbe bie Gegend. Die Iifften $\mathfrak{L}$ aubwälder, in denen es von Perlhiihnern wimmelte, waren längit ver=

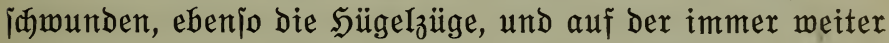
fïb ausbreitenden Ebene war faum mehr ein Baum zu jehen. In einer jolden Ebene liegt Ganjanne Mangu. Der Rame bedeutet Rriegslager bes Mangu, und erinnert an bie 3eiten, in weldyen bie hier wohnenden $\mathfrak{I}\{$ do of o i $i$ mit allen fie umgebenden Stämmen auf bem Rriegsfú Iebten. Dieje Iโđofoji jind uriprünglid arjanteer, die einjt von einem 2rjantefönig auf eine friegerijace Expedition nadj dem Norben geidift wurben. Sie vertrieben bie Leute von $D a=$ boya, wurben bann aber von einem Rönig ber Dagomba befiegt. Sie zogen Darauf hin an ihren jegigen Wohnity

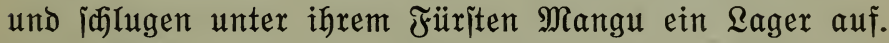
Die Tiøofoli (auch oft Diafoli geidrieben) beziffern fith nad) Sauptmann Mellins 3ähIung auf rund 18500 Men=

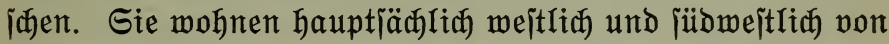
Mangu. Diejes ijt ber Sib ihres Rönigs. J⿹he Spradhe ift ein mit vielen fremben $\mathfrak{B o ̈ r t e r n}$ verjegtes und burch andere Spradjen verändertes T\{đji. Gört man jie in einiger Entfernung miteinander reden, io glaubt man, fie reden ridatiges Ijđi, bört man aber genauer hin, io merft man

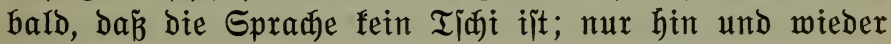
fommt ein mehr oder weniger entitelltes Tiđhimort barin vor. Rurze Rebensarten, wie etwa: Wie heißjt bu? (5ib mir $\mathfrak{B a} \mid l e r$ zu trinfen! find nod) am ehejten veritändich. 
Es wird feine ganz leiđte $\mathfrak{A} u \mathfrak{f g a b e}$ jein zu entiðeiben, mit was für einer Sprade unter den Tidofofi gearbeitet werden folle. Die Mijhjpradje, bie fie jegt iprednen, fann man nidgt zur Gdriftipradge erheben, abgejehen von ber

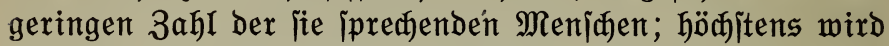
vielleidyt ber bort fünftig arbeitende Miffionar, wenn er von früher eine gute Renntnis bes Ijøi befigt, es auf fith nebmen, jur Beeinflufiung bes Einzelnen und um das Bertrauen des Bolfs zu geminnen, ihre Spradje zu er= Iernen.

In Sanjanne Mangu idjeint der $\mathfrak{s}$ lam bereits einen groß̉en Einfluź erlangt 孔u haben, und das bürfte wohl als eine weitere Eriønerung Der $\mathfrak{A}$ rbeit unter Dem fleitren Bolfsptamm in Betradht fommen. Diejer $\mathfrak{U}$ mitand fällt bei

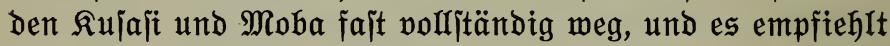
(iid) ifon barum bie baldige Jnangriffnahme ber 2 rabeit unter jenen Stämmen. Was Den Stammescharafter ber

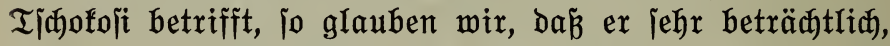
und zwar $\mathfrak{z}^{\mathfrak{u}} \mathfrak{U}$ nguniten von bem der Moba abweidyt. Es ijt Das nidft ju verwundern, benn ein $\mathfrak{B o l k}$, Das leit Meniđhenaltern mit allen $\mathfrak{R a d} b a r n$ in bejtändigem Streit gelebt hat und fid badurd etmas von ber $\mathfrak{A r t}$ eines $\Re a u b=$ tiers angemöhnt hat, wirb niđht jehr liebenswürbig er= idgeinen. Nod jegt fommt es vor, objhon bie beutide $R e=$ gierung ein iđarfes $\mathfrak{A}$ uge barauf ridtet, bá ein fauler Tidofofit, went er Sunger hat, nad Moab hinaufgeht und fich bei einem der gutmütigen Moba ofne weiteres für Bodjen und Monate einquartiert und ein riditiges Sama= roberleben führt, bis ber gute Moba ausgegelfen ijt. Wenn bas jegt nod worfommt, in ber 3eit, in weldyer ein foldher

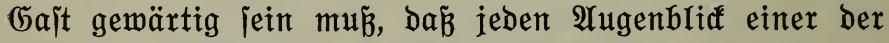
wadjamen Polizijten ihn verhaftet und nadj Mangu $\mathfrak{a} b=$ liefert, wie wirb es bamals gewejen jein, als nod alle

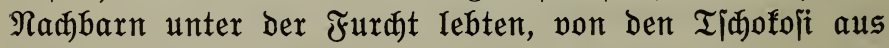

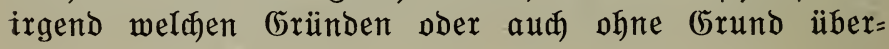


fallen und ausge= raubt zu werben! Das ijt aud, wie wix vom Bezirfs= leiter exfuhren, der Grund, warum die Gegend um Mangu jo öbe und baumlos ijt. Die Ijabloji jelber waren eben aud nie ficher, das fie von ifren zahlreichen Jeinden überfallen murben. $\mathfrak{u m}$ joldse unerwarteten über = fälle zu eridweren, hieben jie alle Bäume, die ben heraniclei= chenden Jeinden als Dectung hätten bie= nen fönnen, im wei= ten Umfreis herum ab. $\mathfrak{A}$ úper in Mangu jelbit wohnen die Ijobofoji in fleinen Dörfern bis in die Gegend von Djere= poni. Man judyt da vergebens nad) jold iđmuden Gehöften wie in Moab, alles îteht verfommen und unjauber aus, wie es Dem Charafter Des Bolfes entipridyt.

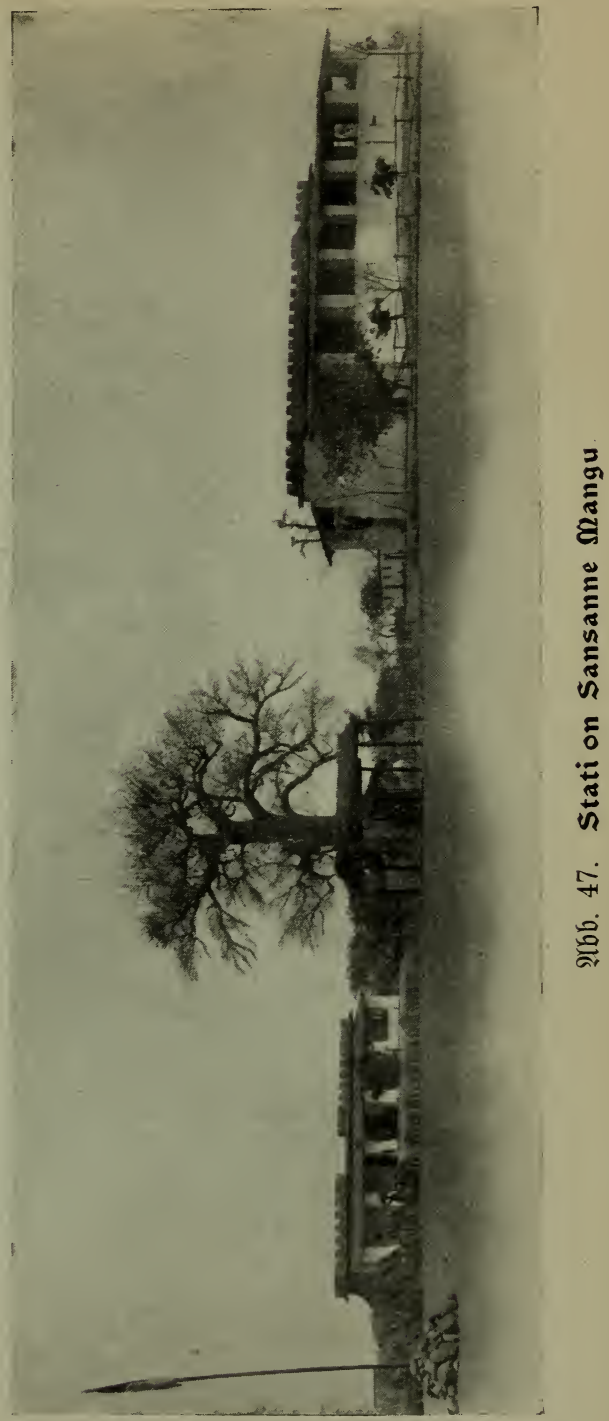


Das Bezirf́samt Ganjanne Mangu mant einen vor=

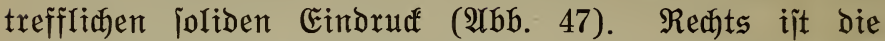
Dienitmohnung bes Bezirfsleiters, ein majifiger $\mathfrak{B a u}$ mit gemaltig bicfen Lehmmauern, mit bretter füblicher und etmas (đ)malerer nörblidjer Beranda und flachem Dađ, das von diffen Lehmpfeilern getragen wirb. Dbjăon das Daa) aus geipaltenen Jä̋rexpalmitämmen jehr jolide gearbeitet

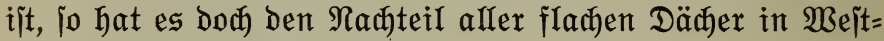

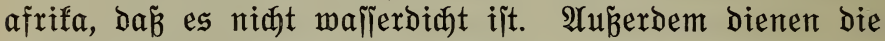

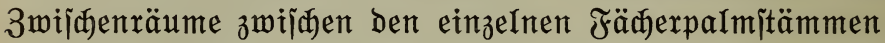
unzähligen fleinen Jledermäulen als Nijtplał, mas manḑe unangenehmen Folgen füx die menjकlidhen Bewohner eines jolden Saujes mit fiđ bringt. Etwas nördich won biejem Gebäude iteht die Dienitwohnung für Den Stationsleiter. Sie ijt im gleiden foliben, fait maifigen Stil gebaut, wie das größere Gebäude; nur fehlt ihm ber 3 Meter hohe Unterbau.

Der Bezirfsleiter, Serr von ßarpart, erwies uns jehr viel Freund lidfeit und beherbergte und verpflegte uns mit groß̉er Riebenswürbigfeit, jobá̉ wix die Tage in Sanjanne Mangu zu unjern jø̈̈njten Reijeerinnerungen zählen, ob=

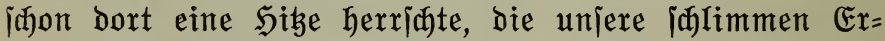
fahrungen, die wix in Rratiani mit ber Sike gemadht hatten, nodj übertraf. 3war gibt es in und um Mangu feine Sijeipeider wie in Rratiði, benn es liegt weit und breit um Mangu fein Fels zutage, aber ber fehlende Baummuds jebt das ganze Land fanonungslos der Sonnenbejtrahlung aus, und die Winde, die über diejen erfigten Boden hin=

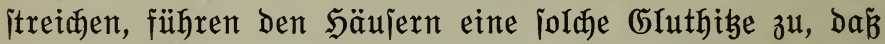

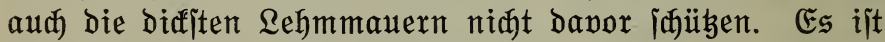
barum ein jehr zu begrü̈endes Unternehmen Der Regie= rung, dá̉ fie dem Baummangel Dura Arnpflanzung von Nubhölzern abzuhelfen juðt. S్xerx von ßaxpart hatte die (5ïte, uns in diejen Bflanzungen herumzuführen. Die Bflanzungen itanden zu unirer Berwunderung trob ber 


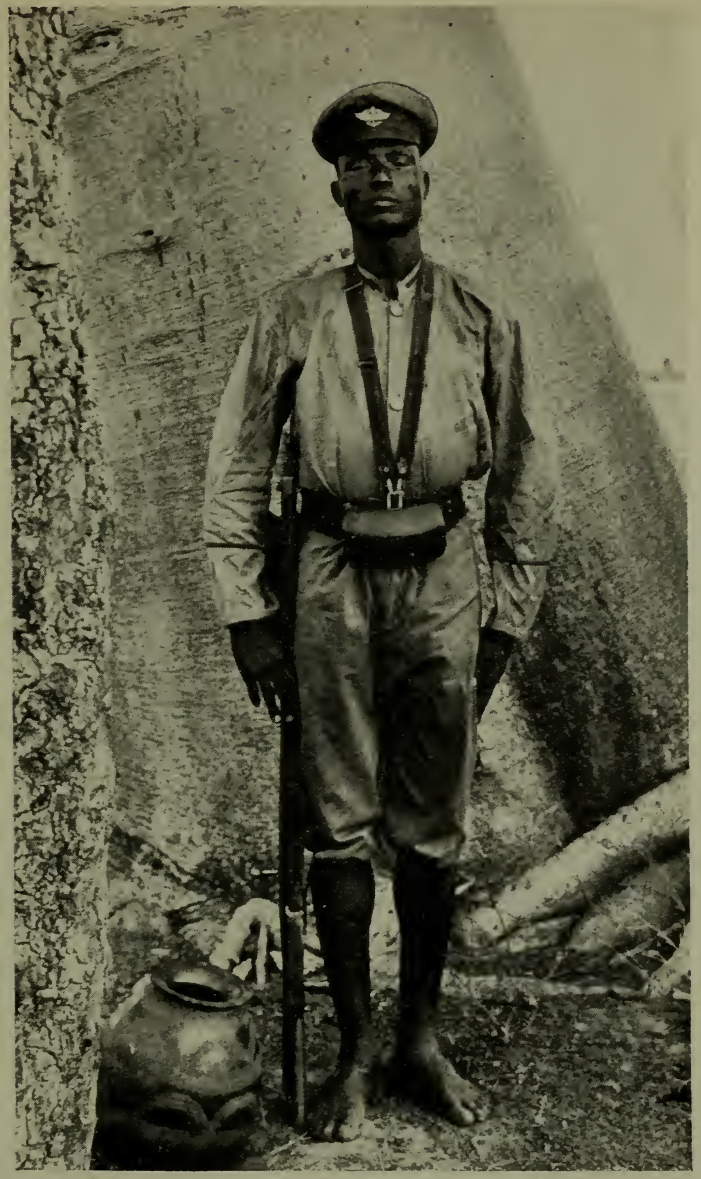

2łbb. 48. anser Begleiter. 
grop̈en Sije und Troďenheit zum Teil ausgezeidnet. Es find ungefähr 270 Seftar $\mathfrak{L a n d}$ mit Teaf, Doum, Bapao, Mahagoni, D̈Ipalmen, Kapod und andern wertoollen $\mathfrak{M u b}=$ bäumen bepflanzt. Beldye Zierbe für Mangu wird bieje Bflanzung in etwa 10-20 Jahren fein, und weldyen ganz bebeutenden Wert werden dann die Bäume repräjentieren

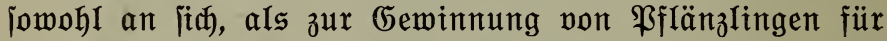

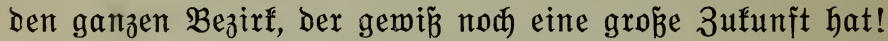

Die 180 Soldaten ber idwarzen S(hugtruppe jahen wir täglid beim Exergieren und hatten unjere Freube an ben itrammen Qeuten. Einer Derielben wurbe uns zugeteilt, um uns bis Bajari zu begleiten, ein anderer war unjer Begleiter von $\mathfrak{B u n f p a r i n e}$ bis Mangu. Beide haben fith ausgezeidnet gehalten. UUnjer Begleiter bis Bajari barf fich Darum wohl in ganzer (5rö̈ße in $\mathfrak{H b h} .48$ woritellen. भud das Maintnengemehr legte uns zu Ërren eine Brobe ab, mozu die Bornehmen der Stadt eingeladen wurben. Sherr von Barpart itand im weí̉en Tropenhelm und Tropenanzug in ber Nähe. Aủer Dem itrammen Ererzieren hatten wir aud Gelegenheit, eine $\mathfrak{B r o b e}$ ber Ireffituerheit ber Goldaten zu jehen. Einer berjelben wurde mit adyt ßatronen verjehen mit jeinem Dienjtgewehr

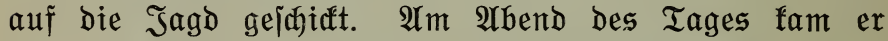
wieder und meldete, er habe eine groß̉e Ruhantilope und zwei fleinere ge[dollen; jodann habe er nod einen erlegt. Bier Patronen bradfte er wieder zurïá. Der Ud ler war ein gemaltiges Tier won fait 3 Meter Spann=

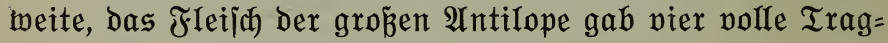
Initen.

Bie widhtig für bie 3ufunft bes Randes bie Sebung

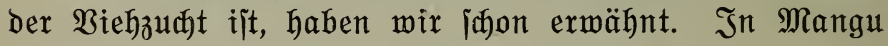
wird bies in erfreulidher Beije erfannt. Es werben won ausgejuhten Tieren Zuchtodjen gezogen und im ganzen Bezirf herum verteilt. Daneben herridgt itramme 3udit und Dromung, und ein Befehl wird nidht wiederholt. Die 


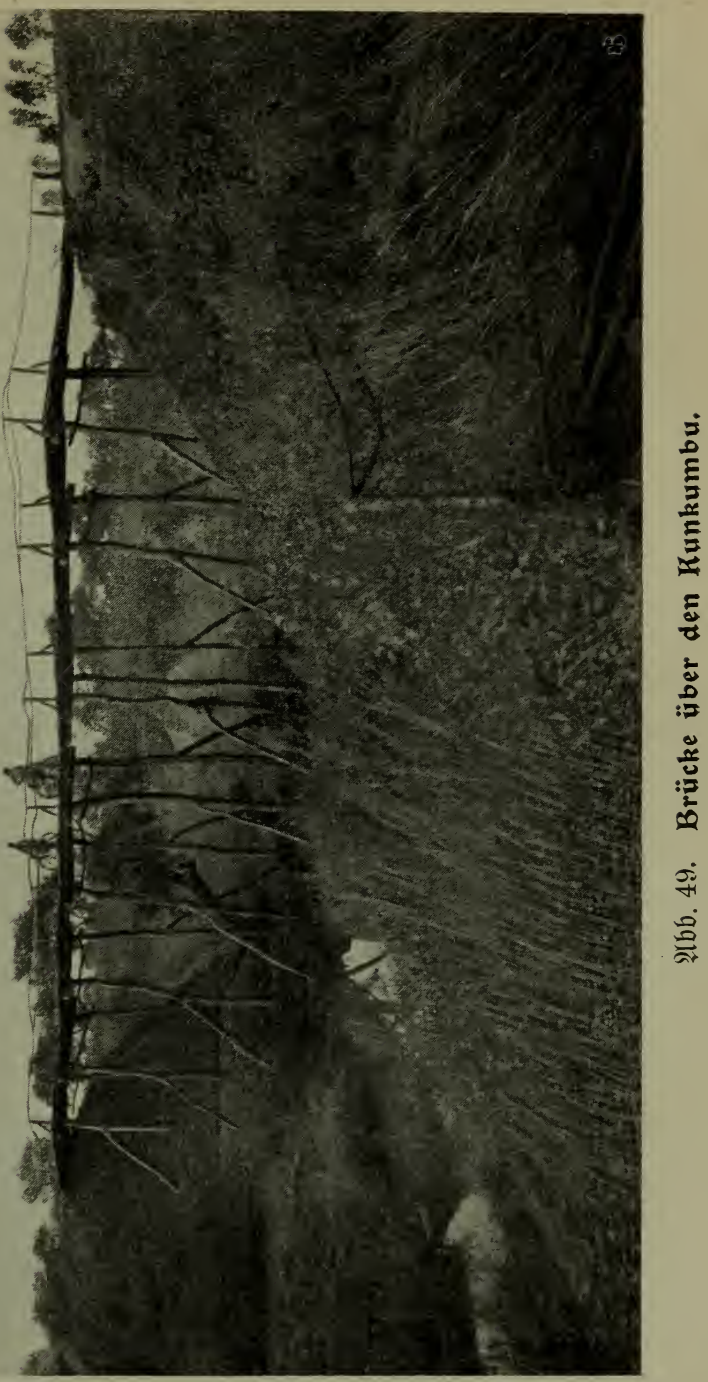


Beiळaffiung von Trägern geitaltete (iં Denn aud jehr ein= jăb. Die Säuptlinge hatten ben Befehl erhalten, um bie beitimmte Stunde io und jo viel Träger bereit zu halten.

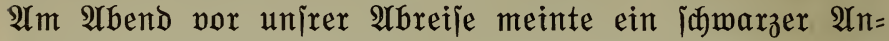
geitellter, es jei za befürdhten, bá bie Träger nidht zux be= itimmten Stunde bereit feien, ob ex nicht den Şäuptlingen nodymals den Befehl jur Stelfung Der Träger übermitteln jolle. Er wurbe aber furzer Sand abgemiejen mit dem Beideid, man jei nidht gewohnt, zweimal zu bejehlen. Berbe der einmalige Befehl nidht ausgeführt, jo mü̈ten ja bie Şäuptringe, was bas auf fid habe. Zur bejtimmten Zeit fehlte benn aud fein Mann.

Bei allem itrengen Regiment ijt ber $\mathfrak{B e r f e h r}$ Der

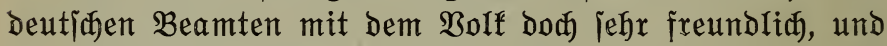
Der günitige Einfịluß eines joldhen Regiments ijt Denn aud) nidgt ju verfenten, bejonders nidgt, wenn man vorher bas unangenehme Berhalten vieler Eingeborenen unter anderm Regiment [amerzlid empfunden hat.

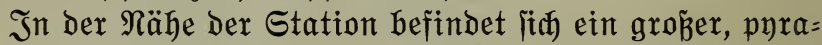
mibenförmiger Şaufen von Eijenfonglomeratblöđen nit

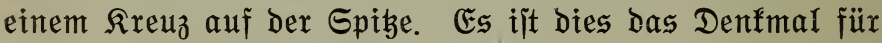
bie in einem Kampj mit Den Ijhofoji gefallenen Golbaten Der. Sđhubtruppe. Das Denfmal haben die I I đololit jelbjt

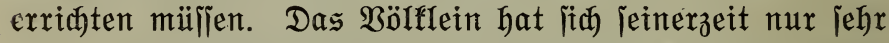
ungern ber beutichen Regierung unterworfen, was bei feiner Bergangenheit nidgt ju verwundern ift.

\section{Bon Ganjante Mangu nad $\mathfrak{B a j a r i}$}

Im 17. Mär $\mathfrak{r}_{\mathfrak{z}}$ verabichiedeten wir uns in ber frühe von unjerm liebenswürbigen Gajtgeber. UUnjer Weg führte jüb= weitlid ïber bie baumloje Grasiteppe. 12 Rilometer von

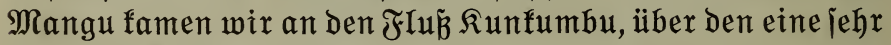

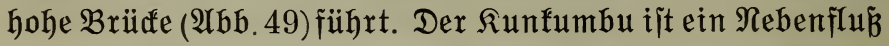
Des Dti und ïberiळmemmt, wie Der Dti jelbit, in Der Regen= 


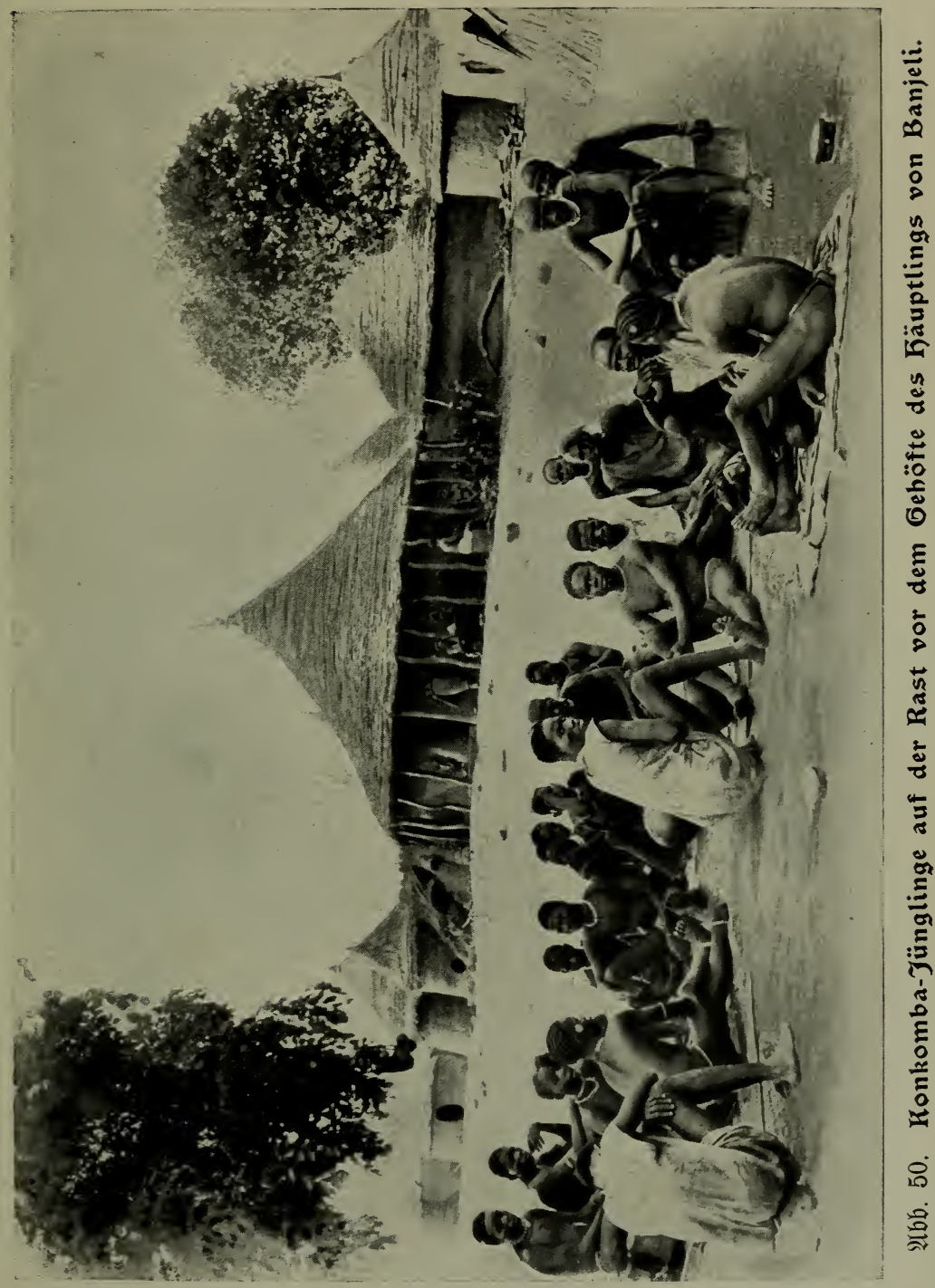



zeit ein weites Gebiet. Die hohen Ufjer find barum nod mit fräftigen Mauern befejtigt, und auf bem Iinfen Ulfer Des Flulfes führt ein etwa zwei Kilometer langer Damm [ither burd bas überidnemmungsgebiet. Weld eine Wohl= tat bas ijt, befamen wir allerbings nidft jelbjit zu ipüren, aber bie Spuren bes Sodhwaflers, die überall zu lehen waren, redeten beutlia genug. Wix freuten uns wieder mit beređtigtem Stolz Der $\mathfrak{A}$ rbeit Der Deutiðen Regierung und ihrer Bertreter.

Die Gegend ijt jehr menidhenleer. Exit 26 Rilometer von Mangu famen wix an ein nod̆ baju jebra ärmlidaes

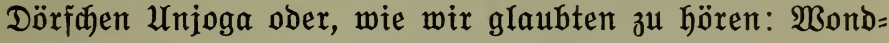

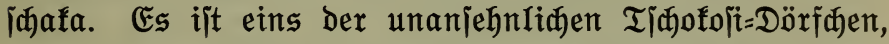
wie fie bünn ge|ät der Straß̧e entIang zu treffen find. Run= bani ijt ein meiteres joldes, und bei Rilometer 35 erreidyten wir Das jeitwärts ber Straß̉e liegende Diereponi, unjer heutiges Reijeziel. $\mathfrak{A} n$ Der Straß̉e liegt ein ganz nettes Raithaus. Im Sof besielben iteht ein interelianter Baum,

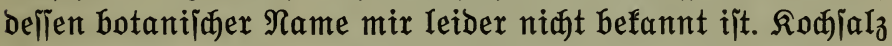
ijt je weiter won ber See Iandeinmärts ein raja im Preis iteigender Sandelsartifel. Sn Den frühern unfithern 3eiten

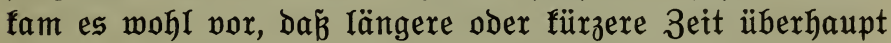
fein $\mathrm{SaI}_{3}$ Durdfommen fonnte. Nun haben merfwüroiger= weije bie Eingeborenen herausgefunden, da á bie Blätter und Brüten biejes Baumes das Salz eriegen fönnen. Sie

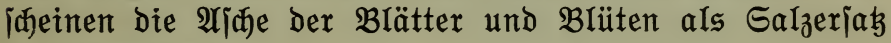
ou verwenden.

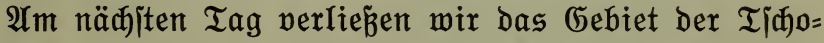

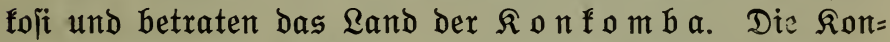
fomba find ein Bölfaden von nahezu 50000 Menidjen. 11000 von ihnen find unter Dagombaherriafaft, 29000 jind jelbjtändig und 9000 gehören ben mit iłnen jehr nahe ver=

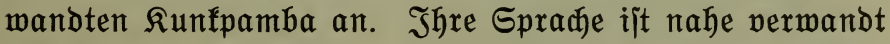
mit Gurma und Moba. Sie wohnen auf beiden Seiten Des Dti; bie auf bem redten Uffer find unter Dagnmba= 


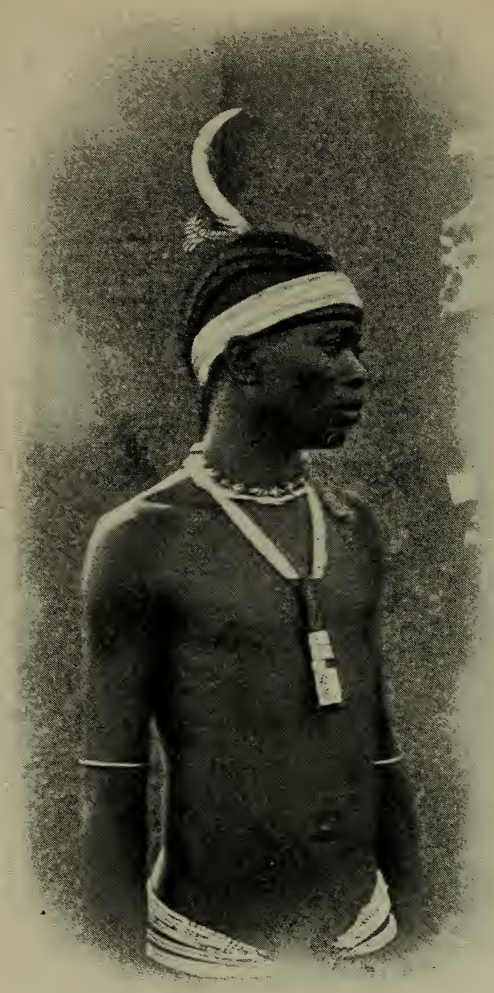

916j. 51. Junger Konkomba.

herriðׁaft, die auf Dem Iinfen jind jelb= itändig. Die $\mathfrak{R u n f}=$ pambawohnenweit = Iidh von Mangu in fleinen Dörfachen jehr zeritreut. Die Ronfombaerinnern vielfadh an ihre Stammerwandten im Norben, bie Moba. Es ijt ein liebenswüroiges, fräftiges $\mathfrak{B o l f}$. $\mathfrak{B} e=$ ionders madht bie Jungmannichaft einen vortrefflichen Eindrud. Arter= bings haben bie Ronfombajungens diefelbe ভ(y)ady= heit, wie bie $\mathfrak{M o b a}=$ jünglinge. Sie

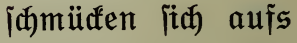
jorgfältigite. Die Ronfomba iiber $=$ treffen barin nod die Moba. Ein Blid auf $\mathfrak{A b b} .50$ und 51 zeigt, mit welder Shingebung und mit weldem Eifer iid bie Burjhen herauspuken.

Meine erite Begegnung mit ßonfombajünglingen hatte

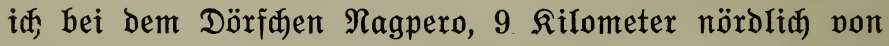
Bapuli. Da erjøienen jie z̆ $\mathfrak{u}$ jeds mit einem gleidhaltrigen Mäbden in ihrer Mitte, wie eben aus ber Erfibutter ge= 


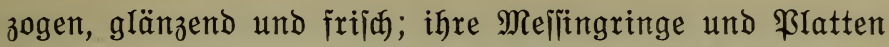

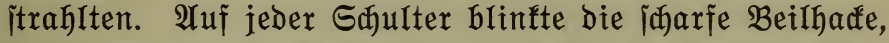
jeber trug jeinen Bogen und eine $\mathfrak{B a r t i e}$ Pfeile. Mut, Lebensfreube und Unternehmungsluit leudtete aus inren (5ejutern und ihrer ganzen Gejtalt; übermütig niaften bie Sahnenfedern mit vornüber geriđteter $\mathfrak{R}$ rümmung bazu. Ein joldes Bild mußste meiner Sammlung von Photo= graphien einverleift werben. Sdinell itieg id pom Rab

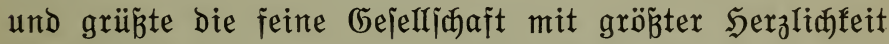
und judte midh bei ifnen anzufreunden, io gut es ofne Renntnis iłrer Spradje ging. Dann bat id fie, ein wentg

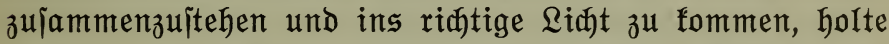
IäßheInd mein Statin und ben immer bereiten $\mathfrak{A p p a r a t ~ u n d ~}$ wollte eben bie Sherriðaften einitellen, als bie ganze Bande wie Spreu vor bem Winde auseinanderitob und in hohen Säben das Beite juchte. Sa fam mir vor wie eine Senne, die Enteneier ausgebrütet hat, und Deren Rinder fï alle

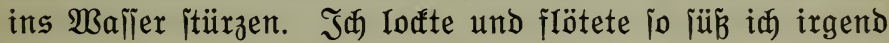
fonnte, aber leiber gänzliðh olnne Erfolg. In ein paar Olugenbliffen waren bie iđjeuen Menichenfinder ver=

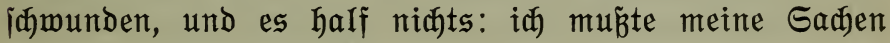
wieder zulammenpaften. Nur ber Trojt blieb mir,

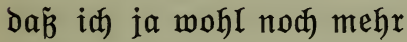
jolde Gelegentheiten haben werbe, und bejann mid) auf alle mir erbenflidgen Edridge, wie id bod) zu meinem 3iel fommen fönnte. In Bapuli ex= wijate id dann einen

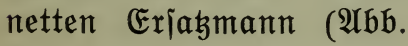
51), aber er hielt nidgt ordentlid itill und nahm es fait als periönlide 2lbb.jla. Junger Konkomba. 


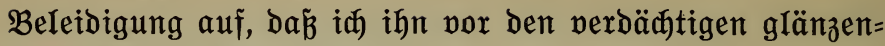
ben Raiten geiterlt hatte.

Das Saar fledten bie Ronfombajünglinge iehr funit= woll in mannigfaltiger Beile, meift in mehr ober meniger zahlreidjen, dem Ropf eng anliegenden Gefledten, zu welden bann Mefítngringe und Blatten reidfich Bermen= bung finden. In $\mathfrak{A b b}$.51a hat ein junger Ronfomba gegen 100 Meffingringe auf feinem ganzen Saarboben in jein Saar geflodyten, und als lebten Sdamud nod eine Sahnen= feber eingeitect. Ein anderer, ausnehmend fräftig gebauter

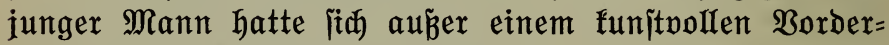
idheitel=Sinterfopfband won Mefing und mehreren taler=

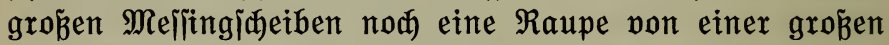
3ahl Mefíngringen wom Sinterfopf ïber ben Sdjeitel ge=

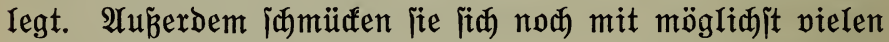
Ober $=$ und $\mathfrak{U n t e r a r m r i n g e n .}$. Die fehlende Rleibung erjegen jehr viele Dura Tätowierung des ganzen Rörpers. Sehr gut nehmen jith die Sahnenfebern aus, bie fith bie lebens=

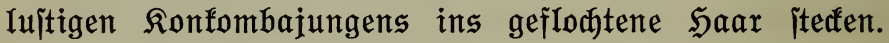

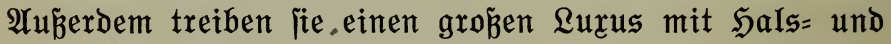
Süftenfetten won grö̈en, weiß̈en Glasperlen und Rauri=

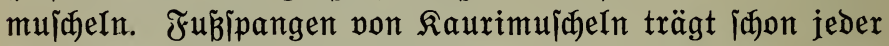
fleine $\mathfrak{R}$ nirps, und zwar wird babei ber redte Fuß bevor=

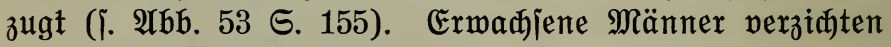
auf joldjen Sdjmuff; Dagegen pflegen fie den Bart zulammen= zubinden, und wirb ex länger, fo fafien fie wohl eine mög=

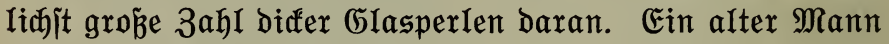
mit langem Bart, an bem viele Berlen aufgefä́t waren, hatte am Ende ein fleines melîngenes Glödthen an= gebunden.

Die jungen Reute tragen fajt alle auf ber $\mathfrak{B r u j t}$ an einer um ben Sals gehängten Sđhur oder an einem Band eine Signalpfeife. Es ijt ein ber \&änge nad und oben bei den

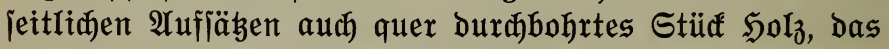
oft mit Silber bejdlagen wirb ober bod mit ein paar Ğlas= 
perTen verziert ijt. über bas am biafern Ende befindridge Munditüa bläit man weg und fann bann burd $\mathfrak{a} b=$ medjelndes 3uhalten ber beiben obern D̈ffnungen an ben jeitlidjen $\mathfrak{A}$ njägen ober ber untern D̈ffnung verjđjieden hohe Töne erzengen, bie in ber $\mathfrak{N a d y t ~ w o h l ~ e i n e n ~ R i l o m e t e r ~ m e i t ~}$

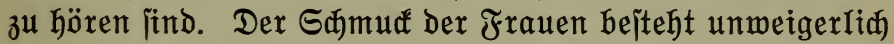
aus Dem inon bejđriebenen zahnförmigen Stein, ber in

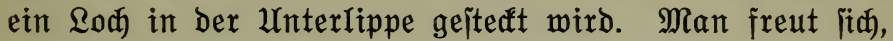
zu jehen, bá hier bie traurigen Blattbüifjel nidjt mebr in (5ebraud find und die Frauen fid ordentlid mit Baumwoll= itoffen zu fleiben pflegen, wenigitens wenn fie ausgehen.

In Bapuli rajteten wir am zweiten $\mathfrak{T a g}$ nach unjerm 2uffbrud won Mangu. Webmütig gedadten wir bes in bem von uns bewohnten Rajthof vor zwei Monaten ge= itorbenen trefflidyen Mannes, Des frühern Bezirfsleiters von Mangu, bes Sauptmanns Mellin.

Shon bei ben Moba famen wir oft an Gehöften vor= bei, bie etwas wie Bierbrauereien voritellten. In groß̈en Töpien itanden hier unter einem Sdattendady an bie 100 Liter Siriebier, bie barauf warteten, bis am IYbend bie Gäjte, wohl bie weitern familienangehörigen, famen und beim Mondenjhein Das Bier tranfen; aber nirgends waren wix

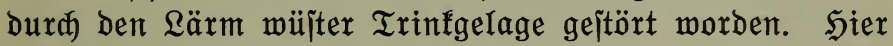
bei ben Ronfomba jahen wir nun zum eritenmal $\mathfrak{B e}=$ trunfene. $\mathfrak{A} u \mathfrak{f}$ Dem Marft in $\mathfrak{B a p u l i}$ wurbe jehr itarfes Bier ausgejđenft. Eine $\mathfrak{A n z a h l ~ j u n g e r ~ u n d ~ a l t e r ~ M a ̈ n t e r ~}$ hatte fith Darüber hergemadt und zu viel bavon getrunfen. Da gab es nun wiberwärtige Aluftritte, und iđ ging rajđ

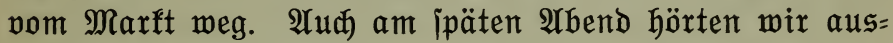
gelaflenes, wildes Getrommel und Singen, bis gegen Mitter= nadft $\Re$ uhe eintrat. Das aber fam uns überall jehr leb=

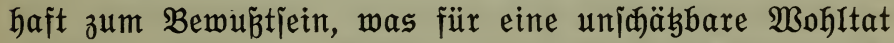
es für bie Bölfer im Rorben Togos und ber Goldfuijte iift.

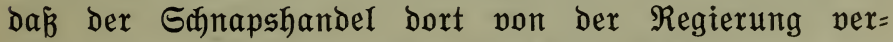

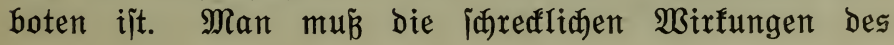


Sdnapstrinfens auf ein $\mathfrak{B}$ olf beobadtet haben, wie id als $\mathfrak{A r}_{3}{ }^{t} 25$ Jahre auf ber Goldfiijte Gelegenheit hatte, um $\mathfrak{z} \mathfrak{u}$ ermellen, welde $\mathfrak{B o h I t a t}$ es fuix ein $\mathfrak{B o l f}$ ift, wenn es be= wahrt wird por biejem nidgt nur bie Gejundheit und bie Beritandesträfte des Einzelnen untergrabenden, fondern audh die Entartung des ganzen Bolfes herbeiführenden Ge= tränf. Man vergleidge einmal bie von Gejunbheit und Kraft itrogende Sungmannichaft ber nörblichen Gebiete mit Den jungen Reuten in ben Gebieten, in weldyen jeit Jahren

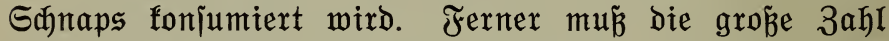
alter Leute auffallen im Gegenjab $\mathfrak{z}^{\mathfrak{u}}$ ben wentgen in ben Sđnaps trinfenden jüblid mohnenden Stämmen. Trob ber mit jedem $\mathfrak{J a h r}$ wahjenden $\mathfrak{B}$ ohlhabenheit der Stämme an ber Goldfuijte wäafit bie Zahl ber Tuberfulöjen, Der Epi= leptifer, ber Geiftesfranfen, und die Gefängnifile fülfen fiț immer mehr. Arbgejehen von ber uns allen offenfundigen Beridledterung Des Bolfscharafters burd den S(jnaps= genuß̈, find für ben Dort lebenden, ridtig beobadtenden $\mathfrak{A r}_{3} t$ bie 3eichen ber Entartung in trauriger Deutlidffeit wahrzanthmen. Wix hoffen jehr, dá die weitblidenden, wohlwollenden werben, Dá̧ bie gelunde Entwifflung ber Rolonien, bie Bohlfahrt ber uns anvertrauten Bölfer und niđht zum wenigiten unjer eigenes Interefle burdjaus bie wirfiame Berhinderung Der Einfuhr Des Ednapies exforbern. Bir vertrauen hier ber wahrhaft für bas $\mathfrak{B o h l}$ ihrer $\mathfrak{B o ̈ l f e r}$ bejorgten beutichen ßolonialregierung und ihrer Energie,

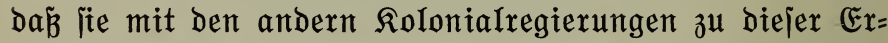
fenntnis fomme. Der Tag, an weldem man Den Entīhluß fallen wird, lieber auf bie groß̈e Einnahme, bie Der Zoll auf Sdnaps ben Rolonialregierungen bringt, zu verzichten, als länger bieje Edhäblidfłeit auf bie Bölfer einmirfen zu Iaffer, wirb ein $\mathfrak{I a g}$ jein, an weldyem alle wohlgejintenten Meniden, Denen bas $\mathfrak{B}$ ohlergehen ber Mitmenidhen höher iteht als bie 3unahme bes eigenen Gelobeutels, fid pon 
Serzen freuen. Diejem Tag wixd eine fröhliche Entwiđflung

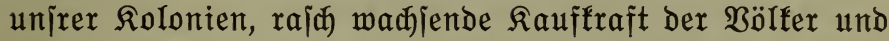
erfreulidxe Entwialung ifres Charafters und ihrer Geijtes= fräfte folgen. Der Ausfall im Einfommen der Rolonien aber wirb babura (đ)neller, als man ermartet, gededt't werben.

Der Weg non Djereponi nađh Wapuli mar fehr er= mübend gemejen, und wix verjuðten im Rajthof von Wapuli ein menig ou jølafen. Den menigiten von uns wollte das glüafen. Es ging ein faît beitändiger 3ug von Rontomba Dura den Rajthof; Daneben haujten noc allerlei Şändlex

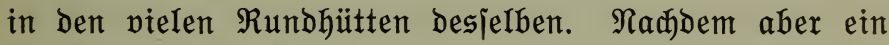
Ejeldhen jein juredfliches Rieb ausgejungen hatte, trat eine Beile Stille ein. Diele Stille nahm Derjenige unter uns, ber mit wahrer Runitfertigfeit es unter now fait un= günjtigeren Berhältnilīen fertig zu bringen prlegte, ein= ¡đlafen zu fönten, wahr und jølief fofort fejt ein. Eine Weile ging bas präđtig, und iđ̆ beneibete ihn im itillen, während ich meine Notizen maate; aber ba nahte fich aud iłm bas Berhängnis, diesmal in Gejtalt eines jöönen meiß̈en S్bahns. Bedächtig itieg diejer auf ein niebriges

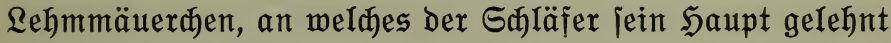
hatte, trippelte bis gerabe über ifn, jah ifn zuerit mit jeinem redyten $\mathfrak{A}$ uge genau an, dann mit jeinem linfen. Das Enbergebnis bex Unter|ưhung mar, bá̉ er völlig be= friebigt mit Den Jlügeln iđ)lug und aus vollem S్ Sals biđt über den Dhren unires jhlafenden Freundes „Riferifi“ rief. Das war aud für ben Sd)laffünjtler zu viel; ver=

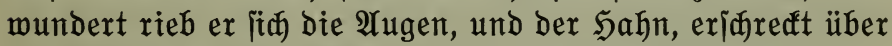

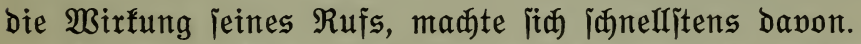

Bapuli ijt fein grożer Drt, und aud auf Dem weiteren Weg, ben wir nun einjhlugen, famen wir nur burळ un= bedeutende Dörfæhen. Wix verlię̧en von Wapuli an die

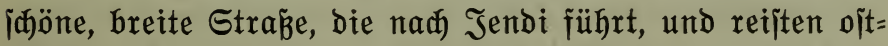

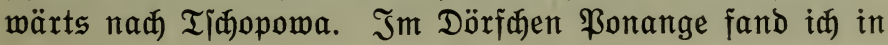


Der Rähe eines Gehöftes eine originelle Rudhenform. Sie ift aus $\mathcal{L} e \mathfrak{h m}$ geformt und gebrannt und hat fieben halb= fugelige Bertiefungen won $10 \mathrm{~cm}$ Durdmellex, in ber $\mathfrak{A} n=$ oromung wie die in ben befannten Spiegeleierpfannen in Europa. Sal eritand bie Form und überrajdte bamit meine Reijegefährten, als wix in Ijđopowa anfamen. Sie begehrten aber feine $\mathfrak{h u d h e n , ~ d i e ~ i n ~ b e r ~ e t w a s ~ j e h r ~ r u ß ̉ i g ~}$ ausjehenden Form gebaďen wären.

Tiðopowa ijt ein jiemlid bedeutender Drt und bejteht aus einer $\mathfrak{A n z a h I ~ D o ̈ r f e r ~ u n d ~ D o ̈ r f d e n , ~ b i e ~ a u f ~ e i n e m ~ j a n f t ~}$ gegen bas Dtital abfallenden niedrigen Sü̈gel liegen. Der Raithof liegt in Der Mitte diejer veridgiedenen Drtidaften. $\mathfrak{I m} \cdot \mathfrak{R a j t h o f ~ j e l b j t ~ i t e h t ~ e i n ~ r i e f i g e r ~} \mathfrak{A} f$ fenbrotfrudtbaum. Leiber ift ex hohl und, was nod falimmer ijt, ex war non einer Menge fleiner Fledermäule bewohnt und bie \&uft in

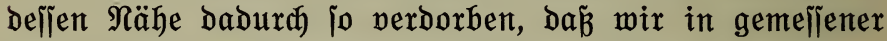

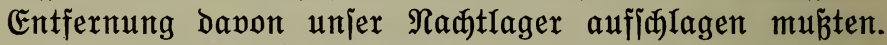
Bon Mangu jiiblid erfennt man wieber die Reigung,

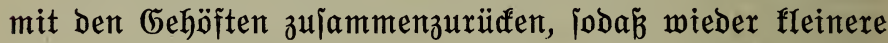
ober grö̈zere richtige Dörfer entitehen. Die Tínofoji lieben feine groß̈en Dörfer; es zeigt fid aud barin eine gewifle $\mathfrak{B e r}=$ wandtiáaft mit ben Moba. Wir befamen ben Eindrudt, be= jonders in Tíhopowa, Dá alle weitern Familienglieber jith beieinander anfiedeln und jo bie vielen fleinen und grö̈̈ern (5ruppen von (Gehöften entitehen, aus benen fid I I (jopowa julammenjebt. Erit in Banjeli und Bajari famen wir wieber in eigentlidje Dörfer. Es ijt nidht nux unjer Eindorud,

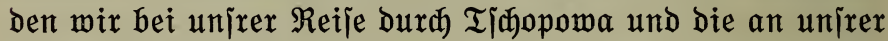
Reijeroute gelegenen Gebiete befamen, Dá̉ Tiđopowa ber biatejt bewohnte Teil bes Ronfombalandes ijt; aud bie wertvolle 3ählung von Sauptmann Mellin gibt für bas

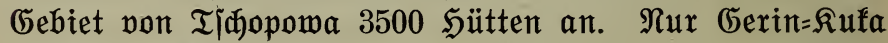
$\mathfrak{a u f}$ Dem Iinfen Dtiufer, genau öjtlidg und in ber Ruftlinie 35 Kilometer won Tichopoma, ijt noch ein Bevölferungs= zentrum, aber mit jeinen 1500 Sütten bod viel bejđeidenex 

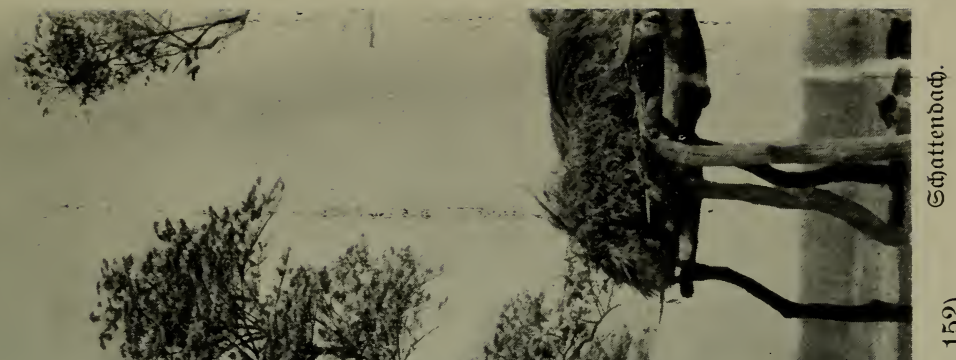

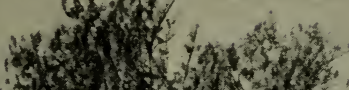

-

(w)

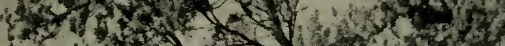

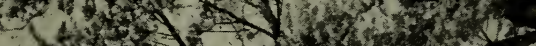

15.

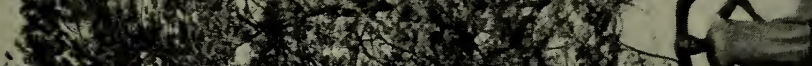

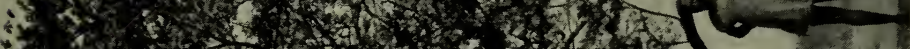

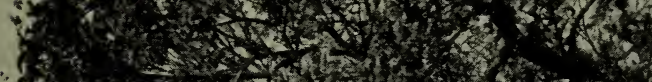

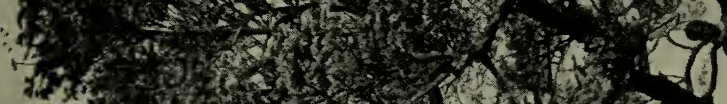

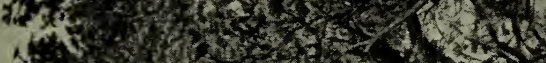

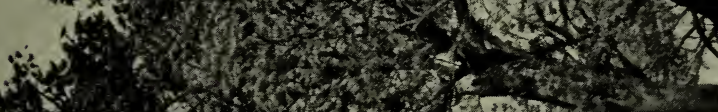

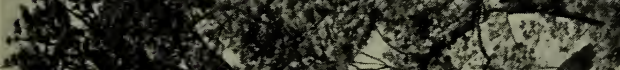

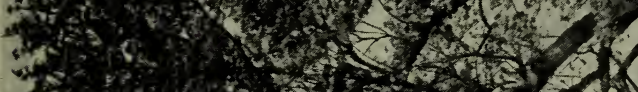

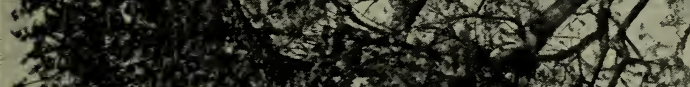

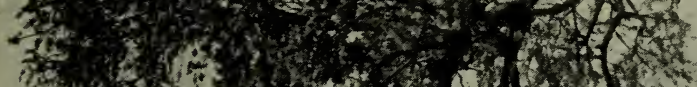

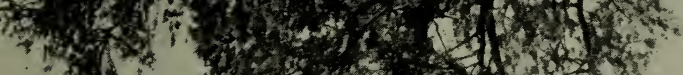

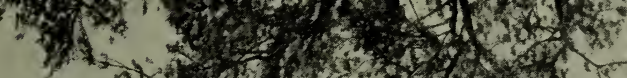

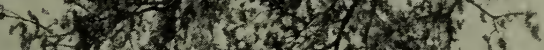

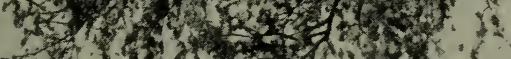

$v=26$.

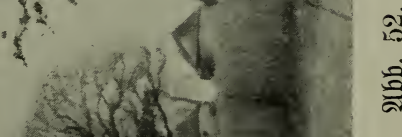

(5)

है *)

trat $x^{2}+1$

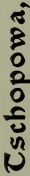

党

วิ่

हैं 

als T\{đopowa. Bei ber fünftigen $\mathfrak{B a h l}$ einer Station wird aber nifft vergelien werben biurfen, dá̉ man mit bem jehr

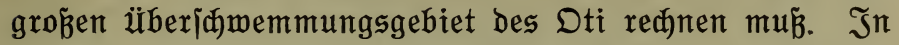

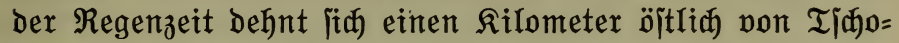
powa bis an ben Dti ein See oder Sumpf von jehr grober

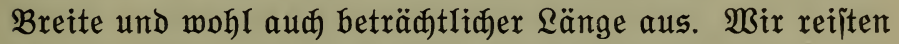
in ber troffenen 3eit und jahen mur bie Spuren banon. Da waren auf groß̈e Stref̛en meterhohe iđmale Dämme auf= geworfen, bie teils bie Berfehrswege zwijđen Den Dörfanen

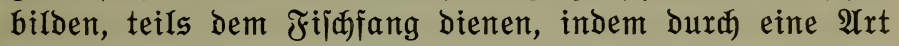
primitiner Sdyleujen Das Wafier eines Teils abgelafien werden fann. Die ganze Gegend ijt Durd joldhe Dämme in groß̉e Felder eingeteilt. Dasfelbe ijt auf bem linfen $\mathfrak{U}$ fer Des Dti Der Fall, wo grö̉e Ebenen in Der Regenzeit offen= bar nahezu meterhoch unter $\mathfrak{B a f l e r ~ i t e h e n ~ u n d ~ e b e n f a l l s ~}$ burd Dämme freuz und quer Durdjđanttten jind. Sehr wahr

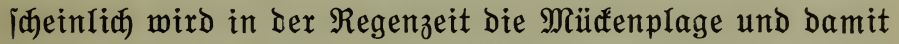
bie Gefahr, mit Malaria angeitedt $\mathfrak{z} \mathfrak{u}$ werben, in ber ganzen Dti=Niederung gró̉ iein. Jmmerhin gibt es in jener Gegend

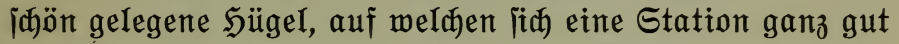
erribten Iäß̈t. Die Gd)wierigfeit, in ber Regenzeit zu reijen, ift bamit freilid nidht gehoben und wirb an bie Energie Der bort einit arbeitenden Miffitonare feine fleinen $\mathfrak{A n f o r b e}=$ rungen itellen. Jedenfalls bürfen aber bei Der Rleinheit ber Bölferitämme bie auf Dem Iinfen Dtiufer wohnenden

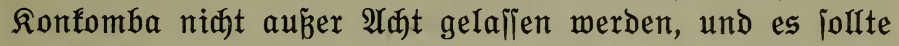
einer (bejellidgaft, weldje bie weitlid vom Dti wohnenden Ronfomba bearbeitet, nidst verwebrt iein, aud bie öjtlid bavon mohnemben zu bearbeiten, gerabe wie es burchaus erforberlid ijt, ba

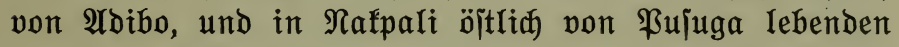
10000 Dagomba von ber im Reid Sendi arbeitenden Ge= iellidjaft hebient werden.

In Tiðopowa fam iđ zufällig an einen Begräbnisplał.

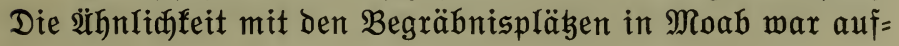




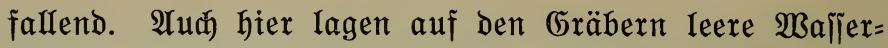

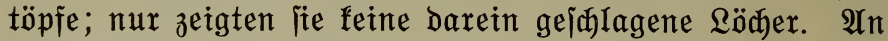
einer Stelle war ein Grab eingefallen und liéb exfennen, báb bie Toten anidheinend nidht mit Erde jugeded werden. Das Grab war mit bünnen Baumitämmánen überdeăt und auf Diejen eine Dïnne Erojđidft. Der Ränge Des Grabes

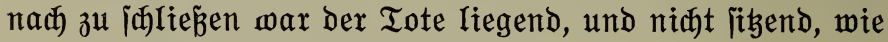
bei ben Moba, begraben worben.

Der furze Weg von Tifjopowa an bie Ufjer Des Dti, etwa 2-3 నilometer, führt Durd einige Gehöft=(Gruppen, won benen Rutejod bie bedsutendite ijt. S(jon gleid) am

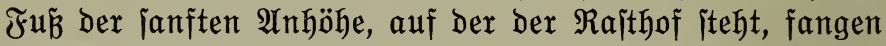
die oben bejđriebenen Dämme an. IIm filuź jelbjt befommt man fạt Den Eindrữ, wie wenn Der Flü eingedämmt jei. Man iteigt nidht unbeträrdtlid in bie $\mathfrak{y o ̈ h e , ~ b i s ~ m a n ~}$ auf Dem ungefähr 20 Meter über Dem Damaligen $\mathfrak{B a} \mid \mathbb{e}=$ itand gelegenen LUferrand anfommt. Der Flu 150 Meter breit, und in jeinem Bett liegen breite, fladje Gandbänfe. Senjeits führte der Beg Durd jehr fladjes Land, bas zum Teil vom Dti, zum Teil von jeinem Reben=

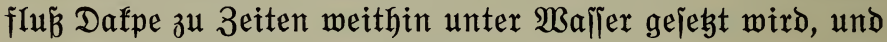
überall fanden wix bie Ebenen Durdjogen won Den be=

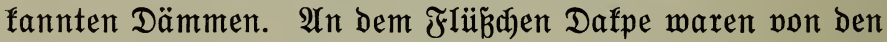

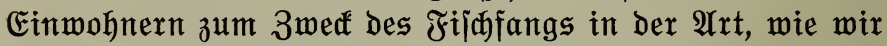
es bei den Mampruji in Boyeni jahen, Steindämme quer

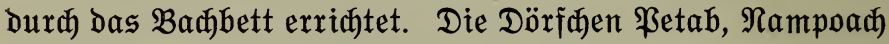
und Rulamong, auf bie wir am Weg itié̉en, find $\mathfrak{u n}=$ bedeutend, die Einwohner aber freundiłd und gefällig. Lialebu, bas lebte Dorf por unjerm Reijeziel Sabji, war nod bas bedeutendite. In Sadji war ber Rajthof ein= geitürat, und bie Einwohner madhten fitch gleid frifa an bie

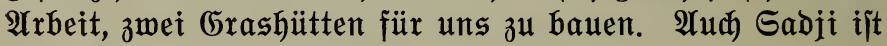
ein unbedeutendes Dörfłen, 24 Rilometer von I I đopowa entfernt.

Es war den Leuten ein grö́es Annliegen, Dá̉ wir 


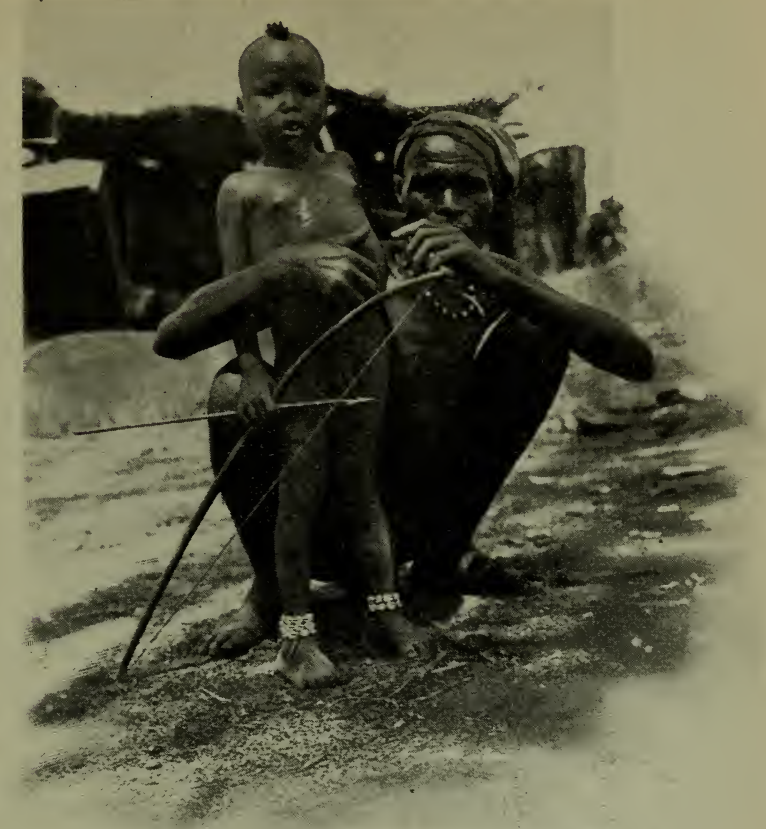

Ább. 53. Kleiner Bogenschütże in Sadji.

alles, was wix brauদten, riðtig exhielten. Dex Şäuptling, ein altes Männđen, fam immer wieber und bradte irgend etwas, was wir leiner Meinung nađ nođ brauden fönnten. Die (5egend ijt offenbar jehr wildreid, und jedermann geht mit Bogen und ßjeil bewaffnet aus. Ein fleiner ßnirps won etwa vier Jahren fam jogar baher mit jeinem Bogen und einem jehr ernithaften $\mathfrak{B} f e i l$, der eine eijerne Spije mit zwei gefährliðen Wiberhafen hatte. Jð wollte das Rerl=

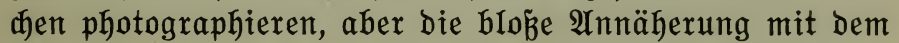
Apparat Iöjte bei iłm einen itarfen Strom von Tränen und 


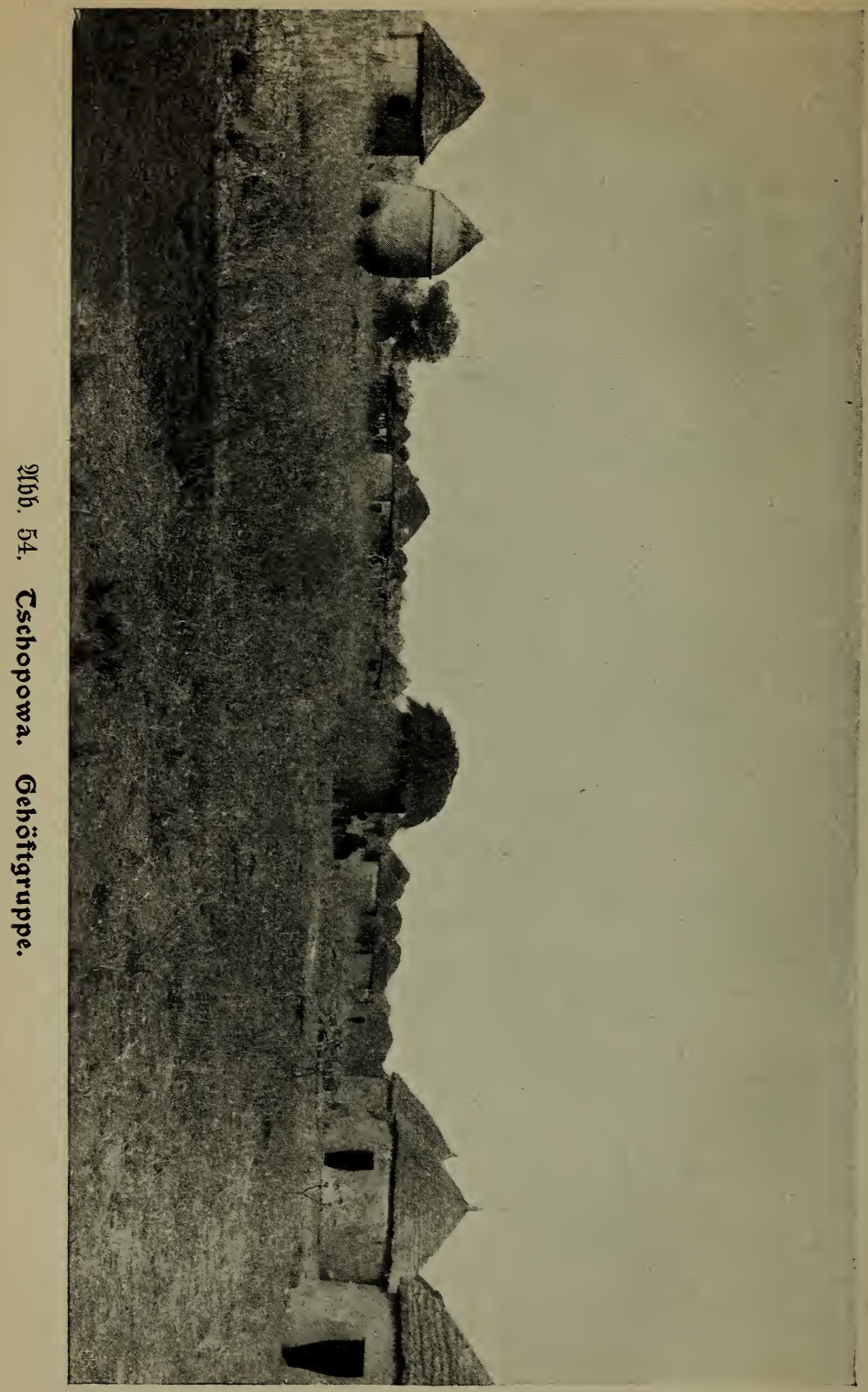


ein grö̉es Geidrei aus. Gein Bater eilte herbei, um bas Unglüa, bas jeinen Sohn betroffen zu haben iđien, zu be= fidtigen. Mit vereinten ßräften gelang es, ben Sammer zu itillen, wobei aud ein paar 3wiebärfe gute Dienjte Ieijteten, und jo fam $\mathfrak{2} \mathfrak{b b}$. 53 zultande. (Gleid) nad der Iufnahme rannte der fleine Jäger heim und zog mit einem aud) mit $\mathfrak{B j e i l}$ und Bogen bewaffneten fleineren $\mathfrak{B r u b e r}$ eiligit aữ bie Jago.

Die Gehöfte Der Ronfomba find wieder ein menig anders gebaut, als bie ber bisher bejudten Stämme. Die Gehöfte find aud mit einer Ringmauer umgeben, bie ein= zelnen Sütten find aber etwas mehr voneinandex getrennt, und zwar burd eine Mauer mit einem freisrumben Gd్lupf $=$ Iod) von etwa $60 \mathrm{~cm}$ Durdmefler, Deffen unteriter Ramb un= gefähr $40 \mathrm{~cm}$ vom Boden entfernt ijt. Nidgt jelten ijt vor ber Sütte bes Sausherrn eine fleine, einfache Beranda an= gebradt. Die Eingangsöffnung in bie Eingangshütte ijt viel höher, als wir fie bei den $\mathfrak{R} u[a j i$ und Moba trafen, und bie untern Eeitenteile ber Türöffnungen find verdiat, joba andern Sütten ber Gehöfte haben aber alle rumbe Shlupf $=$

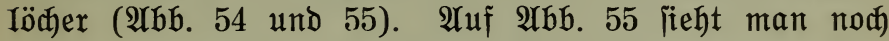

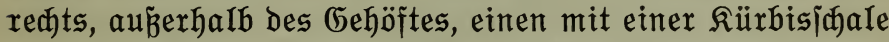
und einem zerbrodenen Rorb bedecten Dien zur (Gemin= nung ber Sđjifutter. Sinfs unten auf $\mathfrak{A b \mathfrak { b } . ~} 48$ (క. 142) fommt nod) iehr glïadid einer ber netten, verzierten $\mathfrak{B a}$ alfer= töpfe Der Ronfomba zur Eridheinung.

Benn uns aud bei unjerm furzen Bejuđ bei ben Ron= fomba feine Zeidjen von Runjtitinn in Form von Berzierung ifrer Gehöfte vorgefommen find, io geben boch ihre gewal=

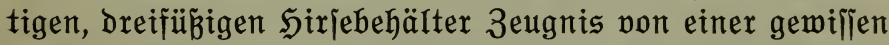
Runjtfertigfeit. Die Ronfomba um Sabji herum idjeinen die Töpfe, wenn jie gefüllt find, nod mit einer Mauer ein=

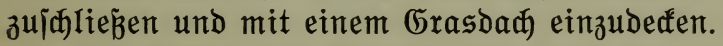

Die flora jenes Gebiets [đjeint uns für einen forjđjer 


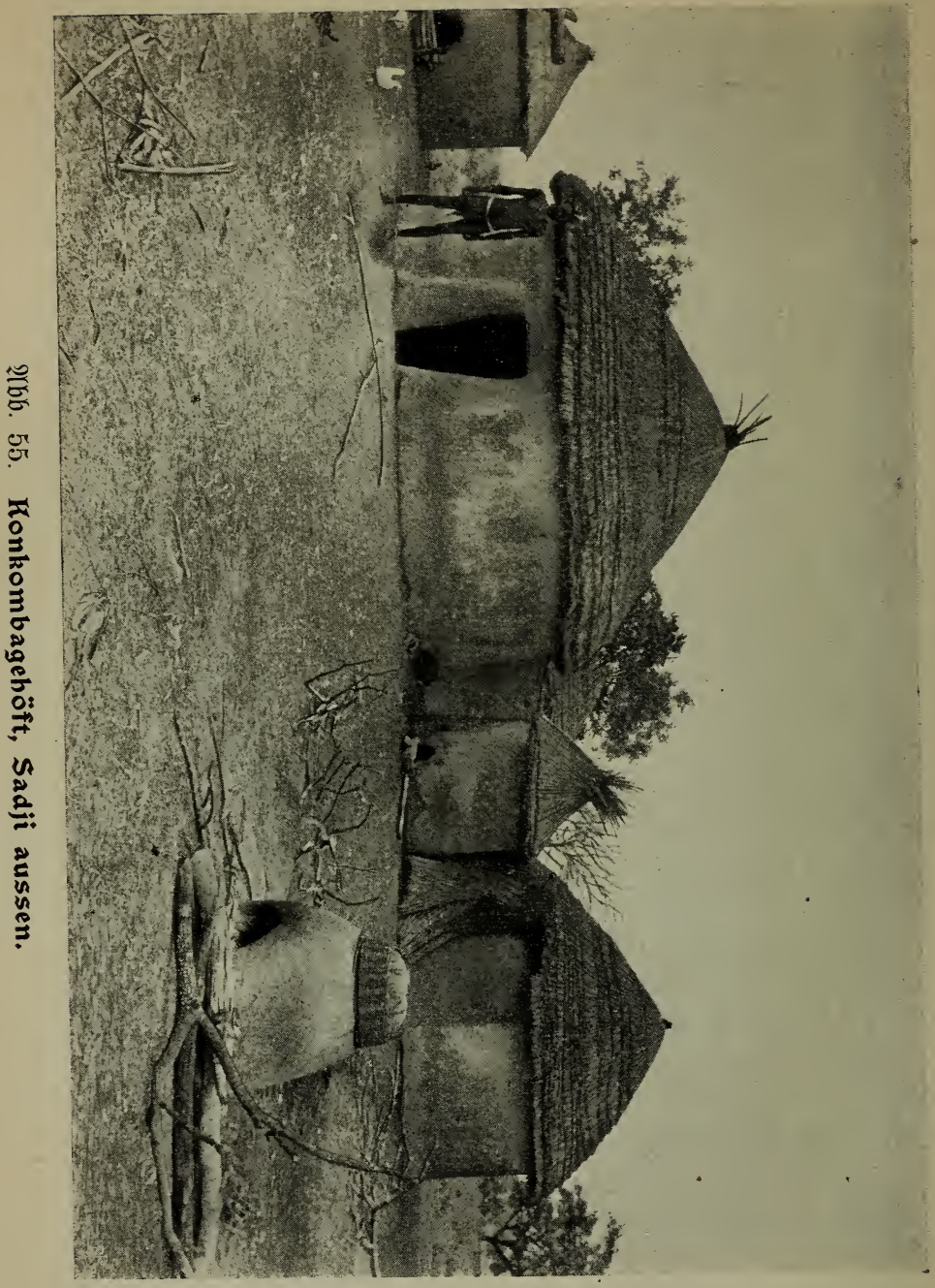


nid,t unintereflant zu jein. Der längere 3eit im Sahre von

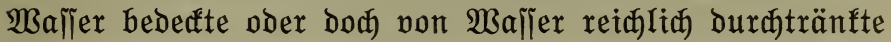
Boden bietet für gewille ßjflanzen ausnahmsmeije günitige Lebensbedingungen. Dit exfreuten zarte Blüten, eben Dem ausgetrofineten Boden entiprofien, unier $\mathfrak{A}$ uge. Berjđiedene Draibeen, Liliaceen, Gilene= ober Dianthusarten, icilla= artige Pflanzen und $\mathfrak{A}$ roibeen fielen uns beim Borüber fabren auf. Eine ¡ðön violettrote Sđmetterlingsblüte eines grö̈ern Straudes exfreute uns mit ifrem herrliden

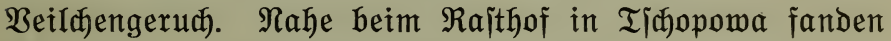
wir bei einem benađbarten Gehöft zwei Bäume in pradt= voller Blüte; fie jahen pon weitem aus wie überreich blühende PfIaumenbäume. Mir ¡đien es eine Caejalpinie zu jein. Inffallend find die überaus zahlreiden Sträuđ̆er von Strophantus hispidus in aflen Ronfombaorten. $3 u m$ Teil itanden fie frei um die Geböfte, zum Ieil waren fie in Ђöhere Gebüĭhe und in Bäume hinaufgeflettert uno waren gerabe bamals mit ben fleinen, gelben Blüten bidt bejest, Deren হronenblätter in lange Jranjen auslaujen.

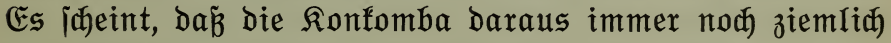
viel ßfeilgift bereiten, wahrianeinlich zur Jago.

Die Ronfomba jheinen jehr gejellig zu jein und ein= ander oft zu bejuden. Sie haben für joldhe Gelegenteiten redt praftijđe, ungefähr $25 \mathrm{~cm}$ hohe, oreibeinige Gtühl=

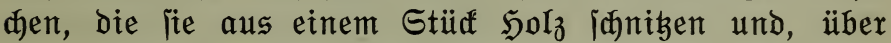

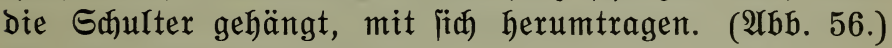
Es jieht jehr viel gemüt= Iicher aus, wenn die Leute mit diejen Felditühlden anrïufen, als wenn fite, wie die Moba, auf Saritt und Iritt ihre blinfenden, melierjaraxen Beilhaten mit (ich auf ber Edulter herumtragen.

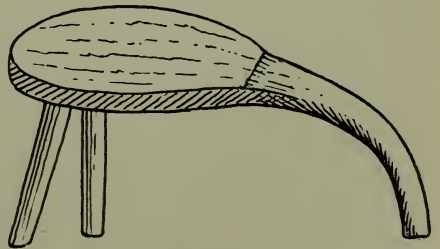

Abb. 56.

Stüblchen der Konkomba. 


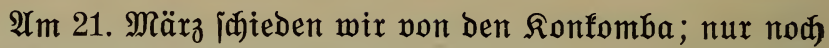
eine $\mathfrak{A n z a h I ~ R o n f o m b a j u ̈ n g l i n g e ~ b e g l e i t e t e n ~ u n s ~ a l s ~} \mathfrak{L a}$ it= träger bis Bajari.

Die $\mathfrak{A}$ ufgabe unjrer Reije mar nun eigentliđ erlebigt. Bohl Iagen now in verloffender Nähe die herrlichen $\mathfrak{B e r g}=$

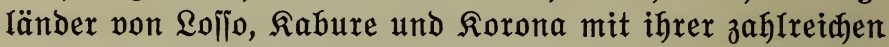
Bevölferung, ferner die füblich pon Mangu lebenden $\Re u=$ mongo und eine Reihe andere Stämme, aber für uns galt es, fïch in exjter Rinie über die uns zunäßjit interefiferenden Bölferitämme in ber weitliçen Särlfte von Togo ou unter=

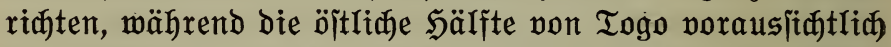
das $\mathfrak{A}$ rbeitsfeld der fatholijanen Mijfiton werben foll. Wenn es aud begreiflichermeije von unjrer Seite bedauert mirb,

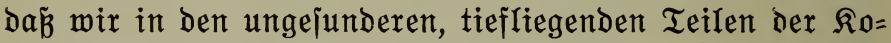
Ionie unjer $\mathfrak{A}$ rbettsfeld zugewiejen erhalten und uns die

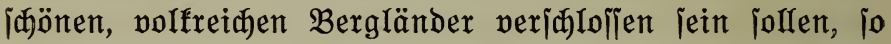
wollen wir barïber niđt flagen, jondern hoffen, die $\mathfrak{A}$ rbeit

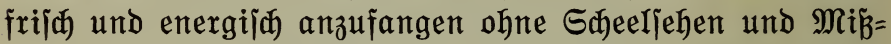
gunit auf andere (5ejelliðaften, Denen jøönere $\mathfrak{A}$ rbeitsfelder zugefallen jinto.

Bir hätten nun über Sanjugu und Rafpari, die öjtlich nom Dti gelegenen Dagombaorte, nach Süben reijen fönnen, und vielleiðt wäre bas Das Riđtigere gewejen; wir zogen aber bod vor, ïber die Stationen Bajari und Sofode nă Utafpame zu reijen, Denn bas wiđtige Banjeli lag auj ber Reijelinie, und aIs fünftigen wiðtigen Induitriemittelpunft jollten wix es boch gejehen haben. Wix reijten aljo nach

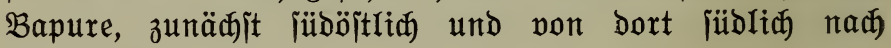
$\mathfrak{Z} \mathfrak{a} \mathfrak{n} \mathfrak{j} \in \mathfrak{I} \dot{i}$.

Bie exfriןळend wirften auf uns die fðönen Formen ber Berge von Banjeli, als wir fie in blauer ferne im

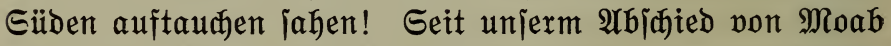
hatten mir feine Berge, faum noch niebrige Sügel zu (Gejtðt befommen. In der Rähe Des groß̉en Rajthofes von Bapure liegen ziemlif ausgedehnte $\mathfrak{B f l a n z u n g e n . ~ D i e ~ v o n ~ M a n i h o t , ~}$ 


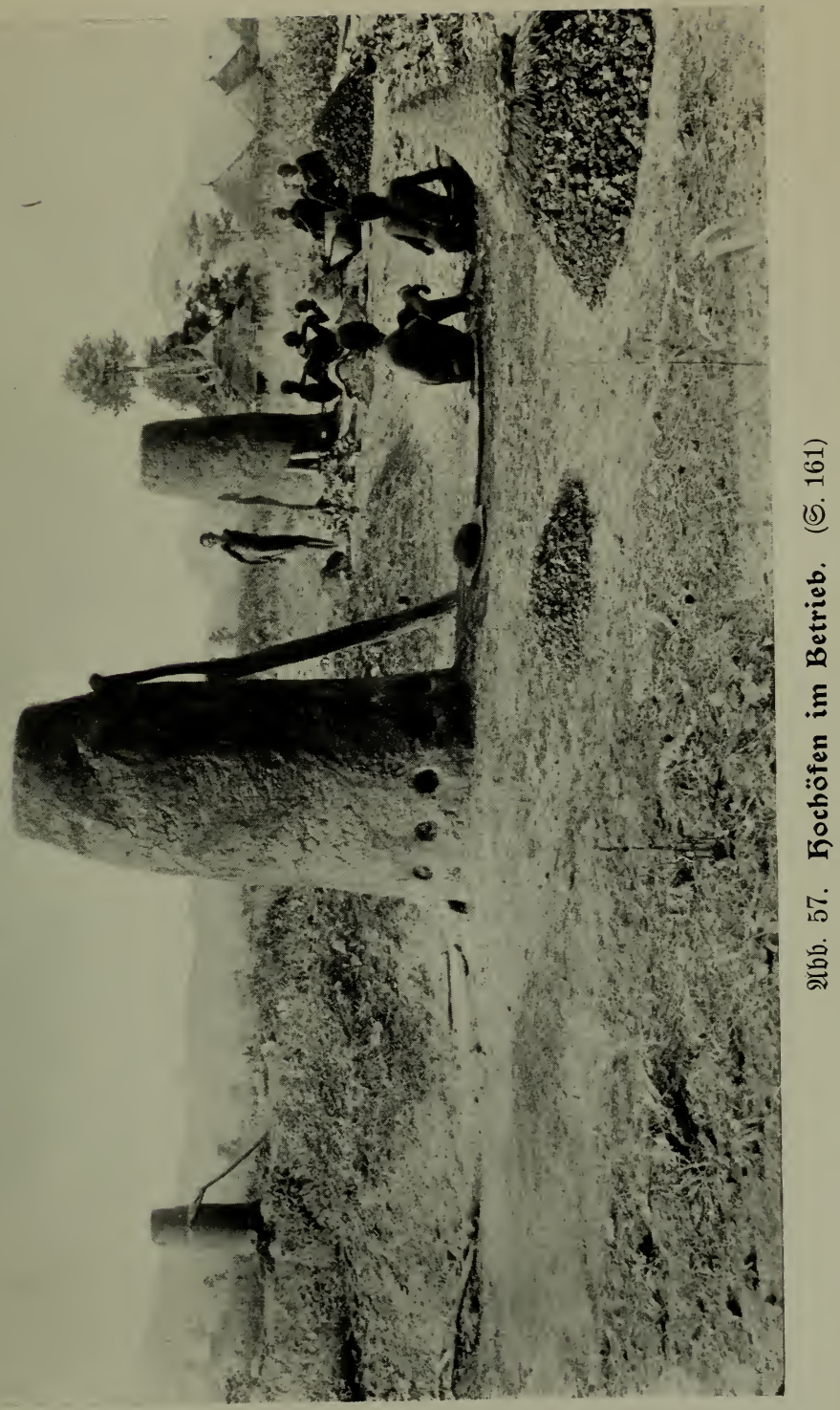





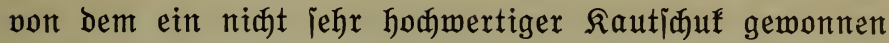
wirb, waren gerabe ganz blattlos und jahen barum niat vielveripreanend aus. Der Rajthof liegt reat weit $a b$ por

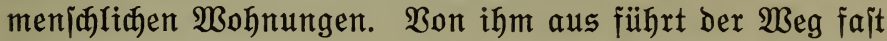
¡đnurgerabe nah Sïben, bireft auf die Berge pon Banjeli 3u. $\mathfrak{A m}$ Fuß ber Berge führt er, an bem Dörfacn Belemele vorbei, in ein Täldhen und über eitren Sattel bes Gebirgs= zuges auf die Gübjeite besfelben. Linfs exblidt man auf einer Terralle bes Berges ein nicht ganz unbedeutendes Dorf Genapare, rechts, im Wejten, auf einer etwas nieb= rigeren Terralle, weit zeritreut Das groß̉e Dorf Banjeli. Es war aber nođ ein heißßer Marið auj tiefiandigen Wegen und in brennender Mittagsionne, bis wix bei dem aus= gezeidnet angelegten, iteu exbauten Rajthof auf ber Iuftigen Bergterraffe anfamen. überall bei Banjeli erblicft man

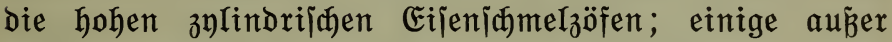
Betrieb jtehende tragen zylindrijade Strohyüte, an andern itehen $\mathfrak{A}$ itgabeln, die als Leitern zum Bejuiden bes

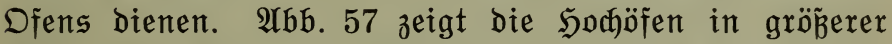
Nähe. Der mittlere ijt in Betrieb, und die zmei jungen Ban= jeli warten, bis jie das bumpje (Geräuj̆ hören, mit dem das Gubitüư auf Den Boden Des DFens finft. Rects im Bild liegt auf einem Saufen Eijenerz Der Shut Des Diens, der inm aufgejest wirb, wenn ex niat in Betrieb ijt. Der andere Dfen, an Dem Der äItere, mehr als mur ipärlich be= fleidete Mann iteht, wird gerabe für einen neuen Brand

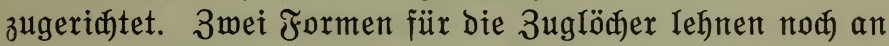
ifm, und neben ben jungen Reuten liegen grože Saufen von flein gejalagenem Eijenerz und Solzfohle, bie fie eben in ben vor ifnen itehenden Rörben hergetragen haben. $\mathfrak{A} n$ Dem Dien Iinfs im Bild lehnt die Leiter, ein fith gabelndes Baumitämmchen, das an ben Dien gelehnt wirb, und auf melchem der ben Dien Speijende von 3eit zu 3eit hinauf= flettert, und mit Silfe belïen ber Dfen, bevor er angezündet wirb, gefüllt wixb. Es murbe uns gejagt, es fomme zuerit 
eine Rage Sand in ben unteriten Teil bes Dfens und bann

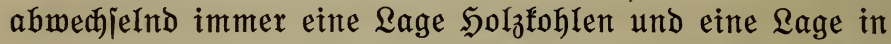

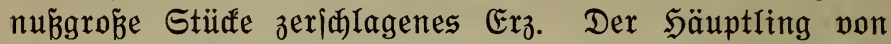
Banjeli war jo freundida und zeigte uns feinen Dien und

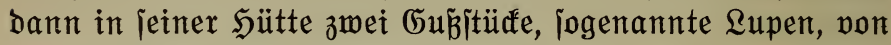
benen jedes nahezu 25 నilo mog.

Die (brasdächer ber $\mathfrak{y a ̈ u j e r ~ i n ~ B a n j e l i ~ f i n d ~ r e d g t ~}$ ipis gebaut, und bas Gras bes Giebels wird mittelit etwas jurecht gefhlagener Salsitüre von Waflertöpfen zulammengehalten und barüber nod) mit Sanüren $z^{\mathfrak{u}}$ einer Spize zujammengebunden.

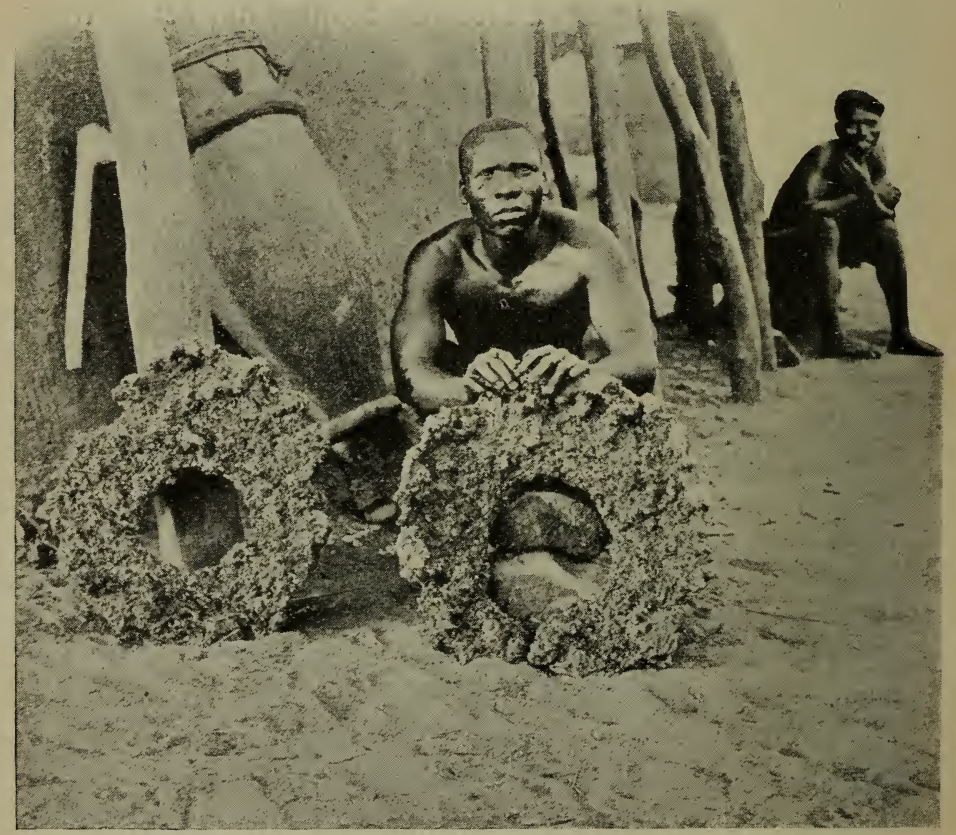

(2łbb. 58.) Eupen. 
Der Rajthof mar ganz neu angelegt und portreffich gebaut. Die Wände ber Shütten waren bif์, jehr jauber ge= glättet und fein mit Dawabama behandelt, jogar etwas wie

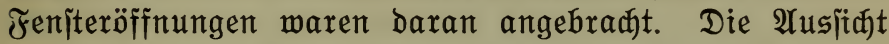
von Der jäbuen Bergterralle auf Die Berge und Ebenen im Diten und bejonders im Bejten eridjien uns nad) unirer langen Reije Durd̆ völlig ebene Ränderitređten bezaubernd ¡đjön, bejonders als ber भbend mit wohltuender Rühle uns exfrijate und bie Lambidaft von ber finfenden Gonne mit herrlidjem goldigem Ğlan

Die Leute von Banjeli erfreuen fith eines gemiflen Wohlitandes, Denn bie Eijenjamelzerei, jo primitiv ite aud ijt und jo wenig ite audi bie Eijenerze ausnügt, bringt bođ ganz nette Sümmden ins Land und jedenfalfs bei ben jegt nod herridenden Preijen der Lebensmittel jehr Iohnende Beiđhäftigung.

Die noch jehr viel Eijenerz enthaltenden Galaďen Iiegen ïberall in Mafien herum, und ber ipärliche Baumwud)s

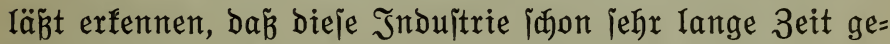
trieben wirb und babei ber Wsald recht tühtig herbeigezogen

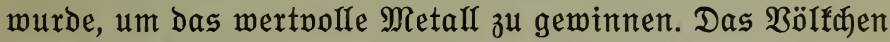
Der Banjeli lebt jo friedlich und vergnügt auf jeinen Bergen,

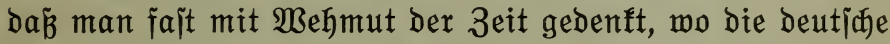
Grob́indujtrie bas Jonll won Banjeli itören und mit ifrem rationellen Groß̈betrieb die Edä̈ze Der Banjeliberge ver= arbeiten wird. Wenn bann gewaltige eleftrijae Ströme, won ben Loflobergen hergeleitet, bie ungeheuren Erajđäbe ber Berge ganz anders ausnüben werben, als es ber ein= fadhe, funtitloje Betrieb ber Landesfinder erlaubt, wirb wohl aud ber naipe findidide Charafter bes Bolfes Berände= rungen erfahren, und eine ganz andere 3eit wirb für bas

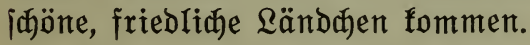

Die Leute von Banjeli find nur Eijenjømelzer. Sie bringen das gemonnene Guß̉eijen nach Bajari auf ben 
Marft, und dort faufen es Gdmiede von Rabure und Lollo. Bir hörten, fie permandeln bas Gukeijen in Sdimiedeeijen, inbem jie bas auf bem Marft gefaufte, jehr poröje (Gußzeifen

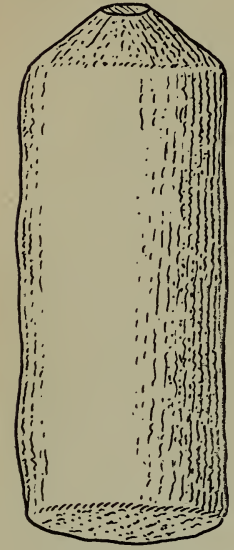

Urbb. 59.

in ganz fleite Stüd

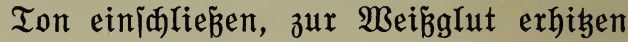
und es bann mit iteinernen Sä̈mmern

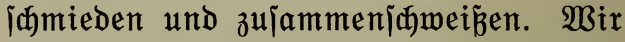
befamen einen jolden 5 ammer zu lehen. Er wog ungefähr 12 hilo, war annähernd zylindrijđ und hatte einen Durdame von etwa 15 und eine Qänge won un= gefähr $40 \mathrm{~cm}$. Das eine Ende war ganz $\mathfrak{f u r}_{\mathfrak{z}} \mathfrak{f e g e l f o ̈ r m i g}$ zugeipigt und hatte eine

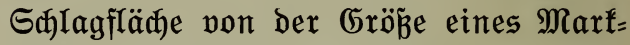
itï̈s. Dieje Sämmer werben mit beiden

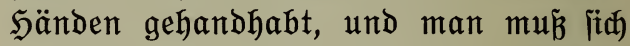
wundern, wie nette, gleiđmäß̈ig geidmie= Dete $\mathfrak{A r b e i t}$ die Reute mit joldhen primi= tiven Berf $z$ eugen zultande bringen.

Б) ammer.

Der Weg von Banjeli nad Bajari führt burch eine faum bewohnte Ëbene. Die ringsum liegenden Bergländer jind bagegen jiemlid biaht bewohnt. Am zweiten $\mathfrak{B a d}$, Dem

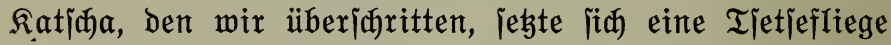
auf meinen Shut, ber vor mir auf bem Rabe hing. Der Rerjud, fie zu fangen, miß̉łang, und id fonnte in bem

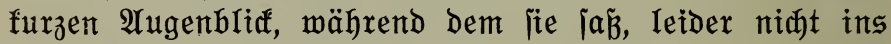
flare fommen, weldher Spezies fie angehörte. Jedenfalls gibt es bort Tletjefliegen. Es war bie exjte, die id, won Rorben fommend, beobaditete.

Die meiften Reute von Banjeli führen noch Pfeil und Bogen. Es ift aber zu ermarten, Dá bald modernere $\mathfrak{B} e=$ waffinung an Stelle berjelben treten werbe. IJ nahm bie belegenheit wahr und bat brei bes Wegs baherfommende junge Leute zwijßjen Banjeli und Bajari, mix nod $j^{\mathfrak{u}}$ einem Bild ju itehen. Beinahe wären fie mir aber 
au币 ausgefniffen, wie die Ronfomba = Sagd = gejerrjart. Der eine von ihnen benubte einen unbemachten Augenbrif und jegte in hohen Eprüngen über Stod und Stein bavon, und es দätte niat viel ge= fehlt, jo wären jeine $6 e=$ nollen ifm ebenfalls nadgeeilt. Sier feierte aber meine Riebens= würdigfeit einen

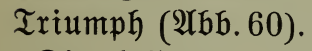

Die beiben blieben tapfer itehen, wenn fie aud nidt be= jonbers freund= Iid)e Gejuthter zeigen. Jeden= falls bürfen fite it(i) in ganzer Jigur jehen

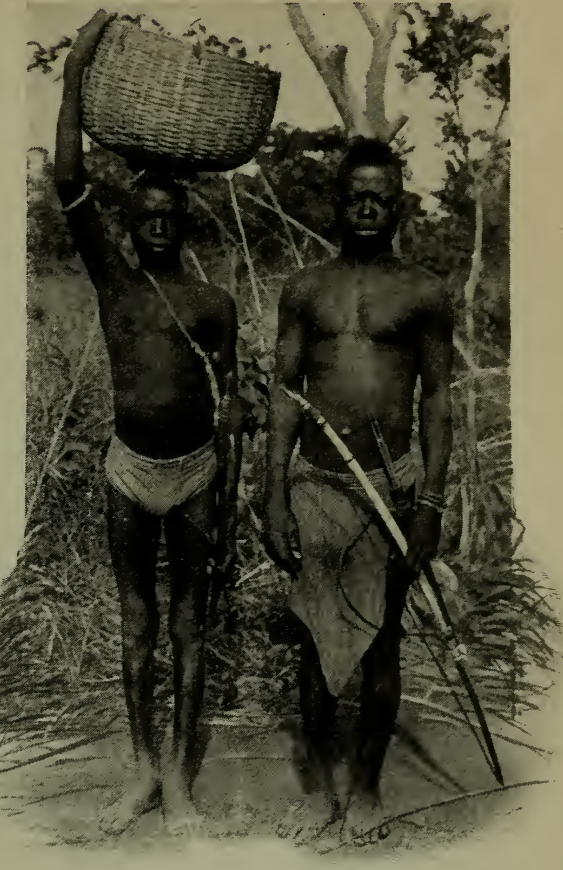

2:bb. 60 .

Huf dem ralege in die pflanz̧ungen. Iafien, Denn von Banjeli an wixd die Kleidung bedeutend belier. Bald nachyer begegneten wir einem itrammen

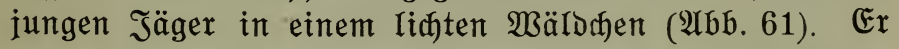
trug nicht nur die unentbehrliche Beilhacte, wie fie die Moba und Ronfomba führen, über der recten Sdulter, jonbern war now mit einer gewaltig langen Steinjhloz= flinte bewaffnet, an melder eine Unmafie Armulette vor und hinter Dem Saloz und nahe der Mündung hingen; alle waren reid)lid mit vertrodnetem Blut von Dpfer tieren beitrichen. Die mannigfaltigen Moden ber $\mathfrak{G a a x}=$ 
tracht find auf beiben Bildern ou erfennen. Die Bogen= ¡đü̈en haben einen breiten Streifen Saar auf Dem Sheitel, Der mit Dem Gemehr Bemaffnete hat nur eine iđmale Raupe itehen Iallen.

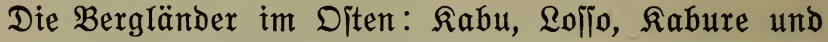
Diambe, jahen mit bejtändig fị veränbernben $\mathfrak{U}$ mailjen zu uns herüber. Die Banjeliberge mit ifrem fich gleich)= bleibenden $\mathfrak{U m r i \tilde { B }}$ winften uns nod lange $3 \mathfrak{u}$, und oft

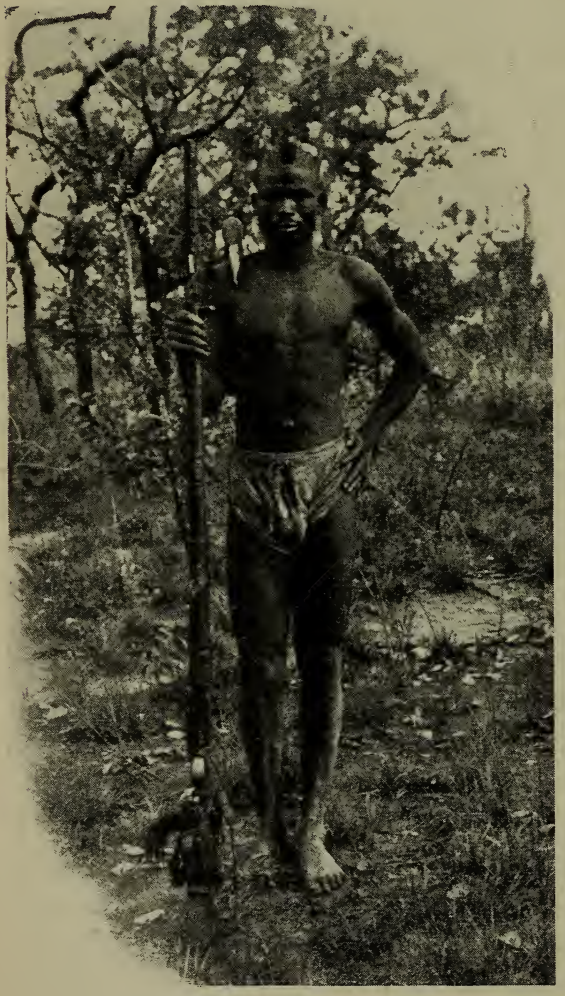

Ibb. 61. Huf der Jagd. nod verweilten $\mathfrak{u n}=$ jere Gedanfen bei den freundritben, waffern Eijen= idmelzern in ben Dörfern jener Berge.

Immer näher rürte nun auch dex ¡ðöne Gebirgsitod ber Bajariberge. Bon Norben ex= jheint er als hoher,

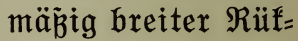
fen, Dem im Weiten ein fegelförmiger, mehr vereinzelt itehender Berg vor= gelagert ift. Die projeftierte Eijen= bahn nach Banjeli und Ijaopowa joll, wie wix hörten, in Der Niederung $\mathfrak{z}^{\mathfrak{w} \mathbf{i}=}$ jđen diejem Berg, dem Rafi und ben Bajaribergen 


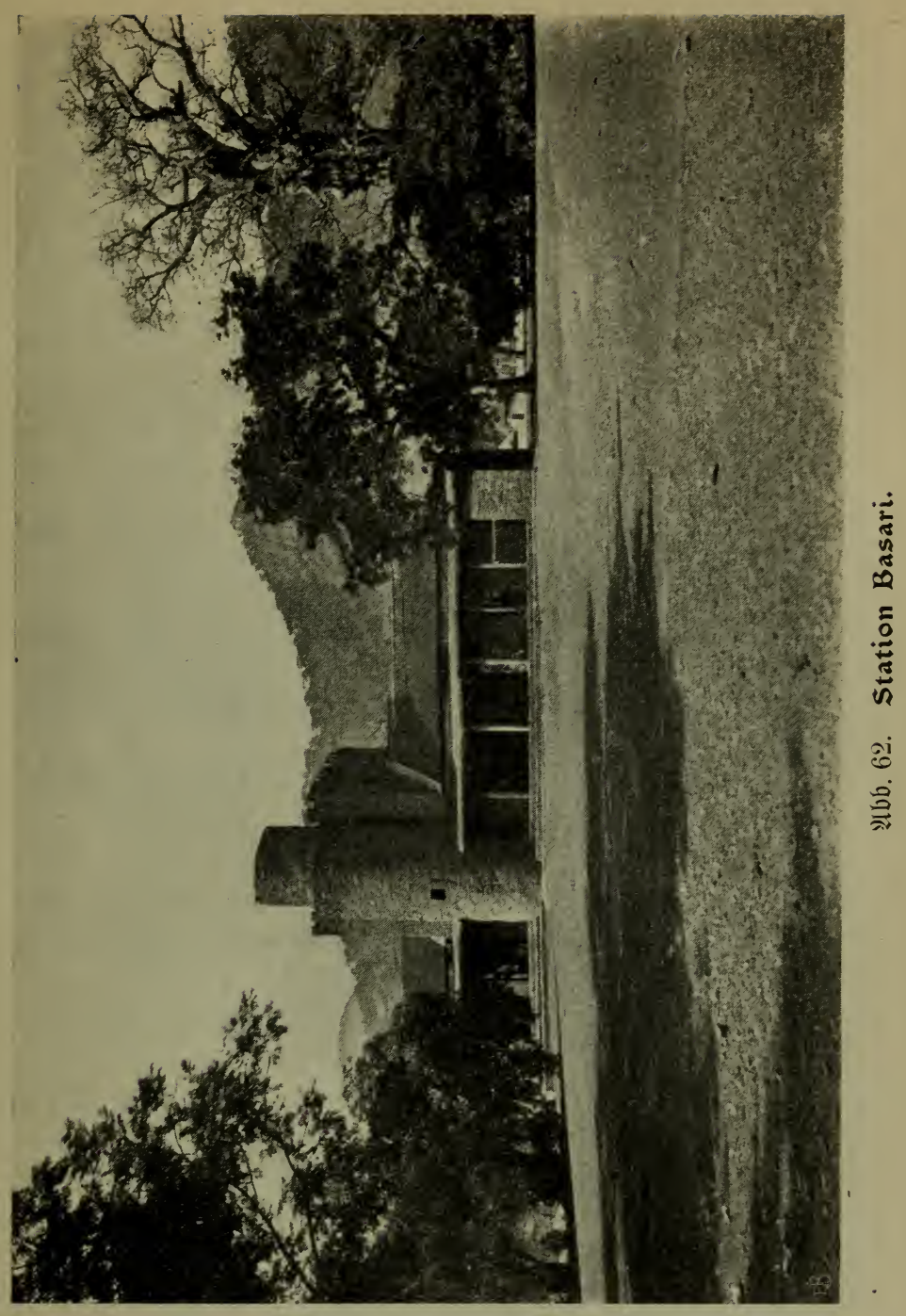


Durchiüren. Je näher wir famen, deito deutlidber

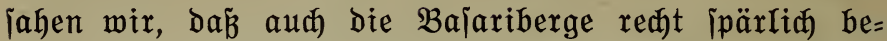
waldet jind. ilberall jahen grö̈ere und fleinere fels=

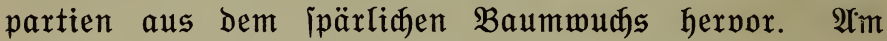
Rorbojtfú bes $\mathfrak{B a j a r i b e r g e s ~ e r h e b t ~ f i đ ~ d i e ~ n i đ t ~ u n b e b e u = ~}$ tende Stadt. Eintge Teile banon Iiegen auf etwas höher gelegenen Terraffen, andere in tieferen $\mathfrak{L} a g e n$, und etwa einen Rilometer weiter, am Ditfúp des Berges, bie $\mathfrak{R} e=$ gierungsitation $\mathfrak{B} \mathfrak{a} \mathfrak{i} \mathfrak{a} \mathfrak{i}$.

Der Stationsleiter, Sherr Sofbauer, empfing uns mit

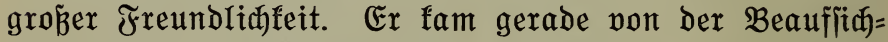
tigung eines Brïffenbaus über den Kamaa, einen Neben=

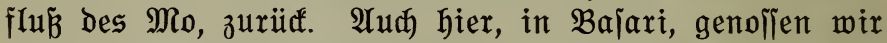
bie reidje (5ajtfreundjđaft und ianelgten in Geniüfen, bie

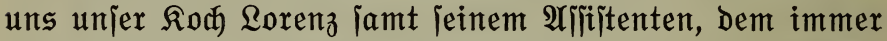

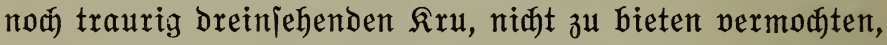

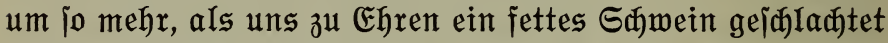
murde und Megeljuppe und andere Creniilfe uns geboten murben.

Bejtli() von Der Station führt ein iđjön angelegter

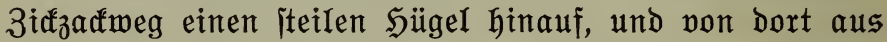

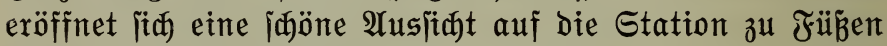

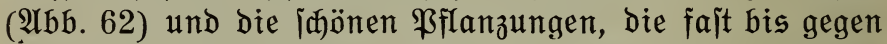
Nambam im Diten hinüber reiden, und bann auf bie fernen

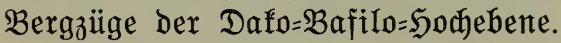

Der Marft in Bajari ift jonjt jehr bejudt. In ber Zeit, in welder wir Dort waren, herriđte gerabe eine Epidemie non Genicfitarre in Den öjtlichen Gebieten, und man ipürte es Dem Marftwerfehr an. Reben Den veridiedenen Erzeug= niflen ber Lanbwirtidaft befam man aber bod aud bie

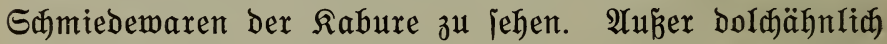

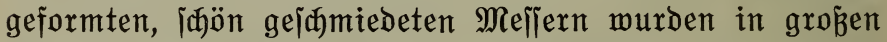
Mengen bie runden, Dünn ausgeidmiebeten Eijenplatten für bie Saden ber Bauern jum Rauf angeboten. 
Im G(hatten einiger G̈̈̈tten jä̉en Banjelijungen und

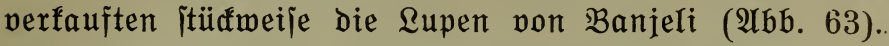
Der eine von ihnen trägt ein lebernes (Geldtäjđduen an einem Riemen, und neben ihm itehen die Rürbisflajaen mit $\mathfrak{B a}$ ifer.

Der Stationsleiter hatte bie Riebensmürdigfeit, uns in Dem jehenswerten botanijøen Garten herumzuführen, ber mandies uns nod Uanbefannte enthielt. Wix trafen aud alte Befannte von ber Reije her, fo namentlid eine pradt= volle Aroibee, beren Spata vom tiefiten jammtenen DunfeI = braun bis zum helliten Gelbbraun in feinen Streifen einen.

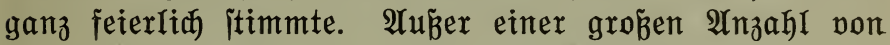
Frudtbäumen, bie wir nođ) niăt fannten, itanden in Garten ein paar herrlidge Eucalyptus citriodora, bie vor= trefflid gedeihen und bie, wie wir ipäter in Itafapame jahen, in grof̉er 3ahl angepflanzt werden. Was aber im Diten. ber Station gepflanzt iijt, ijt nod das Benigite. An ber Strä̉e nach Solode entlang reidhen die $\mathfrak{B f l a n z u n g e n ~ n o d , ~}$ jehr weit, und bem $\mathfrak{B e g}$ entlang ijt eine 3 Rilometer lange. A̛lee von herrlidien Mangobäumen gepflanzt. $3 \mathfrak{u}$ unierm. großzen Reid waren bie frühte nod nidyt reif.

In Bajari verlié́ uns ber Goldat von Mangu. Er $\mathfrak{i}=$ wohl als jeine Frau, bie ifn begleitete, baben fitc bis $j^{\mathfrak{u}}=$ legt ganz ausgezeidnet gehalten. Seine Frau wükte fin bei jebermann Rejpeft ju veriøaffen. Sie war bie erite am

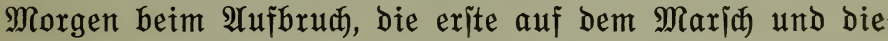
erite bei ber $\mathfrak{A r b e i t ~ a m ~ R a j t o r t , ~ i m m e r ~ f r o ̈ h l i c h ~ u n d ~ g u t e r ~}$ Dinge. Es war uns ganz leid, ben wad́ern Leuten nidht auá) etwas Drbentlides bieten zu fönnen.

\section{Bon Bajari nadi Sofode.}

$\mathfrak{A} m$ 24. März bradben wir auf. $\mathfrak{A} m$ Ende ber brei Rilometer langen Mangoallee famen wir an bas tief ein = geidnittene Tal bes Kamaa. Die neue Brüafe mar nod. 


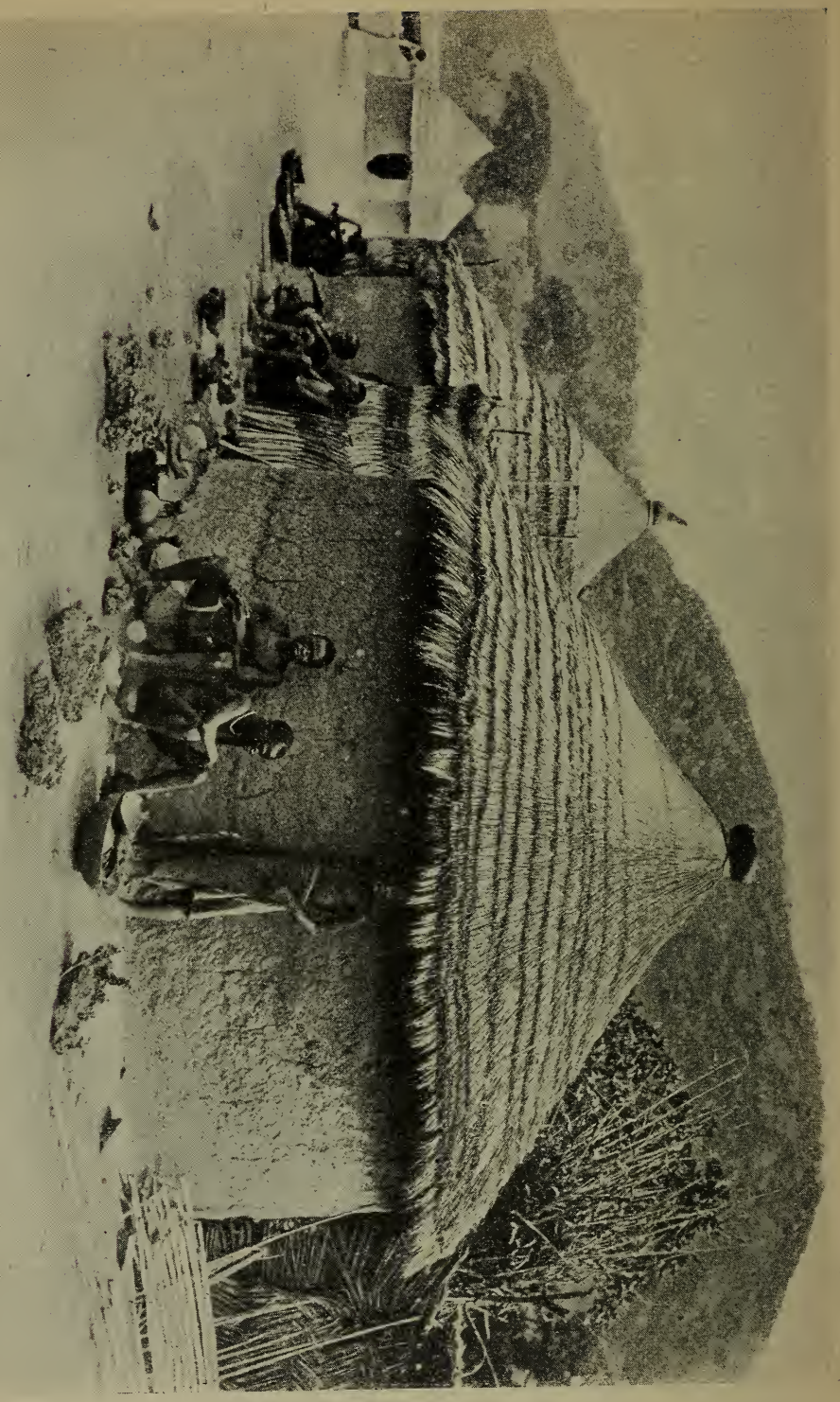


nidft fertig, wir zollten aber ber Bieljeitigfeit ber beutichen Beamten bie verbiente $\mathfrak{A}$ rerfentung, als wir bie mädtigen Balfen jahen, mit welden bie Brüfé belegt wirb, und bie hohen hörzernen Pfeiler, auf benen fie iteht. Der Gejtaltung

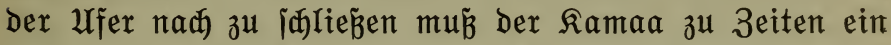
redt wilder Gejelle jein, went aud vielleidht niagt jo will, wie jetn Gefährte, Der $\mathfrak{B e m p e u , ~ m i t ~ D e m ~ D e r ~ \Re a m a a ~ v e r = ~}$ eint in ben $\mathfrak{M} 0$ mündet. Das $\mathfrak{B}$ ett bes $\mathfrak{B e m p e u}$ füfrte nur menig Wafjer, aber es war angefüflt mit eritaunlichen Mafien von Quarzgeröll in allen Größ̈en. $\mathfrak{A} n$ einem jehr

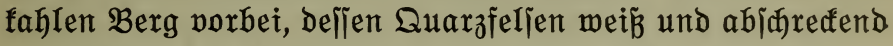
unfrudtbar ins Land hinaus leudteten, führte ber $\mathfrak{B e g}$ in ein Tal, Das bald iteil anjtieg und an einem gemaltigen Bergabhang endete. Ėin flares Bergbädhlein erquifte uns, und im Sđatten ber Bäume fanden wir eine herrlide $D \mathfrak{r}=$ hibee. Es war aber ein beidwerlides Gtüa Arbeit, mit ben iawerbepađten Räbern ben hohen, iteilen Berg hinauí= zuflettern, wo oft die Straß̉e faum noch angedeutet war.

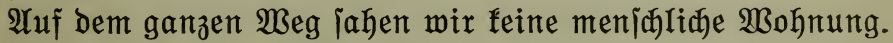

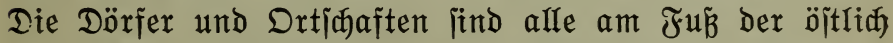

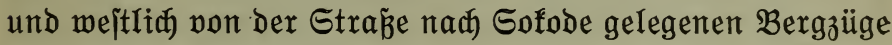

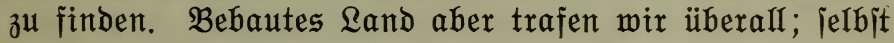
auf einer Ierrafle bes jonft jo iteinigen Bergzuges fand fith eine üppig itehende $\mathfrak{B f l a n z u n g , ~ u n d ~ e i n i g e ~ F r a u e n ~ f o r t e n ~}$ am Weg Epeije für Durdhreijende. Endlid waren wir auf

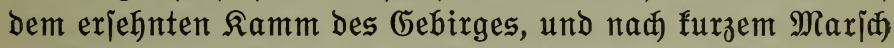

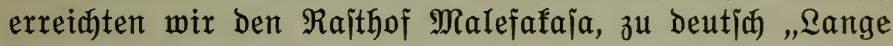
Frinte", nidgt weit unter Dem ßamm Des Gebirges, in menjhenleerer Einöbe gelegen, 29 ßilometer von Bajari. Die beiben gró̉en Rundhütten murden von uns bezogen, und faum waren wir angelangt, fo rannte am jenjeitigen গ̛b̆ang, in einer Entfernung von etwa 250-300 Metern, ein Ruber ßaviane ben Berg hinaụ, voraus ein märtiges Männđhen. Einer der Soldaten war gleiđ bereit, fid) und ieinen (benofien einen Braten zu veridaffen. $\mathfrak{u} u($ mir 
fuhr bie $\mathfrak{J} a g d \mathfrak{l u j t}$ ins $B \mathfrak{l u t}$, um fo mehr, als es fith um Faviane handelte, bie überall befannt find als Bermüiter

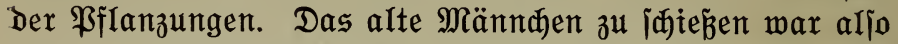
nod ein gutes Werf. Ja nahm barum bas Gewehr bes Soldaten und nahm den alten $\mathfrak{P a v i a n}$ aujs Rorn. Die

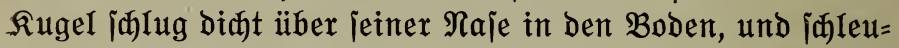

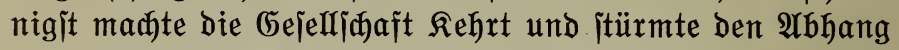
Jinunter. Die Goldaten ifnen nad). Nad einer halben Stunde, während weldher brunten im Tal nod weitere Sđjülie gefallen waren, bradten jie bas Iter herauf. 3wei Männer hatten genug an ihm zu tragen. Es war ein un=

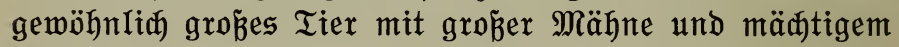
rebiä.

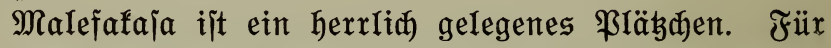
cinen Durd geijtige $\mathfrak{2}$ rbeit und bas Einerlei Des Dienjtes erjö̈pften Mann gift es nidhts Baflenderes, als bie itille Einjamfeit bes abgelegenen Rajthofes mit ber herrliden Yusfidyt, die je nad dem Stand der Gonne immer wieder meue Saböneiten offenbart. Im Rorbojten jieht man bas

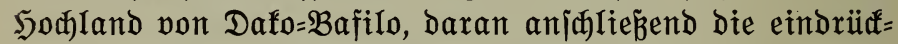

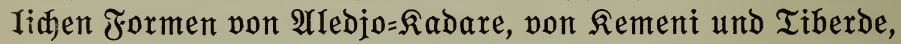
im Süboiten bas breite Roronagebirge mit bem hod)=

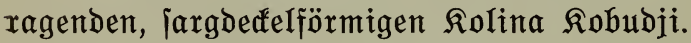

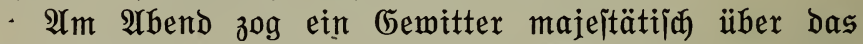
Soronagebirge bin, und am Morgen fonnten wir uns fajt nidyt trennen won ber $\mathfrak{P r a d g t}$, weldhe die über ben Rerede= berg aufiteigende Gonne über $\mathfrak{B e r g}$ und $T$ al ausgoj. Möge bod bald ber Tag fommen, da es audh in ben Sherzen ber Bewohner jener Berge hell wird burd das wahre Lidyt der Belt!

Mit joldhen Gedanfen exfüllt, itiegen wir himunter ins Tal und am Abhang breiter, wöllig unbemohnter bügel= rü̋fen wieder hinauf. Beit und breit fein menichliches Bejen. Rađ 12 Rilometern erreidften wix ben Mo. Sein Bett ijt bort jehr felfig und tief eingeriflen; bas wenige 


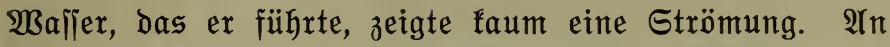
jeinem Iinfen Ufer fanden wir ein armjeliges Dörfảen, bas einzige auf Dem 29 నilometer langen $\mathfrak{B e g}$.

Wohl 6 Rilometer vor Sofode überrajate uns der Bezirf́sleiter, Serr Dberleutnant Säring. Trob jeiner jehr exjüitterten Gejunbheit wax ex uns jøon am vorber = gchenden Tag entgegengeritten und hatte fith die Mühe

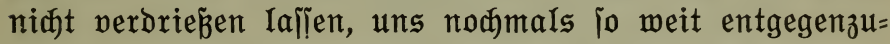
fommen und uns freundich bei fïd zu Gajte zu Iaden.

Sofode madyt einen ausgezeidneten Eindrua. Das mafifive, aus Steinen und Lehm erbaute $\mathfrak{B o h n a u s ~ D e s ~} \mathfrak{B} e=$ jirfsamts zeigt in leiner Anlage und Einriđtung überall die Spuren bes exfahrenen und äuß̈erjt tühtigen frühern Bezirf́sleiters, des Dr. von Reriting. Es enthält hohe, Iuftige und fühle Räume und gegen Sonne und Regen gut geinübte Beranden. Im Saal fehlt jogar bas behag=

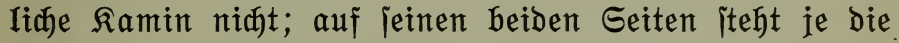
Sälfte eines Elefantenjđäbels als Samud, vor inm liegt als Ieppiđ eine হömenhaut, und um ben Iijø herum Iaben in Sofode perfertigte behaglidhe Stühle zum Sigen ein. Am Ditende ift eine herrliche grože Salle, die als Beriamm= Iungsort und Geriatshalle bient.

Reats im Bilde fieht man einen jehr felfigen Sügel mit ber Flaggenitange. Bon jeiner Spize aus ijt $\mathfrak{U} b \mathfrak{b} .65$ ge= nommen. Bom Bezirfsamt jieht man nur bas mit Matten won Blattrippen Der Raphiapalme gejäjute Dit=Ende. In Der Mitte Des Bildes ift Das Gefängnis, Das Saus mit Dem balb offenen Giebel, davor die doppelfegelförmigen $\mathfrak{B} e=$ hälter für die Sirje. Ganz Iinfs im Bille ijt das Gebäude

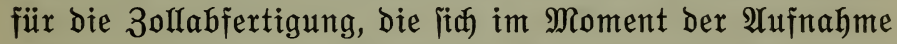
vollzog. Shinter dem Bezirfsamt fieht man die zahlreidjen Runbhütten ber Goldatenfamilien, und meiterhin fann man gerade noch die groźartigen \$flanzungen erfennen, die jüb= Iich pon Gofode gelegen find und 270 Seftar umfalien. Etwas linfs vom Bezirfsamt iteht ein jđattiger Baum, und 
unter ihm ruht ein waderer Deutiðer, Franz Brajhe, Der nor elf Jahren in Sofode an Gdwarzwallerfieber itarb.

In der Nähe der Station ift eine Baummoll= entfernungsanlage untergebradt. Es fam, als wir dort waren, eine $\mathfrak{R}$ aramane von über 100 Irägern von $\mathfrak{B a g u}$ mit Baumwollaiten. Durah die Güite Des Stationsafiiftenten.

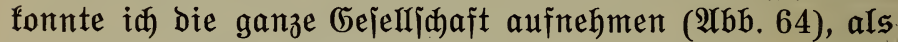
iie gerabe an ber Rüuffeite ber Baummolfreinigungsanlage ausruhte. Die $\mathfrak{A r b e i t ~ D e s ~ E n t f e r n e n s ~ w a r ~ b a l d ~ g e i d e h e n , ~}$

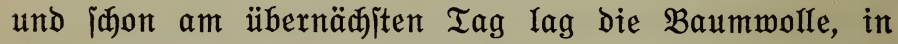

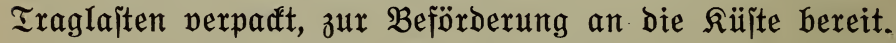
Die Regierung liefert Den Baumwollpflanzern bas Gaatgut

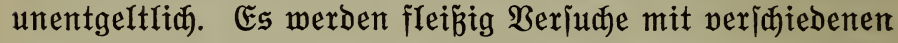
Baummollarten in Den Regierungspflanzungen angeitelft,

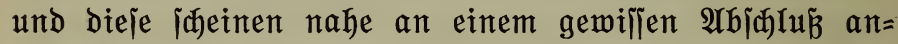
gelangt zu jein. Die $\mathfrak{A} r t:$ gossypium neglecta ideint für jenes Gebiet bie empfehlenswertejte ju jein. Der Bezirfs= leiter hatte in jener 3eit bei feinen Bemiihungen, bie $\mathfrak{B i e h}=$

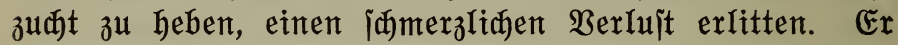
fatte mit grober Sorgfalt einige prädtige 3udtodjen her= angezogen und jie in einem [änen, Iuftigen Stall unter= gebradt. Einige Tage vor unirer $\mathfrak{A n f u n f t}$ erfranften vier Der präđtigen Tiere und itarben $\mathfrak{f u r}_{\mathfrak{z}}$ nacheinander an $\mathfrak{M i l}_{\mathfrak{z}}=$ brand. $\mathfrak{A} u \mathfrak{d}$ bie ïbrigen vier waren nidgt ganz wohl: Soffentlid find dieje wenigitens erhalten geblieben.

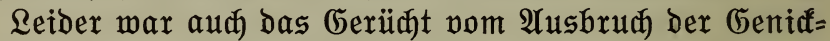
itarre in Rabure $\mathfrak{B a h r h e i t , ~ u n d ~ i d ~ h a t t e ~ j o g a r ~ G e l e g e n h e i t , ~}$

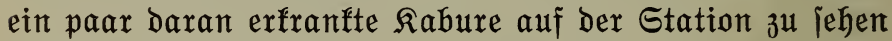
und $\mathfrak{u}$ tun, was id für fie tun fonnte. 2 d, es war jo menig, roas man ben in tiefer Bemußtlopigfeit Riegenden an= gebeihen Iallen fonnte. Es war mir Ieider unmögriç, zu entidgeiden, ob wirflid Genideftarre vorlag, oder ob es fid nidht um bie fehr idwer verlaufende form von franfheit, die bas Bild ber Gehirnentzündung annimmt, handle. Mit Sdreefen Dadten wir Daran, weld furdtbare 


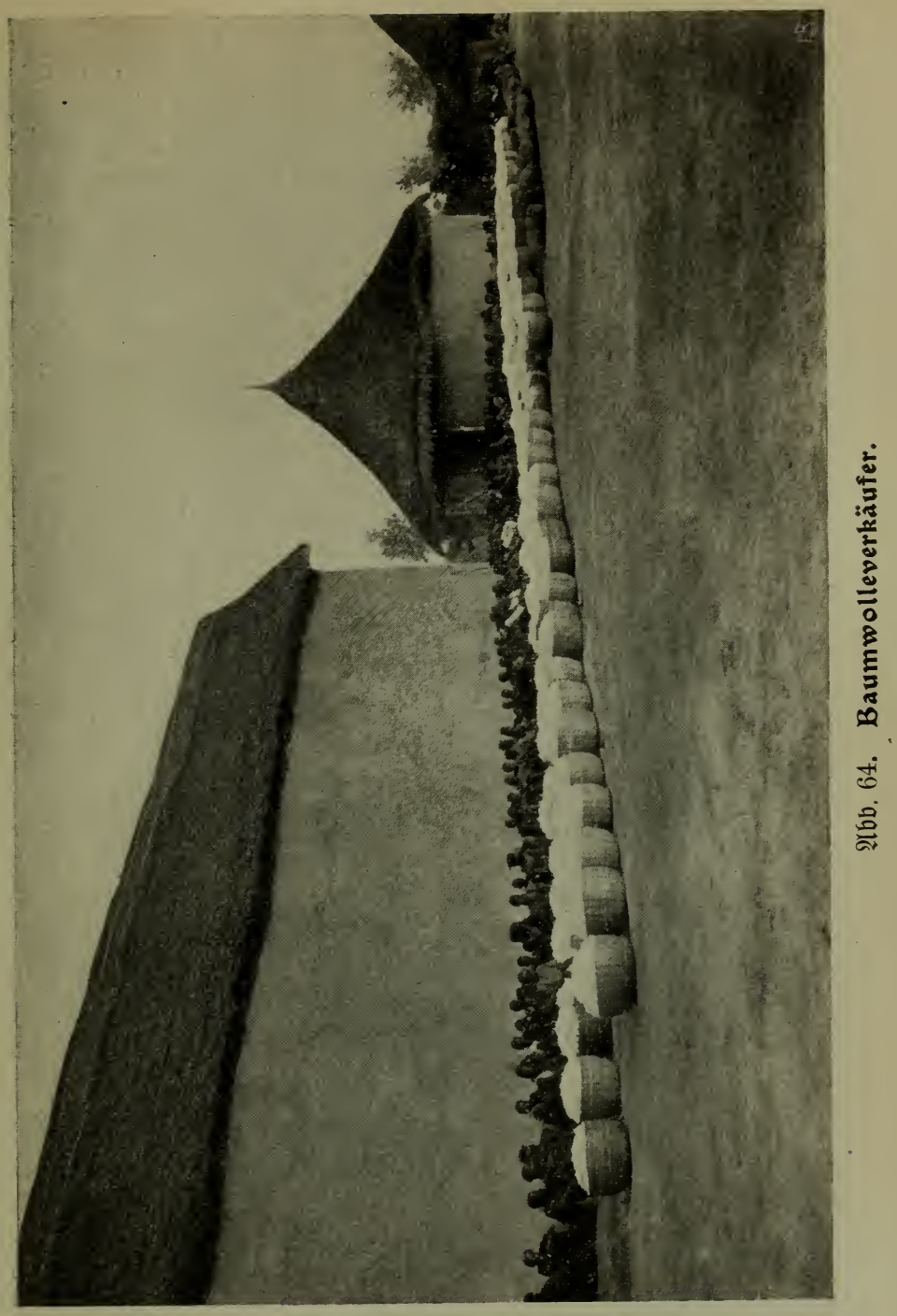


Rerheerungen bieje entiebline Rranfheit in ben englijhen Gebieten nörblich von Rintampo vor einigen $\mathfrak{J} a \mathfrak{h r e n}$ an= geridatet hatte. Man iprach Damals von 75000 Meriaden, sie ber Seuche zum Dpfer gefallen feien, und in Tamale er: zählte uns ein Dffiłjier, bá̉ in jenen Gegenden nod jegt ganze Shaufen von Meniđjengebeinen auf ben Shügeln herum= liegen und fajt bie ganze Einwohnerihaft von ber Rrant:

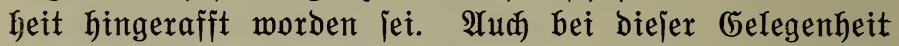

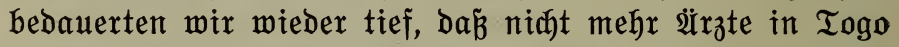
itationiert find. Wie viel fönnte bod ein Regierungsarat in jolden erniten Beiten tun, und wie mandes Menjahen= leben fönnte Durd inn gerettet werden!

Am Morgen nad unirer $\mathfrak{A n f u n f t}$ in Sofode hatte

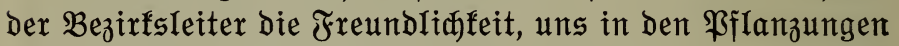
herumzuführen. Da befamen wir aufs neue einen Eindrud von ber grózzügigen $\mathfrak{A}$ rbeit, bie auf ben Stationen in biejer Sinfidyt getan wirb. Die groźen Landitürfe, bie mit Teaf,

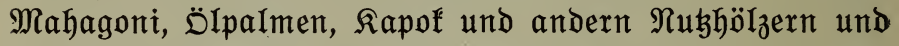
Frudtbäumen bepflanzt find, madhten einen vortrefflidhen Eindrư์. 3ugleid werben bie Einmogner auf alfe möglidge Weije ermuntert, ebenfalls joldje Bäume zu pflanzen. Dieje weitfithtige $\mathfrak{A}$ rbeit ber Regierung fann nidft anders als hoderfreulidje friüte für bie Rolonie tragen, und was für ein herrlidher Sdamut werden dieje fein, wenn fie in wentgen $\mathfrak{J} a \mathfrak{h r e n}$ bie prärbtigiten $\mathfrak{B a ̈ l}$ ber bilben merben! überall Den Strä̧en entlang itanden mit Früdten reiø belabene Mangobäume, und unier Bebauern, nidgt ein paar Bodjen ipäter hier zu jein, bas wir finon in Bajari empfumben hatten, erteuerte itch.

Im lebten Radhmittag, an weldem wir in Solobe waren, hatte ber Bezirfsleiter bie Freundidffeit, ben Rönig

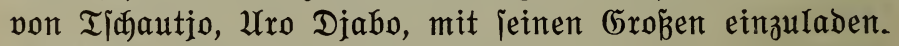
Sie famen gegen 4 uhr alle zu $\mathfrak{B f e r d}$, zum Teil ausnehmend gut beritten. Sie verjammelten ita gleid nad ifrer $\mathfrak{A n}=$

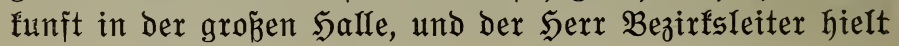




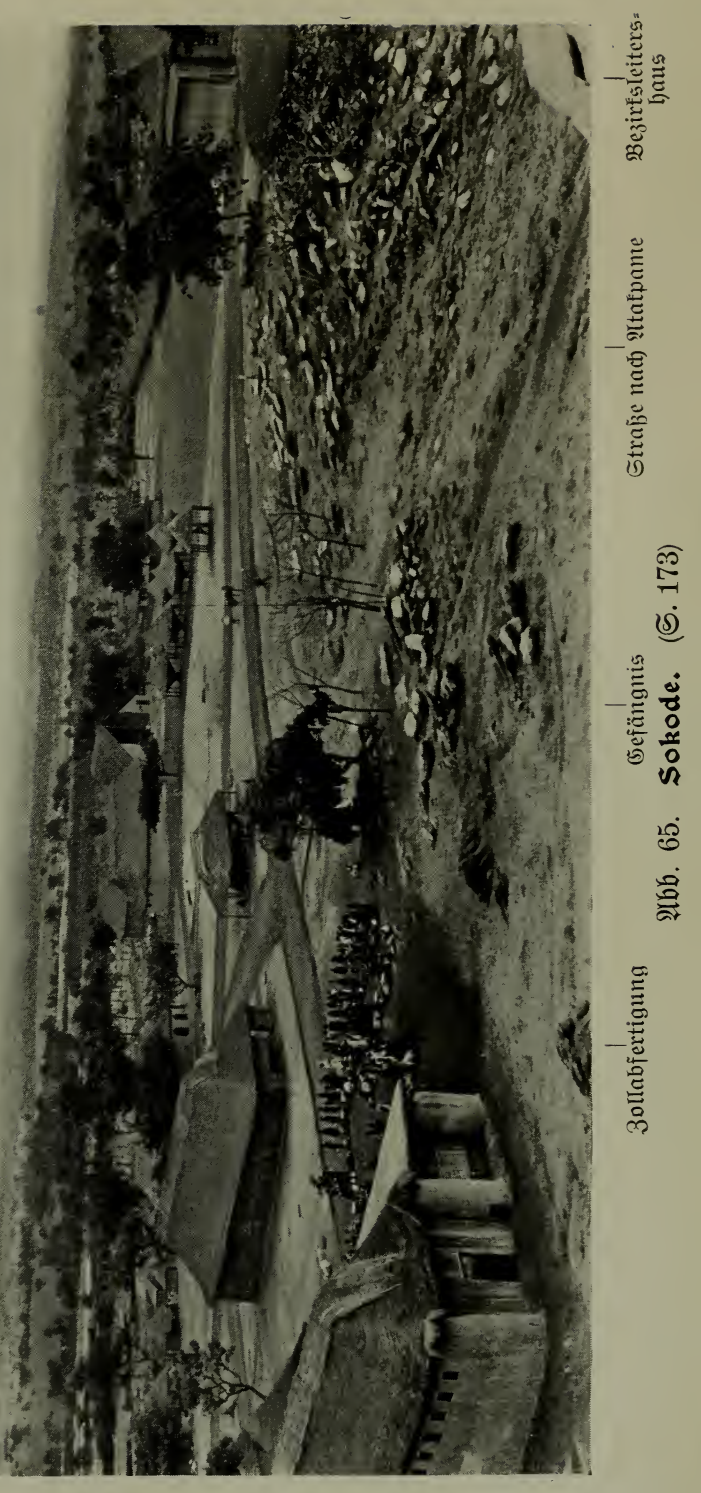



ifnen eine $\mathfrak{A n j p r a d x e , ~ i n ~ w e l d ) e r ~ e r ~ u n j e r ~ u n d ~ D e s ~ 3 m e d ́ s ~}$ unjrer Reije ermähnte und fie bann bat, boc ja bie nötigen

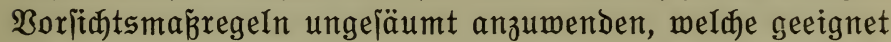
ieien, Die beiben jhlimmen Rranfheiten, die Genidfitarre und den Milzbrand zu befämpfen. Uro Djabo ijt ein lebr bunfelfarbiger, forpulenter, ausnebmend fräftig gebauter

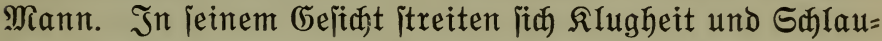
heit um Den Borrang. Die weichern Züge, weldhe Serzens=

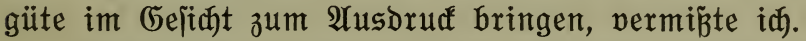

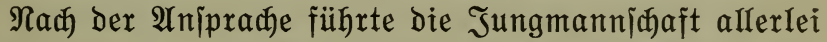
Spiele auf. In die Mitte itellte fich die Mufffbande mit groß̉en und fleinen Trommeln auf; um fie herum bildeten (itr) zwei Rreile pon je etwa 25-30 Mann. Jeber hatte ein langes Mefier in Der Sand, und im Taft Der IrommeIn brehten fich nun die হreije in entgegengejegter Ridhtung. Die Spielenden freuzten babei mit jebem, ber an ifren

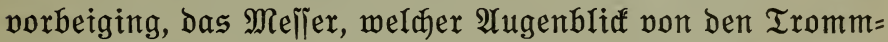
Iern bejonders betont wurbe. Sin und wieber rannte ber cine oder andere aus jeinem Rreis heraus, itürste fich vor einem Der S̆äuptlinge auf Das eine Rnie und hieb joinbar mit voller Rraft mit jeinem Mefier auf die innere Geite jeines Dberiđenfels. Niemals trat babei eine Berlebung ein; nux nahmen jolche dann etma veritohlen einen Gras= büichel oder ein paar Blätter, rieben auf ben getroffenen Stellen fräftig und majiferten wohl auj bieje Weije fleine BIutaustritte unter ber Saut meg. IUa ein Ermahjener, ber offenbar bas Spiel leitete, bearbeitete die blož̉e Brult und ben Baud mit jeinem Mefier, indem ex bamit freuz und quer Darüber hin fuhr und auch andere in ber Weije be=

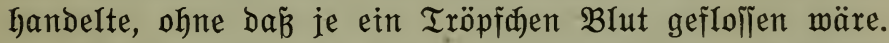

Biel aniprechender mar ein Stabreigen, Der nă diejem wilden Edwertertanz folgte. Es bildeten (ïd) wieder zwei Rreije. Jeber Ieilnehmer hatte einen furzen Stab in Der Sand, und im Taft Der Irommeln gingen nun die Stab= träger in Der gleiden Ridtung, freuzten aber immer 


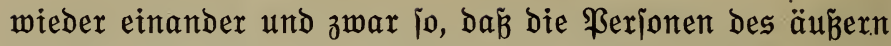
Sreijes nadh ein paar Gdritten im innern $\mathfrak{R}$ reis waren und umgefebrt; im $\mathfrak{A}$ ugenblidx, wenn fie aneinander vorbei=

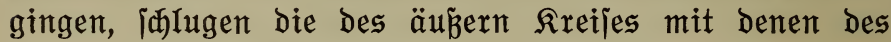
innern die Stäbe zujammen. Diejer Moment entiprad immer einem bejondern $\mathfrak{A}$ uftaft bes Trommelfonzerts. 3wijhen hinein wurben an bie Spielenden Rolanilile und Tüher verteilt, und die Groß̈en jorgten bafür, Dá̉ fie

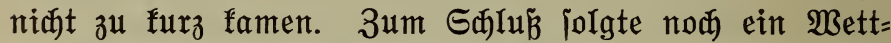
ronnen auf furze Entfermung, wobei aber bie \$ferbe jehr geplagt wurben, indem fie mitten im tolliten Jagen plöblid mit aller Madyt angehalten wurben. Smmerhin gab es Gelegenheit, bie eritaunlidje Gattelfeitigfeit, jelbit ber ganz jungen Buriden, zu bewundern.

\section{Bon Sofode nad Âtafpame.}

Raç Dreitägigem $\mathfrak{A}$ ufenthalt in Gof́de verabjđiedeten

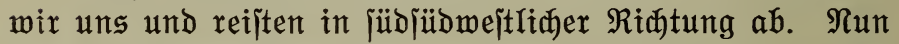
lagen bie Berge hinter uns, und bie weite Ebene Dehnte fid. vor uns aus. Nur im Beiten jahen wir nod die niebrigen Berge von Fajau und $\mathfrak{B}$. Die Gegend idheint reedt bünn be=

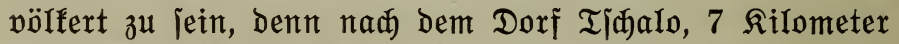
won Gofode, famen wir an fein Dorf mehr, bis bei ßilo= meter 20 Jare= Jare, ein jehr bürftiges Dörflein, am Wege eriøien. Reun weitere Rilometer bradten uns nadh $\mathfrak{A} \mathfrak{u}$,

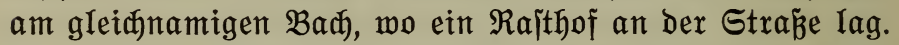
Er hat leider aud einen etwas fosmopolitijaen Charafter, wie Der von Diereponi und Bapuli. Allerlei Krämernolf hatte fid darin eingenijtet, und pogar ein armer, an Genid"= itarre erfranfter Mann war von leinen 2 ngehörigen in ben Rajthof gebradyt worben. Wir musten ifn in eitre ge= eignetere Siutte umquartieren, wenn won eitrer foldhen über= haupt bie Rede fein fonnte, da bas $\mathfrak{A}$ nwejen won allen mög= Iiçen Reuten bejegt war. Die $\mathfrak{A n m e j e n h e i t ~ d e s ~ \Re r a n f e n ~}$ 


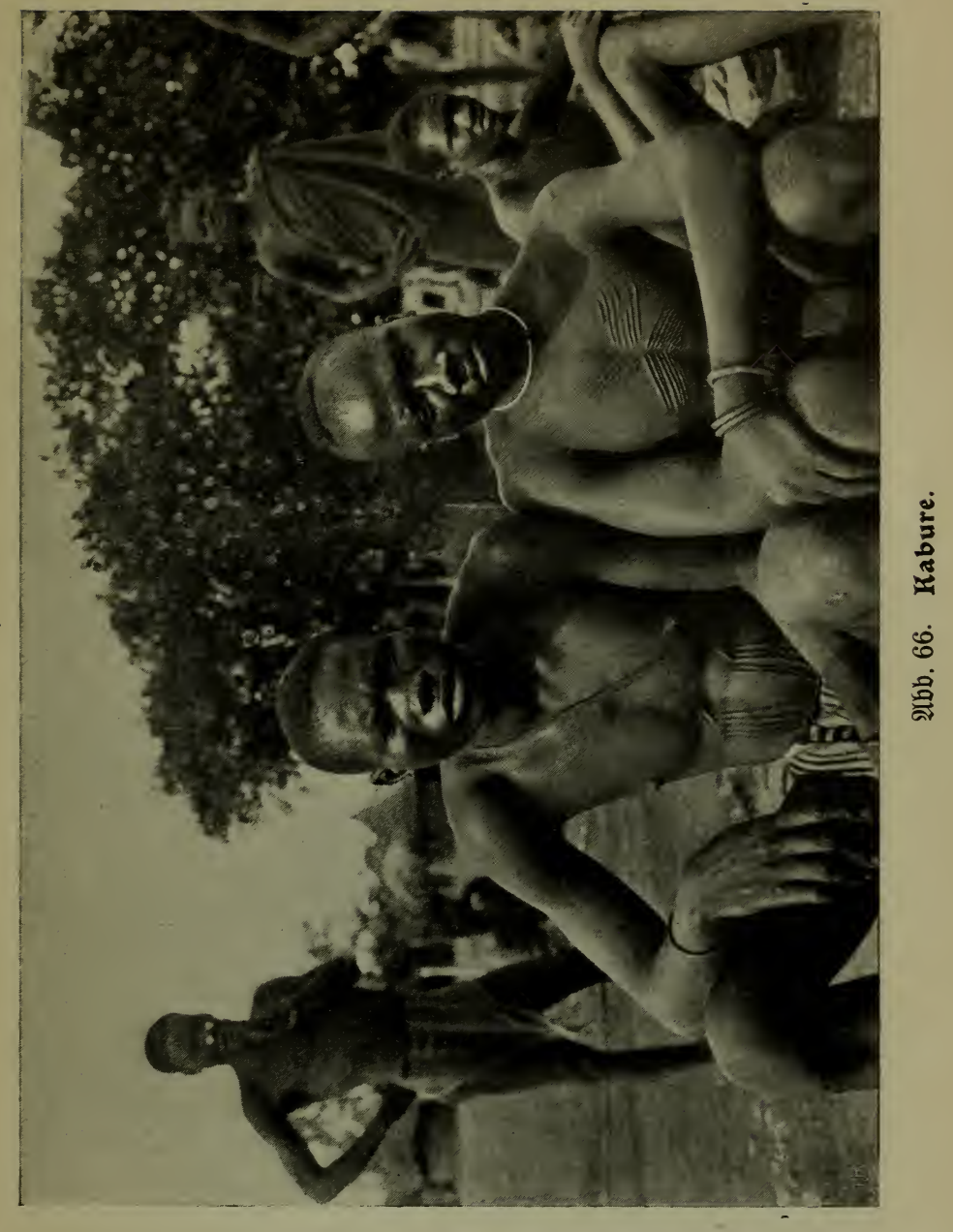


hinderte aber bie Rente nidgt, bis in bie tieje Radyt hinein lärmend und fingend im Rajthof $\mathfrak{u}$ tanzen, bis wir $\Re$ uhe geboten. Wir waren zul einem wentiger zart angelegten Bolfsitamm gefommen. $\mathfrak{A} u$ und das weiter jïblid an ber Etraß̉e gelegene Dorf Djabotaure find, wie wir hörten, $\mathfrak{B e r}=$

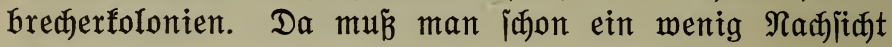
haben.

Im nädjiten Tag fuhren wir an Diabotaure porbei. Der Dortige Rajthof war nod um ein gut Teil belebter als ber in $\mathfrak{A}$. Die Rleidung ber Leute murde wieder bedenflici fnapp; itatt ihrer glauben fie auf eine uns neue und un= gewohnte $\mathfrak{2}$ rt ihrex Shönheit aufauhelfen. 3wei junge Rabure in $\mathfrak{A b b} .66$ zeigen bieje abjonderlidbe Berzierung Sie tragen in beiben $\mathfrak{R a j e n f l i ̈ g e l n ~} 15 \mathrm{~mm}$ breite Echeiben

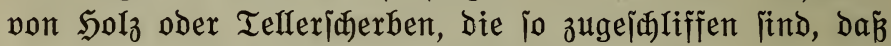

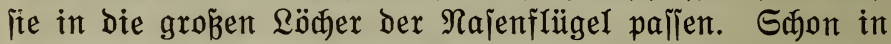
Sofode hatte id bieje Röder bei einem an Genidétarre ex= franften Ћabure geiehen und war zuerit ganz iiberrajht,

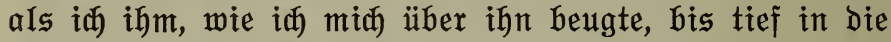

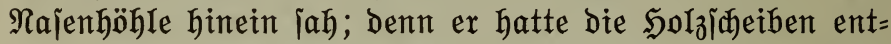
fernt. Der junge Mann Iinfs im Bild trägt nod die $\mathfrak{H}_{0} I_{3}=$ ineiben, ber redgts jajon bie moderneren Sdjerben in ben

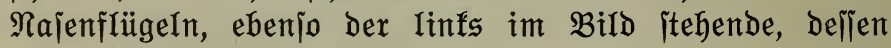

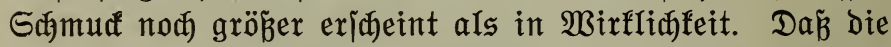
Rabure das Tätowieren veritehen, zeigen bie „jwönen“ Tätowiernarben auf $B \mathfrak{B u}$ it und Baud der jungen Buriđen.

Djabotaure liegt am frú eines jehr iteinigen Berges,

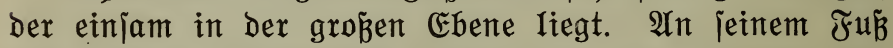
find ziemlid umfangreidye $\mathfrak{B f l a n z u n g e n ~ v o n ~ M a n i f o t ~ a n = ~}$ gelegt. In Der Gegend jollen häufig Söwen vorfommen, aber wir jahen niđts won ifnen. Bir fuhren weiter nad) Blita ober Bilta. Im $\mathfrak{R a j t h a u s ~ v o n ~ B i l t a ~ h a t t e n ~ f i c h ~ g e = ~}$ rabe bie Reute mit ben Baummollballen won Sofode ein= geniitet und múpten nun leiber ausquartiert werden. Ein Baumwolfballen biente uns aber, in Ermanglung eines 


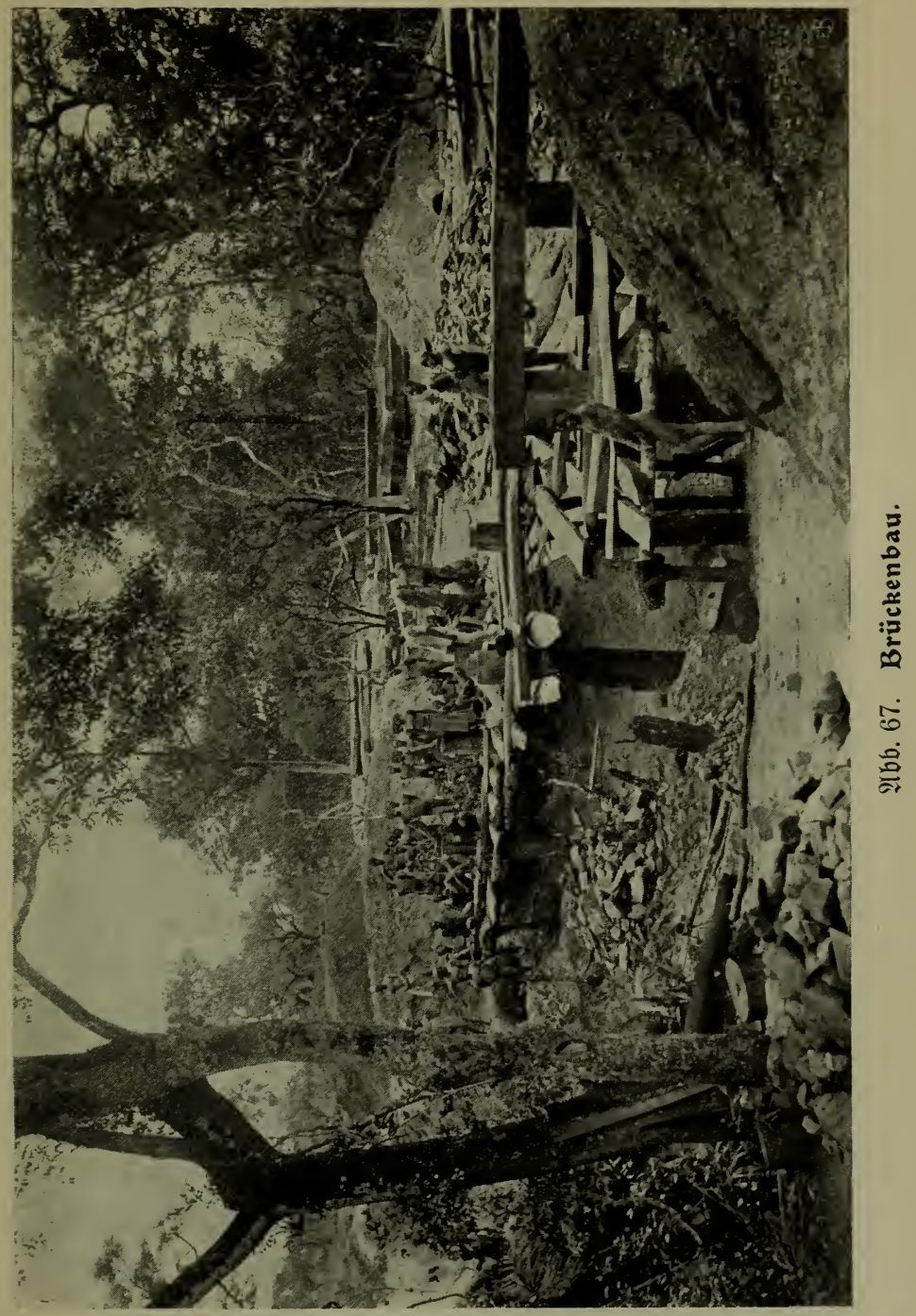


beflern, als Tilid, und zwei andere als Stühle, und fo hielten wix bort ein etwas färglidjes $\mathfrak{M a h l}$, Denn unjere

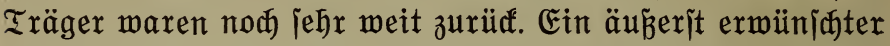
3eitwertreib nahte uns. Während wir auf ben Baummoll= ballen jä́en, trat ein freundlicher, bärtiger Mann mit einer Dienitmü̈be auf bem $\mathfrak{R o p f}$, in unire Siüte und über= gab uns Briefe von unjern Rieben auf ber Goldfiilte. Wie er uns hier auffand, ijt uns wieber als ein Beweis ber berühmen Findigfeit ber beutiden Pojt erjhienen, und wir

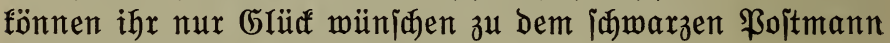
zwijan Sofode und Âtafpame.

Das Dorf Blita ift auperordentlid iđmulsig. Die Seute halten viele Sdyeine, und da bieje, wie hier zu Lande alle Tiere frei herumlaufen, jo erflärt fiđ die Menge des vielen $\mathfrak{U}$ nats und die unglaublidge Zahl von Mäulen und Ratten, die am hellen Tag herumrennen. Es itehen eine

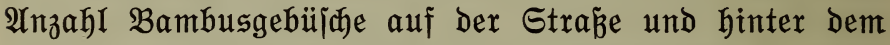
Raithof, und bie find natürlid ein Sammelplag für alfen möglixhen Sđhmug und eine Sherberge für bie Mäule und Ratten. Blita ijt Das völlige Gegenteil Der Dörfer in Moab. Das Dorf ijt io eng als nur immer möglid gebaut, $\mathfrak{a l s}$ ob alles Seil baran liege, Dá̉ man faum im Dorf Gerumgehen fönne vor unglaublid engen, winfeligen Gtraß̉en. Rađts itreiften Syänen herum, und wir hatten Die (Eenugtuung, wor Ende Der Reije bod nod eine Syäne heulen zu hören. Sie judte fiø mohl eines ber vielen Sdyeine, erwifidte aber feines. In Der Nadyt brad ein Gemitter Ios, und ber Donner rollte majeitätijø. Man befam den Einorud, Der Gduall erfülle Den weiten Raum jwijhen Erde und Bolfen und rolle mit ungeheurer Ednelligfeit bis in bie weitejte Ferne mit majejtätijader Gemalt.

$\mathfrak{A} m$ näajten Tag gelangten wir nađh $\mathfrak{A g b a n d i . ~ D i e ~}$ Etraß̉e ijt im Bau begriffen. Wir freuten uns ber joliden Arbeit, bie hier getan wirb. Die Strá̧e hat einen guten 


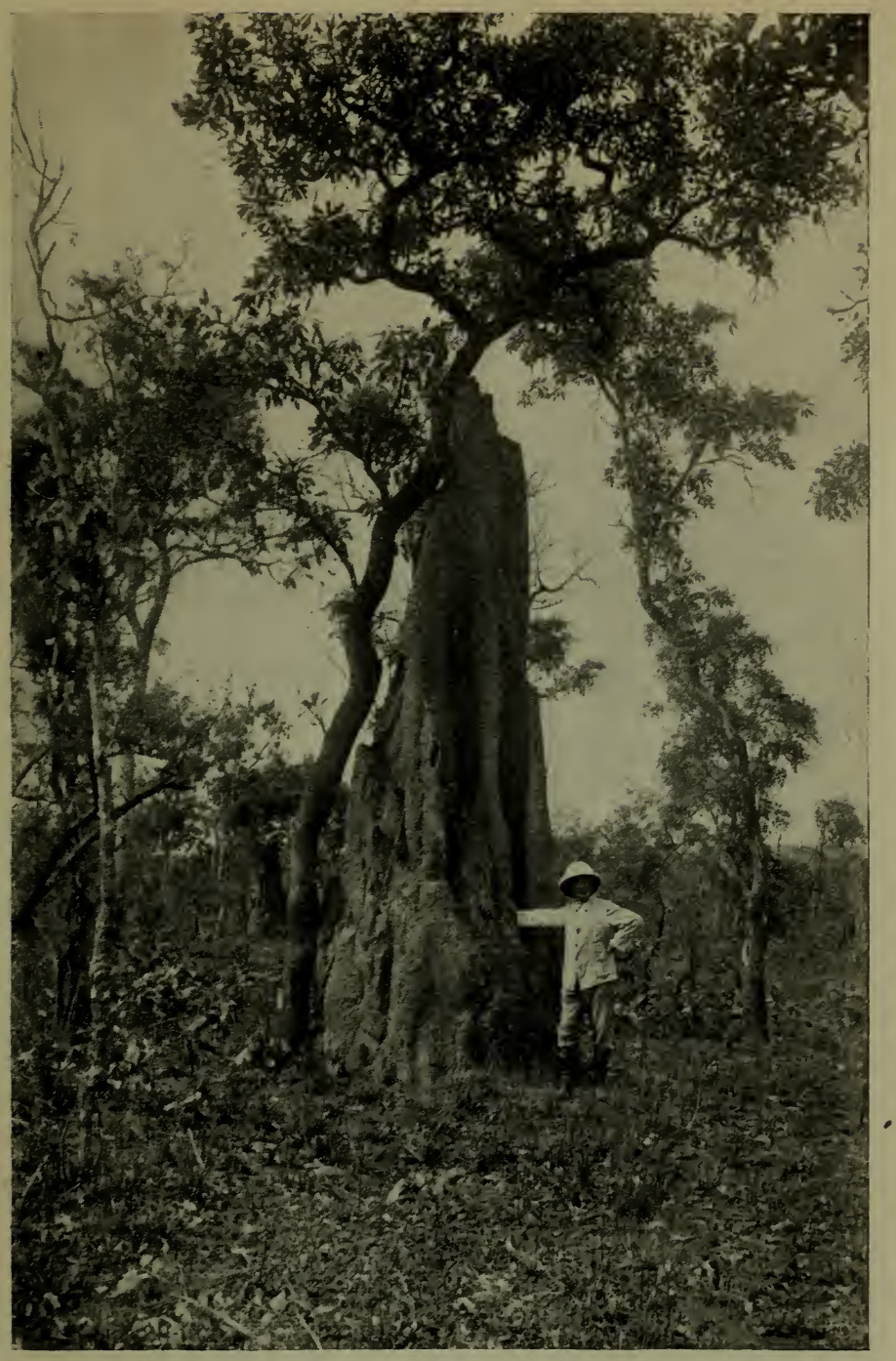

2łbb. 68. Cermitenbügel. 
Steinunterbau; die Bäde, melde die Straß̉e freuzen, werben mit bauerhaften Brïren veriehen. $2 \mathfrak{b b} 67$ zeigt eine joldhe Brü̈fe während bes Baues.

Bei $\mathfrak{U g h a n d i}$ famen wir an ganz ausnahmsweije hohen

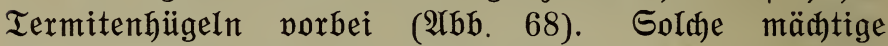
İmeijenbauten jind, unjrer Beobadtung nad, immer ein gutes 3eiðhen für die Ertragfähigfeit eines Landes, indem jie tiefes, meijt frudtbares Eroreid anzeigen.

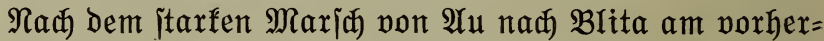
gehenden Tag mit nahezu 51 Rilometer muß̈ten wir um ber Träger willen uns am folgenden Tag mit meniger be= gnügen. Wir xajteten barum in 2 gbandi, objøon wix nux 23 Rilometer won Bita entfernt waren. IIgbandi wer=

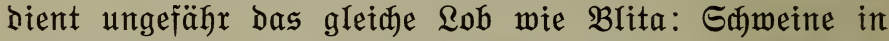
Menge, bie (iđ bejonders bie wilden feigen ber mädtigen Bäume im Rajthof jamedfen Iafjen und fajt nidft wegzu= treiben find, äuß̉erjt eng zulammengebaute Gütten, wie

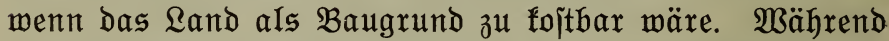
in Błita nod das Rajthaus Spuren von Dawadawa=2lnjtrich zeigte, vermi

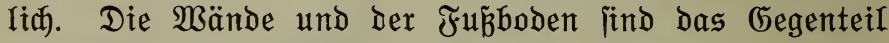

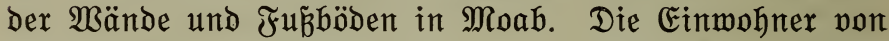

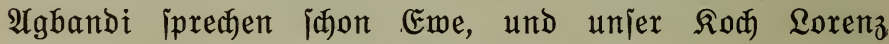
idyamm in Wonne, nun wieder unter Randsleuten zu jein.

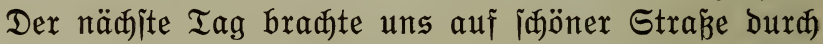
liłbten, frühlingsmä̈̈ig iproflenden und blühenden $\mathfrak{B a l d}$

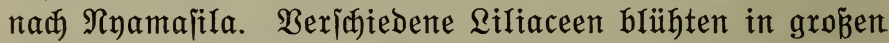
Mengen. Reben einer jiemlid Derben, die oft adyt Blüten auf einem Blütenitiel getrieben hatte, und die in ben Iälern meijt in Malle vorfam und einen prädtigen $\mathfrak{A} n=$ britf gewährte, fommt eine andere auß̉erorbentlich zarte Silie meniger häufig por; ohne Blütenitiel exjheint bie

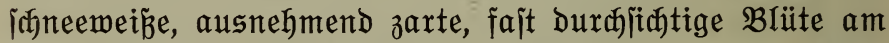
friihen Morgen, und faum ift fie aufgebriift, fo verwelft fite idon wieder. So herritid fie am frühen Morgen ift, wenn 


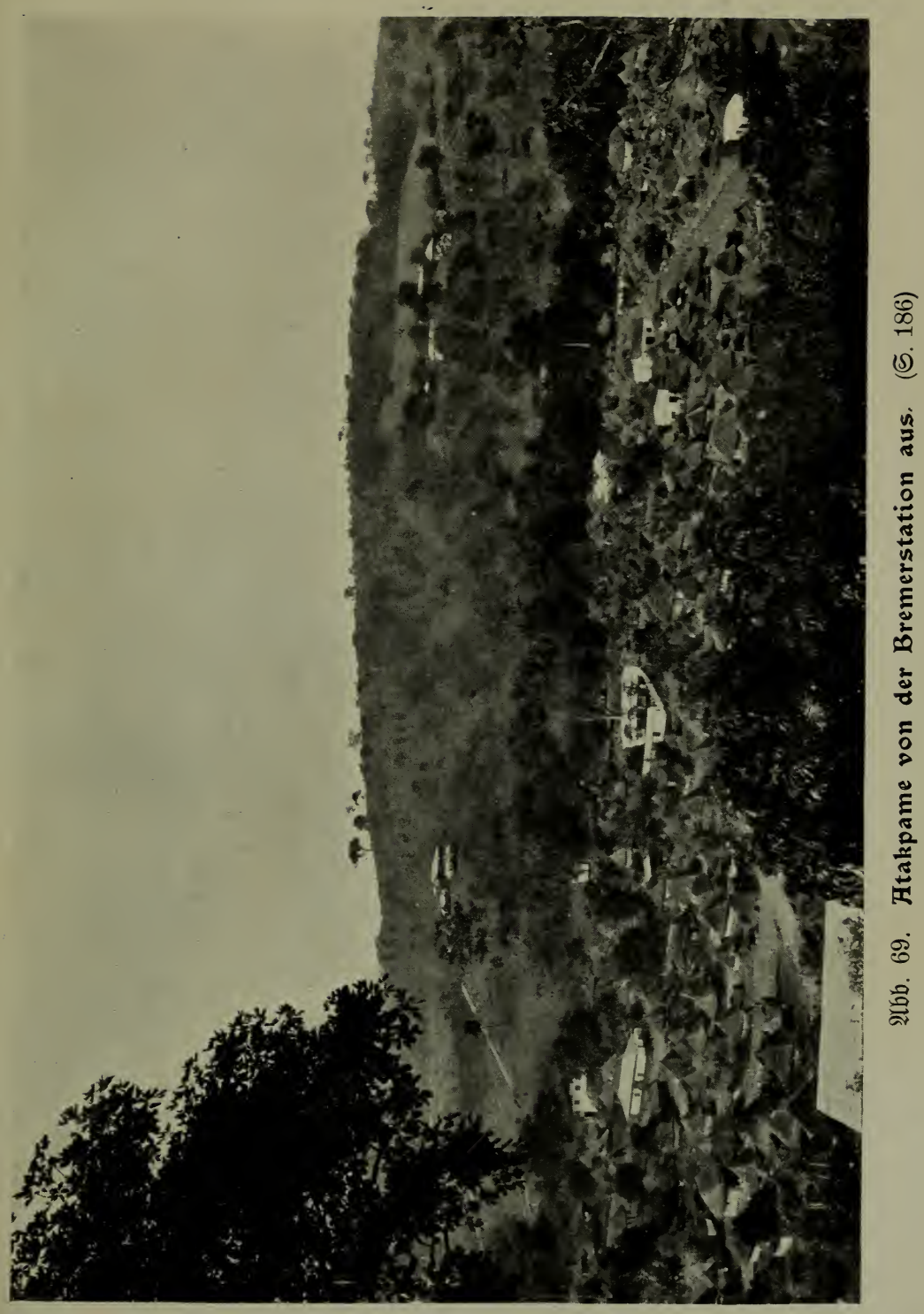



nod Dex Tau auf ifr funfelt, jo traurig fieht fie aus, went ite nux ein paar Stunden nach her matt und iđlaff ihr eben

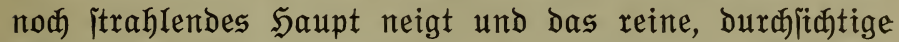
Saneeweib einen toten gelben Ton annimmt. Daneben blühte eine gelbe, crocusartige Pflanze mit jehr tief hinab= reibender fajeriger Wurzelfnolle, und im Sabatten pon Bäumen und Sträuळern erịreute uns eine ganz niebrige Sribee mit ¡ð̈önen, hellviolettroten Blüten. Sin und wieder niaften mehr als meterhohe Dratbeen im iprofilenden Gras ber Ebenen, und eine bejonders jhöne fand fith, ber Form

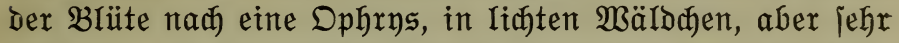
ipärliç. In Den feudten Tälern fam neben ber einen frä $f=$ tigen Rilie eine Scilla mit langem, hohem Blïtenitand häufig vor und føeint bis hinauf nach Banjeli fehr ver= breitet $\mathfrak{u}$ jein.

Nyamajila ijt ungefähr wie die Dörfer Blita und $\mathfrak{I} g=$

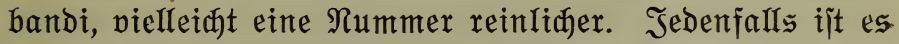
eine Wohltat, Dá̉ Der Rajthof am jübriđen Ende Des Dorfes iīt, während für die jđmarzen Reijenden am nörblichen Eingang in Das Dorf meitläufige Unterfunftshütten $\mathfrak{c r}=$

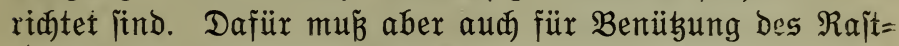
haujes jeber Reijende 2 Marf an die Randesfalle abliefern. Irobdem wax der Aufenthalt in Dem Sauje fein befonderer Genuz, Denn die Dedfe der zwei 3immer brohte den खhmungslojen zu peridülten. Wix famen aber now heil und ganz am näđjiten Morgen heraus und madten uns auf Den Weg nad) Itaf́pame. In Ingä brad aber über einen

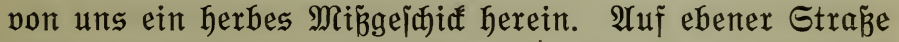
brach plöglich bas eine Bebal jeines Rabes ab. Es blieb

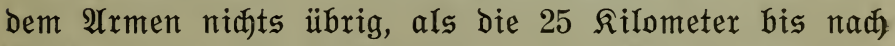

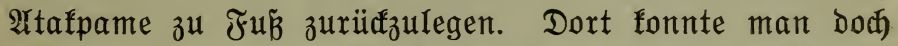
mohl das in der Rurbel itectende Shraubenende des Bebals herausbohren und ein Rejerpepedal einjegen. Wela ein

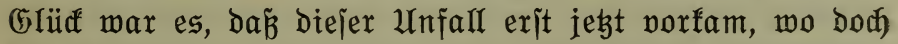
rie. Möglidfeit, Den Sֲaden auszubeflern, in erreidbarer 


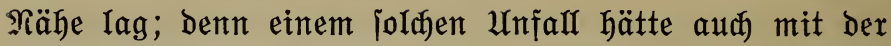
bejten Sägefeile nidgt abgeholfen werben fönnen, wie $b a=$ mals dem Sthaden an meinem $R a d$ in Jendi. So inön die

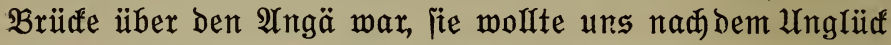
unires Mitreijenden nidjt mehr recht freuen.

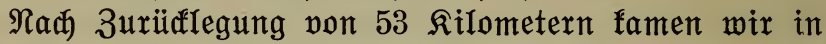

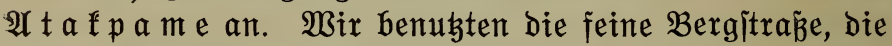
an Das Nordende ber Stadt führt. Eine andere, äItere führt mit etwas mehr Steigung am Bezirfsamt vorbei in bie Mitte Der Stadt. Şier waren wir mun wieder bei unjern lieben Freunden, Den Bremer Miffionaren. Bon ifrem Saus aus hat man eine ¡đöne $\mathfrak{A}$ wițt

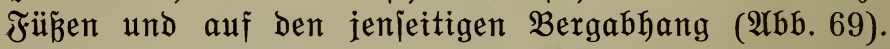
Ređts auf bex Söhe liegt bas Bejixfsamt, Iinfs bas Saus

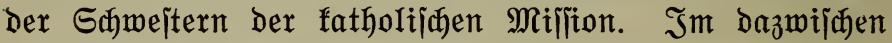
Iiegenden Tal Iagert bie Stadt. Die Strápen find breit, ge= rabe und jehr jauber gehalten, mit gefalften Steinen be=

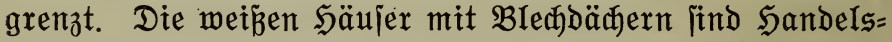
häuler, bas in ber Mitte bes Bildes ijt die faftorei von Bietor. Die Şäujer ber Eingeborenen verraten bie Rähe ber von alters her gebraudten Rumbłütten. Nur mit ben

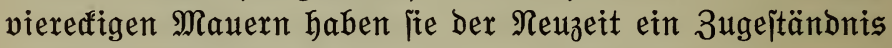
gemadt; Das Dad ijit nod ipis, entiprechend dem quabra=

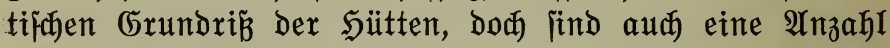
red)tecfiger Şäuler mit Giebeload worhanden.

Serr von Döring war gerabe in Atafpame anmejend; er empfing uns mit größ̈ter Liebenswürdigfeit und zeigte

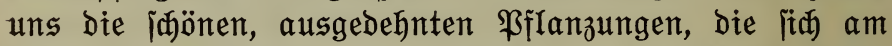
$\mathfrak{H h a n g}$ bes Berges, auf weldem das Bejirfsamt iteht, hinziehen. In gleidjer Beije, wie in Sanjanne Mangu, Bajari und Sofode, find veridtedene hodwertige Nub̧örzer und Frudtbäume in grö̉en Mengen angepflanzt. Den Begen entlang itehen pradtwolle Arleen won Mango= bäumen, Cajuarinen und Eucalyptus citriodora in prađt: vollen Exemplaren. 
Die Regierung hat zwei idönte, reidhlidhe Quellen am

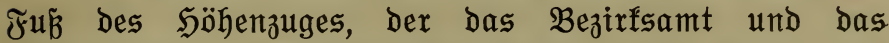

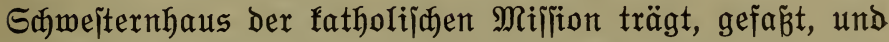
ifgr $\mathfrak{B a}$ alfer ipeijt nun zwei öffentlidge Brunnen. Der eine

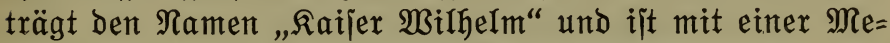
baille und bem Bilb Raijer Bilfelms bes Eriten geiđmiüt; ter andere ift ber Bismardsbrunnen und trägt in gleidjer Beife eine Medaille mit Bismard's Billo.

Ytafane liegt in einem Satter Des Lobogebirges.

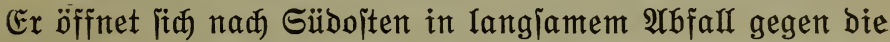

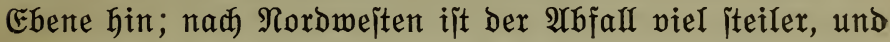
eine jehr gut angelegte Straß̉e führt bort hinunter. Dann wendet jie jiđ gegen Siidwejten, nađ) Mijahöhe hit, am.

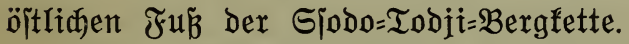

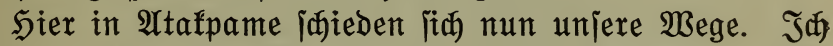
mollte auf fürzejtem Bege wieber auf bie Golofiüte zurïd=

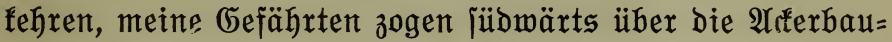
iaule in Nuatja nad) Lome, um bem (5ouperneur, Graf

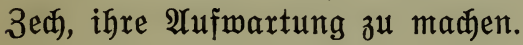

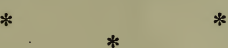

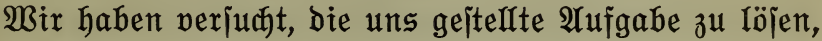
bie ber Miffiton in ben nördichen Gebieten fï eröffnenden

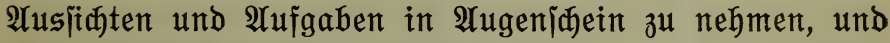
ourd) unjere Beridte ber Mififonsleitung und ber Mifíions= gemeinde, ja alfen benen, weldye bie gejunde und gebeiflithe Entwiaflung ber Rolonien am Serzen liegt, über bie bort

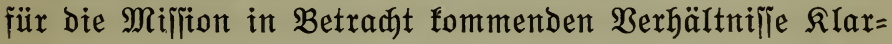
heit zu veriøaffen. Wir befennen frei und offen, bá wir überzengt jind, Dá̉ zu einer gebeihlidjen Entwioflung eines Bolfes Das Evangelium won Jeju Chrijto, Dem Gohne Gottes, Dem Sheiland Der Welt, unumgänglid̆ nötig î́t; benn nur bura die gläubige $\mathfrak{A n n a h m e ~ b i e j e r ~ w u n b e r b a r e n ~}$ Botiðaft fönnen bie iđlummernden Fähigfeiten bes Men= iđen entwidelt, verebelt und in ben Dienit bes Ganzen 
geitellt werben. Die Gejhidhte bezeugt in gewaltiger Spradhe Dasfelbe. Es find freilid feine groß̈en, mächtigen Bölfer, bie uns im Rorben ber englijhen und beutichen Rolonie exwarten. Reine groß̈en, weltgejhidtlidjen $\mathfrak{B} e=$ gebenheiten werben (it d, alfer Borausfitht nađ, an jene Bölfer und ihre Entwioflung anjhließ̉en. Es find fleine, unbedeutende Bölfden, mit denen bie Miffiton es $z^{\mathfrak{u}}$ tun Jaben wird, und bentod ift es wohl ber Mühe und bes Echmeißes wert, ja ber Darangabe jelbit des Lebens, die

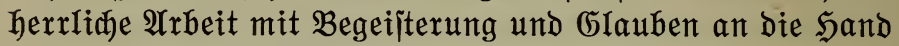
zud nehmen. $2 \mathfrak{A}$ Miffitonaren wirb es niđt fehIen, die von Serzen willens find, bie iłnen verliehenen Kräfte und iłre ganze ßexjon ber $\mathfrak{A}$ rbeit an jenen $\mathfrak{B o ̈ l f e r n ~ z u ~ w i o m e n ~ u n d ~}$ es aIs bie $\mathfrak{A}$ ufgabe ifres Rebens aufaufalfen, Gottes herr = Iides, emiges Reid bis an bie Grenzen unierer Rolonien $\mathfrak{a} \mathfrak{u} \mathfrak{z} \mathfrak{u b r e i t e n .}$

Wir wollen nidgt Shalt madjen mit bex Berfündigung Des Enangeliums an ben Grenzen ber englijđen Rolonie. Bollen wir nur die Dagbane ipredenden Namumba und Dagomba in Togo mit ber frohen Botjafaft beglüafen und Den grö̈́cen Teil ber Dagomba jamt den Mampruj und Rujaji liegen Iallen, Deren Spradhe wix jowiejo erTernen und in Edrifift jegen mïifen? Wix werden uns ber $\mathfrak{A} u \tilde{f}=$ gabe nidyt entzitehen fönnen, jene Bölfer aud in bex eng= Iijđen Rolonie zu bearbeiten. Die Basler Mifjiton ijt ja iđon mit ben Berhältnifjen in ber englijđen Rolonie ver= traut. Benn wir aud mandyerlei Shemmung in ber gegen= wärtigen Stufe ber Entwid lung auf ber Goldfiilte Durch bie Drgane Der Regierung erfahren, io ift uns Dod bie eng= Iijase Rolonialregierung im ganzen burdaus wohlgejinnt, und viefleidyt fommt nodh bie Zeit, wo alle bie vielen Dpfer an Menichenleben, Arbeit und Geld, welde die Mififion auf ber Goldfijite gefojtet hat, won jener Seite mehr ge=

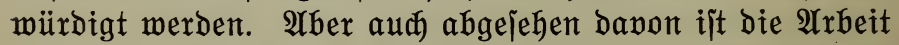
und bas 3iel ber evangelifaen Mififion nidht begrenzt burd 
die Grenzpfähle des Seimatlandes, und wir dürfen bei aller Berechtigung, bie barin liegt, bie Gaben und ßräfte ben Rolonien bes Mutterlandes zu erhalten, nicht zurüd = ¡đredfen vor $\mathfrak{A}$ ufgaben, die uns ber Lage der BerhäItnifie nad) ̈̈ber bie Grenzen Der heimatlichen Rolonie hinüber=

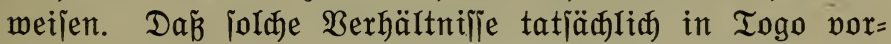
handen find, glauben wir Durd uniere Reife und beren Er= gebnilie feitgeitellt zu haben.

Bohlan! Sind Mifilionare vorhanden, weldje die $\mathfrak{A} u \mathfrak{f}=$ gabe mit Freuben auf fid nebmen wollen, find bie Türen geöffnet zu jenen $\mathfrak{B o ̈ l f e r n , ~ b e r e n ~ B i l d e r ~ a n ~ u n s ~ p o r b e i = ~}$ gezogen find, hängt es alfo nux an bix, lieber Lejer, bem Gebot unires Sherrn und Rönigs zu gehorchen: „Gehet hin in alle Belt und perfïndiget Das Evangelium alfer Kreatur!“, bann bejinne bidh, ob du nidgt mithelfen jollteit, und zwar mit Freuden, Das Deine bazu beizutragen, ba das Liđt der Welt hineinjđeinen fönte, wo es noch jo dunfel

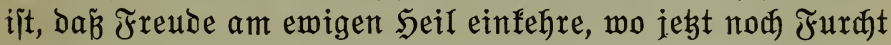

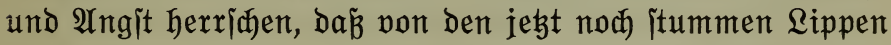
Robge|änge ertönen zu Éhren Des Sheilands Der Melt. Mit ben 2Uufgaben wäafit bie Rraft, und noch find gewaltig großje Cebiete, bie auf uns warten, wenn erít die jegt nod veriळlofienen Gebiete des gewaltigen franjöjifden Bejizes im Euban geöffnet werben, Gebiete, bie zu bearbeiten weit ïber bie Rraft Des evangelijhen Franfreid)s geht. Darum, lieber Sejer, bete und arbeite für bie भufridtung bes Reidjes (Gottes aud in Togo. (Gott will es! Wolle aud bu!

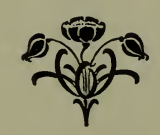




\section{Inhaltžverzeichniz.}

1. Sin̈̈̈ber ïber den $\mathfrak{B o l t a ! ~ . ~ . ~ . ~ . ~} 5$

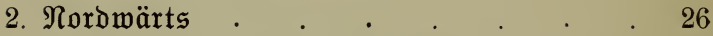

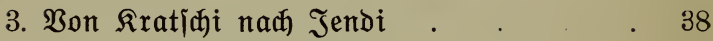

4. Bon Jendi naদ̆ Tamale . . . . . 61

5. Bon Gambaga bis zur Deutjaen Grenze - 105

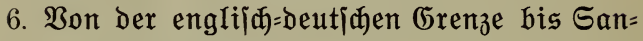
janne Mangu . . . . . . 112

7. Bon Sanjanne Mangu nad̆ Bajari . . 144

8. Bon Bajari nach Sofode . . . . . 170

9. Bon Sof́ode nad Itałpame . . . . 178 
In Demielben $\mathfrak{B e r l a g}$ find erichienen:

\section{Neuerjicheinungen 1911:}

Gamuel Sebich, Der erfte Gendbote Der Babler Miffiton in Indien.

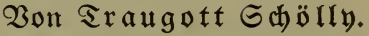

260 ङ. $8^{0}$. Nit 8 Bilberbeilagen. Geb. Fr. 3. $=$ N. 2.40.

Rudolf Lechler, ein Lebenzbild auz Der Bazler Miffiton in Ebina. Bon Pfarrer 23. Gd)latter in Gt. Gallen. 208 ङ. Mit 8 Bilderbeilagen. Geb. Fr. 3.- = M. 2.40.

Im finfern Tal. (befdichten umb Lieber auz (Ehina. Zon Elifabeth Oehler=Seimerdinger. (Fa. 240 Geiten. Fein geb. ca. Fr. $4 .-=$ M. 3.20.

Bon Derjelben Berfafierin:

Jch) harre auz. (Gejchichten von chinefifchen Frauen. (Eleg. geh. $\mathfrak{F r}$. $2.25=\mathfrak{M} .1 .80$, fein geb. Fr. $3 .-=\mathfrak{N} .2 .40$.

Die Enticheidungsitunde ber $\mathfrak{B e l t m i f f i o n ~}$ und wir.

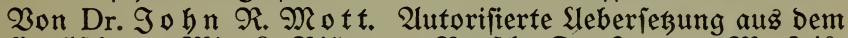
Englifichen. Mit 8 Bildern. Brofdh. Fr. 3.- = M. 2.40, geb. Fr. $4 .-=$ N. 3.20

bilbet Band IV Der Sandbürther zur Miffitonałunde,

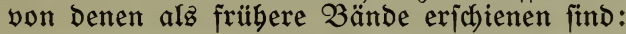

1. Band. Daz neue China. Nach Dem englifchen Original von A. S. Smith, bearbeitet yon Quife Oefler. Mit Bilbern und Rarten. $\mathcal{B}$ roich. Fr. 3.- = M. 2.40, geb. Fr.4.-= Fr.3.20.

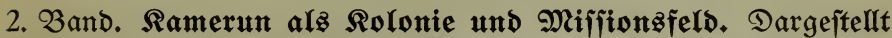
von P. Steiner. Mit Bildern und Rartenifizze. Broifbiert $\mathfrak{F r} .1 .75=\mathfrak{N} .1 .40$, gebunden $\mathfrak{F}$ r. $2.50=\mathfrak{N}$. 2.

3. $3 a n d$. Die $\mathfrak{B a z l e r}$ Mififion auf ber Golbfiijte. Bon $\mathfrak{P}$. Steiner. Mit Bildern, Sabellen und Rartenifizze. Brojdiert $\mathfrak{F r} .1 .75=\mathfrak{N} .1 .40$, geb. $\mathscr{J} r .2 .50=\mathfrak{N} .2$.-

\section{Die CEDinburger $\mathfrak{B e r t}=$ Mifîtonz=:Ronferenz.}

Bilder und Berichte von Bertretern Der Deutfchen Miffitonz: (Gejellichaften, gefammelt von 2.23 . Sch reiber, Direftor ber Nordd. Miffitonz=-(Befellichaft. Reinertrag zu guniten dez Gyri= fiben Waaijenhaujes in Serufalem. 3weite 2luflage. Mit 4 Bildertafeln. 180 S. $8^{0}$. Fr. $2.50=\mathfrak{M}$. 2.-, in Leimwand geb. $\mathscr{F r} .3 .50=\mathfrak{N} .2 .80$. 
Zohner, $\mathfrak{H}_{+}, \mathfrak{I m}$ Lande Dez Fetijchez. (Fin Lebenşbild alz Epiegel afrifan. Bolfglebens. 3weite 2luflage. Mit Bildern. Broich. $\mathfrak{F r} .2 .25=\mathfrak{N}$. 1.80, in Leinwand $\mathfrak{F r}$. $3 .-=\mathfrak{N} .2 .40$.

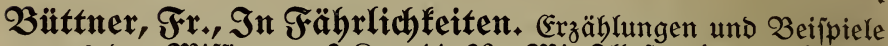
auz Der Miffiton zu 2 Ror. 11, 26. Mit Slluitrationen. Sǘbid brofd.). Fr. $1.50=\mathfrak{N} .1 .20$, in Qeinwand $\mathfrak{F r} .2 .50=\mathfrak{N}$. 2.-.

Flad, $\mathfrak{I}_{+}$China in $\mathfrak{B o r t}$ und $\mathfrak{B i l l}$. Geheftet mit ele=

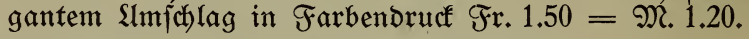

(Beyjer, Paul, Mit eijernem $\mathfrak{B i l l e n . ~ ( E i n e ~ ( E ́ r z a ̈ h l u n g ~ a u z ~}$ Dem Qeben Dez Indianermifitionarg $\mathfrak{J} 0 \mathrm{~h}$. Meyer. (Gleg. broíd). $\mathfrak{F r} .1 .75=\mathfrak{M} .1 .40$, geb. $\mathscr{F} r .2 .50=\mathfrak{M} .2 .-$.

Oebler, L., Die Frattenmifî̃on in Den Seidenländern. Gebeftet $\mathfrak{F r}$. 1.- = 80 Pf., in Leinwand $\mathfrak{F r} .2 .-=\mathfrak{N}$. 1.60. Peyer, Gajt., V.D.M., Françoiz Coillard, ber Apoitel Der Gambefi=Maiffion. Mit Bilbern und 2 Rarten. Ele= gant brofchiert $\mathfrak{F r} .1 .50=\mathfrak{N} .1 .20$, geb. $\mathscr{F} r .2 .50=\mathfrak{N}$. 2.-.

G(h)aal, $L_{+}$Freud u. Leid unter Dem 3eichen dez Rreuzez. Bilber auz Dem Reben won Mifítionaren. Mit Bilbern. Bro= fchiert $\mathcal{F r} .1 .-=80$ Pf., in Leinwand $\mathscr{F} r .1 .50=\mathfrak{N}$. 1.20 .

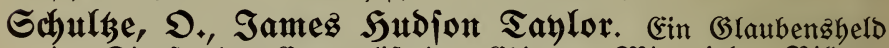
im Diente Der Evangelifation Chinas. Nit vielen Bildern und einer Rartenifizze. (Geh. mit Slmichlag in Farbendruct $\mathfrak{F r} .2 .25=\mathfrak{N} .1 .80$, geb. $\mathscr{F r}$. 3. $=\mathfrak{N} .2 .40$.

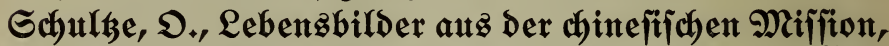

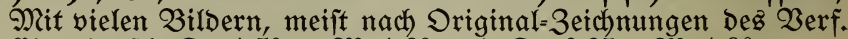
(Fleg. brofd). $\mathfrak{F r} .1 .50=\mathfrak{M} .1 .20$, geb. $\mathscr{F} r .2 .25=\mathfrak{M} .1 .80$.

Gteiner, P., $\mathfrak{I m}$ Seim dez afrifanijchen $\mathfrak{B a t e r m}$. Sfizzen auż ber $\mathfrak{B a s l e r}$ Mififion im 3 ujwland. Mit Zildern. Broid. Fr. 1.-- $=80$ Pf., in Leinw. geb. Fr. $1.50=\mathfrak{M} .1 .20$.

Zortifd, Dr. med. SH, Sin und Ser auf Der Goldfiijte. Tagebuchblätter einez Mifionzarztez. Mit Titelbild in Farben= bruct und vielen Glluitrationen. Broichiert $\mathfrak{F r} .3 .-=\mathfrak{M} .2 .40$, bübict) gebunden $\mathfrak{F r}$. $3.75=\mathfrak{M}$. 3.-.

Sohn Williamz, Der Apoftel der Giibjee. Bon $\mathfrak{~}$. N. Mit Titelbild in Farbendrucf. 3 rofftiert $F r$. $1 .-=80$ Pf., hübjch) geb. Frr. $1.50=\mathfrak{N} .1 .20$.

Unter Den Mongolen. Lebenzbild bes Mongolenmifítonar

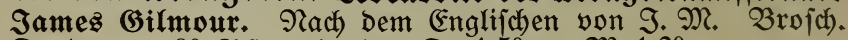
$\mathfrak{F r} .1 .-=80 \mathfrak{P}$., gebunden $\mathfrak{F r} .1 .50=\mathfrak{N} .1 .20$. 


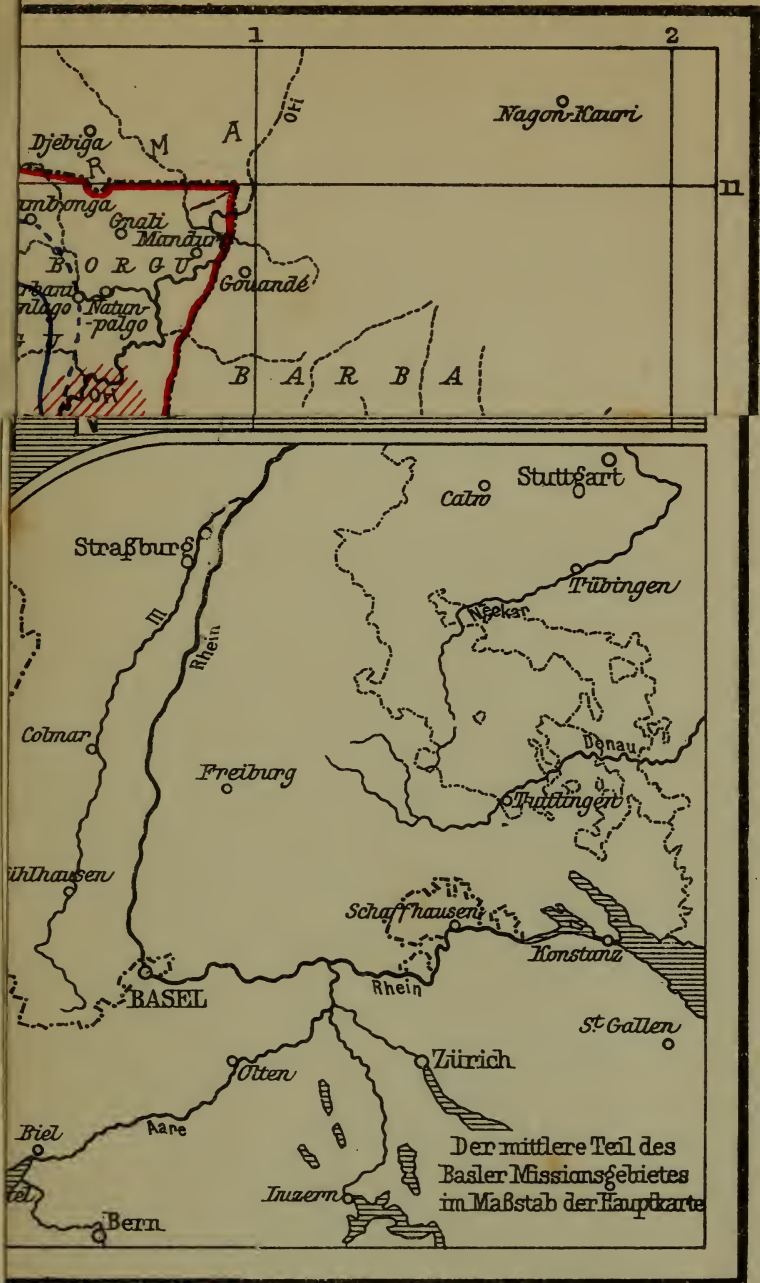

"Frobenius" A.G.Basel.

nd rot unterstrichen.

itern" besuchtes Gebiet.

Steyler-Mission.

906.

nd Dr. Fisch 1910. 



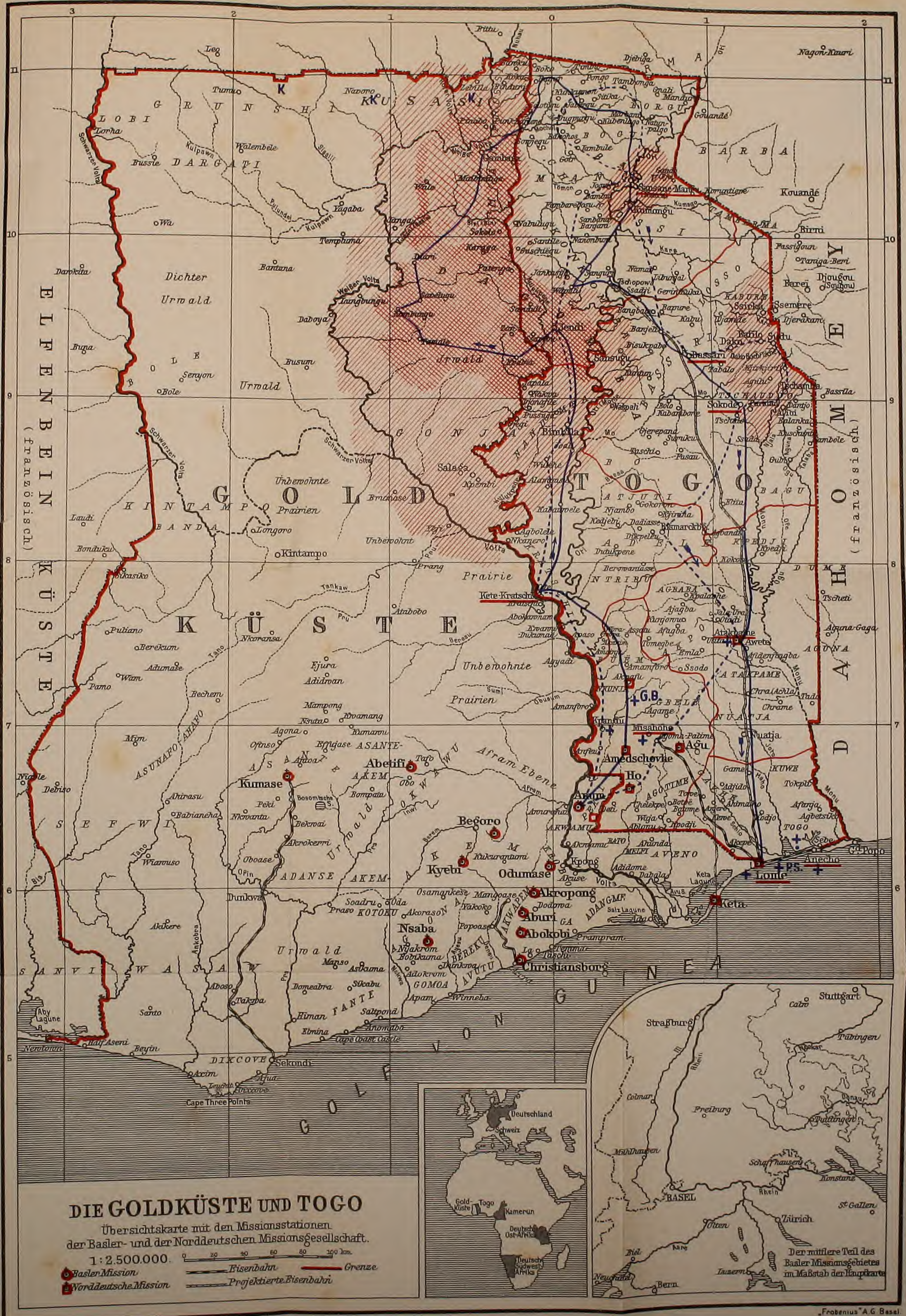






SMITHSONIAN INSTITUTION LIBRARIES

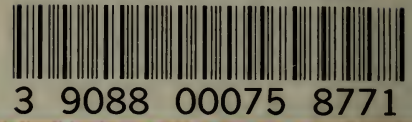

